\author{
UNIVERSIDADE DE SÃO PAULO \\ ESCOLA DE ENGENHARIA DE SÃO CARLOS
}

JORGE LUIS RODRIGUES PANTOJA FILHO

\title{
AVALIAÇÃO DA UTILIZAÇÃO DE DIFERENTES MATERIAIS SUPORTE NA BIOFILTRAÇÃO DE SULFETO DE HIDROGÊNIO
}


JORGE LUIS RODRIGUES PANTOJA FILHO

\section{AVALIAÇÃO DA UTILIZAÇÃO DE DIFERENTES MATERIAIS SUPORTE NA BIOFILTRAÇÃO DE SULFETO DE HIDROGÊNIO}

Dissertação apresentada à Escola de Engenharia de São Carlos, da Universidade de São Paulo, como parte dos requisitos necessários à obtenção do título de Mestre em Engenharia.

Área de Concentração: Hidráulica e Saneamento

Orientador: Prof. Dr. Edson Luiz Silva

São Carlos - SP

2008 


\section{FOLHA DE JULGAMENTO}

Candidato: Engenheiro JORGE LUIS RODRIGUES PANTOJA FILHO

Dissertação defendida e julgada em 25/04/2008 perante a Comissão Julgadora:

$\frac{\text { Odison f. Silva }}{\text { Prof. Dr. EDSON LUIZ SILVA (Orientador) Aprovado }}$

(Universidade Federal de São Carlos/UFSCar)

$\frac{\text { Prof. Dr. JOSÉ ALBERTO DOMINGUES RODRIGUES }}{\text { POT }}$

APRONADO

(Escola de Engenharia Mauá/EEM)

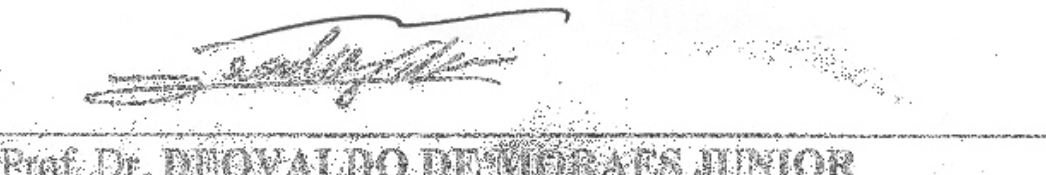

Hans

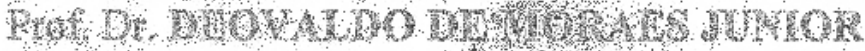

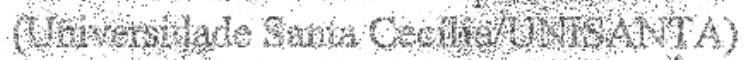
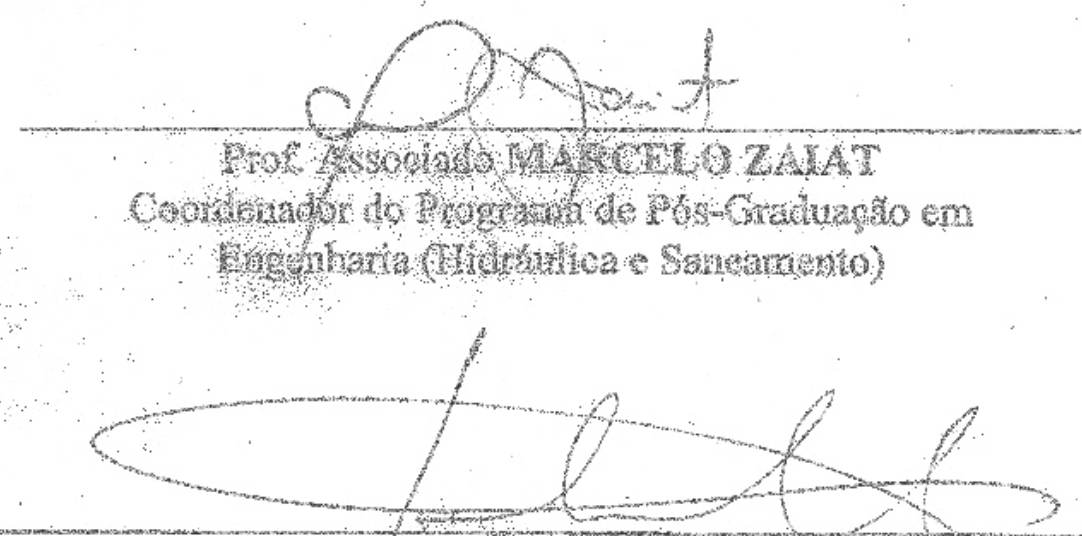

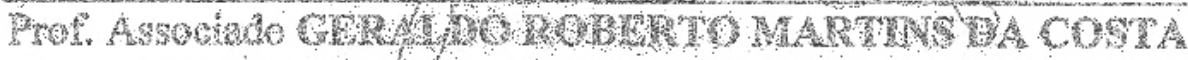

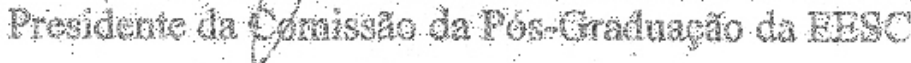


AUTORIZO A REPRODUÇÃO E DIVULGAÇÃO TOTAL OU PARCIAL DESTE TRABALHO, POR QUALQUER MEIO CONVENCIONAL OU ELETRÔNICO, PARA FINS DE ESTUDO E PESQUISA, DESDE QUE CITADA A FONTE.

-

Ficha catalográfica preparada pela Seção de Tratamento da Informação do Serviço de Biblioteca - EESC/USP

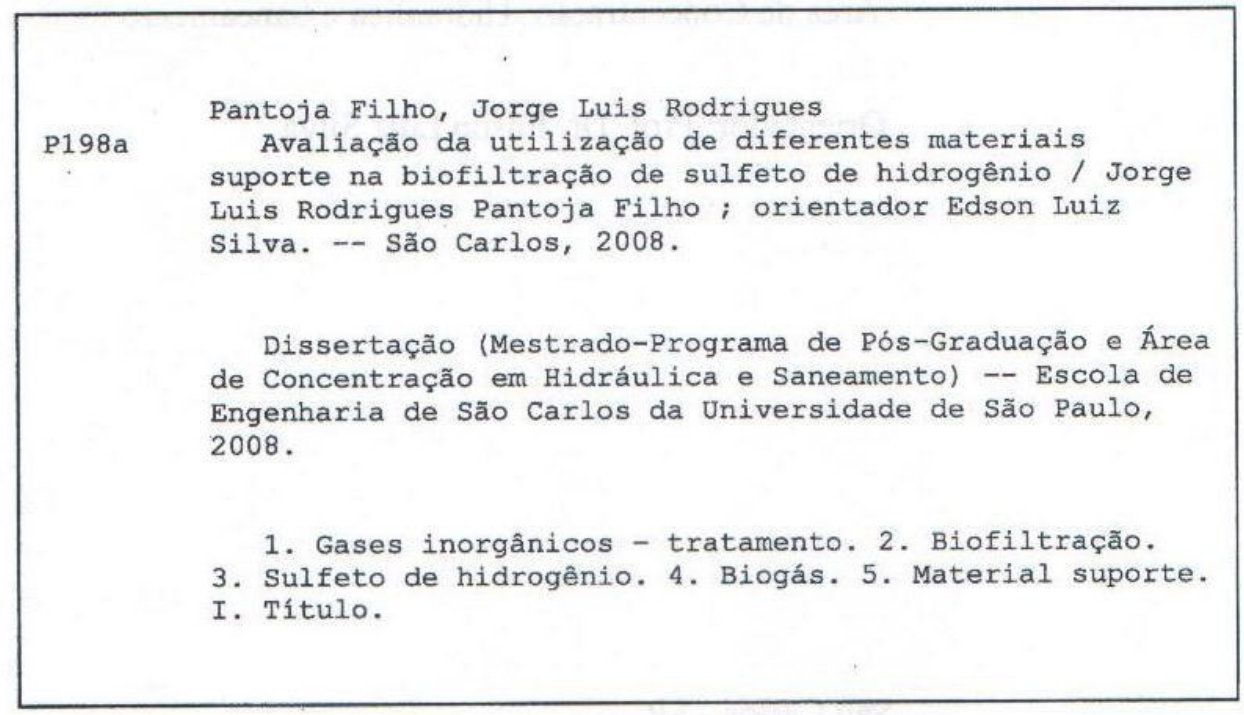




\section{DEDICATÓRIA}

Aos meus pais e grandes mestres da vida: Jorge e Sirlei Pantoja. Aos meus irmãos: Joelma, Jordan e Joyce.

In memoriam: Vó Sebastiana.

Obrigado pelo incentivo, compreensão e amor.

Amo todos vocês! 


\section{AGRADECIMENTOS}

A Deus. Mesmo sendo uma pessoa extremamente racional, sempre me deparo diante do transcendental, que, constantemente, está imerso no mais profundo de mim. E é por não ter noção de toda essa grandiosidade, que não posso ter outra atitude a não ser a da mais profunda reverência.

À minha família: meus pais, Jorge e Sirlei Pantoja, pelo carinho demonstrado durante todo o percurso de uma vida. Meus irmãos, Jordan, Joelma e Joyce Pantoja, por todos esses anos de consideração e respeito. Muito obrigado.

Ao professor e orientador Edson Luiz Silva, pelo aprendizado e pela preciosa oportunidade de trabalhar numa pesquisa relevante, o que contribuiu sobremaneira para a solidificação da minha formação profissional.

Aos professores do Departamento de Hidráulica e Saneamento, em particular aos professores Marcelo Zaiat, Eugenio Foresti, Marco Reali, José Roberto Campos, José Alberto Rodrigues, Harry Schulz e Jurandyr Povinelli.

Ao Departamento de Hidráulica e Saneamento da Escola de Engenharia de São Carlos da Universidade de São Paulo e demais professores pela preocupação constante com o avanço tecnológico brasileiro e ensino de qualidade. Também pela oportunidade de participar do Seminário Temático.

À Tininha, Kátia e Heloísa pelas análises microbiológicas.

À Pavi, Sá e Rose, pelos serviços prestados durante o curso de mestrado.

Ao Departamento de Engenharia Química da Universidade Federal de São Carlos.

À todos do Laboratório de Controle Ambiental 2, que conviveram e compartilharam comigo uma etapa de vida tão importante:

- ao Alexandre, pelas dicas e a ajuda na montagem do sistema de biofiltração;

- um mais do que especial agradecimento à Gessia, à Laura, à Sylvia, ao Eduardo, à Aruana e ao Gilberto, pessoas com as quais eu gostaria sempre de manter contato. 
Foi uma grande satisfação para esse reles ser amazônico ter convivido tão intensamente com pessoas tão especiais, cada uma ao seu modo. Por tudo, foi uma honra!

Ao "mão-santa", que responde pelo nome de Oscar, pela confecção dos reatores e pelo sempre prestimoso auxílio nas horas complicadas.

Ao Instituto de Física de São Carlos, representado aqui pela pessoa do Sr. Nelson Gallo, pelas análises de microscopia eletrônica de varredura e de EDX.

Aos Professores Deovaldo de Moraes Júnior e José Alberto Rodrigues por terem sido membros da banca avaliadora deste trabalho.

À todos os meus colegas de mestrado, em especial aos Engenheiros Guilherme Peixoto, Ricardo Polisaitis e Gustavo Mockaitis. "Força e Honra!".

À todos os pesquisadores que trabalham com o tão fascinante campo da biorremoção de compostos tóxicos e/ou odorosos, fica o meu respeito.

À todos os professores que contribuíram para a minha formação, desde o longínquo maternal até hoje.

À todas as pessoas que contribuem para o arcabouço intelectual da humanidade e nos legam o seu mais precioso patrimônio: suas idéias!

À Mozart, Chopin, Beethoven, Tchaikovsky, Schubert, Mahler, Rossini, Wagner, Schumann, Dvorák, dentre tantos outros grandes gênios, cujas canções embalavam minhas solitárias noites nas quais as respostas teimavam em não aparecer.

À CAPES, pela bolsa de mestrado concedida e à FAPESP, por financiar o projeto temático. 


\section{NAIVETY}

Now look at me!

My naivety

And strange location

Take incredible priority

over some kind of... reputation!

Now look at us!

That's our second step

Our great inspiration

All those lights went out

over some kind of... imagination!

Look at the mirror, the lines are dancing

Look up at night, it's growing faceless

Find a way, the special service

keep it down, keep it harmless

Fight the fire, the stars are jumping

Start that heart, it's not about loneliness

Like a spy... in the fire, from the secret service

Keep it down, cure your blindness

Just keep it round, just keep it harmless

Yeah, your naivety does not find out the secret rival

Just keep hearing (any sound!)

It's strange, but everything is slowly turning around

Do not run like me!

Oh, no! You're laughing at the situation!!!

Keep it in secret...

Mission complete!

(Jorge L. R. Pantoja Filho (01/02/2005)) 


\section{RESUMO}

PANTOJA FILHO, J. L. R. Avaliação da utilização de diferentes materiais suporte na biofiltração de sulfeto de hidrogênio. Dissertação (Mestrado) - Escola de Engenharia de São Carlos, Departamento de Hidráulica e Saneamento, Universidade de São Paulo, São Carlos, 2008.

O sulfeto de hidrogênio é um gás que pode causar os mais diversos danos se lançado ao meio ambiente devido, principalmente, à sua elevada toxicidade, corrosividade, odores indesejáveis e alta demanda de oxigênio. Atualmente existem diferentes processos físico-químicos estabelecidos para o tratamento desse composto, entretanto são consideradas técnicas onerosas do ponto de vista econômicoambiental. Os processos biológicos constituem-se como uma alternativa bastante interessante quando comparados aos processos físico-químicos, sendo que a biofiltração é o processo mais amplamente utilizado. Neste trabalho foram avaliados três tipos diferentes de materiais suporte, sendo um sintético - espuma de poliuretano e dois orgânicos - fibra de côco e bagaço de cana -, para a biofiltração de uma mistura gasosa contendo $\mathrm{H}_{2} \mathrm{~S}$. Como inóculo, optou-se pela utilização de cultura mista originária de duas fontes: a) unidade de biofiltro aerado submerso pertencente ao Serviço Autônomo de Água e Esgoto da Cidade de São Carlos, b) unidade de lodos ativados pertencente a São Carlos S/A - Indústria de Papel e Celulose. A adaptação do inóculo foi realizada em meio nutriente específico. Foi observado um período de partida de somente 2 dias nos três sistemas. Com o intuito de avaliar o impacto do aumento progressivo das taxas de carregamento mássico no desempenho dos três biofiltros, os mesmos foram submetidos a taxas de 19, 32, 54 e $70 \mathrm{~g} / \mathrm{m}^{3} . \mathrm{h}$ (concentrações afluentes médias de 184, 328, 526 e 644 ppm para tempo de retenção do gás de, aproximadamente, 50 segundos). As eficiências remoção média em todos os sistemas mantiveram-se sempre acima dos 99,3\%. A capacidade eliminação máxima alcançada pelos biofiltros oscilou entre 74 e $80 \mathrm{~g} / \mathrm{m}^{3}$.h. As perdas de carga verificadas no ensaio hidrodinâmico foram baixas, variando entre 0,59.10-2 a 0,68 10-2 mca, para a velocidade superficial utilizada durante o estudo. O modelo matemático empregado na previsão do desempenho dos sistemas ajustou-se bem aos dados experimentais. Portanto, pode-se concluir que os materiais suportes testados são adequados para a biofiltração de sulfeto de hidrogênio.

Palavras-chave: Tratamento de gases. Biofiltração. Sulfeto de Hidrogênio. Biogás. Material suporte. 


\begin{abstract}
PANTOJA FILHO, J. L. R. Utilization of different packing materials in the hydrogen sulfide biofiltration. Dissertation (Master of Engineering) - São Carlos School of Engineering, Department of Hydraulics and Sanitation, University of São Paulo, São Carlos, 2008.
\end{abstract}

Hydrogen sulfide is a gas which has high restrictions regarding to its disposal in the environment, mainly, because of its high toxicity, malodors, high oxygen demand, etc. Currently, there are many different physical-chemical processes established in order to treat this compound, nevertheless they are considered expensive techniques by the point of economical and environmental views. Biological processes are very interesting alternatives when they are compared to the physical-chemical ones, and biofiltration is the most used process. In this work, three different materials as support media were evaluated, - a synthetic one - represented by the polyurethane foam, - two organic ones - represented by coconut fiber and sugar bagasse -, for a biofiltration of a gaseous mixture containing $\mathrm{H}_{2} \mathrm{~S}$. Microorganisms were obtained from two sources: a) submerged aerated biofilter unit, b) activated sludge unit. Inoculum's adaptation was realized in specific nutrient media. It was observed a 2 days start-up period in the three systems. In order to evaluate some impact caused by the progressive increasing of mass loading rate on the biofilters performance, were applied rates of 19, 32, 54 e 70 g.m $\mathrm{m}^{-3} \mathrm{~h}^{-1}$ (average influent concentrations of 184, 328, 526 e 644 ppm to the empty bed retention time of, approximately, 50 seconds). Average removal efficiencies in the systems were always above 99,3\%. Maximum elimination capacities reached by the biofilters were in the range of 74 e $80 \mathrm{~g} \cdot \mathrm{m}^{-3} \cdot \mathrm{h}^{-1}$. Loss pressure verified by the hands of hydrodynamic essays varied between $0,59 \cdot 10^{-2}$ a $0,6810^{-2} \mathrm{mca}$, to a superficial velocity utilized during the work. Mathematical model used to predict the performance of the systems fitted reasonably the experimental data. Then, it can be concluded that the three packing materials are appropriated for the hydrogen sulfide biofiltration.

Keywords: Gas treatment. Biofiltration. Hydrogen sulfide. Biogas. Packing material. 


\section{LISTA DE ILUSTRAÇÕES}

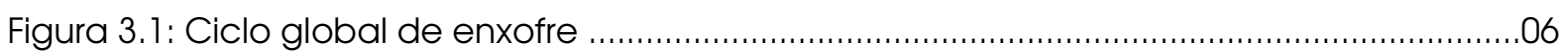

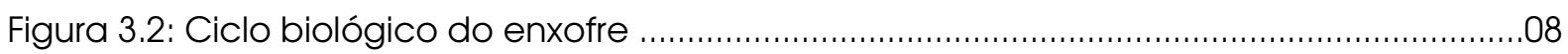

Figura 3.3: Esquema dos sistemas mais comuns de tratamento biológico de gases ................17

Figura 3.4: Ampliação do leito do biofiltro e visualização do biofilme .......................................22

Figura 3.5: Capacidade de eliminação típica versus carga aplicada ....................................31

Figura 3.6: Três situações para a expressão cinética considerada por Ottengraf e Van de

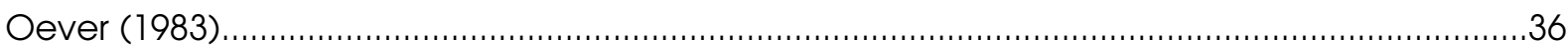

Figura 3.7: Modelo biofísico de penetração do substrato …...............................................36

Figura 3.8: Previsão do processo de biofiltração de acordo como o modelo semi-empírico

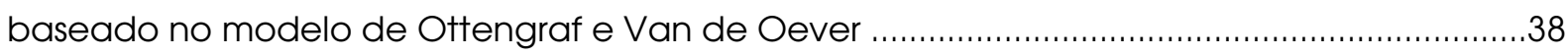

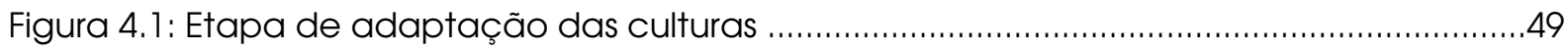

Figura 4.2: Ełapas de preparação dos meios suportes orgânicos .......................................50

Figura 4.3: Materiais suportes prontos para serem inseridos no biofiltro (da esquerda para direita: espuma de poliuretano, bagaço de cana e fibra de coco) .......................................51

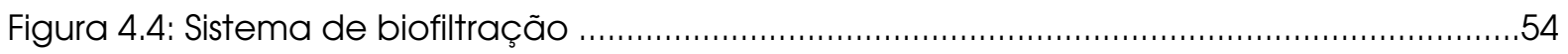

Figura 4.5: Visão geral do sistema (vista diagonal) .........................................................56

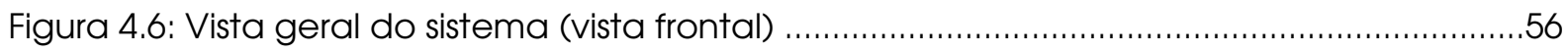

Figura 5.1: Perda de carga da espuma de poliuretano seca em função da velocidade superficial do ar......

Figura 5.2: Perda de carga do bagaço de cana seco em função da velocidade superficial do ar.

Figura 5.3: Perda de carga da fibra de coco seca em função da velocidade superficial do ar. 
Figura 5.4: Comparativo entre os valores médios de perda de carga dos leitos preenchidos com espuma de poliuretano, bagaço de cana e fibra de coco.

Figura 5.5: Curva de Ruptura para o Biofiltro preenchido com Espuma de Poliuretano.

Figura 5.6: Curva de Ruptura para o Biofiltro preenchido com Fibra de Coco.

Figura 5.7: Curva de Ruptura para o Biofiltro preenchido com Bagaço de Cana.

Figura 5.8: Microscopia ótica das amostras brutas de Lodo ativado (a1 e a2) e Biofiltro Aerado Submerso (b1 e b2).

Figura 5.9: Microscopia ótica das amostras enriquecidas em meio ATCC 290-S6, para Thiobacillus sp. Lodo ativado (a 1 e a2) e Biofiltro Aerado Submerso (b1 e b2)... 84

Figura 5.10: Microscopia ótica das amostras enriquecidas em meio ATCC 290-S6, para Thiobacillus sp, tendo como fonte de enxofre o $\mathrm{H}_{2} \mathrm{~S}$ ao invés de tiossulfato. Lodo ativado (a 1 e a2) e Biofiltro Aerado Submerso (b1 e b2)...... 85

Figura 5.11: Microscopia ótica das amostras misturadas, enriquecidas em meio ATCC 290-S6, para Thiobacillus sp., tendo como fonte de enxofre o $\mathrm{H}_{2} \mathrm{~S}$, ao invés de tiossulfato.

Figura 5.12: Microscopia eletrônica de varredura da base, do centro e do topo do biofiltro preenchido com Espuma de poliuretano. .86

Figura 5.13: Microscopia eletrônica de varredura da base (a), do centro (b) e do topo (c) do biofiltro preenchido com Bagaço de cana.

Figura 5. 14: Microscopia eletrônica de varredura da base (a), do centro (b) e do topo (c) do biofiltro preenchido com fibra de coco. .88

Figura 5.15: Concentração afluente (^), efluentes e eficiências de remoção para os biofiltros preenchidos com espuma de poliuretano ( $\bullet$ ), fibra de coco ( $₫$ ) e bagaço de cana ( $\Delta$ ) .....92 Figura 5.16: Concentração afluente ( $\bullet$ ), efluente $(\boldsymbol{\bullet})$ e eficiências de remoção $(\bullet)$ para o biofiltro preenchido com espuma de poliuretano, durante a primeira fase de operação .....93 Figura 5.17: Concentração afluente ( $\bullet$, efluente $(\boldsymbol{\bullet})$ e eficiências de remoção $(\bullet)$ para o biofiltro preenchido com bagaço de cana, durante a primeira fase de operação 94

Figura 5.18: Concentração afluente (•), efluente $(\boldsymbol{\bullet})$ e eficiências de remoção $(\bullet)$ para o biofiltro preenchido com fibra de coco, durante a primeira fase de operação

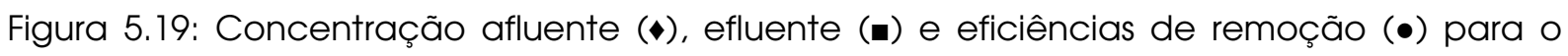


biofiltro preenchido com espuma de poliuretano, durante a segunda fase de operação ...98 Figura 5.20: Concentração afluente $(\bullet)$, efluente $(\boldsymbol{\bullet})$ e eficiências de remoção $(\bullet)$ para o biofiltro preenchido com bagaço de cana, durante a segunda fase de operação 98

Figura 5.21: Concentração afluente $(\bullet)$, efluente $(\boldsymbol{\bullet})$ e eficiências de remoção $(\bullet)$ para o biofiltro preenchido com fibra de coco, durante a segunda fase de operação 99 Figura 5.22: Concentração afluente ( $\bullet$ ), efluente $(\bullet)$ e eficiências de remoção $(\bullet)$ para o biofiltro preenchido com espuma de poliuretano, durante a terceira fase de operação....102 Figura 5.23: Concentração afluente $(\bullet)$, efluente $(\bullet)$ e eficiências de remoção $(\bullet)$ para o biofiltro preenchido com bagaço de cana, durante a terceira fase de operação 102 Figura 5.24: Concentração afluente ( $\bullet$ ), efluente $(\boldsymbol{\bullet})$ e eficiências de remoção $(\bullet)$ para o biofiltro preenchido com fibra e coco, durante a terceira fase de operação 103 Figura 5.25: Concentração afluente ( $\bullet$ ), efluente $(\bullet)$ e eficiências de remoção $(\bullet)$ para o biofiltro preenchido com espuma de poliuretano, durante a quarta fase de operação...... 106 Figura 5.26: Concentração afluente ( $\bullet$ ), efluente $(\boldsymbol{\bullet})$ e eficiências de remoção $(\bullet)$ para o biofiltro preenchido com bagaço de cana, durante a quarta fase de operação 106 Figura 5.27: Concentração afluente ( $\bullet$ ), efluente $(\bullet)$ e eficiências de remoção $(\bullet)$ para o biofiltro preenchido com fibra do coco, durante a quarta fase de operação. Figura 5.28: Taxas de carregamento mássico e eficiência de remoção para os biofiltros preenchidos com espuma de poliuretano ( $\downarrow)$, fibra de coco $(₫)$ e bagaço de cana ( $\Delta$ )....109 Figura 5.29: Capacidade de eliminação como função da concentração afluente de $\mathrm{H}_{2} \mathrm{~S}$ para os biofiltros preenchidos com espuma de poliuretano ( $($ ), fibra de coco $(₫)$ e bagaço de cana ( $\Delta)$

Figura 5.30: Capacidade de eliminação como função da taxa de carregamento mássico de $\mathrm{H}_{2} \mathrm{~S}$ para os biofiltros preenchidos com espuma de poliuretano ( $\left.\diamond\right)$, fibra de coco ( $\square$ ) e bagaço de cana $(\boldsymbol{\Lambda})$

Figura 5.31: Perfis de degradação de sulfeto para biofiltros preenchidos com espuma de poliuretano(a), bagaço de cana(b) e fibra de $\operatorname{coco}(c)$, durante a primeira fase de operação. 116 
Figura 5.32: Perfis de degradação de sulfeto para biofiltros preenchidos com espuma de poliuretano(a), bagaço de cana(b) e fibra de $\operatorname{coco}(c)$, durante a segunda fase de operação.

Figura 5.33: Perfis de degradação de sulfeto para biofiltros preenchidos com espuma de poliuretano(a), bagaço de cana(b) e fibra de $\operatorname{coco}(c)$, durante a terceira fase de operação.

Figura 5.34: Perfis de degradação de sulfeto para biofiltros preenchidos com espuma de poliuretano(a), bagaço de cana(b) e fibra de $\operatorname{coco}(c)$, durante a terceira fase de operação. 119

Figura 5.35: Rebaixo de leito observado nos biofiltros preenchidos com espuma de poliuretano (a), bagaço de cana (b) e fibra de coco (c). 122

Figura 5.36: Formação de depósitos na cor branca nos biofiltros preenchidos com espuma de poliuretano, bagaço de cana e fibra de coco.......

Figura 5.37 - Variação do pH para os biofiltros preenchidos com espuma de poliuretano ( fibra de $\operatorname{coco}(₫)$ e bagaço de cana $(\Delta)$ durante a operação contínua dos sistemas 124 Figura 5.38: Previsão do processo de biofiltração, tendo a espuma como material suporte, de acordo com o modelo de Ottengraf e Van de Oever (1983) (regime de limitação pela difusão), para uma concentração de entrada de 320 pm.

Figura 5.39: Previsão do processo de biofiltração, tendo o bagaço de cana como material suporte, de acordo com o modelo de Ottengraf e Van de Oever (1983) (regime de limitação pela difusão), para uma concentração de entrada de aproximadamente 320 ppm.

Figura 5.40: Previsão do processo de biofiltração, tendo a fibra de coco como material suporte, de acordo com o modelo de Ottengraf e Van de Oever (1983) (regime de limitação pela difusão), para uma concentração de entrada de aproximadamente 320 ppm. 


\section{LISTA DE TABELAS}

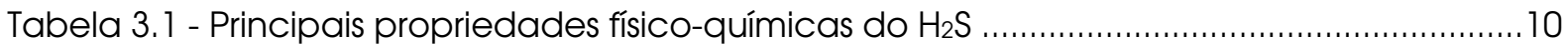

Tabela 3.2 - Exposições à diferentes concentrações de $\mathrm{H}_{2} \mathrm{~S}$ e sintomas decorrentes ...............11

Tabela 3.3 - Exemplos de fontes de energia para quimiotróficos representativos .................... 14

Tabela 3.4 - Características de algumas espécies de microrganismos utilizado na

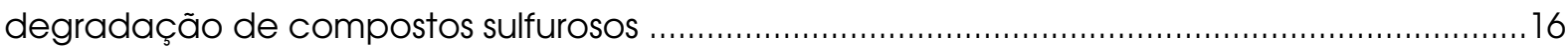

Tabela 3.5 - Vantagens e desvantagens dos reatores biológicos .............................................19

Tabela 3.6 - Parâmetros utilizados para o projeto e análise de biofiltros ...................................30

Tabela 3.7 - Fatores típicos para o projeto de biofiltros …...................................................

Tabela 3.8 - Resumo das principais características de alguns modelos matemáticos aplicados

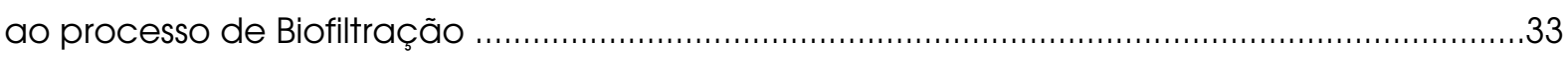

Tabela 3.9 - Pesquisas realizadas sobre remoção de sulfeto de hidrogênio em Biofiltros.........46

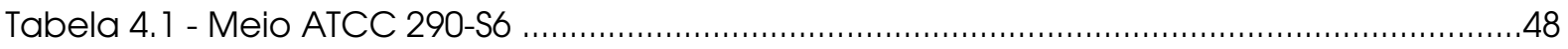

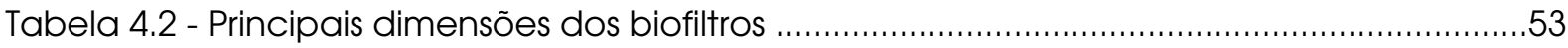

Tabela 4.3 - Componentes e suas respectivas finalidades no processo de biofiltração ..........55

Tabela 4.4 - Condições de operação do sistema .....................................................................57

Tabela 4.5 - Freqüência de análises dos ensaios de adsorção ...........................................63

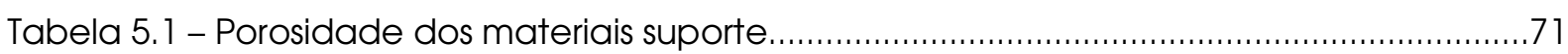

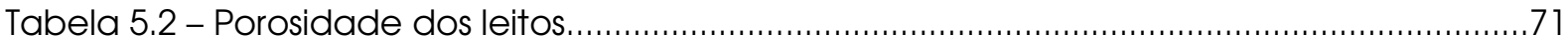

Tabela 5.3 - Comparação dos resultados de perda de carga da literatura com os obtidos

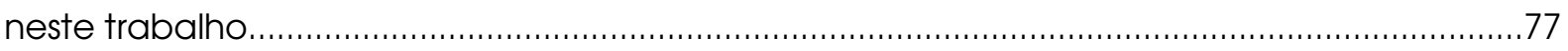

Tabela 5.4 - Permeabilidade dos leitos de espuma de poliuretano, bagaço de cana e fibra de coco. 
Tabela 5.5 - Dados obtidos no ensaio de adsorção para o Biofiltro preenchido com Espuma de Poliuretano.

Tabela 5.6 - Dados obtidos no ensaio de adsorção para o Biofiltro preenchido com Fibra de Coco 80

Tabela 5.7 - Dados obtidos no ensaio de adsorção para o Biofiltro preenchido com Bagaço de Cana. .80

Tabela 5.8 - Resultados obtidos a partir da análise de EDX. 89

Tabela 5.9 - Panorama geral da operação contínua dos sistemas.......

Tabela 5.10 - Concentrações afluentes, efluentes e eficiências de remoção para os biofiltros preenchidos com Espuma de Poliuretano, Fibra de Coco e Bagaço de Cana para a Fase 1 de operação do sistema

Tabela 5.11 - Concentrações afluentes, efluentes e eficiências de remoção para os biofiltros preenchidos com espuma de poliuretano, fibra de coco e bagaço de cana para a fase 2 de operação do sistema

Tabela 5.12 - Concentrações afluentes, efluentes e eficiências de remoção para os biofiltros preenchidos com espuma de poliuretano, fibra de coco e bagaço de cana para a fase 3 de operação do sistema 104 Tabela 5.13 - Concentrações afluentes, efluentes e eficiências de remoção para os biofiltros preenchidos com espuma de poliuretano, fibra de coco e bagaço de cana para a fase 4 de operação do sistema 108 Tabela 5.14 - Capacidades de eliminação verificadas na literatura 114 Tabela 5.15 - Resultados do ensaio experimental realizado para a modelagem matemática nos biofiltros preenchido com espuma de poliuretano, bagaço de cana e fibra de coco. 126

Tabela 5.16 - Valores calculados para a espessura do biofilme nos biofiltros preenchidos com espuma de poliuretano, bagaço de cana e fibra de coco e comparação com dados da literatura. 


\title{
LISTA DE ABREVIATURAS E SIGLAS
}

\author{
APHA American Public Health Association \\ ASTDR Agency for Toxic Substances and Disease Registry \\ ATCC American Type Culture Collection \\ CONAMA Conselho Nacional de Meio Ambiente \\ EPA Environmental Protection Agency \\ ETE Estação de Tratamento de Esgoto \\ HMDS Hexametildesilasani \\ MEV Microscopia Eletrônica de Varredura \\ US OSHA Occupational Safety and Health Administration
}




\section{LISTA DE SÍMBOLOS}

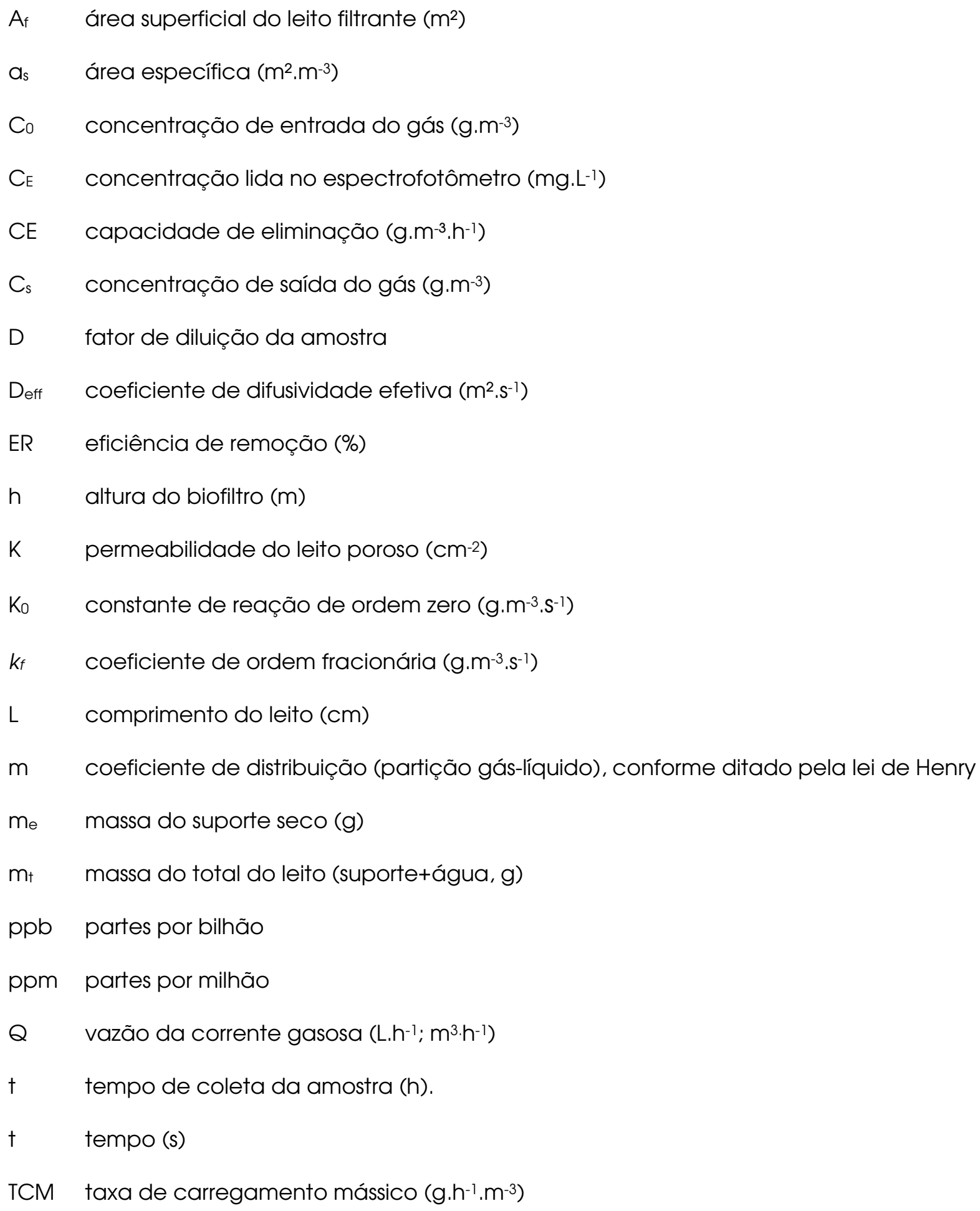


TCMS taxa de carregamento superficial $\left(\mathrm{m}^{3} \cdot \mathrm{m}^{-2} \cdot \mathrm{h}^{-1}\right)$

TCMV taxa de carregamento volumétrico $\left(\mathrm{m}^{3} \cdot \mathrm{m}^{-3} \cdot \mathrm{h}^{-1}\right)$

TRLV tempo de residência do leito vazio (h)

TRV tempo de residência verdadeiro $(h, \min , s)$

V volume de água no leito $\left(\mathrm{cm}^{3}\right)$

Va velocidade superficial $\left(m \cdot s^{-1}\right)$

Vf volume total do leito filtrante $\left(\mathrm{m}^{3}\right)$

V $\quad$ volume da amostra (L)

$V_{\dagger} \quad$ volume total do leito $\left(\mathrm{cm}^{3}\right)$

$V_{v} \quad$ volume de vazios $\left(\mathrm{cm}^{3}\right)$

24,44 volume molar corrigido para $1 \mathrm{~atm}$ e $25^{\circ} \mathrm{C}\left(\mathrm{L} . \mathrm{mol}^{-1}\right)$

$\delta \quad$ espessura do biofilme $(m)$

$\Delta \mathrm{P} \quad$ queda de pressão $\left(\right.$ dyn. $\left.\mathrm{cm}^{-2}\right)$

$\varepsilon$ porosidade

$\mu \quad$ viscosidade do fluido $\left(\mathrm{g} \cdot \mathrm{cm}^{-1} \cdot \mathrm{s}^{-1}\right)$

م massa específica da água a $25^{\circ}\left(\mathrm{g}_{\mathrm{g}} \mathrm{cm}^{-3}\right)$ 
RESUMO

ABSTRACT

LISTA DE ILUSTRAÇÕES iii

LISTA DE TABELAS vii

LISTA DE ABREVIATURAS E SIGLAS IX ix

LISTA DE SÍMBOLOS $\quad$ X

1 INTRODUÇÃO

2 OBJETIVOS $\quad 5$

3 REVISÃO DE LITERATURA

3.1 CICLO DO ENXOFRE 6

3.1.1 Ciclo biológico do enxofre $\quad 8$

3.2 CARACTERÍSTICAS DO SULFETO DE HIDROGÊNIO 9

3.3 TRATAMENTO DO SULFETO DE HIDROGÊNIO 11

3.3.1 Processos físico-químicos 12

3.3.2 Processos biológicos 13

3.3.2.1 Microrganismos utilizados na biorremoção de sulfetos 13

3.3.2.2 Biorreatores utilizados para remoção de $\mathrm{H}_{2} \mathrm{~S}$

3.4 O PROCESSO DE BIOFILTRAÇÃO 20

$\begin{array}{lr}3.4 .1 \text { Introdução } & 20\end{array}$

3.4.2 Fatores operacionais do processo 23

3.4.2.1 Material suporte 23

3.4.2.2 Teor de Umidade 26 
3.4.2.3 pH - Potencial Hidrogeniônico

$\begin{array}{ll}3.4 .2 .4 \text { Temperatura } & 28\end{array}$

3.4.2.5 Concentração dos poluentes 28

3.4.2.6 Nutrientes 38

3.4.3 Parâmetros de projeto e operação de biofiltros 30

3.4.4 Modelos matemáticos aplicados ao processo de biofiltração 33

$\begin{array}{ll}3.4 .5 \text { Resultados de pesquisas } & 39\end{array}$

$\begin{array}{ll}\text { 3.4.6 Considerações finais } & 47\end{array}$

4 MATERIAIS E MÉTODOS $\quad 48$

4.1 MICRORGANISMOS E MEIO DE CULTURA 48

4.2 MEIOS SUPORTE: ESPUMA DE POLIURETANO, BAGAÇO DE CANA E FIBRA DE COCO 49

4.3 EMPACOTAMENTO DO RECHEIO 51

4.4 APARATO EXPERIMENTAL E CONDIÇÕES DE OPERAÇÃO

4.5 ADIÇÃO DE NUTRIENTES

4.6 POROSIDADE DO LEITO

4.7 ENSAIOS FLUIDODINÂMICOS

4.7.1 Equações utilizadas $\quad 59$

4.7.2 Obtenção experimental dos dados / fluidodinâmica 60

4.8 METODOLOGIAS ANALÍTICAS UTILIZADAS 61

4.8.1 Determinação de sulfeto 61

4.8.2 Determinação do pH 62

4.9 ENSAIO DE ADSORÇÃO 62

4.10 MICROSCOPIA ÓPTICA E ELETRÔNICA DE VARREDURA 63

4.11 CAP. DE ELIMINAÇÃO, TAXA DE CARREGAMENTO E EFICIÊNCIA DE REMOÇÃO 65

4.12 DESCRIÇÃO MATEMÁTICA DO PROCESSO 66

4.12.1 Modelo utilizado 66

4.12.2 Obtenção experimental dos dados/modelo matemático 69 
5.1 ENSAIOS HIDRODINÂMICOS

$\begin{array}{ll}\text { 5.1.1 Porosidade } & 70\end{array}$

5.1.2 Perda de Carga $\quad 72$

5.2 ENSAIO DE ADSORÇÃO 78

5.3 MICRORGANISMOS 82

5.3.1 Pré-inoculação: Microscopia ótica $\quad 82$

5.3.2 Operação contínua: Microscopia eletrônica de varredura 86

5.4 OPERAÇÃO CONTÍNUA DOS SISTEMAS 90

$\begin{array}{ll}\text { 5.4.1 Abordagem geral } & 90\end{array}$

5.4.2 Desempenho durante a Fase 1

5.4.3 Desempenho durante a Fase 2 97

5.4.4 Desempenho durante a Fase $3 \quad 101$

5.4.5 Desempenho durante a fase 4

5.5 TAXA DE CARREGAMENTO MÁSSICO 109

5.6 CAPACIDADE DE ELIMINAÇÃO 11

5.7 PERFIL DE DEGRADAÇÃO DO SULFETO AO LONGO DO LEITO 115

$\begin{array}{ll}\text { 5.8 COLMATAÇÃO DO LEITO } & 121\end{array}$

5.9 POTENCIAL HIDROGENIÔNICO - pH 124

5.10 APLICAÇÃO DO MODELO MATEMÁTICO 126

6 CONCLUSÕES

7 SUGESTÕES $\quad 135$

8 REFERÊNCIAS 136

9 APÊNDICE 


\section{INTRODUÇÃO}

O aumento notório da emissão de poluentes atmosféricos, devido principalmente ao desenvolvimento industrial e urbano, tem preocupado a sociedade. O acréscimo das concentrações atmosféricas destas substâncias, a sua deposição no solo, nos vegetais e nos materiais é responsável por danos à saúde, redução da produção agrícola, danos florestais, degradação de construções e, de forma geral, origina desequilíbrios nos ecossistemas.

Entenda-se por poluente atmosférico como qualquer forma de matéria ou energia com intensidade e em quantidade, concentração, tempo ou características em desacordo com níveis estabelecidos, e que tornem ou possam tornar o ar impróprio, nocivo ou ofensivo à saúde; danoso aos materiais; e prejudicial à segurança, ao uso e gozo da propriedade e às atividades normais da comunidade, dentre outros (CONAMA, 1989).

A problemática da poluição atmosférica está integrada a alguns componentes ditos básicos, tais como: as fontes de emissão de poluentes, atmosfera e corpos receptores. As fontes emissoras lançam os poluentes na atmosfera, estes são transportados, dispersos e modificados quimicamente ou fisicamente no meio atmosférico e finalmente alcançam os corpos receptores.

Dentre os diversos poluentes lançados na atmosfera destacam-se, por seu alcance em escala local e global, os compostos orgânicos voláteis (etanol, acetona, butanol, benzeno, acetato de butila, dietilamina, hexano, metanol, entre outros), amônia $\left(\mathrm{NH}_{3}\right)$, óxidos de nitrogênio $\left(\mathrm{NO}_{x}\right)$, dióxido de enxofre $\left(\mathrm{SO}_{2}\right)$, óxidos de carbono $\left(\mathrm{CO}_{\mathrm{x}}\right)$, hidrocarbonetos (HCs), oxidantes fotoquímicos (PAN, $\mathrm{O}_{3}$, dentre outros), material particulado (MP), ácido fluorídrico (HF), bifenilas policloradas (PCBs) e gás sulfídrico $\left(\mathrm{H}_{2} \mathrm{~S}\right)(\mathrm{MAlA}, 2003$; TACLA, 2004) .

Em especial, o sulfeto de hidrogênio $\left(\mathrm{H}_{2} \mathrm{~S}\right)$ - também conhecido como gás sulfídrico, ácido sulfídrico e gás hidrosulfúrico - pode causar graves danos ambientais se lançado ao 
meio ambiente, devido a sua elevada toxicidade, corrosividade, odores indesejáveis e alta demanda de oxigênio (SYED et al., 2006; ROCHA, 2007).

Este composto está presente, em grande quantidade, nos poluentes gasosos emitidos pelas indústrias de celulose e papel, matadouros, curtumes, indústrias petroquímicas e de alimentos (CHUNG, HUANG e TSENG, 1996). As concentrações de $\mathrm{H}_{2} \mathrm{~S}$ no biogás variam de 0,1 a $2 \%$ da concentração total do efluente gasoso produzido (50 - 1000 ppm), que é suficiente para causar os mais diversos problemas, desde o desconforto ambiental até a morte (SYED et al., 2006).

Os impactos da inalação do sulfeto de hidrogênio por seres humanos são, em geral, graves, pois o mesmo reage com as enzimas da corrente sanguínea, inibindo a respiração celular, resultando em paralisia pulmonar, colapso súbito e morte (SYED et al., 2006). Segundo Oyarzún et al. (2003), nos ambientes onde a concentração do sulfeto de hidrogênio encontrar-se acima de 600 ppm, a exposição por períodos superiores a 30 minutos pode ser fatal.

Barona et al. (2004) destacam que os problemas relativos à saúde humana devido à exposição a altas concentrações de $\mathrm{H}_{2} \mathrm{~S}$ são conhecidos, contudo ainda há pouca informação a respeito dos impactos desta exposição quando ocorrida à baixas concentrações e por um longo período de tempo.

No intuito de remover esse gás altamente tóxico de fluxos gasosos, foram desenvolvidos e estabelecidos diferentes tipos de processos físico-químicos, tais como: lavadores de gás, oxidação, precipitação química, adsorção e incineração. Essas técnicas apresentam boas eficiências de remoção e até a recuperação de enxofre elementar, contudo possuem alto custo operacional e de manutenção (JEONG e KIM, 1999; ABBATI e SILVA, 2005; BAQUERIZO et al., 2005). Tais processos podem, ainda, requerer a utilização de aditivos químicos, o que leva a geração de problemas ambientais, que incluem a possível formação, por exemplo, de compostos orgânicos clorados (FUTIWAKI, 2004).

Por apresentar gastos energéticos relativamente mais baixos e não necessitar de aditivos químicos adicionais, a via biológica de remoção de sulfetos tem sido estudada como uma alternativa aos métodos físico-químicos tradicionais (KOBAYASHI, STENSTROM e 
MAH, 1983; HENSHAW e SYED, 2003). Syed et al. (2006) corroboraram essas informações quando afirmaram que os processos biológicos de remoção de sulfeto de hidrogênio possuem potencial para superar algumas ou, até mesmo, todas as desvantagens dos processos físico-químicos, inclusive com recuperação do enxofre elementar, conforme reportado em trabalhos como os de Chung, Huang e Tseng (1996) e Kim, Rene e Park (2007).

Dentre as opções biotecnológicas existentes, destaque tem sido dado aos biorreatores de células imobilizadas, nos quais se encontra o biofiltro, por isso os mesmo têm emergido como um dos processos biológicos mais importantes no tratamento de $\mathrm{H}_{2} \mathrm{~S}$. Sabese que os biofiltros possuem baixo custo de implantação e operação para sua regeneração e recirculação, menor necessidade de energia e possuem aceitação pública como um processo interessante do ponto de vista ambiental, por reduzirem a poluição secundária (BOHN e BOHN, 1999; DELGADO 1999 et al., 1999 ' apud MA, YANG e ZHAO, 2006).

Nos biofiltros, o $\mathrm{H}_{2} \mathrm{~S}$ escoa por um leito fixo com biomassa aderida, que tem a finalidade de convertê-lo em produtos menos impactantes. O gás poluente é absorvido pela biomassa e, subseqüentemente, oxidado a produtos finais, tais como: dióxido de carbono, enxofre elementar e sulfatos. Muitos fatores importantes, dentre eles, a qualidade do meio suporte, o tamanho das partículas, a diversidade microbiana, a umidade e os nutrientes, associados às condições fluidodinâmicas, que incluem o tempo de residência do gás e sua distribuição, determinam o desempenho de sistemas de biofiltração.

É consenso na literatura que o material suporte tem importância fundamental nos processos de biofiltração. Desta forma, neste trabalho, três tipos de meio suporte, incluindo a espuma de poliuretano (meio sintético), o bagaço de cana e a fibra de coco (meios orgânicos), foram utilizados como materiais de enchimento para a imobilização de cultura mista na biofiltração de $\mathrm{H}_{2} \mathrm{~S}$.

Dentro desse contexto, apesar de bastante difundidos nos países desenvolvidos, são escassos os estudos relacionados ao tratamento biológico de efluentes gasosos na América Latina e, em especial, no Brasil; neste caso podem ser citados alguns trabalhos realizados

I DELGADO, S.; ALVAREZ, M.; RODRIGUEZ-GOMES, L.E. (1999) $\mathrm{H}_{2} \mathrm{~S}$ Generation in a reclaimed urban wastewater pipe. Case study: Tenerife. Water Research, n. 33, p. 539-547. 
pelo Departamento de Engenharia Sanitária e Ambiental da Universidade Federal de Santa Catarina, pelo Departamento de Engenharia Química da Universidade Federal do Paraná e pelo Departamento de Engenharia Química da Universidade Federal de São Carlos em parceria com o Departamento de Hidráulica e Saneamento da Escola de Engenharia de São Carlos da Universidade de São Paulo.

O número de trabalhos ainda é escasso, dessa forma, fica clara a necessidade do desenvolvimento de processos biotecnológicos capazes de degradar de forma eficiente fluxos gasosos contendo compostos tóxicos em âmbito nacional, justamente para verificar a viabilidade técnico-econômica desses processos. 


\section{OBJETIVOS}

O objetivo geral deste trabalho foi avaliar o desempenho do tratamento biológico de sulfeto de hidrogênio $\left(\mathrm{H}_{2} \mathrm{~S}\right)$ utilizando biofiltro.

Os objetivos específicos foram:

a) avaliar a depuração de fluxo gasoso contendo $\mathrm{H}_{2} \mathrm{~S}$, utilizando tais biofiltros com diferentes tipos de materiais suporte, sendo dois materiais orgânicos (bagaço de cana e fibra de coco) e um sintético (espuma de poliuretano).

b) verificar o efeito da utilização da mistura de diferentes inóculos na partida dos sistemas;

c) analisar a fluidodinâmica dos respectivos leitos por meio de ensaios de perda de carga em função da vazão de ar e da umidade do leito;

c) verificar o efeito da adsorção nos materiais suporte;

d) aplicar o modelo proposto por Ottengraf e Van de Over (1983). 


\section{REVISÃO DE LITERATURA}

\subsection{CICLO DO ENXOFRE}

O ciclo do enxofre envolve, principalmente, o sulfeto de hidrogênio $\left(\mathrm{H}_{2} \mathrm{~S}\right)$, o dimetil sulfeto $\left(\mathrm{CH}_{3}\right)_{2} \mathrm{~S}$, o dióxido de enxofre $\left(\mathrm{SO}_{2}\right)$, o anidrido sulfídrico $\left(\mathrm{SO}_{3}\right)$ e sulfatos $\left(\mathrm{SO}_{4}{ }^{2}\right)$.

Esses e outros compostos de enxofre entram na atmosfera, devido principalmente às atividades humanas. Aproximadamente 100 milhões de toneladas/ano de enxofre são incorporados à atmosfera global via fontes antropogênicas, principalmente na forma de $\mathrm{SO}_{2}$, originário da combustão de carvão e óleo combustivel residual (MANAHAN, 2000).

A Figura 3.1 apresenta os principais aspectos do ciclo global de enxofre.

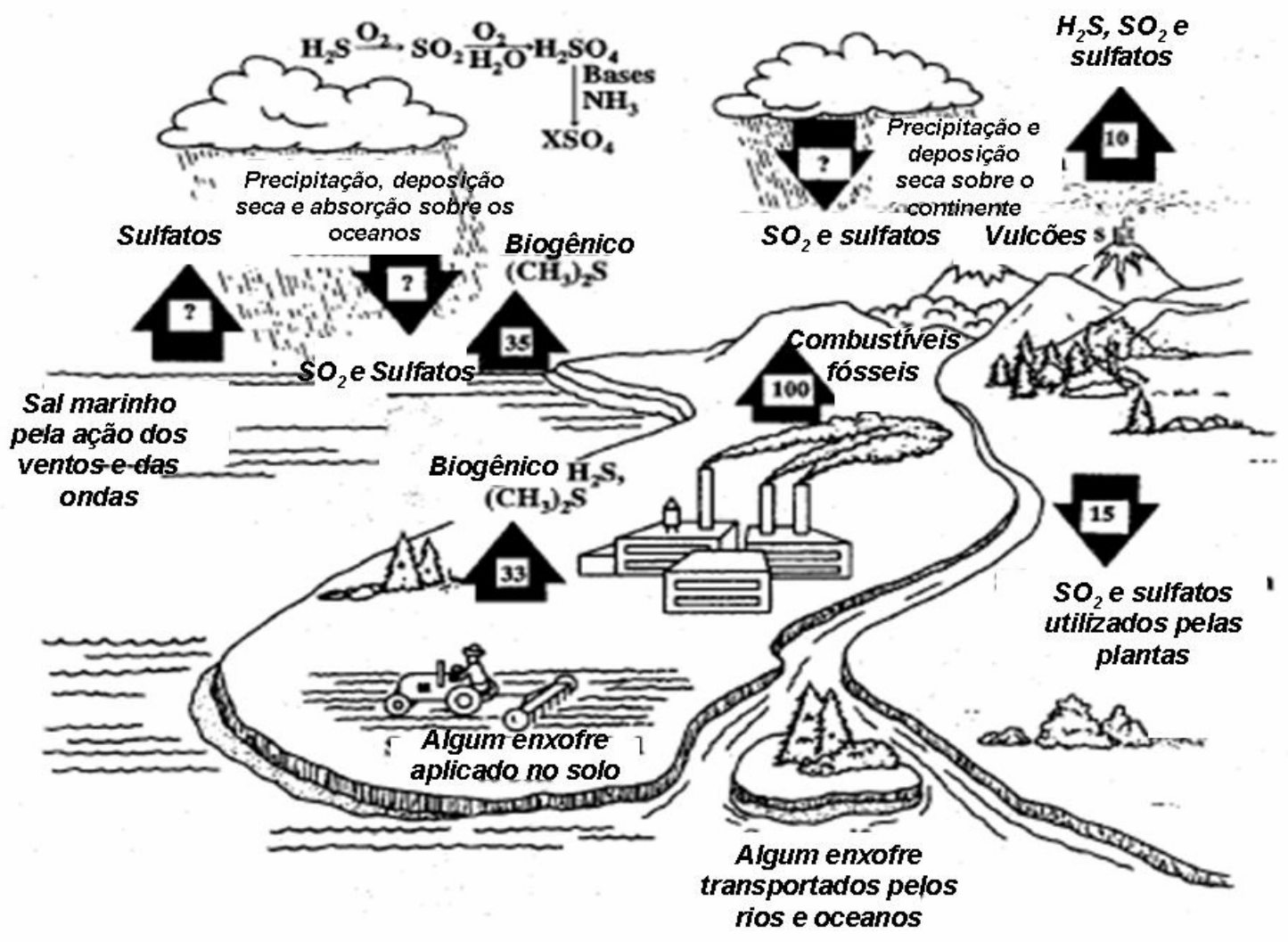

Figura 3.1: Ciclo global de enxofre. Os fluxos de enxofre representados pelas setas estão em milhões de toneladas por ano. As interrogações representam quantidades incertas de enxofre (muito provavelmente, atingem a ordem de 100 milhões de toneladas por ano). Fonte: MANAHAN (2000). 
Manahan (2000) afirma que as maiores incertezas quanto ao aspecto quantitativo do ciclo estão ligadas ao enxofre não-antropogênico, que adentra a atmosfera principalmente como $\mathrm{SO}_{2}$ e $\mathrm{H}_{2} \mathrm{~S}$, lançados por vulcões; e $\left(\mathrm{CH}_{3}\right)_{2} \mathrm{~S}$ e $\mathrm{H}_{2} \mathrm{~S}$, gerados via biodegradação da matéria orgânica e redução de sulfato. Acredita-se que a única fonte considerável de enxofre natural lançado na atmosfera seja o $\left(\mathrm{CH}_{3}\right)_{2} \mathrm{~S}$ biogênico, via fontes marinhas. Já $\circ \mathrm{H}_{2} \mathrm{~S}$ oxida-se rapidamente a dióxido de enxofre $\left(\mathrm{SO}_{2}\right)$, podendo também ser oxidado pelo oxigênio atômico e molecular e, ainda, pelo ozônio.

A reação de oxidação entre sulfeto de hidrogênio e o ozônio é apresentada na Equação 3.1:

$\mathrm{H}_{2} \mathrm{~S}+\mathrm{O}_{3} \rightarrow \mathrm{H}_{2} \mathrm{O}+\mathrm{SO}_{2}$

Estima-se que o tempo de "vida" de 1 ppb de $\mathrm{H}_{2} \mathrm{~S}$ exposto a 50 ppb de $\mathrm{O}_{3}$, na presença de 15.000 partículas $/ \mathrm{cm}^{3}$, é de aproximadamente duas horas (SEINFELD2, 1978 apud TACLA, 2004).

Com isso, pode-se afirmar que $\mathrm{O}_{2} \mathrm{~S}$ é um dos diversos gases que contribui para a destruição da camada de ozônio e, conseqüentemente, para o aquecimento global, pois na reação descrita na Equação 1, ocorre a diminuição do número de moléculas de ozônio na atmosfera, devido as mesmas atuarem na oxidação do $\mathrm{H}_{2} \mathrm{~S}$ a $\mathrm{SO}_{2}$ (Environmental Protection Agency - EPA, 2006).

O dióxido de enxofre $\left(\mathrm{SO}_{2}\right)$, produto da reação descrita na Equação 3.1, é oxidado a $\mathrm{SO}_{3}$ pelo oxigênio atmosférico. Finalmente, $\mathrm{O} \mathrm{SO}_{3}$ reage com o vapor d'água presente na atmosfera e é convertido a ácido sulfúrico $\left(\mathrm{H}_{2} \mathrm{SO}_{4}\right)$, que retorna ao solo na forma de "chuva ácida" (Equações 3.2 e 3.3).

\footnotetext{
2 SEINFELD, J.H. Contaminación atmosférica: fundamentos físico y químicos. Tradução: Rafael Mujeriego. Ph.D. e Geneviève Derouex. Madrid: Instituto de Estúdios de Administración Local, 1978. 558 p.
} 
$2 \mathrm{SO}_{2}+\mathrm{O}_{2} \rightarrow \mathrm{SO}_{3}$

$\mathrm{SO}_{3}+\mathrm{H}_{2} \mathrm{O} \rightarrow \mathrm{H}_{2} \mathrm{SO}_{4}$

A chuva ácida é retida pelas nuvens e pode viajar até $500 \mathrm{~km}$ por dia, dependendo da direção e força do vento. Devido à sua composição, estas chuvas alteram a composição química do solo, provocam e envenenamento dos cursos de água, fauna e flora, atingindo a cadeia alimentar, sendo ainda responsáveis pela corrosão de metais, rochas e edifícios (ACID RAIN, 2007).

\subsubsection{Ciclo biológico do enxofre}

Os processos biológicos para a remoção de compostos sulfurosos são baseados no ciclo biológico do enxofre apresentado na figura 3.2.

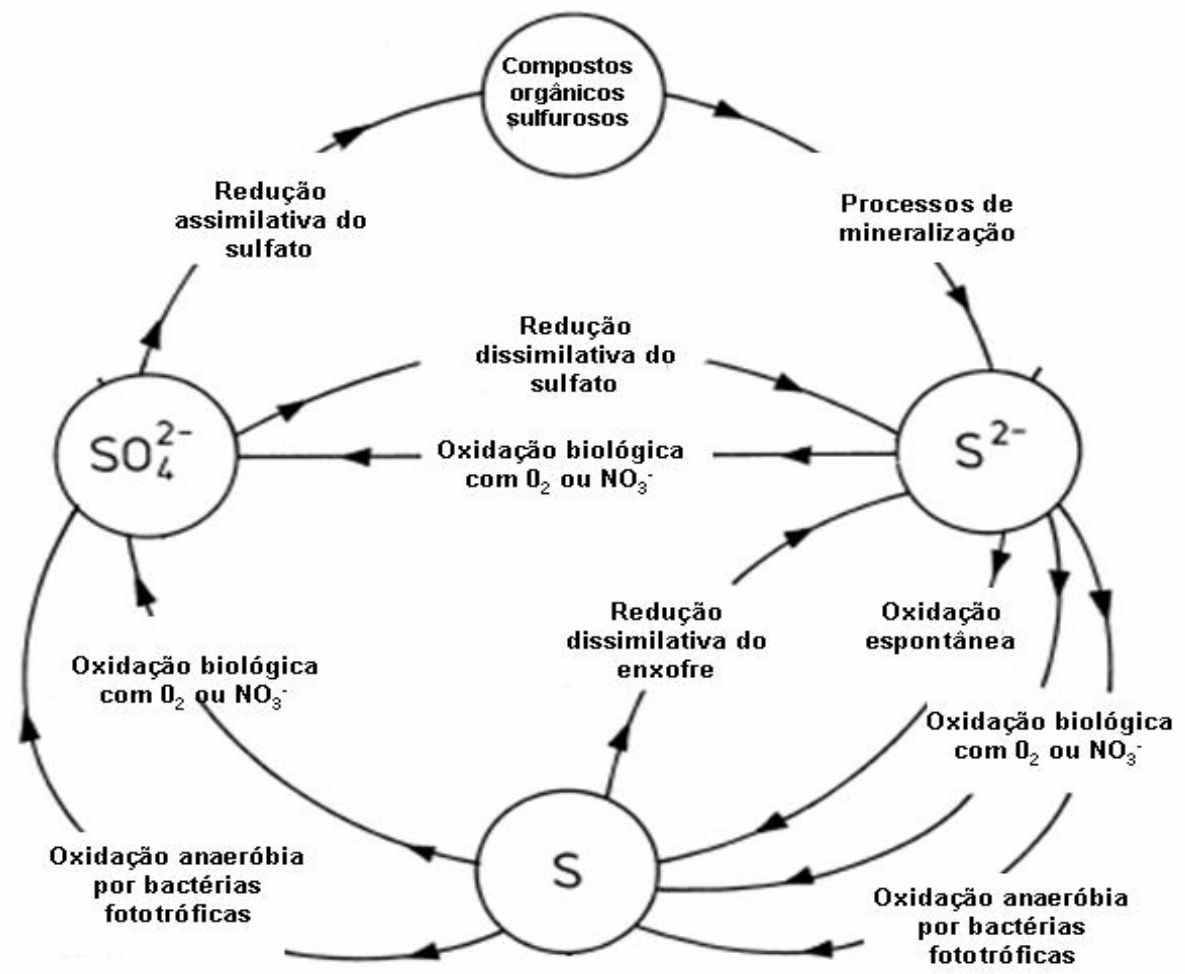

Figura 3.2: Ciclo biológico do enxofre

Fonte: LENS e KUENEN (2001). 
Conforme pode ser observado na Figura 3.2, o sulfato $\left(\mathrm{SO}_{4}^{2-}\right)$, forma mais oxidada do enxofre, é reduzido a compostos orgânicos sulfurosos por plantas, fungos e vários procariotes no processo conhecido com redução assimilativa do sulfato. Então, estas moléculas orgânicas podem sofrer o processo de dessulfurização, no qual produzem o sulfeto de hidrogênio (LENS e KUENEN, 2001).

A oxidação do sulfeto de hidrogênio produz enxofre elementar (S०), reação realizada pelas bactérias fotossintéticas verdes e púrpuras e, ainda, por alguns quimiolitotróficos. enxofre elementar é oxidado a sulfato por bactérias que podem utilizar tanto o oxigênio como o nitrato como aceptores de elétrons ou, ainda, reduzido para sulfeto de hidrogênio, no processo conhecido como redução dissimilativa do enxofre.

Finalmente, através do processo de redução dissimilativa do sulfato, os organismos redutores geram sulfeto de hidrogênio, que pode ser convertido diretamente a sulfato por meio da oxidação biológica, tendo o $\mathrm{O}_{2}$ e $\mathrm{N} \mathrm{NO}_{2}$ como aceptores de elétrons.

\subsection{CARACTERÍSTICAS DO SULFETO DE HIDROGÊNIO}

É fácil reconhecer a presença de algum composto que contenha sulfeto, devido ao seu forte odor (característico de ovo podre). Ele geralmente é encontrado na forma de sulfeto de hidrogênio, um gás mais denso que o ar, extremamente inflamável, muito tóxico por inalação, que se acumula em espaços confinados e forma mistura explosiva com o ar, nas condições normais de temperatura e pressão (FUTIWAKI, 2004).

Segundo a ATSDR $^{3}$ (1999) apud Tacla (2004), o sulfeto de hidrogênio ocorre naturalmente no petróleo, gás natural, pântanos, reservatórios de esterco e nos gases vulcânicos. Este gás também é produzido na decomposição do lixo urbano e industrial e durante a combustão de carvão e óleos derivados do petróleo e do xisto betuminoso.

${ }^{3}$ ATSDR - AGENCY FOR TOXIC SUBSTANCES AND DISEASE REGISTRY. Managing hazardous materials incidents. Vol. 3 Medical Management Guidelines for Acute Chemical Exposures: hydrogen sulfide. Department of Health and Human Services, Public Health Service. Atlanta, GA. 1999. 
A Tabela 3.1 apresenta as principais propriedades físico-químicas do $\mathrm{H}_{2} \mathrm{~S}$.

Tabela 3.1 - Principais propriedades físico-químicas do $\mathrm{H}_{2} \mathrm{~S}$

\begin{tabular}{cc}
\hline Propriedades & Valores \\
\hline Massa molecular $\left(\mathrm{g} \cdot \mathrm{mol}^{-1}\right)$ & 34,08 \\
Ponto de fusão $\left({ }^{\circ} \mathrm{C}\right)$ & $-84,15$ \\
Ponto de ebulição $\left({ }^{\circ} \mathrm{C}\right)$ & $-60,15$ \\
Temperatura crítica $\left({ }^{\circ} \mathrm{C}\right)$ & 99,85 \\
Pressão crítica $(\mathrm{Pa})$ & 8940000 \\
Pressão de vapor $\left(20^{\circ} \mathrm{C}\right)(\mathrm{Pa})$ & 1880000 \\
Densidade relativa (gás) & $1,2(\mathrm{ar}=1)$ \\
Densidade relativa (líquido) & $0,92($ água $=1)$ \\
Solubilidade (mg.L-1 água) & 3980 \\
Cor (aparência) & Incolor \\
Odor & Ovo podre \\
Temperatura de ignição $\left({ }^{\circ} \mathrm{C}\right)$ & 270 \\
Faixa de inflamabilidade $(\%$ em volume no ar) & $4,3-45,5$
\end{tabular}

Fonte: Adaptado de TACLA (2003) e FUTIWAKI (2004).

O sulfeto de hidrogênio pode envenenar diversas partes do corpo humano. A inalação deste composto pode causar tonturas, dores de cabeça, náusea, falha na respiração, coma ou inconsciência (TACLA, 2004).

Segundo reportado pela EPA (2006), o $\mathrm{H}_{2} \mathrm{~S}$ causa efeitos danosos ao sistema nervoso central, metabolismo e trato intestinal. A exposição prolongada a pequenas concentrações pode resultar em edema pulmonar. A inalação contínua a baixas concentrações de sulfeto de hidrogênio causa fadiga e irritação nos olhos. Em altas concentrações, o sulfeto de hidrogênio causa deficiência de oxigênio no ambiente, especialmente se liberado em áreas com pouca ventilação ou espaços fechados.

Na Tabela 3.2 são apresentados os sintomas resultantes da exposição do sulfeto de hidrogênio para cada faixa de concentração. 
Tabela 3.2 - Exposições à diferentes concentrações de $\mathrm{H}_{2} \mathrm{~S}$ e sintomas decorrentes

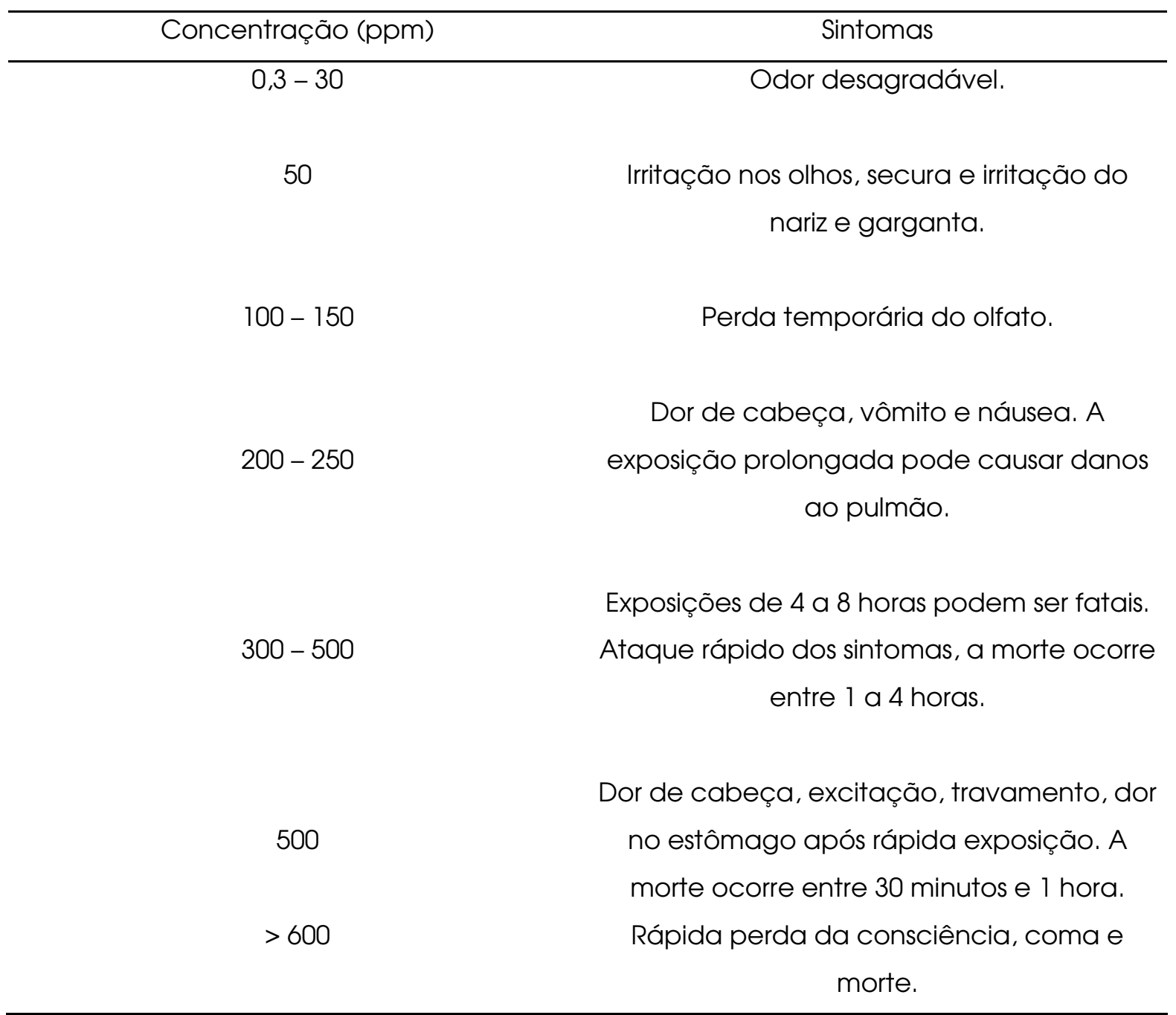

Fonte: US OSHA 4 et al. (2002) apud TACLA (2004)

\subsection{TRATAMENTO DO SULFETO DE HIDROGÊNIO}

Neste item serão abordadas as possibilidades de tratamento do sulfeto de hidrogênio, com breve descrição dos processos físico-químicos mais importantes. Maior ênfase será dada às biotecnologias disponiveis e, em especial, ao processo de biofiltração, que é o objeto deste trabalho.

4 U.S. OSHA: CMA; ANSI; WHMIS. Material safety data sheet: helium/hydrogen sulfide gas mixtures MSDS. New Jersey, 2002. $11 \mathrm{p}$. 


\subsubsection{Processos físico-químicos}

Técnicas convencionais, representadas pelos processos físicos e químicos (ex: absorção, adsorção, oxidação por ozônio e incineração), têm sido utilizadas com a finalidade de remover poluentes em efluentes gasosos. Contudo, os custos de disposição destes métodos tradicionais são elevados e, via de regra, geram poluentes secundários (MA, YANG e ZHAO, 2006).

- Absorção

Dentre os processos físicos, pode-se destacar a absorção, caracterizada basicamente pelo contato entre líquido e gás, na qual um ou mais componentes do gás dissolvem-se no líquido. O princípio da operação é a diferença de solubilidade, sendo que o agente é o líquido não volátil na temperatura do processo. O processo difusional que ocorre em cada lado da interface gás-líquido determina a taxa de transferência do poluente gasoso para o meio líquido.

Desse modo, BUONICORE e DAVIS (1992), afirmam que a taxa de absorção é determinada pelas taxas de difusão de ambas as fases.

- Adsorção

A adsorção é um processo físico-químico muito utilizado no tratamento de poluentes gasosos. Segundo Moraes Jr. (1991), o fundamento deste processo baseia-se na retenção, por meio de forças físicas ou químicas, de moléculas dos líquidos, gases ou vapores (adsorvato), na superfície de um sólido (adsorvente). Portanto a adsorção deve ser distinguida da absorção, pois na primeira a substância fica retida na superfície, não se difundindo para o seio do líquido, como ocorre na segunda.

Como é comum nos processos físicos, a adsorção pode gerar resíduo, nos quais o material adsorvido não consegue mais ser removido. A poluição secundária deve ser 
considerada neste tipo de operação, uma vez que a geração de sólidos ou líquidos tão poluentes como o gás a ser tratado inviabiliza o processo (RODRIGUES, 2002).

\section{- Incineração}

Dentre os processos químicos, o mais utilizado no tratamento de poluentes gasosos é a incineração, cujos fundamentos são os mesmos da combustão. A combustão, em suma, promove uma combinação rápida do oxigênio com vários compostos químicos. Seu princípio baseia-se em fornecer ao sistema temperaturas mais altas que aquelas de ignição dos gases, que são temperaturas mínimas para este processo (BUONICORE e DAVIS, 1992).

Alguns problemas, além dos altos custos de implantação e manutenção, típicos deste tipo de processo, podem ser enumerados, sendo um dos mais conhecidos representado pela combustão incompleta de muitos compostos orgânicos, que resulta na formação de ácidos orgânicos ou aldeídos, que por sua vez, ocasionam problemas ambientais adicionais (RODRIGUES, 2002; MAIA, 2003; ROCHA, 2007).

\subsubsection{Processos biológicos}

\subsubsection{Microrganismos utilizados na biorremoção de sulfetos}

Diversos organismos quimiotróficos são aptos a biodegradar $\circ \mathrm{H}_{2} \mathrm{~S}$ em reatores biológicos, tais como: gêneros Xanthomonas sp. (Cho, Hyrai e Shoda, 1992a), Pseudomonas sp. (Chung, Huang e Tseng, 2001; Rodrigues, 2002) e Thiobacillus sp. (Chung. Huang e Tseng, 1996; Chung et al., 2000; Cho, Ryu e Lee, 2000; Rodrigues, 2002), Acidithiobacillus sp. (Lee, Cho e Ryu, 2005), dentre outros.

Estes organismos podem crescer e produzir novo material celular por meio da utilização de carbono inorgânico $\left(\mathrm{CO}_{2}\right)$ como fonte de carbono e energia química a partir da oxidação de compostos inorgânicos reduzidos, tais como o $\mathrm{H}_{2} \mathrm{~S}$. Na presença de fontes reduzidas de carbono orgânico (glicose, aminoácidos, etc.), alguns destes microrganismos 
podem crescer heterotroficamente, utilizando o carbono orgânico como fonte de carbono e um composto inorgânico como fonte de energia (PRESCOTT, HARLEY e KLEIN, 2003).

A biodegradação $\mathrm{H}_{2} \mathrm{~S}$ por quimiotróficos ocorre em condições aeróbias tendo o oxigênio $\left(\mathrm{O}_{2}\right)$ como aceptor de elétrons ou em condições anaeróbias com aceptores de elétrons alternativos como, por exemplo, o nitrato, dependendo do tipo de bactéria (PRESCOTT, HARLEY e KLEIN, 2003).

Os produtos resultantes da oxidação dependem da linhagem dos microrganismos. Muitas espécies são capazes de oxidar o $\mathrm{H}_{2} \mathrm{~S}$ a enxofre elementar. Este poderá ser oxidado a sulfato quando a concentração de $\mathrm{H}_{2} \mathrm{~S}$ do ambiente for baixa e, nesse caso, a redução do pH acarretará no retardo da atividade microbiana e inibição da oxidação do $\mathrm{H}_{2} \mathrm{~S}$ (CHUNG, HUANG e LI, 1997).

Em particular, as bactérias quimioheterotróficas do gênero Thiobacillus sp. parecem ser as mais aceitas com relação à biorremoção de sulfetos devido às suas simples necessidades nutricionais, facilidade no desenvolvimento utilizando o $\mathrm{H}_{2} \mathrm{~S}$ como fonte de energia, alta eficácia, resistência às substâncias tóxicas e viabilidade em ampla faixa de pH. Microrganismos deste gênero têm sido estudados em diversas pesquisas (CHO, HIRAl e SHODA, 1992b; CHUNG, HUANG E TSENG, 1996; CHUNG et al., 2000; CHO, RYU e LEE, 2000;

CHUNG, HUANG E TSENG, 2001; RODRIGUES, 2002; MAIA, 2003; OYARZÚN et al. , 2003).

Exemplos de fontes de energia para Thiobacillus são apresentados na Tabela 3.3.

Tabela 3.3 - Exemplos de fontes de energia para quimiotróficos representativos

\begin{tabular}{ccccc}
\hline Bactéria & $\begin{array}{c}\text { Doador de } \\
\text { elétron }\end{array}$ & $\begin{array}{c}\text { Aceptor de } \\
\text { elétron }\end{array}$ & $\begin{array}{c}\text { Fonte de } \\
\text { carbono }\end{array}$ & Produtos \\
\hline Thiobacillus $s p$. & $\mathrm{S}^{0}, \mathrm{H}_{2} \mathrm{~S}, \mathrm{~S}_{2} \mathrm{O}_{3}{ }^{2-}$ & $\mathrm{O}_{2}$ & $\mathrm{CO}_{2}$ & $\mathrm{SO}_{4}^{2-}$ \\
Thiobacillus denitrificans & $\mathrm{S}^{0}, \mathrm{H}_{2} \mathrm{~S}, \mathrm{~S}_{2} \mathrm{O}_{3}{ }^{2-}$ & $\mathrm{O}_{2}, \mathrm{NO}_{3}-$ & $\mathrm{CO}_{2}$ & $\mathrm{SO}_{4}^{2-}, \mathrm{N}^{2}$ \\
Thiobacillus ferooxidans & $\mathrm{Fe}^{2+}, \mathrm{S}^{0}, \mathrm{H}_{2} \mathrm{~S}$ & $\mathrm{O}_{2}$ & $\mathrm{CO}_{2}$ & $\mathrm{Fe}^{3+}, \mathrm{SO}_{4}{ }^{2-}$ \\
\hline
\end{tabular}

Fonte: SYED et al. (2006) 
Diversos trabalhos sobre biofiltração relatam a utilização do lodo ativado de estações de tratamento de efluentes industriais como fonte microbiana para o tratamento de gases poluentes, incluindo o sulfeto de hidrogênio (DUAN et al., 2006).

De acordo com Oyarzún et al. (2003), a inoculação de lodo ativado aos sistemas de biofiltração permite o estabelecimento de uma população microbiana capaz de oxidar o $\mathrm{H}_{2} \mathrm{~S}$ e possibilita condições de seleção microrganismos com alta atividade de degradação, no entanto, a eficiência é limitada e a capacidade de remoção do $\mathrm{H}_{2} \mathrm{~S}$ não é constante. Uma estratégia de sucesso para obter populações microbianas com alta atividade de degradação do $\mathrm{H}_{2} \mathrm{~S}$ seria selecionar e enriquecer uma cultura mista de microorganismos para a inoculação do biofiltro. A Tabela 3.4 apresenta as características de alguns microrganismos utilizados na degradação do $\mathrm{H}_{2} \mathrm{~S}$. 
Tabela 3.4 - Características de algumas espécies de microrganismos utilizadas na degradação de compostos sulfurosos.

\begin{tabular}{|c|c|c|c|c|c|c|c|c|}
\hline & \multicolumn{7}{|c|}{ Microrganismos } & \multirow[b]{2}{*}{$\begin{array}{l}\text { Thioalkalispira } \\
\text { microaerophila }\end{array}$} \\
\hline & $\begin{array}{l}\text { Thiobacillus } \\
\text { ferrooxidans }\end{array}$ & $\begin{array}{l}\text { Thiobacillus } \\
\text { thiooxidans }\end{array}$ & $\begin{array}{c}\text { Thiobacillus } \\
\text { novellus }\end{array}$ & $\begin{array}{l}\text { Thiobacillus } \\
\text { thioparus }\end{array}$ & $\begin{array}{l}\text { Thiobacillus } \\
\text { denitrificans }\end{array}$ & $\begin{array}{c}\text { Thermothrix } \\
\text { azorensis }\end{array}$ & Thiothix nivea & \\
\hline $\begin{array}{c}\mathrm{pH} \text { de } \\
\text { Crescimento }\end{array}$ & - & $0,5-6,0$ & $5,7-9,0$ & $5-9$ & - & $6,0-8,5$ & $6,0-8,5$ & $8-10,4$ \\
\hline $\begin{array}{l}\text { Temperatura } \\
\text { Ótima }\left({ }^{\circ} \mathrm{C}\right)\end{array}$ & $30-35$ & $28-30$ & 30 & 28 & $28-32$ & $76-78$ & $15-30$ & - \\
\hline $\begin{array}{l}\text { Forma e } \\
\text { tamanho }\end{array}$ & $\begin{array}{c}\text { Bacilo } \\
0,5-1 \mu \mathrm{m}\end{array}$ & $\begin{array}{c}\text { Bacilo } \\
0,5 \times 1,1-2 \\
\mu \mathrm{m}\end{array}$ & $\begin{array}{c}\text { Bacilo } \\
0,4-0,8 \times 0,8- \\
2 \mu \mathrm{m}\end{array}$ & $\begin{array}{c}\text { Bacilo } \\
0,9-1,8 \mu \mathrm{m}\end{array}$ & $\begin{array}{c}\text { Bacilo } \\
0,5 \times 1-3 \mu \mathrm{m}\end{array}$ & $\begin{array}{c}\text { Bacilo } \\
0,3-0,8 \times 2-5 \\
\mu \mathrm{m}\end{array}$ & $\begin{array}{c}\text { Bacilo } \\
0,7-2,6 \times 0,7- \\
5 \mu \mathrm{m}\end{array}$ & $\begin{array}{c}\text { Espirilo } \\
0,3-0,45 \times 1- \\
4 \mu \mathrm{m}\end{array}$ \\
\hline Nivel trófico & $\begin{array}{l}\text { Quimiautotrófica } \\
\text { Obrigatória }\end{array}$ & $\begin{array}{c}\text { Quimiautotrófica } \\
\text { obrigatória }\end{array}$ & $\begin{array}{l}\text { Quimiautotrófica } \\
\text { facultativa }\end{array}$ & $\begin{array}{c}\text { Quimiautotrófica } \\
\text { obrigatória }\end{array}$ & $\begin{array}{c}\text { Quimiautotrófica } \\
\text { obrigatória }\end{array}$ & $\begin{array}{c}\text { Quimiautotrófica } \\
\text { obrigatória }\end{array}$ & $\begin{array}{l}\text { Quimiautotrófica } \\
\text { facultativa }\end{array}$ & $\begin{array}{c}\text { Quimiautotrófica } \\
\text { obrigatória }\end{array}$ \\
\hline $\begin{array}{l}\text { Fontes de } \\
\text { energia }\end{array}$ & $\begin{array}{l}\text { Íons ferrosos } \\
\text { e compostos } \\
\text { sulfurosos } \\
\text { reduzidos }\end{array}$ & $\begin{array}{l}\text { Sulfeto de } \\
\text { Hidrogênio, } \\
\text { plitionatos } \\
\text { enxofre } \\
\text { elementar. }\end{array}$ & $\begin{array}{c}\text { Sulfeto de } \\
\text { Hidrogênio, } \\
\text { metil } \\
\text { mercaptanas, } \\
\text { dimetil sulfeto, } \\
\text { dimetil disulfeto }\end{array}$ & $\begin{array}{l}\text { Tiosulfato, } \\
\text { sulfeto }\end{array}$ & $\begin{array}{l}\text { Tiosulfato, } \\
\text { tetrationato, } \\
\text { tiocianato, } \\
\text { sulfeto, enxofre } \\
\text { elementar. }\end{array}$ & $\begin{array}{l}\text { Tiosulfato, } \\
\text { tetrationato, } \\
\text { sulfeto de } \\
\text { hidrogênio, } \\
\text { enxofre } \\
\text { elementar. }\end{array}$ & $\begin{array}{c}\text { Enxofre } \\
\text { inorgânico, } \\
\text { compostos } \\
\text { orgânicos } \\
\text { simples, açúcar. }\end{array}$ & $\begin{array}{l}\text { Sulfeto, } \\
\text { polisulfeto, } \\
\text { enxofre } \\
\text { elementar, } \\
\text { tiosulfato }\end{array}$ \\
\hline $\begin{array}{l}\text { Necessidade } \\
\text { de oxigênio }\end{array}$ & $\begin{array}{l}\text { Facultativo } \\
\text { Anaeróbio* }\end{array}$ & Aeróbio estrito & Aeróbio estrito & Aeróbio estrito & $\begin{array}{l}\text { Facultativo } \\
\text { Anaeróbio }\end{array}$ & Aeróbio estrito & $\begin{array}{c}\text { Aeróbio estrito } \\
e \\
\text { microaerofilico }\end{array}$ & $\begin{array}{c}\text { Aeróbio estrito e } \\
\text { microaerofilico }\end{array}$ \\
\hline $\begin{array}{l}\text { Deposito de } \\
\text { enxofre }\end{array}$ & - & - & - & Extracelular & & Intracelular & Intracelular & Intracelula \\
\hline Referência & $\begin{array}{l}\text { Colorado } \\
\text { School of } \\
\text { mines }\end{array}$ & $\begin{array}{l}\text { TAKANO et al. } \\
\text { (1997) }\end{array}$ & $\begin{array}{l}\text { CHA et al. } \\
\text { (1999); KELLY } \\
\text { et al. (2000) }\end{array}$ & $\begin{array}{l}\text { VLASCEANU } \\
\text { et al. (1997) }\end{array}$ & $\begin{array}{c}\text { KELLY e } \\
\text { WOOD (2000) }\end{array}$ & $\begin{array}{l}\text { ODINTSOVA et } \\
\text { al. (1996) }\end{array}$ & $\begin{array}{l}\text { PRESCOTT et } \\
\text { al. (2003) }\end{array}$ & $\begin{array}{l}\text { SOROKIN et al. } \\
\text { (2002) }\end{array}$ \\
\hline
\end{tabular}

Fonte: Adaptado de SYED et al. (2006). 


\subsubsection{Biorreatores utilizados para remoção de $\mathrm{H}_{2} \mathrm{~S}$}

Diversas configurações de reatores são utilizadas para remover sulfeto de hidrogênio, sob condições aeróbias e anaeróbias, funcionando em condições quimiotróficas ou fotossintéticas e operando sob diferentes condições fluidodinâmicas.

Os biorreatores mais utilizados para o tratamento de gases tóxicos, dentre eles $\circ \mathrm{H}_{2} \mathrm{~S}$, podem ser divididos entre aqueles em que as células são livremente suspensas na fase líquida (biolavadores) e aqueles em que as células são imobilizadas em material inerte (biopercoladores e biofiltros).

A Figura 3.3 apresenta os sistemas mais utilizados para o tratamento biológico de gases.

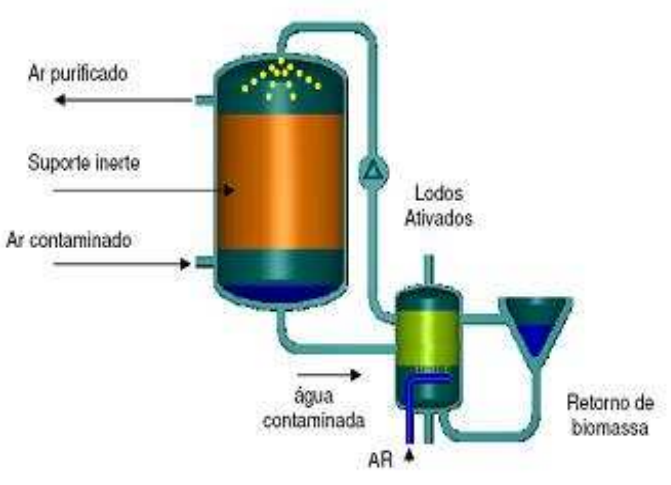

BIOLAVADOR

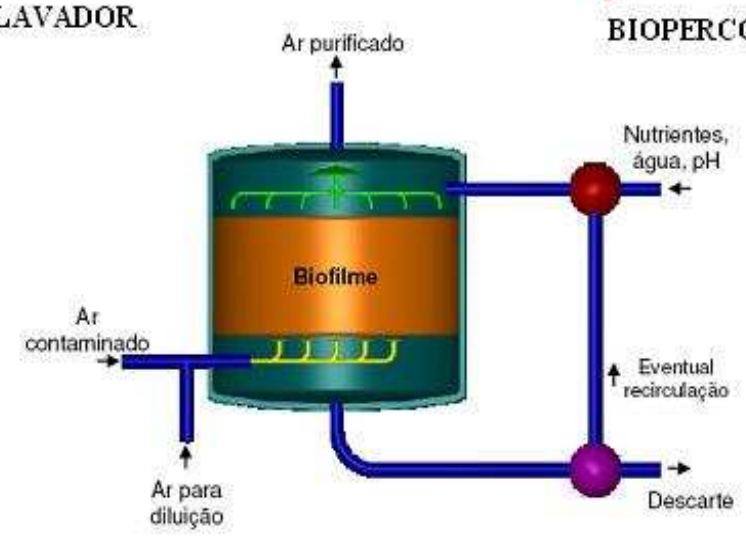

BIOFILTRO

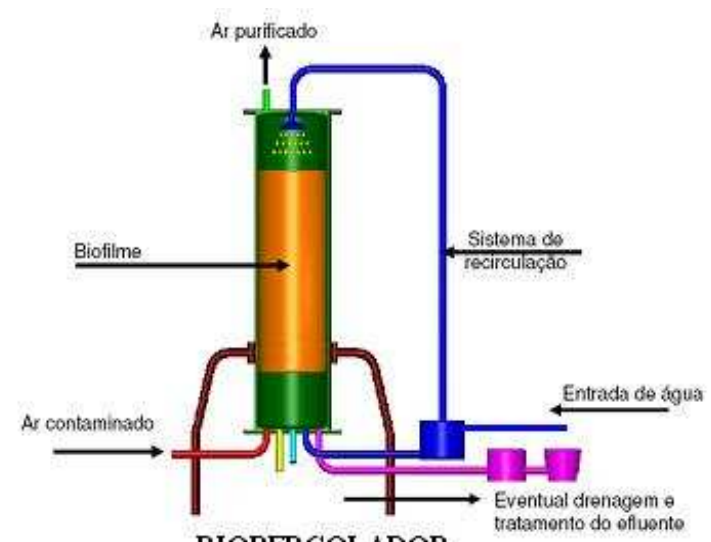

IOPERCOLADOR 
O biolavador consta de uma coluna de absorção (scrubber), na qual os poluentes solúveis em água são absorvidos e em parte oxidados, e de um reator aerado (unidade de regeneração) onde se completa a oxidação. A suspensão, uma vez regenerada, é continuamente recirculada pelo topo da coluna para melhorar a eficiência do processo (CABRAL e BELLI, 2005).

Segundo Burgess, Parsons e Stuetz (2001), durante o curto tempo de residência, o crescimento da biomassa tem que ser controlado para reduzir o descarte de resíduos sólidos e para aumentar a eficiência do sistema.

Outro reator biológico utilizado na depuração de gases poluentes é o biopercolador, no qual ocorre a circulação contínua do líquido, a favor ou contra corrente, no meio suporte. Geralmente, o líquido é circulado ao reator após passar por uma etapa de redução de concentração.

Nesses biorreatores a taxa de alimentação e a concentração de nutrientes são baseadas na expectativa de requerimento de nutrientes pela cultura microbiana. Os biopercoladores, geralmente, recebem menos nutrientes do que precisam estequiometricamente. Isto acontece porque os nutrientes são internamente reciclados através de células mortas, digestão de biomassa endógena e por predadores tais como protozoários e rotíferos. A limitação de nutrientes pode ser uma escolha do operador na tentativa de limitar o crescimento da biomassa (COX e DESHUSSES, 2000).

Biofiltros também são reatores de leito fixo, nos quais os microrganismos são imobilizados em meio suporte, geralmente orgânicos, para a remoção de poluentes de uma corrente de gás contaminado. Neste biossistema, ocorre a transferência de massa dos poluentes da fase gasosa para a fase líquida através do biofilme (DEVINNY, DESHUSSES e WEBSTER, 1999).

Dentre os processos microbiológicos, a biofiltração é dos mais promissores devido a seu baixo custo capital e operacional, baixos requerimentos de energia, alta eficiência de remoção e a ausência de produtos residuais que requeiram futuro tratamento ou disposição, e possui aceitação pública por ser considerado um processo "ambientalmente amigável" (LEE et al., 2006; MA, YANG e ZHAO, 2006). 
Na Tabela 3.5 são apresentadas vantagens e desvantagens de cada um dos tipos mais comuns de reatores biológicos empregados na remoção de poluentes gasosos.

Tabela 3.5 - Vantagens e desvantagens dos reatores biológicos.

\begin{tabular}{|c|c|c|}
\hline Reator & Vantagens & Desvantagens \\
\hline Biofiltro & $\begin{array}{l}\text { - Operação Simples } \\
\text { - Baixos Custos de Investimento } \\
\text { - Baixo Custo de operação } \\
\text { - Degradação de menos poluentes } \\
\text { solúveis em água } \\
\text { - Redução satisfatória de odores }\end{array}$ & $\begin{array}{l}\text { - Baixo fluxo volumétrico de } \\
\text { efluente gasoso } \\
\text { - Apenas baixas concentrações } \\
\text { de poluente } \\
\text { - Impossivel o controle do processo } \\
\text { - Formação de canal preferencial } \\
\text { de fluxo é comum }\end{array}$ \\
\hline Biopercolador & $\begin{array}{l}\text { - Operação Simples } \\
\text { - Baixos Custos de Investimento } \\
\text { - Baixo Custo de operação } \\
\text { - Satisfatório para contaminações } \\
\text { moderadas de efluente gasoso } \\
\text { - Possibilidade de adição de nutrientes }\end{array}$ & $\begin{array}{l}\text { - Limitado controle do processo } \\
\text { - Formação de canais pode ser } \\
\text { um problema } \\
\text { - Vida limitada do leito } \\
\text { - Excesso de biomassa não } \\
\text { disponível }\end{array}$ \\
\hline Biolavador & $\begin{array}{l}\text { - Boa possibilidade de controle do } \\
\text { processo } \\
\text { - Alta transferência de massa } \\
\text { - Satisfatório para modelagem do } \\
\text { processo } \\
\text { - Alta estabilidade operacional } \\
\text { - Possibilidade de adição de nutrientes }\end{array}$ & $\begin{array}{l}\text { - Alto custo de investimento } \\
\text { - Altos custos operacionais } \\
\text { - Produção de excesso de } \\
\text { biomassa } \\
\text { - Disposição da água } \\
\text { - Possível entupimento (absorção) }\end{array}$ \\
\hline
\end{tabular}

Fonte: EDWARDS \& NIRMALAKHANDAN (1996). 


\subsection{O PROCESSO DE BIOFILTRAÇÃO}

\subsubsection{Introdução}

A biofiltração é um processo que utiliza microrganismos imobilizados em um leito fixo de material poroso. O fluxo de gás contaminado escoa ao longo do leito filtrante, que por sua vez absorve os compostos biodegradáveis, para que, em uma última etapa, os microrganismos os convertam a compostos menos poluentes (OYARZÚN et al., 2003).

Tacla (2004) cita que, em geral, as biofiltros são simples de serem instalados, operam de forma contínua e não requerem grande manutenção. Os parâmetros que influenciam o processo são: material suporte, umidade do leito, $\mathrm{pH}$, temperatura, concentração dos poluentes, microorganismos e nutrientes.

O princípio do processo de biofiltração baseia-se na interação dos poluentes da fase gasosa com o meio suporte. A atividade de degradação deriva de microrganismos que vivem e desenvolvem-se no leito filtrante, de tal modo que os compostos indesejáveis no gás sejam absorvidos ou removidos (Morgan-Sagastume e Noyola, 2006). Os gases poluentes são distribuídos lentamente ao longo do biofiltro, o que permite aos microrganismos degradarem os poluentes e produzirem energia e subprodutos metabólicos na forma de dióxido de carbono e água. O processo biológico que ocorre no interior do biofiltro é uma oxidação por microrganismos e pode ser escrita como segue (DEVINNY, DESHUSSES e WEBSTER, 1999):

Gás poluente $+\mathrm{O}_{2} \rightarrow$ Biomassa $+\mathrm{CO}_{2}+\mathrm{H}_{2} \mathrm{O}$

Especificamente na remoção do sulfeto de hidrogênio, Oyarzún et al. (2003) apresentam as seguintes reações biológicas gerais ocorridas no processo:

$2 \mathrm{HS}^{-}+\mathrm{O}_{2} \rightarrow 2 \mathrm{~S}^{0}+2 \mathrm{OH}^{-}$

$2 \mathrm{~S}^{0}+3 \mathrm{O}_{2} \rightarrow 2 \mathrm{SO}_{4}^{2-}+2 \mathrm{H}^{+}$ 
Via de regra, em virtude de ser um dos produtos finais da reação de oxidação do $\mathrm{H}_{2} \mathrm{~S}$, o íon $\mathrm{H}^{+}$provoca a queda significativa do $\mathrm{pH}$, provocando a acidez do meio (MELO e AZEVEDO, 1997).

Chung, Huang e Tseng (1996), após analisarem o produto resultante da operação de um biofiltro inoculado com Thiobacillus thioparus imobilizado em alginato de cálcio para remover sulfeto de hidrogênio, apresentaram as seguintes equações:

Para concentrações de 60 ppm:

$\mathrm{H}_{2} \mathrm{~S} \rightarrow 0,25 \mathrm{SO}_{4}^{2-}+0,72 \mathrm{~S}+0,02 \mathrm{SO}_{3}^{2-}+0,005 \mathrm{~S}^{2-}$

Para concentrações de 5 ppm:

$\mathrm{H}_{2} \mathrm{~S} \rightarrow 0,75 \mathrm{SO}_{4}^{2-}+0,18 \mathrm{~S}+0,05 \mathrm{SO}_{3}^{2-}+0,007 \mathrm{~S}^{2-}$

A partir do início do processo, à medida que ocorre a umidificação do leito do biofiltro, há a formação de uma camada líquida sobre os microrganismos e, conseqüentemente, sobre as partículas do material suporte. O conjunto desta película que se forma sobre cada partícula recebe o nome de biofilme e é dentro dele que os microrganismos atuam (MORGAN-SAGASTUME e NOYOLA, 2006).

A Figura 3.4 apresenta a ampliação de pequena parte do leito do biofiltro, na qual podem ser visualizados o material suporte e o biofilme. Nessa figura, a fase sólida representa o material suporte; a fase ar, os espaços intersticiais entre os materiais suportes empacotados no interior do biofiltro; e a fase líquida, o biofilme. 


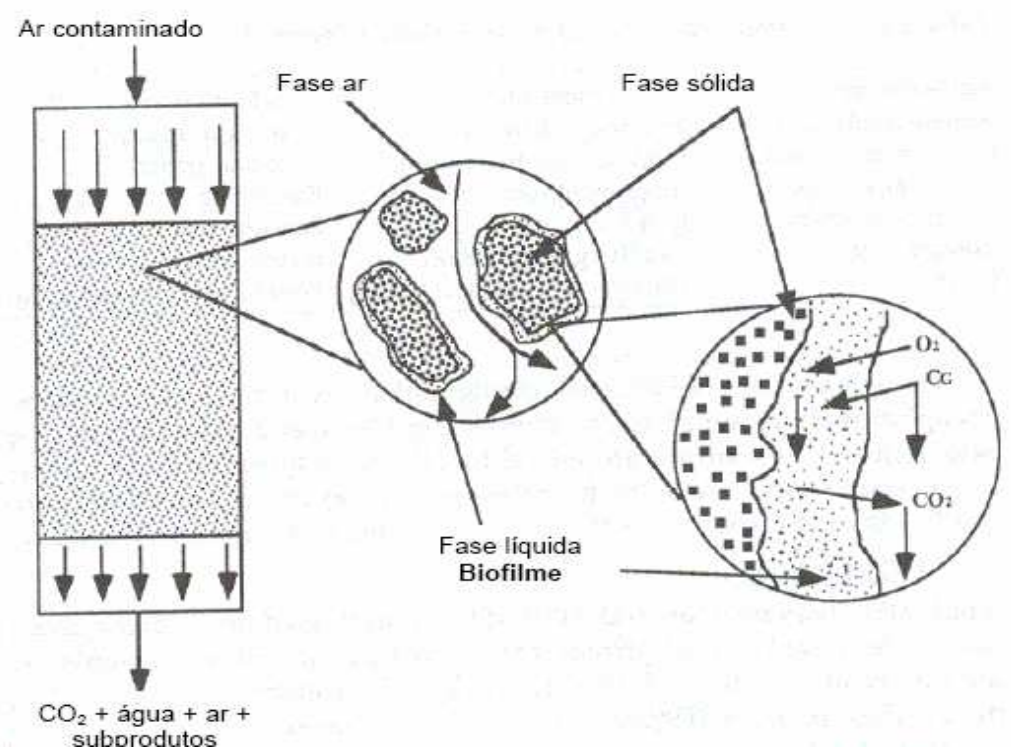

Figura 3.4: Ampliação do leito do biofiltro e visualização do biofilme Fonte: DEVINNY, DESHUSSES e WEBSTER (1999).

Quando o gás poluente $\left(\mathrm{C}_{G}\right)$ e o ar $\left(\mathrm{O}_{2}\right)$ passam pelos espaços existentes no interior do biofiltro (fase ar), moléculas deste gás e do oxigênio penetram na camada superficial do biofilme (fase líquida), onde estão presentes os microrganismos que irão degradar os poluentes em presença do oxigênio. O gás poluente que passa pelo leito pode penetrar o biofilme ou desviá-lo, para ser difundido posteriormente. Os produtos resultantes da degradação no interior do biofilme serão: água, gás carbônico e outros produtos que dependem do gás poluente que estiver no processo (RODRIGUES, 2002).

No biofiltro, os poluentes transferidos através da interface gás-líquido são usados como fonte de nutrientes pelos microrganismos imobilizados no leito. A utilização dos poluentes como substrato cria um gradiente de concentração no biofilme, que promove a difusão de moléculas de substrato, desde a fase gás até a fase líquida do biofilme (CORSI e SEED, 1995).

Gostomski, Sisson e Cherry (1997) afirmam que a água, geralmente presente dentro do biofilme, encontra-se no estado estacionário, sendo que a difusão molecular é a única forma de transporte químico para o interior das células. Quando os microrganismos estão ativos, eles convertem o poluente mais rapidamente do que este pode dispersar-se no meio. 
De acordo com Cohen (2001), a espessura do biofilme é influenciada por muitos fatores, que incluem a vazão do gás tratado no biofiltro, a composição do material suporte e o próprio biofiltro. O biofilme não é totalmente ativo e a sua atividade aumenta com a espessura. Existe uma espessura chamada ativa, a partir da qual é possivel converter os reagentes. A partir de determinada espessura do biofilme, a difusão dos nutrientes se torna limitante e controla a velocidade global da reação.

\subsubsection{Fatores operacionais do processo}

Diversos fatores operacionais influenciam o desempenho de um biofiltro. Os fatores mais importantes são: umidade, pH e temperatura do leito (DEVINNY, DESHUSSES e WEBSTER, 1999). A seguir são apresentados estes parâmetros.

\subsubsection{Material suporte}

O leito do biofiltro é basicamente constituído de material suporte, que pode ser de origem orgânica, inorgânica ou sintética, ao qual se adicionam microrganismos, nutrientes e outros compostos que sejam necessários ao crescimento microbiano e ao tratamento do gás.

De acordo com Barona et al. (2005), o material suporte é considerado o "coração" do sistema de biofiltração, especialmente porque se constitui como o local onde a biomassa ativa está imobilizada. Ademais, quando o desempenho da biodegradação não é efetivo, a habilidade da superficie do material suporte em reter ou adsorver o contaminante torna-se uma propriedade desejável. O meio suporte ainda desempenha papel fundamental para a distribuição das fases líquida e gasosa, bem como para a transferência de massa (DUAN et al. (2006). 
De acordo com Clark e Wnorowski4 (1991) apud Ramírez-Lopez et al. (2003), quase todos os compostos orgânicos podem ser utilizados em biofiltros. Bohn5 (1996) apud RamírezLopez et al. (2003) listaram 13 importantes características físicas, químicas e biológicas, sendo as mais importantes: a) alta área superficial específica; b) baixa densidade global; c) alto número de diferentes bactérias naturalmente presentes no suporte; d) nutrientes suficientes (ex: nitrogênio, fósforo e potássio); e) alta capacidade de retenção de água e f) $\mathrm{pH}$ neutro ou ligeiramente alcalino, bem como capacidade tampão.

É consenso na literatura que a seleção do material suporte tem significativa influência sobre o desempenho dos biofiltros, visto que afeta a freqüência de substituição do leito, a atividade bacteriana e a perda de carga, Portanto, influencia a eficiência de remoção dos poluentes e os custos operacionais (CHO, HIRAl e SHODA, 1992a).

De acordo com a literatura, vários materiais têm sido utilizados como meio suporte para o crescimento dos microrganismos, tais como: lascas de madeira (Van Langenhove, Wuyts e Schamp,1986), fixação bacteriana em alginato de cálcio (Chung, Huang e Tseng, 1996; Chung et al., 2000; Chung, Huang e Tseng, 2001), esterco de cavalo, lodo, mistura de solo e algas, mistura de esterco de porco e serragem (Barona et al., 2004), turfa (Ottengraf et al., 1986; Cabral e Belli, 2002), lava solidificada (Cho, Ryu e Lee, 2000), bagaço de cana (Christen et al. 2002; Tacla, 2004), solo (Rodrigues, 2002), contas de alginato/quitosana (Maia, 2003), lodo granular (Malhautier et al., 2003), carvão ativado (Duan et al. ,2006; Ma, Yang e Zhao, 2006) e espuma de poliuretano (Rodrigues, 2002; Maia, 2003; Rocha, 2007).

- Espuma de poliuretano

A espuma de poliuretano é um material muito versátil (variando desde os bem conhecidos blocos de espuma elástica para colchões até espumas quase rígidas para

\footnotetext{
${ }^{4}$ CLARK, R.; WNOROWSKI, A. Biofilters for sewer pump station vents: influence of matrix formulations on the capacity and efficiency of odorant removal by an experimental biofilters. Biotechniques for Air Pollution Abatement and Odour Control Policies. Elsevier, The Netherlands, p. 183-186, 1991.

5 BOHN, H.L. Biofilter media. Air \& Waste Manage. Assoc. $98^{\text {th }}$ Annual Meeting \& Exhibition. Nashville, Tennesee, $98-$ WP87A-01, 1996.
} 
brinquedos, automotivos e calçados), pois segundo os aditivos e sistemas de fabricação utilizados, consegue-se obter características muito diferentes e destinadas para usos diferentes, tais como: em colchões como componente principal ou como integrante de capas; em móveis, sofás, cadeiras etc.; na construção civil como isolante térmico e como enchimento; na indústria automotiva como elemento principal dos bancos, estofamentos etc.; dentre outras diversas aplicações (ESPUMA, 2007).

Moe e Irvine (2000 a,b) monitoraram este material desde a etapa de produção até sua utilização em biofiltros. Os autores citaram que este meio suporte pode ser preparado com materiais hidrofílicos promovendo uma reumidificação mais eficiente no caso de problemas de secagem do leito. Rodrigues (2002), Maia (2003) e Rocha (2007) também preencheram seus biossistemas com esse material suporte no tratamento de $\mathrm{H}_{2} \mathrm{~S}$.

Rocha (2007) verificou que a espuma de poliuretano apresentou um ótimo teor de umidade, cujo valor aproximado foi de $92 \%$. Nos ensaios de perda de carga, o autor observou valores abaixo de 0,8.10-2 mca. Apesar de ser um valor superior aos encontrados por Moe e Irvine (2000b), Rodrigues (2002) e Maia (2003), que verificaram perdas de carga sempre inferiores a 0,2.10-2 mca, ainda assim foi definido, por si só, como ótimo.

Em contraposição, Ramírez-Lopez et al. (2003) afirmaram que, pelo fato de estarem disponíveis em grandes quantidades, a utilização de produtos de origem agrícola seria uma alternativa viável aos meios suportes convencionais como a turfa, por exemplo.

- Bagaço de cana

O bagaço de cana surgiu como alternativa, após sua valorização biotecnológica ter sido demonstrada por Pandey et al.6 (2000) e Mitchel et al.7 (1992) apud Christen et al. (2002).

\footnotetext{
6 PANDEY, A.; SOCCOL, C. R.; NIGAM, P.; SOCCOL, V. T. Bioresource Technology, v. 74, p. 69, 200.

7 MITCHELL, D.A.; TARGONSKI, Z.; ROGALSKI, J. LEONOWICZ, A. Solid Substrate Cultivation. Elsevier, London, p. 29-52, 1992.
} 
Tacla (2004) também fez referências às vantagens da utilização do bagaço de cana como suporte de imobilização para os microrganismos, no sentido de que se trata de um material tido como o maior resíduo da agroindústria brasileira. A autora salienta que as próprias usinas utilizam este bagaço como fonte energética, substituindo o óleo combustivel no processo de aquecimento das caldeiras para a geração de energia elétrica.

- Fibra de coco

O consumo da água de coco verde no Brasil é crescente e significativo. Estima-se que a produção anual de coco seja na faixa de 1,5 bilhões de unidades, estando o país entre os 10 maiores produtores da fruta no mundo. Já a produção da fibra de coco brasileira é superior a 7 mil toneladas. Da indústria de processamento de coco verde ou maduro, origina-se uma quantidade significativa de resíduos dos quais as cascas de coco, entre $80 \%$ a $85 \%$ do peso bruto do fruto, são geralmente utilizadas como combustivel em caldeiras, sendo outra parte depositada em lixões e às margens de estradas.

Portanto, a valorização do resíduo sólido, com a utilização da casca do coco verde processada, além da importância econômica e social, é extremamente importante do ponto de vista ambiental (FIBRA DE COCO, 2007).

De acordo com Gabriel et al. (2007), que monitorou pelo período de um ano um biofiltro preenchido com fibra de coco no tratamento de amônia, este material tem algumas propriedades interessantes, como a alta capacidade de armazenamento de água e relação balanceada de Carbono/Nitrogênio/Fósforo.

\subsubsection{Teor de Umidade}

Gostomski, Sisson e Cherry (1997) estudaram, especificamente, a influência da umidade no processo de biofiltração. Os autores afirmaram que, embora os biofiltros possam ser operados de forma estável por anos, uma das condições mais importantes é manter a quantidade de água suficiente no leito. Na maioria dos reatores biológicos, água está em 
excesso e é facilmente manipulada. Nos biofiltros, o material suporte não é normalmente saturado e não possui uma fase de fluxo livre de água.

Os autores comentaram ainda sobre a forma como a umidade afeta tanto os mecanismos físicos quanto biológicos do sistema. A umidade em excesso causa o aumento da perda de carga no sistema. Por sua vez, estas altas perdas de carga aumentam os custos de operação para o recalque do fluxo gasoso para o biofiltro. Outro problema da umidade em excesso é promover limitações com relação aos aspectos difusionais no leito, especialmente para compostos com baixa solubilidade em água.

Por outro lado, a quantidade inadequada de água pode reduzir a degradação microbiológica do leito, visto que isto causa a baixa atividade do biofilme (NEAL e LOEHR, 2000).

\subsubsection{3 pH - Potencial Hidrogeniônico}

No processo de biofiltração o pH neutro é considerado ideal. O valor usual para o processo encontra-se na faixa de 6 a 8 , embora em alguns casos, por exemplo, no tratamento de compostos reduzidos de enxofre, valores de $\mathrm{pH}$ tão baixo quanto 2 e 4 tenham sido observados (Furusawa et al.8, 1984; Webster et al.9, 1996 apud Devinny, Deshusses e Webster, 1999) sem importantes perdas de performance nas eficiências de remoção. Morgan-Sagastume e Noyola (2006) observaram um decréscimo nos valores de pH de 7,5 para 4,5 durante os primeiros 25 dias de operação de seu sistema na remoção de sulfeto de hidrogênio também sem nenhum comprometimento aos reatores com relação à eficiência de remoção.

No trabalho de Chung, Huang e Tseng (1996), o pH não apresentou variações durante o experimento, mantendo-se em faixa próxima a neutralidade. Em Duan et al. (2006), a população bacteriana demonstrou capacidade de degradação de $\mathrm{H}_{2} \mathrm{~S}$ em ampla

\footnotetext{
8 FURUSAWA, N.; TOGASHI, I.; HIRAI, M. SHODA, M.; KUBOTA, K. Removal of $\mathrm{H}_{2} \mathrm{~S}$ by a biofilter with fibrous PEAT. Journal of Fermentation Technology, v. 62, p. 589, 1984.

9 DEVINNY, J.S.; TORRES, E.M.; BASRAI, S.S.. Biofiltration of odors, toxics and volatile organic compounds from publicy owned treatment works. Environmental Progress, v. 15, p. 141, 1996.
} 
faixa de $\mathrm{pH}$ (1-7), sem comprometer a eficiência de remoção. Ma, Yang e Zhao (2006) alertaram sobre a possibilidade de valores de $\mathrm{pH}$ consideravelmente altos em virtude da formação de produtos não ácidos em excesso no sistema.

\subsubsection{Temperatura}

Os microrganismos aeróbios que normalmente estão presentes nos biofiltros são os mesófilos e, portanto, a temperatura deve ser mantida na faixa de $20^{\circ} \mathrm{C}$ a $40^{\circ} \mathrm{C}$, com valor ótimo de 35 C (DEVINNY, DESHUSSES e WEBSTER, 1999). O problema das altas temperaturas está ligado ao fato de que a reação ocorre tão rapidamente que a coordenação metabólica é dilacerada. Por outro lado, se a temperatura do sistema for baixa, observa-se a redução do metabolismo e da atividade celular dos microorganismos, o que reduz a remoção dos poluentes (TACLA, 2004).

\subsubsection{Concentração dos poluentes}

Picos de alta concentração de poluentes podem afetar sobremaneira a população microbiana. Tal fato pode ser observado principalmente em Jorio et al. (2000), no qual foi avaliado o impacto da sobrecarga de vapor de xileno em biofiltro. Os autores verificaram que o poluente foi "arrastado" do sistema antes que a sua degradação fosse completada. Burguess, Parsons e Stuetz (2001) afirmaram que o desempenho do biofiltro é afetado tanto pela concentração média de entrada como também pela sua variabilidade.

\subsubsection{Nutrientes}

A operação de um biofiltro com bom desempenho requer que os nutrientes estejam disponibilizados na forma e na quantidade que atenda à necessidade da atividade microbiana. O meio composto orgânico apresenta vantagem em relação à presença de nutrientes, uma vez que estes estão naturalmente presentes no meio. O composto pode ser 
preparado das mais variadas formas, sempre como mistura de vários elementos, tais como resíduos de plantas e lodo de ETEs (TACLA, 2004).

Os materiais suportes inorgânicos tais como pedra, carvão ativado, peças plásticas ou espuma de poliuretano não contêm suprimento apropriado de nutrientes; portanto eles devem ser adicionados, quando o biofiltro é colocado em operação, sob a forma de sais de nitrogênio, fósforo e potássio solubilizados em água. Moe e Irvine (2000b), utilizando meio sintético (espuma de poliuretano), verificaram que as limitações de nutrientes foram freqüentes, o que causou a rápida diminuição do desempenho do biofiltro. 


\subsubsection{Parâmetros de projeto e operação de biofiltros}

Os termos estabelecidos na literatura e as relações comumente utilizadas para descrever o desempenho de biofiltros estão resumidos na Tabela 3.6 (DEVINNY, DESHUSSES e WEBSTER, 1999; METCALF e EDDY, 2002).

Tabela 3.6 - Parâmetros utilizados para o projeto e análise de biofiltros.

\begin{tabular}{|c|c|c|}
\hline Parâmetro & Equação & Definição \\
\hline \multirow{2}{*}{$\begin{array}{l}\text { Tempo de residência } \\
\text { do leito vazio }\end{array}$} & $T R L V=V f / Q$ & TRLV = tempo de residência do leito vazio (h) \\
\hline & & $V f=$ volume total do leito filtrante $\left(\mathrm{m}^{3}\right)$ \\
\hline \multirow{2}{*}{$\begin{array}{l}\text { Tempo de residência } \\
\text { verdadeiro no filtro }\end{array}$} & $T R V=V f . \varepsilon / Q$ & $Q=$ vazão volumétrica $\left(m^{3} \cdot h^{-1}\right)$ \\
\hline & & $\begin{array}{l}\text { TRV = tempo de residência verdadeiro (h, } \\
\qquad \min , s)\end{array}$ \\
\hline $\begin{array}{c}\text { Taxa de carregamento } \\
\text { superficial }\end{array}$ & $\mathrm{TCS}=Q / \mathrm{Af}$ & $\varepsilon=$ porosidade do leito filtrante \\
\hline \multirow{2}{*}{$\begin{array}{l}\text { Taxa de carregamento } \\
\text { mássico superficial }\end{array}$} & $T C M S=Q . C_{0} / A f$ & $\begin{array}{l}\text { TCMS = taxa de carregamento superficial } \\
\qquad\left(\mathrm{m}^{3} \cdot \mathrm{m}^{-2} \cdot \mathrm{h}^{-1}\right)\end{array}$ \\
\hline & & Af = área superficial do leito filtrante $\left(m^{2}\right)$ \\
\hline $\begin{array}{c}\text { Taxa de carregamento } \\
\text { volumétrico }\end{array}$ & $\vee=Q / V f$ & $\begin{array}{c}\mathrm{TCMV}=\text { taxa de carregamento volumétrico } \\
\qquad\left(\mathrm{m}^{3} \cdot \mathrm{m}^{-3} \cdot \mathrm{h}^{-1}\right)\end{array}$ \\
\hline \multicolumn{3}{|l|}{ Taxa de carregamento } \\
\hline mássico volumétrico & $\mathrm{TCMV}=Q \cdot \mathrm{C}_{0} / \mathrm{Vf}$ & $E R=$ eficiência de remoção (\%) \\
\hline Eficiência de remoção & $E R=\left(C_{0}-C s\right) / C e .100$ & $\mathrm{C}_{0}=$ concentração entrada de gás $\left(\mathrm{g} \cdot \mathrm{m}^{-3}\right)$ \\
\hline Capacidade de & & CE $=$ capacidade de eliminação $\left(g \cdot m^{-3} \cdot h^{-1}\right)$ \\
\hline \multirow[t]{2}{*}{ eliminação } & $\mathrm{CE}=Q\left(\mathrm{C}_{0}-\mathrm{Cs}\right) / \mathrm{Vf}$ & \\
\hline & & Cs $=$ concentração saída de gás $\left(\mathrm{g} \cdot \mathrm{m}^{-3}\right)$ \\
\hline
\end{tabular}

Fonte: METCALF e EDDY (2002) 
O dimensionamento de biofiltros baseia-se, comumente, no tempo de residência no leito, na taxa de carregamento e na capacidade de eliminação dos gases. O tempo de residência do leito vazio (TRLV) é utilizado para definir as relações entre o volume de leito e a vazão volumétrica de gás. O tempo de residência verdadeiro é determinado pela incorporação da porosidade à fórmula. A capacidade de eliminação é utilizada para comparar desempenho de diferentes sistemas de controle de gases.

Valores essencialmente lineares de capacidade de eliminação para taxa de carregamento crítica têm sido observados no tratamento de sulfeto de hidrogênio e outros compostos odorosos, conforme pode ser observado na Figura 3.5 (METCALF e EDDY, 2002):

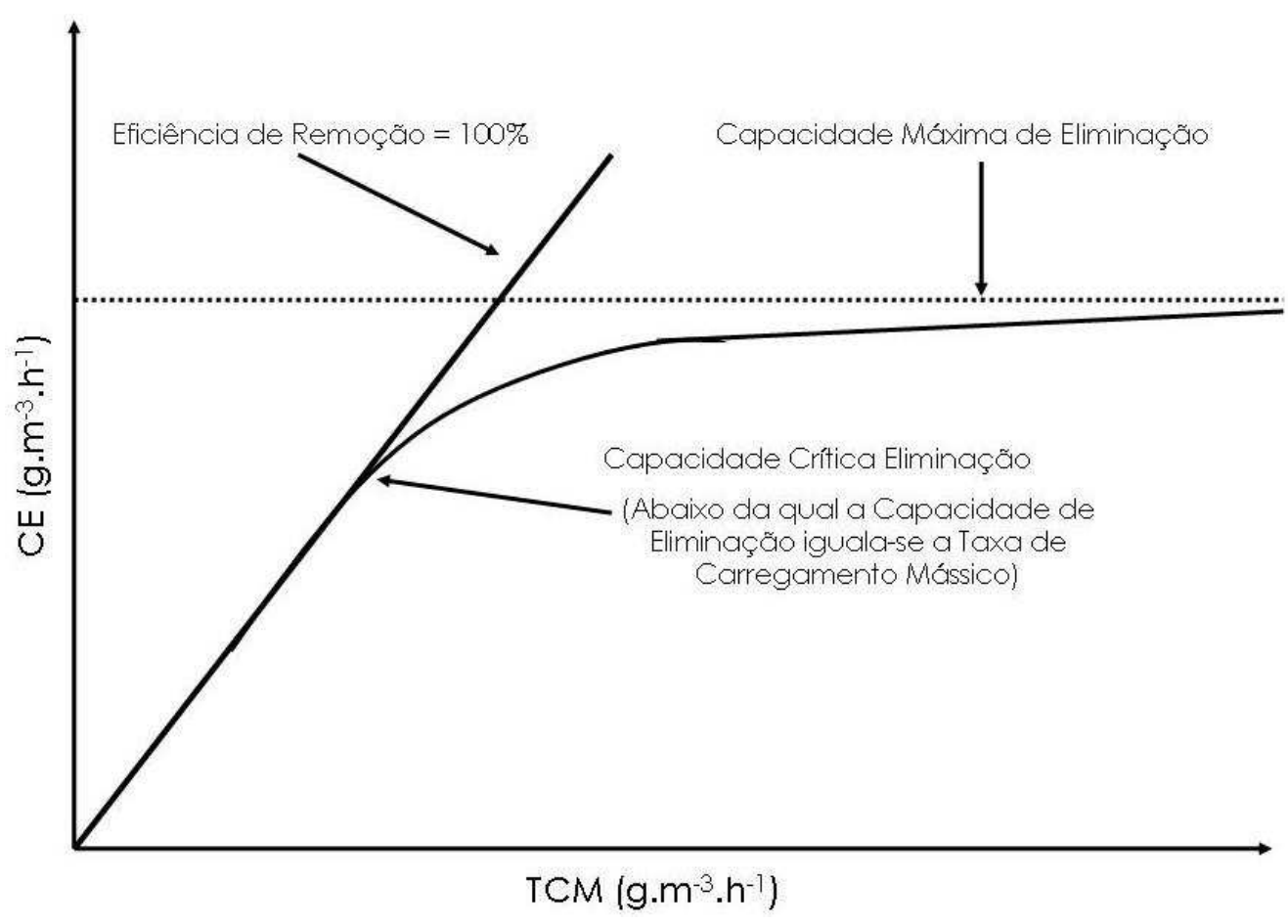

Figura 3.5: Capacidade de eliminação típica (CE) como função da taxa de carregamento mássica aplicada (TCM). (A relação é linear até um valor crítico, após o qual a capacidade de eliminação aborda um máximo valor assintoticamente).

Fonte: METCALF e EDDY (2002).

Os critérios típicos para projetos de biofiltros são encontrados na Tabela 3.7. 
Tabela 3.7 - Fatores típicos para o projeto de biofiltros

\begin{tabular}{|c|c|c|}
\hline Item & Unidade & Valores \\
\hline Concentração de oxigênio & $\begin{array}{c}\text { Partes de oxigênio / partes } \\
\text { de gases oxidável }\end{array}$ & 100 \\
\hline \multicolumn{3}{|l|}{ Mistura } \\
\hline Leito composto & $\%$ & $50-65$ \\
\hline Meio Sintético & $\%$ & $55-65$ \\
\hline Temperatura, ótimo & ${ }^{\circ} \mathrm{C}$ & $15-35$ \\
\hline $\mathrm{pH}$ & adimensional & $6-8$ \\
\hline Tempo de residência do gás & s & $30-60$ \\
\hline Altura do leito & $\mathrm{m}$ & $1-1,25$ \\
\hline $\begin{array}{c}\text { Concentração de gás } \\
\text { poluente afluente }\end{array}$ & $g \cdot m^{-3}$ & $0,01-0,5$ \\
\hline $\begin{array}{c}\text { Taxa de carregamento } \\
\text { superficial }\end{array}$ & $m^{3} \cdot m^{-2} \cdot h^{-1}$ & $10-100$ \\
\hline $\begin{array}{c}\text { Taxa de carregamento } \\
\text { volumétrico }\end{array}$ & $m^{3} \cdot m^{-3} \cdot h^{-1}$ & $10-100$ \\
\hline $\begin{array}{c}\text { Taxa de eliminação } \\
\text { (capacidade) } \mathrm{H}_{2} \mathrm{~S} \text { (em leito }\end{array}$ & $g \cdot m^{-3} \cdot h^{-1}$ & $80-130$ \\
\hline composto) & & \\
\hline
\end{tabular}

Fonte: METCALF e EDDY (2002) 


\subsubsection{Modelos matemáticos aplicados ao processo de biofiltração}

Diversos modelos matemáticos têm sido desenvolvidos para tentar descrever o processo de biofiltração, conforme pode ser observado na Tabela 3.8:

Tabela 3.8 - Resumo das principais características de alguns modelos matemáticos aplicados ao processo de Biofiltração.

\begin{tabular}{|c|c|c|c|c|}
\hline Modelo & Características & Solução & Válido para & $\begin{array}{c}\text { Aplicação de } \\
\text { projeto }\end{array}$ \\
\hline $\begin{array}{l}\text { Ottengraf e Van } \\
\text { de Oever (1983) }\end{array}$ & $\begin{array}{l}\text { Modelo simples de } \\
\text { estado-estacionário, } \\
\text { assume cinética de } \\
\text { ordem um e zero }\end{array}$ & Analítica & $\begin{array}{l}\text { Turfa e } \\
\text { Composto }\end{array}$ & $\begin{array}{l}\text { Possível com algumas } \\
\text { restrições devido as } \\
\text { hipóteses cinéticas }\end{array}$ \\
\hline $\begin{array}{c}\text { Devinny e Hodge, } \\
1995\end{array}$ & $\begin{array}{l}\text { Modelo dinâmico, } \\
\text { assume sólido } \\
\text { uniforme/fase água }\end{array}$ & $\begin{array}{l}\text { Numérica, } \\
\text { diferenças finitas }\end{array}$ & $\begin{array}{l}\text { Carvão e } \\
\text { composto }\end{array}$ & $\begin{array}{c}\text { Possivel por alguns } \\
\text { aspectos }\end{array}$ \\
\hline $\begin{array}{c}\text { Deshusses et al., } \\
1995\end{array}$ & $\begin{array}{l}\text { Modelo dinâmico, } \\
\text { inclui sorção e } \\
\text { inibição cruzada } \\
\text { entre os poluentes }\end{array}$ & $\begin{array}{l}\text { Numérica, } \\
\text { diferenças finitas }\end{array}$ & Composto & Possivel/ difícil \\
\hline $\begin{array}{c}\text { Cherry e } \\
\text { Thompson, } 1997\end{array}$ & $\begin{array}{l}\text { Modelo dinâmico, } \\
\text { inclui limitação pelo } \\
\text { nutriente, } \\
\text { crescimento celular } \\
\text { e consumo de } \\
\text { poluente pela célula } \\
\text { para propósito de } \\
\text { manutenção celular }\end{array}$ & Numérica & $\begin{array}{l}\text { Hexanos } \\
\text { misturados, } \\
\text { composto }\end{array}$ & Incerto \\
\hline Zarook et al, 1997 & $\begin{array}{l}\text { Modelo dinâmico, } \\
\text { inclui sorção e } \\
\text { inibição cruzada } \\
\text { entre os poluentes }\end{array}$ & $\begin{array}{l}\text { Estado quase- } \\
\text { estacionario e } \\
\text { solução } \\
\text { numérica geral }\end{array}$ & $\begin{array}{l}\text { Turfa; remoção } \\
\text { de benzeno e } \\
\text { tolueno }\end{array}$ & Possivel/ difícil \\
\hline
\end{tabular}

Dentre os modelos apresentados na Tabela 3.8, o único que apresenta solução analítica para o processo é o de Ottengraf e Van de Oever (1983). Os autores foram os primeiros a apresentar a microcinética de degradação nos biofiltros. Este modelo baseia-se nos desenvolvimentos feitos para a biodegradação de substratos não adsorviveis em 
biofilmes submersos por Jennings, Snoeyink e Chanin10 (1976) apud Devinny, Deshusses e Webster (1999).

Ottengraf e Van de Oever (1983) somente adaptaram seu modelo para acomodar biofilmes de fase gasosa e líquida. Os autores também incluíram o estudo de três situações básicas, nas quais se espera que sejam comumente encontradas em biofiltros para tratamento de efluentes gasosos, como por exemplo, cinéticas de ordem um, cinética de ordem zero com limitação da velocidade de reação e cinética de ordem zero com limitação da velocidade de difusão.

O princípio do modelo supõe que o fluxo gasoso que escoa no interior do biofiltro seja do tipo pistonado, e que a degradação siga a típica equação de Monod. Diversos trabalhos experimentais (Yang e Allen, 1994); Chung, Huang e Li, 1997 e Oyarzún et al., 2003) demonstraram que as cinéticas de ordem zero são tipicamente observadas nos biofiltros durante a biodegradação de diversos compostos voláteis, mesmo em concentrações muito baixas.

Ainda de acordo com a proposta do modelo, o material suporte é cercado pelo biofilme no qual ocorre a transferência das moléculas de poluente e de oxigênio dispersas na fase gasosa. Devido à atividade metabólica dos microrganismos aeróbios, forma-se um gradiente de concentração responsável pela transferência contínua do poluente da fase gasosa à fase líquida. Ao mesmo tempo, os produtos da biodegradação aeróbia $\left(\mathrm{CO}_{2}, \mathrm{H}_{2} \mathrm{O}\right.$, compostos inorgânicos, etc.) difundem-se na direção oposta, sendo arrastados pelo fluxo ascendente e, conseqüentemente, expurgados do biofiltro.

O modelo de Ottengraf e Van de Oever (1983) baseia-se nas seguintes hipóteses:

a) cinética: dois casos limitantes (ordem 0 e ordem 1), nas concentrações de nutrientes, sendo que o oxigênio é implicitamente admitido como estando em excesso, embora a limitação por oxigênio na cinética tenha sido ignorada;

10 JENNINGS, P.A.; SNOEYINK, V.L.; CHANIN, E.S.K. Theoretical model for a submerged biological filter. Biotechnology Bioengineering, $v .18$, p. 1249, 1976. 
b) a espessura do biofilme (ס) é pequena comparada com o diâmetro das partículas suporte, sendo utilizada por todo o leito, a despeito das mudanças nas concentrações dos gases poluentes ao longo da coluna;

c) o transporte dos nutrientes para o biofilme ocorre por difusão;

d) o fluxo da fase gasosa é do tipo pistonado.

Com relação às hipóteses supracitadas, sabe-se que muitas são bem razoáveis, outras são muito restritivas. A primeira pode ser explicada pela correlação empírica para a transferência de massa gás/líquido (Thoenes, 1958 apud Devinny, Deshusses e Webster (1999). O comportamento do fluxo pistonado pode ser realizado experimentalmente pela medida da dispersão de um pulso de um traçador inerte dentro do biofiltro. A análise da distribuição do tempo de residência demonstrou que em muitos casos, para biofiltros operando sob condições padrão (TRLV de 0,5 a 2 min), o fluxo pistonado ocorre.

Existem grandes incertezas com relação ao valor da difusividade efetiva (até duas ordens de magnitude). Os biofilmes diferem bastante e a medida experimental da difusão efetiva em biofilmes é muito difícil, sendo que coeficiente de difusão pode variar com a profundidade do biofilme, devido a acumulação de exopolímeros produzidos pelo processo de cultura.

A questão da geometria está muito provavelmente errada, porém, devido não haver uma "geometria universal de biofilme", adotar a geometria como sendo plana é aceitável.

As três possíveis situações de operação previstas no modelo de Ottengraf e Van de oever (1983) são: cinética de ordem 1, cinética de ordem zero com limitação pela velocidade de reação e cinética de ordem zero com limitação pela velocidade de difusão. A principal razão para isto é que estas condições permitem uma solução analítica de equações diferenciais. Todavia, trata-se de uma limitação importante do modelo, porque duas ou três destas situações podem muito bem ser encontradas no mesmo biofiltro, mas em diferentes posições em seu interior. A simplificação das cinéticas das três situações está resumida na Figura 3.6. 


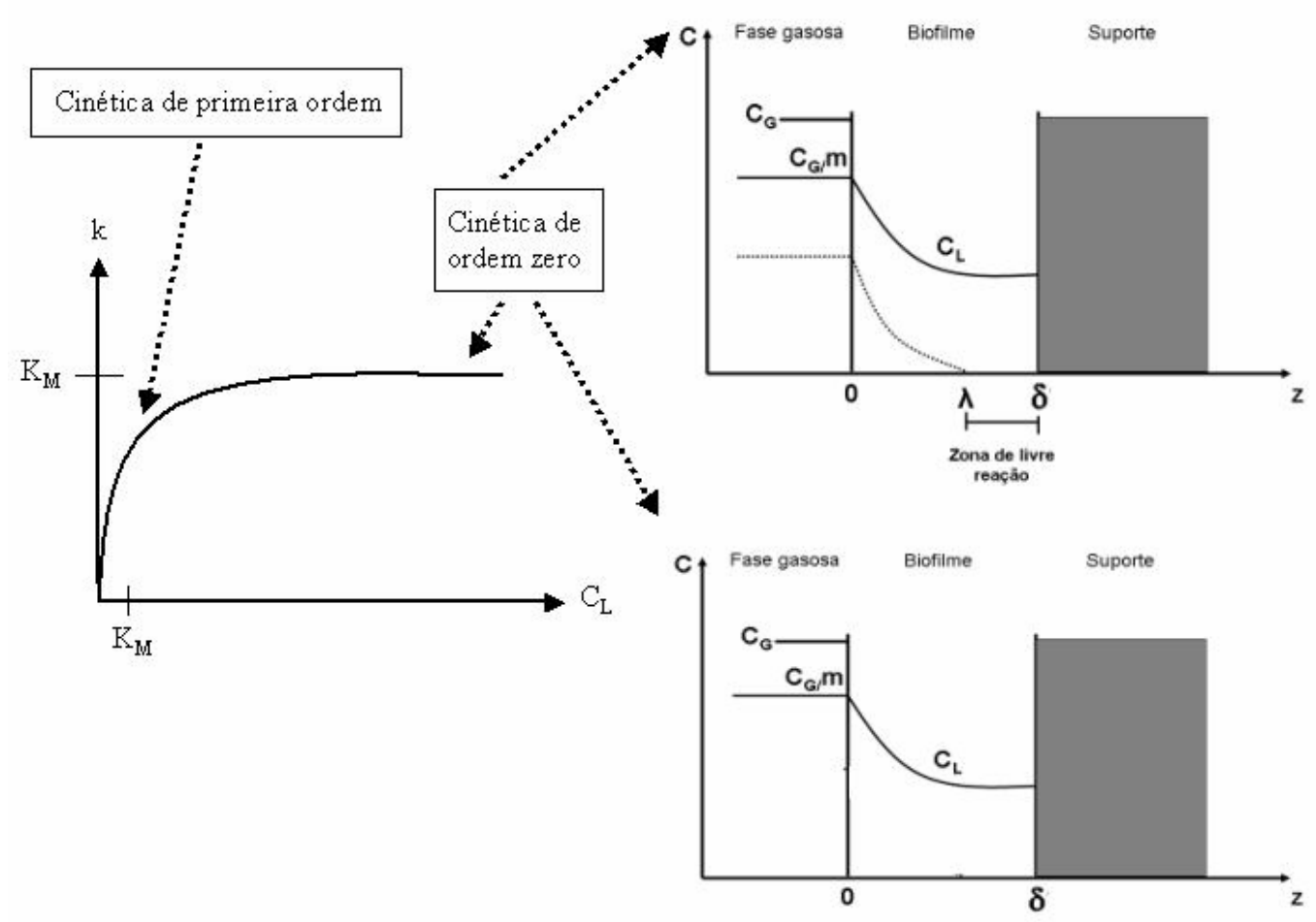

Figura 3.6: Três situações para a expressão cinética considerada por Ottengraf e Van de Oever (1983).

A geometria considerada por Ottengraf e Van de Oever (1983) para seu modelo biofísico é apresentada na Figura 3.7 (considerando limitação pela difusão, pois se considerarmos que a reação limita o processo, não existe a zona de livre reação):

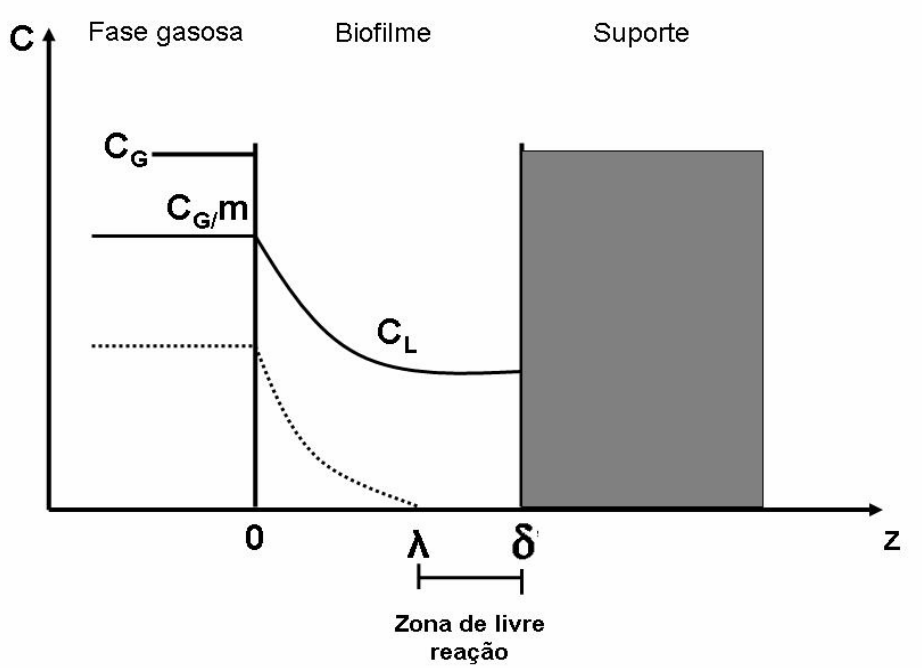

Figura 3.7: Modelo biofísico de penetração do substrato (considerando a limitação pela difusão)

Fonte: OTTENGRAF e VAN DE OEVER (1983). 
Os resultados para a concentração do poluente na fase gasosa com respeito a altura do biofiltro para cinética de ordem zero, com limitação pela difusão, são dadas pela Equação 3.9:

$$
\frac{C s}{C_{0}}=\left[1-\frac{h}{v_{a}} \sqrt{\frac{K_{0} D_{e f f} a_{s}}{2 m C_{0} \delta}}\right]^{2}
$$

Em que:

Cs é a concentração de saída do gás ( $\left.g \cdot \mathrm{m}^{-3}\right)$;

Co é a concentração de entrada do gás $\left(g \cdot \mathrm{m}^{-3}\right)$;

h é a altura do biofiltro $(m)$;

Va é a velocidade superficial $\left(m \cdot s^{-1}\right)$;

Ko é a constante de reação de ordem zero $\left(\mathrm{g} \cdot \mathrm{m}^{-3} \cdot \mathrm{s}^{-1}\right)$;

m é o coeficiente de distribuição (partição gás-líquido), conforme ditado pela lei de Henry;

$a_{s}$ é a área específica $\left(m^{2} \cdot m^{-3}\right)$;

Deff é o coeficiente de difusividade efetiva $\left(m^{2} \cdot s^{-1}\right)$;

$\delta$ é a espessura do biofilme (m).

Zarook, Shaikh e Ansar (1997) afirmaram que embora este modelo seja baseado em algumas hipóteses simplistas, ele é amplamente utilizado devido à facilidade de obtenção das expressões analíticas que a solução do modelo oferece. Com isso, essas simples expressões analíticas não têm sido usadas apenas na validação de dados experimentais obtidos em sistemas de bancada, mas também nos projetos de unidades piloto de biofiltros.

Cabe ressaltar que a aplicabilidade deste modelo a qualquer mistura gasosa composta por diversos poluente é limitada pela complexidade teórica do sistema, pois ocorre a biodegradação dos vários compostos simultaneamente. Isso significa que, em presença de correntes gasosas com vários poluentes, são necessários ensaios em escala 
piloto para planejar corretamente sistemas em escala industrial (ZAROOK e SHAIKH, 1997; CONVERTI e ZILLI, 2001).

Um dos trabalhos mais relevante sobre remoção de $\mathrm{H}_{2} \mathrm{~S}$ em biofiltros, cuja modelagem tenha sido baseada no modelo de Ottengraf e Van de Oever (1983), foi o realizado Oyarzún et al. (2003). Os autores obtiveram altas capacidades de eliminação (até $55 \mathrm{~g} \cdot \mathrm{m}^{-3} \cdot \mathrm{h}^{-1}$, sendo que o sistema alcançou eficiências de 100\% quando alimentado com 255 ppm de $\mathrm{H}_{2} \mathrm{~S}$ e vazão de $0,039 \mathrm{~m}^{3} \cdot \mathrm{h}^{-1}$. Quando a concentração de entrada de $\mathrm{H}_{2} \mathrm{~S}$ foi aumentada, as eficiências de remoção decresceram, atingindo 90 e $60 \%$ a $0,070 \mathrm{~m}^{3} \cdot \mathrm{h}^{-1} \mathrm{e}$ $0,140 \mathrm{~m}^{3} \cdot \mathrm{h}^{-1}$, respectivamente.

Especificamente na modelagem, os autores consideraram a difusão como fator limitante do seu sistema. Na Figura 3.8 é apresentado o gráfico, considerando limitação pela difusão, para concentração de entrada de 257 ppm. Conforme pode se observado, esta abordagem simples ajusta-se razoavelmente bem aos dados experimentais e pode ser utilizada para prever performances gerais e projetos de biofiltros.

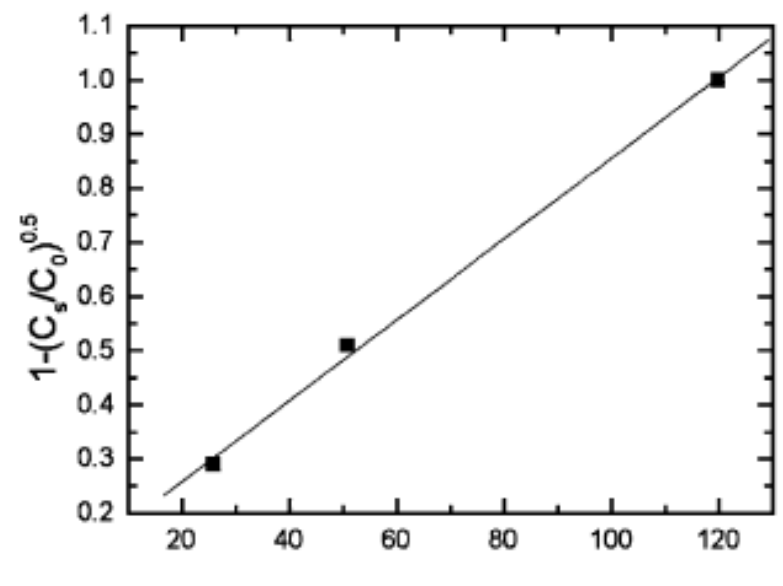

t(s)

Figura 3.8: Previsão do processo de biofiltração de acordo como o modelo semi-empírico baseado no modelo de Ottengraf e Van de Oever (1983), no caso de limitação da difusão, para concentrações de entrada de $\mathrm{H}_{2} \mathrm{~S}$ de 257 ppmv.

Fonte: OYARZÚN et al. (2003). 


\subsubsection{Resultados de pesquisas}

Em um dos trabalhos pioneiros sobre a biofiltração de sulfeto de hidrogênio, Van Langenhove et al. (1986) utilizaram lascas de madeira como material suporte, por afirmarem que o material promovia menor perda de carga do que a turfa, até então os únicos recheio utilizados, além de possuir menores custos variáveis. Utilizaram um biofiltro com altura de leito de $0,9 \mathrm{~m}$, com carga superficial de $65 \mathrm{~m}^{3} \cdot \mathrm{m}^{-2} \cdot \mathrm{h}^{-1}$ (o equivalente a $10 \mathrm{ppm}$ de $\mathrm{H}_{2} \mathrm{~S}$ ) e verificaram que o gás foi eficientemente eliminado do fluxo no qual estava inserido. Estabeleceram a umidade do meio suporte como parâmetro mais importante para o bom funcionamento do filtro, sendo o valor ótimo de $65 \%$. Ainda sobre a umidade, os autores verificaram que pareceu ser preferivel promover condições de umidade relativa de ar na entrada do biofiltro em detrimento ao jateamento na parte superior do mesmo.

Os autores fizeram referências aos processos de absorção e adsorção, afirmando que esses fatores não prevaleceram no mecanismo de biofiltração. No tocante a oxidação do sulfeto, verificaram ser o sulfato o produto da oxidação. Também fizeram referências à oxidação química, a qual afirmaram ser muito lenta, atribuindo, portanto, a maior parte da oxidação do poluente ao mecanismo de oxidação biológica.

Chung, Huang e Tseng (1996) isolaram Thiobacillus thioparus $\mathrm{CH} 11$ em alginato de cálcio para produzir pellets de material suporte para a biorremoção de $\mathrm{H}_{2} \mathrm{~S}$ utilizando biofiltro. Avaliaram a influência de alguns parâmetros operacionais (tempo de retenção do gás, temperatura e a concentração afluente de $\mathrm{H}_{2} \mathrm{~S}$ ) na eficiência de remoção, bem como na capacidade de eliminação do sistema. Conseguiram manter níveis elevados de eficiência de remoção durante a operação e observaram que o tempo de retenção ótimo do gás foi de 28 s, visto que este tempo correspondeu a eficiências de remoção maiores que 98\%. É um dos poucos trabalhos na literatura em que pode ser observado que a variação de $\mathrm{pH}$ foi insignificante durante a operação do sistema. A carga de enxofre ótima para o sistema foi de $25 \mathrm{~g} \mathrm{~m}^{-3} \cdot \mathrm{h}^{-1}$. É interessante observar que os autores estabeleceram os critérios necessários para o amento de escala desse sistema e realizaram balanços de enxofre para as várias cargas aplicadas no sistema. 
Operando um biofiltro em escala piloto durante 45 dias, Shojaosadati e Elyasi. (1999) removeram eficientemente sulfeto de hidrogênio de ar contaminado. O lodo da indústria de curtumes foi inoculado em um composto de cogumelos, misturado com ostras na proporção concha/composto, 1:5, que foi utilizado para tamponar o leito devido ao declínio do pH durante a operação. Eficiências maiores que $99 \%$ de $\mathrm{H}_{2} \mathrm{~S}$ foram atingidas. $\mathrm{O}$ valor ótimo de pH durante a operação ficou entre 6-7.

Chung et al. (2000) utilizaram o Thiobacillus thioparus $\mathrm{CH} 11$ - aplicado no tratamento de $\mathrm{H}_{2} \mathrm{~S}$ (10 a 100 ppm) como único gás poluente em Chung, Huang e Tseng (1996) - e a Nitrosomonas europaea - capaz de tratar $\mathrm{NH}_{3}$ a várias concentrações (10 100 ppm) em Chung \& Huang (1998) apud Chung et al. (2000) -, no tratamento de mistura gasosa composta por $\mathrm{H}_{2} \mathrm{~S}$ e $\mathrm{NH}_{3}$. Os microrganismos foram imobilizados com alginato de cálcio (técnica considerada eficiente em Chung, Huang e Tseng, 1996) e inseridos no biofiltro. Os autores monitoraram a eficiência e a cinética de remoção, a perda de carga, bem como as relações de $\mathrm{H}_{2} \mathrm{~S} / \mathrm{NH}_{3}$. De acordo com os resultados obtidos, verificaram que a eficiência global de remoção permaneceu constante, independentemente das relações $\mathrm{H}_{2} \mathrm{~S} / \mathrm{NH}_{3}$ utilizadas. Notaram que a concentração de $\mathrm{NH}_{3}$ teve pouca influência na eficiência de remoção de $\mathrm{H}_{2} \mathrm{~S}$, embora tenham verificado que altas concentrações de $\mathrm{H}_{2} \mathrm{~S}$ e $\mathrm{NH}_{3}$ suprimiram significativamente a remoção de $\mathrm{NH}_{3}$. Por meio da análise do produto, os autores puderam verificar que o controle da concentração de entrada de $\mathrm{H}_{2} \mathrm{~S}$ e $\mathrm{NH}_{3}$ poderia evitar a acidificação do sistema e, dessa forma, permitir a estabilidade operacional. Os autores estabeleceram, ainda, critério para a operação do biofiltro, que cumpre os padrões atuais de emissões de $\mathrm{H}_{2} \mathrm{~S}$ e $\mathrm{NH}_{3}(0,1$ e 1 ppm) no local de estudo - Taiwan. Definiram que a máxima concentração afluente não deveria exceder 58 ppm para $\mathrm{H}_{2} \mathrm{~S}$ e 164 ppm para $\mathrm{NH}_{3}$ e o tempo de residência deveria ser mantido em $72 \mathrm{~s}$.

Dando continuidade aos estudos de remoção da mistura gasosa constituída por $\mathrm{H}_{2} \mathrm{~S}$ e $\mathrm{NH}_{3}$ em biofiltros, Chung, Huang e Tseng (2001) estudaram várias relações da respectiva mistura, tendo como material suporte, células co-imobilizadas de Arthrobacter oxydans $\mathrm{CH} 8$ para $\mathrm{NH}_{3}$ e Pseudomonas putida $\mathrm{CH} 11$ para $\mathrm{H}_{2} \mathrm{~S}$. Similarmente a Chung et al. (2000), os autores realizaram testes para determinar a eficiência e cinética de remoção, bem como a 
perda de carga dos biossistemas. Eficiências de remoção maiores que 95\% para $\mathrm{NH}_{3}$ e 90\% para $\mathrm{H}_{2} \mathrm{~S}$ foram observadas, independente das relações das misturas de $\mathrm{H}_{2} \mathrm{~S}$ e $\mathrm{NH}_{3}$. De acordo com os resultados, os autores verificaram que a remoção de $\mathrm{H}_{2} \mathrm{~S}$ do sistema foi afetada sobremaneira por altas concentrações de $\mathrm{H}_{2} \mathrm{~S}$ e $\mathrm{NH}_{3}$, constatação contrária àquela feita por Chung et al., (2000), na qual altas concentrações de ambos os poluentes afetaram a concentração de $\mathrm{NH}_{3}$. No caso de altas concentrações de $\mathrm{NH}_{3}$, a parca eficiência de remoção de $\mathrm{H}_{2} \mathrm{~S}$ pôde ser atribuída à acidificação do biofiltro, fenômeno causado pelo acúmulo de metabólito ácido de $\mathrm{NH}_{3}$. Utilizando um modelo baseado na equação de Michaelis-Menten, perceberam que as concentrações máximas afluentes (estimadas pelo modelo) refletiram bem os dados experimentais para velocidades de 50 a $150 \mathrm{~h}^{-1}$.

A desodorização biológica do sulfeto de hidrogênio foi estudada, aplicando-se lava como material de fixação para o Thiobacillus thiooxidans, por Cho, Ryu e Lee (2000). Para tanto, os autores testaram três diferentes amostras de lava, que definiram como A, B e C. As capacidades de retenção de umidade das amostras A, B e C foram 0,38; 0,25 e 0,47 g $\mathrm{H}_{2} \mathrm{O} / \mathrm{g}$ lava, respectivamente. $\mathrm{O} \mathrm{pH}$ e a densidade das amostras analisadas ficaram na faixa de 8,25 a 9,24 e 920 a $1190 \mathrm{Kg}^{-3} \mathrm{~m}^{-3}$, respectivamente. Os biofiltros A e C apresentaram

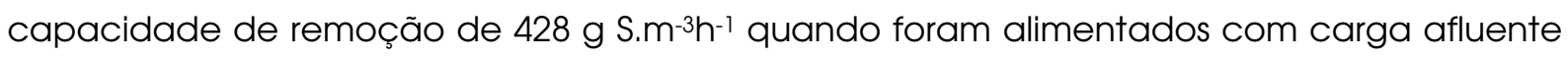
de $428 \mathrm{~g} \mathrm{~S} \cdot \mathrm{m}^{-3} \cdot \mathrm{h}^{-1}$ e velocidade superficial de $300 \mathrm{~h}^{-1}$. O biofiltro B, submetido a mesma carga de entrada e velocidade superficial apresentou capacidade de remoção menor, de $396 \mathrm{~g}$ S. $\mathrm{m}^{-3} \mathrm{~h}^{-1}$. As cargas críticas dos sistemas A, B e C, para velocidade superficial de $400 \mathrm{~h}^{-1}$, foram

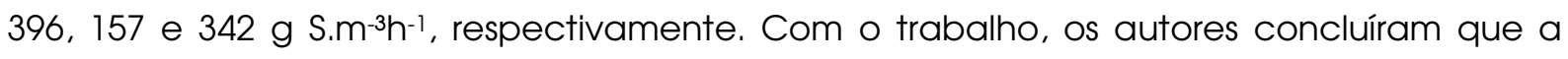
lava porosa é um bom material suporte para a fixação de microrganismos em sistemas de biofiltração.

Elias et al. (2002) utilizaram material suporte baseado em esterco de porco e serragem no processo de biofiltração. O biofiltro foi construído com três módulos removiveis e a operação foi realizada durante 2500 h, período no qual a taxa de carregamento mássico de $\mathrm{H}_{2} \mathrm{~S}$ foi aumentada de 10 até $45 \mathrm{~g} \mathrm{~m}^{-3} \mathrm{~h}^{-1}$ para duas velocidades superficiais de gás (100 e $\left.200 \mathrm{~m} \cdot \mathrm{h}^{-1}\right)$. As eficiências de remoção do biofiltro inteiro, considerando os três módulos, deveram-se principalmente a atividade de degradação dos módulos 1 e 2. 0 
material de enchimento provou ser quimicamente e mecanicamente apropriado durante todo o período de operação. O principal produto obtido no processo de biodegradação foi o enxofre elementar, sendo este quantificado como mais de $82 \%$ do total de enxofre acumulado no material suporte, acompanhado por sulfatos e tiossulfatos $(<18 \%)$. Os autores notaram que a deposição de enxofre não provocou a colmatação do leito para o período de operação estudado e o biofiltro foi facilmente limpo por retrolavagem.

Malhautier et al. (2003), baseados nas características físico-químicas do lodo granulado, resolveram utilizar este material como suporte de imobilização para os microrganismos na biofiltração de sulfeto de hidrogênio. Para tanto, dois biofiltros em escala piloto foram utilizados. Aplicaram carga volumétrica de $680 \mathrm{gH}_{2} \mathrm{~S} \cdot \mathrm{m}^{-3} \cdot \mathrm{dia}^{-1}$ e $85 \mathrm{gNH}_{3} \cdot \mathrm{m}^{-3}$. dia-1, durante 8 semanas em leito vazio, depois aplicaram a mesma carga em outra coluna preenchida com logo granular e, principalmente, alimentada com amônia. A eliminação da amônia e do sulfeto de hidrogênio ocorreu nos biofiltros de forma simultânea. As eficiências de remoção de $\mathrm{H}_{2} \mathrm{~S}$ e $\mathrm{NH}_{3}$ atingidas foram altas, e similares às observadas em Chung, Huang e Tseng (2001): 100\% e 80\% para as colunas empacotadas com lodo ativado e, principalmente, amônia; 100 e $80 \%$ para as colunas também empacotadas com lodo ativado, mas tendo como principal substrato $\circ \mathrm{H}_{2} \mathrm{~S}$. Uma observação interessante neste trabalho foi o erro no balanço de massa do nitrogênio em ambos os sistemas (valores em torno de $36 \%$ ), devido ao processo de desnitrificação, provocado pela possivel ocorrência de zonas anaeróbias. Os autores fizeram afirmações no sentido de que a oxidação de altas quantidades de sulfeto de hidrogênio pode ter influenciado a atividade nitrificante, devido algum estresse ambiental sobre o crescimento e a atividade desses organismos.

Morgan-Sagastume et al. (2003), investigaram mudanças nas propriedades físicas de um biofiltro preenchido com composto tratando sulfeto de hidrogênio. Colunas de biofiltros em escala de bancada preenchidas com composto, consistindo de composto maturado derivado de alimentos, folhas, resíduos de jardinagem e excremento de cavalo, foram utilizadas. As eficiências de remoção de $\mathrm{H}_{2} \mathrm{~S}$ decresceram de 100 para $90 \%$ após 206 dias de operação. Os autores concluíram que a variação no conteúdo da mistura e na área 
superficial específica pode explicar o decréscimo da eficiência de remoção com o tempo. Também mencionaram que o acúmulo de $\mathrm{SO}_{4}$, que reduziu o $\mathrm{pH}$ de 7,5 para 4,5, poderia ser um importante fator. Após misturarem novamente o meio composto, a eficiência de remoção retornou ao patamar de $100 \%$.

Barona et al. (2004) testaram 4 materiais suportes orgânicos (esterco de cavalos, lodo, solo e algas, esterco de porco e serragem) na biofiltração de sulfeto de hidrogênio. Atingiram as maiores eficiências de remoção de $\mathrm{H}_{2} \mathrm{~S}$ para concentrações na faixa entre 0,03 a 0,32 $\mathrm{g} \cdot \mathrm{m}^{-3}$, quando preencheram o sistema com material baseado na mistura de esterco de porco e serragem. Após selecionarem este material, estudaram a reposta do sistema a mudanças graduais e repentinas na taxa de carregamento e na vazão de $\mathrm{H}_{2} \mathrm{~S}$. A combinação de altas concentrações de gás afluente $\left(0,28 \mathrm{~g} \cdot \mathrm{m}^{-3}\right)$ e altas vazões $\left(1,3 \mathrm{~m}^{3} \cdot \mathrm{h}^{-1}\right)$, com tempo de residência do leito vazio menor que $22 \mathrm{~s}$ ) requereram a instalação de dois biofiltros em série, a fim de assegurar que a taxa de carregamento mássico efluente fosse menor que $15 \mathrm{~g} \cdot \mathrm{m}^{-3} \mathrm{~h}^{-1}$. Os autores notaram que o material utilizado como enchimento foi apto a recuperar as altas taxas de degradação após período de interrupção no suprimento de substrato, contudo o aumento na vazão de 0,81 para $1,85 \mathrm{~m}^{-3} \cdot \mathrm{h}^{-1}$ inverteu a capacidade de eliminação (um subseqüente aumento nas quantidades de contaminante efluente não degradado), mesmo quando a concentração afluente de $\mathrm{H}_{2} \mathrm{~S}$ foi gradualmente diminuída de 0,55 para $0,26 \mathrm{~g} \cdot \mathrm{m}^{-3}$.

Lee, Cho e Ryu (2005) isolaram Acidithiobacillus thiooxidans a partir de lodo ativado para inoculá-lo em biofiltro utilizado para o tratamento de $\mathrm{H}_{2} \mathrm{~S}$ e $\mathrm{NH}_{3}$. Notaram que, quando o $\mathrm{H}_{2} \mathrm{~S}$ foi o único poluente a ser introduzido ao sistema, manteve-se a eficiência de remoção em quase $100 \%$ até que a concentração afluente de $\mathrm{H}_{2} \mathrm{~S}$ atingisse $900 \mu \mathrm{L}$. L-1 e a velocidade

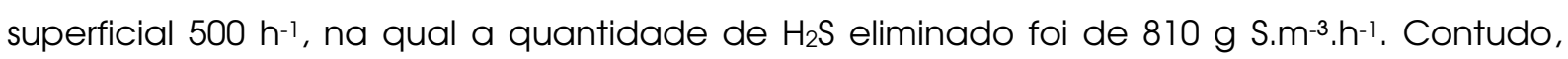
quando a $\mathrm{NH}_{3}\left(50\right.$ - $500 \mu{\left.\mathrm{L} . L^{-1}\right)}^{-1}$ foi simultaneamente adicionado ao sistema de forma concomitante ao $\mathrm{H}_{2} \mathrm{~S}$, a máxima quantidade de eliminação do $\mathrm{H}_{2} \mathrm{~S}$ decresceu para $650 \mathrm{~g}$ $S \cdot \mathrm{m}^{-3} \cdot \mathrm{h}^{-1}$. A inibição da remoção de $\mathrm{H}_{2} \mathrm{~S}$ pelas baixas concentrações de $\mathrm{NH}_{3}\left(50\right.$ - $\left.200 \mu \mathrm{L} . \mathrm{L}^{-1}\right)$ foi similar aquela obtida para altas concentrações de $\mathrm{NH}_{3}\left(300\right.$ - $500 \mu \mathrm{L} . \mathrm{L}^{-1}$ ). A carga crítica 
de entrada de $\mathrm{H}_{2} \mathrm{~S}$, que resultou em mais de $99 \%$ de remoção, foi estabelecida como sendo de $400{\mathrm{~g} \mathrm{~S} . \mathrm{m}^{-3} \mathrm{~h}-1}^{-1}$ em presença de amônia.

Duan et al. (2006) avaliaram a viabilidade da utilização de carvão ativado como material suporte no processo de biofiltração de $\mathrm{H}_{2} \mathrm{~S}$, por meio do balanço ótimo e da combinação da capacidade de adsorção do carvão somada à biodegradação do poluente pelas bactérias imobilizadas no material. Operaram dois biofiltros, com dimensões idênticas, em escala de bancada, sendo um preenchido com carvão biológico ativado e outro com carvão virgem, sem imobilização bacteriana. Várias concentrações afluentes de $\mathrm{H}_{2} \mathrm{~S}$ (até 125 ppm) foram utilizadas para determinar o desempenho ótimo das colunas. Um rápido período de partida (de poucos dias) foi observado. Para carga de carregamento volumétrico de $1600 \mathrm{~m}^{3} \cdot \mathrm{m}^{-1} \cdot \mathrm{h}^{-1}$ (87 ppm de concentração afluente do gás), a capacidade de eliminação do carvão biológico ativado foi de $181 \mathrm{~g} \mathrm{H}_{2} \mathrm{~S} \cdot \mathrm{m}^{-3} \cdot \mathrm{h}^{-1}$ e a eficiência de remoção atingida foi de 94\%. A população bacteriana demonstrou capacidade de degradação de $\mathrm{H}_{2} \mathrm{~S}$ em uma ampla faixa de pH (1-7). Há evidências experimentais de que o carvão biológico ativado utilizado poderia ser novamente introduzido no biofiltro anteriormente preenchido com o mesmo.

No primeiro trabalho sobre biodepuração de gases, desenvolvido pelo Laboratório de Controle Ambiental, vinculado ao departamento de Engenharia Química da Universidade Federal de São Carlos, Rodrigues (2002) imobilizou Thiobacillus thioparus e Pseudomonas Putida em biofiltro preenchido com espuma de poliuretano e solo para investigar a biorremoção de sulfeto de hidrogênio. As concentrações afluentes variaram de 15 a 245 ppm, todavia o meio suporte solo apresentou dificuldades operacionais. Somou-se a isso o fato de que a cultura de Pseudomonas Putida não ter se adaptado como o esperado, vide Chung, Huang e Tseng (2001). Portanto, o estudo foi realizado apenas para a cultura de Thiobacillus thioparus imobilizado em espuma de poliuretano, mantendo-se a faixa de concentração especificada, para qual as eficiências se mantiveram sempre acima dos $90 \%$.

Maia (2003) utilizou Thiobacillus thioparus, bactéria considerada eficiente na remoção de $\mathrm{H}_{2} \mathrm{~S}$ em Rodrigues (2002) e em outros diversos trabalhos, imobilizada em espuma 
de poliuretano e contas de alginato/quitosana, no tratamento de $\mathrm{H}_{2} \mathrm{~S}$ em biofiltro. As dimensões dos sistemas foram idênticas àquelas de Rodrigues (2002), sendo $5 \mathrm{~cm}$ de diâmetro útil e $25 \mathrm{~cm}$ de altura. Logo após um período de adaptação a eficiência de remoção atingiu $98 \%$ para a coluna com alginato/quitosana e $90 \%$ para a coluna com espuma de poliuretano.

O aprimoramento de unidade experimental de biofiltração, com relação aos trabalhos de Rodrigues (2002) e Maia (2003), para depuração de uma corrente gasosa contendo $\mathrm{H}_{2} \mathrm{~S}$ foi realizado por Rocha (2007). Aproveitando a experiência dos autores que o sucederam no tocante ao material suporte, o autor preencheu seu biossistema com espuma de poliuretano. Foi avaliada a resposta do reator submetido ao aumento progressivo da concentração de entrada do poluente, na faixa de 141 a 1264 ppm, aproximadamente, para tempo de retenção de $58 \mathrm{~s}$. As dimensões do biofiltro para a altura de leito e diâmetro interno foram de $76 \mathrm{~cm}$ e 5,2 cm, respectivamente. Ao contrário de Rodrigues (2002) e Maia (2003), que utilizaram culturas puras, Rocha (2007) utilizou um consórcio de microrganismos, proveniente de uma unidade de lodos ativados. A adaptação do inóculo foi realizada por 7 dias com tiossulfato e 7 dias com $\circ \mathrm{H}_{2} \mathrm{~S}$. As perdas de carga obtidas no sistema foram inferiores a 0,8.10-2 mca. Obteve eficiência média do biofiltro, durante os mais de 120 dias de operação, acima dos 96\%. A umidade do leito se manteve acima de $92 \%$. Foram observadas capacidades de eliminação máxima (ECmáx) de capacidade de eliminação ótima (ECótimo) de, aproximadamente, $155 \mathrm{~g} \cdot \mathrm{m}^{-3} \cdot \mathrm{h}^{-1}$ e $139 \mathrm{~g} \cdot \mathrm{m}^{-3} \cdot \mathrm{h}^{-1}$, respectivamente. O principal produto da degradação do $\mathrm{H}_{2} \mathrm{~S}$ encontrado foi o enxofre elementar.

Na Tabela 3.9, podem ser verificados alguns estudos sobre biofiltração de $\mathrm{H}_{2} \mathrm{~S}$. 
Tabela 3.9 - Pesquisas realizadas sobre remoção de sulfeto de hidrogênio em biofiltros.

\begin{tabular}{|c|c|c|c|c|c|c|c|c|c|}
\hline Escala & Tipo de Leito & $\begin{array}{l}\text { Volume } \\
\text { do Leito }\end{array}$ & $\begin{array}{c}\text { Poluentes tratados e } \\
\text { concentrações de entrada }\end{array}$ & $\begin{array}{l}\text { Vazões e } \\
\text { tempos de } \\
\text { residência }\end{array}$ & $\begin{array}{l}\text { Tempo de } \\
\text { Operação }\end{array}$ & Microrganismo & $\begin{array}{l}\text { Eficiência } \\
\text { de } \\
\text { remoção }\end{array}$ & Inoculação & Autor \\
\hline Laboratório & $\begin{array}{c}\text { Células } \\
\text { imobilizadas } \\
\text { Alginato de } \\
\text { Cálcio }\end{array}$ & $0,7 \mathrm{~L}$ & Corrente de $\mathrm{Ar}$ com $\mathrm{H}_{2} \mathrm{~S}$ (5-100ppm) & $18-150 \mathrm{~L} / \mathrm{h}$ & 87 dias & T. thioparus & $\begin{array}{c}85-99 \% \\
\left(\mathrm{H}_{2} \mathrm{~S}\right)\end{array}$ & $\begin{array}{c}\text { Imobilização em Alginato de } \\
\text { Cálcio }\end{array}$ & CHUNG et al. (1996a) \\
\hline Laboratório & $\begin{array}{l}\text { Resíduo de } \\
\text { jardinagem }\end{array}$ & $18 \mathrm{~L}$ & $\begin{array}{l}\text { Corrente de ar com } \mathrm{H}_{2} \mathrm{~S} \text { (10- } \\
\qquad 450 \mathrm{ppm}) \text {. }\end{array}$ & $\begin{array}{c}1,7 \mathrm{~m}^{3} / \mathrm{h} \\
38 \mathrm{~s}\end{array}$ & 30 dias & Cultura mista & $\begin{array}{c}90-100 \% \\
\left(\mathrm{H}_{2} \mathrm{~S}\right)\end{array}$ & Lodo Ativado & WANI et al. (1999) \\
\hline Laboratório & $\begin{array}{l}\text { Células } \\
\text { imobilizadas } \\
\text { Alginato de } \\
\text { Cálcio }\end{array}$ & $0,7 \mathrm{~L}$ & $\begin{array}{c}\text { Corrente de ar com } \mathrm{H}_{2} \mathrm{~S}(60- \\
\text { 120ppm), } \\
\mathrm{NH}_{3}(60-120 \mathrm{ppm})\end{array}$ & $\begin{array}{c}36 \mathrm{~L} / \mathrm{h} \\
72 \mathrm{~s}\end{array}$ & 30 dias & $\begin{array}{l}\text { Pseudomonas } \\
\text { putida, } \\
\text { Arthrobacter } \\
\text { oxydans }\end{array}$ & $\begin{array}{l}>90 \%\left(\mathrm{H}_{2} \mathrm{~S}\right) \\
>95 \%\left(\mathrm{NH}_{3}\right)\end{array}$ & $\begin{array}{c}\text { Imobilização de } \\
\text { Pseudomonas putida e } \\
\text { Arthrobacter oxydans em } \\
\text { alginato de cálcio }\end{array}$ & CHUNG et al. (2001) \\
\hline Laboratório & $\begin{array}{l}\text { Estrume de } \\
\text { porco + } \\
\text { serragem }\end{array}$ & $5,9 \mathrm{~L}$ & $\begin{array}{l}\text { Corrente de ar com } \mathrm{H}_{2} \mathrm{~S}(10-45 \\
\left.\qquad \mathrm{g} / \mathrm{m}^{3} . \mathrm{h}\right)\end{array}$ & $13,5-27 \mathrm{~s}$ & 2500 horas & Cultura Mista & $>90 \%\left(\mathrm{H}_{2} \mathrm{~S}\right)$ & Não Houve & ELIAS et al. (2002) \\
\hline Real & $\begin{array}{l}\text { Espuma de } \\
\text { Poliuretano }\end{array}$ & $\begin{array}{l}500 \mathrm{~m}^{3} \\
(6 \\
\text { unidad } \\
\text { es })\end{array}$ & $\begin{array}{l}\text { Efluente de Indústria de tabaco } \\
\qquad \text { com } \mathrm{H}_{2} \mathrm{~S} \text { (800-1200ppm) }\end{array}$ & $11 \mathrm{~s}$ & 42 dias & - & $>90 \%\left(\mathrm{H}_{2} \mathrm{~S}\right)$ & - & COX \& DESHUSSES (2002) \\
\hline Laboratório & Lodo Granulado & $10 \mathrm{~L}$ & $\begin{array}{l}\text { Corrente de ar com } \mathrm{H}_{2} \mathrm{~S}(170- \\
\left.680 \mathrm{~g} / \mathrm{m}^{3} . \mathrm{d}\right), \mathrm{NH}_{3}\left(340 \mathrm{~g} / \mathrm{m}^{3} . \mathrm{d}\right)\end{array}$ & - & $\begin{array}{c}21 \\
\text { semanas }\end{array}$ & $\begin{array}{c}\text { Bactéria nitrificante, } \\
\text { bactéria oxidadora } \\
\text { de sulfeto }\end{array}$ & $\begin{array}{l}100 \%\left(\mathrm{H}_{2} \mathrm{~S}\right) \\
80 \%\left(\mathrm{NH}_{3}\right)\end{array}$ & Lodo Adaptado & MALHAUTIER et al. (2003) \\
\hline Laboratório & $\begin{array}{l}\text { Composto } \\
\text { Maturado }\end{array}$ & $8 \mathrm{~L}$ & Corrente de ar com $\mathrm{H}_{2} \mathrm{~S}$ (50ppm) & 10L/min & 206 dias & Cultura mista & $\begin{array}{c}90-100 \% \\
\left(\mathrm{H}_{2} \mathrm{~S}\right)\end{array}$ & Não Houve & $\begin{array}{c}\text { MORGAN-SAGASTUME et } \\
\text { al. (2003) }\end{array}$ \\
\hline
\end{tabular}

Fonte: Adaptado de SYED et al. (2006). ${ }^{*} \mathrm{MM}=$ metil mercaptana; DMS = dimetil sulfeto; DMDS = dimetil disulfeto 


\subsubsection{Considerações finais}

Os trabalhos apresentados na literatura reafirmam as grandes vantagens dos sistemas biológicos quando comparados aos sistemas físico-químicos de remoção de sulfeto em fase gasosa, em função de serem sistemas que apresentam altas eficiências de remoção, certa habilidade a suportar sobrecargas, baixos custos, simplicidade operacional e serem considerados processos interessantes do ponto de vista ambiental, pois não geram os poluentes secundários comumente produzidos pelos processos físico-químicos.

Os três tipos de reatores que atualmente dominam o tratamento biológico de fluxos gasosos são os biofiltros, biofiltros percoladores e os biolavadores. A despeito de serem sistemas de dificil controle operacional e apresentarem modificações de sua hidrodinâmica durante a operação, os biofiltros têm sido mais amplamente utilizados para o tratamento de efluentes gasosos por serem mais simples de operar, possuir custos mais baixos de implantação e operação, e ainda, serem sistemas robustos. Eficiências de remoção maiores de 90\% não são exceções no caso dos poluentes mais comuns presentes nas emissões industriais, como álcoois, éteres, aldeídos, cetonas e compostos voláteis monoaromáticos. Essas características fizeram com que diversas unidades fossem instaladas e estejam em operação e muitos estudos sejam realizados no sentido de tentar compreender melhor esse sistema.

Apesar dessa consolidação efetiva, principalmente nos países desenvolvidos, é consenso entre os pesquisadores que o desenvolvimento e as possiveis novas aplicações desta tecnologia dependerão da possibilidade real de utilizar novos microrganismos em cultura pura ou consórcios selecionados para as condições peculiares presentes nos biofiltros, bem como a utilização de materiais suporte alternativos que sejam tecnicamente, economicamente e ambientalmente viáveis. 


\section{MATERIAIS E MÉTODOS}

\section{1 MICRORGANISMOS E MEIO DE CULTURA}

Optou-se pela utilização de cultura mista originária de duas fontes: a) unidade de biofiltro aerado submerso (pós-tratamento de reator anaeróbio de manta de lodo) pertencente ao Serviço Autônomo de Água e Esgoto da Cidade de São Carlos (SAEE), b) unidade de lodos ativados (tratamento secundário), pertencente a São Carlos S/A - Indústria de Papel e Celulose.

No cultivo das culturas foi utilizado o meio nutricional ATCC290-S6 para Thiobacillus sp., esse meio é composto por sais minerais que suprem as necessidades nutricionais das bactérias, sendo sua composição descrita na Tabela 4.1.

\begin{tabular}{cc} 
Tabela 4. 1 - Meio ATCC 290-S6 \\
\hline Reagente & Massa $\left(\mathrm{g} \cdot \mathrm{L}^{-1}\right)$ \\
\hline $\mathrm{MnSO}_{4}$ & 0,02 \\
$\mathrm{KH}_{2} \mathrm{PO}_{4}$ & 1,20 \\
$\mathrm{MgSO}_{4} .7 \mathrm{H}_{2} \mathrm{O}$ & 1,80 \\
$\left(\mathrm{NH}_{4}\right)_{2} \mathrm{SO}_{4}$ & 0,10 \\
$\mathrm{CaCl}_{2}$ & 0,10 \\
$\mathrm{FeCl}_{3}$ & 0,02 \\
$\mathrm{Na}_{2} \mathrm{~S}_{2} \mathrm{O}_{3}$ & 10,0
\end{tabular}

A adaptação dos microrganismos foi realizada em 2 barriletes (um para cada cultura) de 25 L com solução nutriente ATCC 290-S6 e lodo na proporção de 50\% (v/v), sendo $10 \mathrm{~L}$ de lodo e $10 \mathrm{~L}$ de meio nutriente. $\mathrm{O}$ barrilete foi mantido sob aeração sendo adicionada solução nutriente a cada 48 horas (supondo-se que todo o nutriente já houvesse 
sido consumido nesse período). A fonte de enxofre utilizada neste período foi o tiossulfato $\left(\mathrm{Na}_{2} \mathrm{~S}_{2} \mathrm{O}_{3}\right)$.

Decorrido esse período, juntou-se as duas culturas já adaptadas à primeira fonte de enxofre em barrilete de $50 \mathrm{~L}$. Manteve-se à adição de nutriente, porém substituiu-se o tiossulfato pelo gás sulfídrico, com a finalidade de promover a adaptação dos microrganismos a nova fonte de enxofre.

A etapa de adaptação das culturas pode se observada na Figura 4.1.

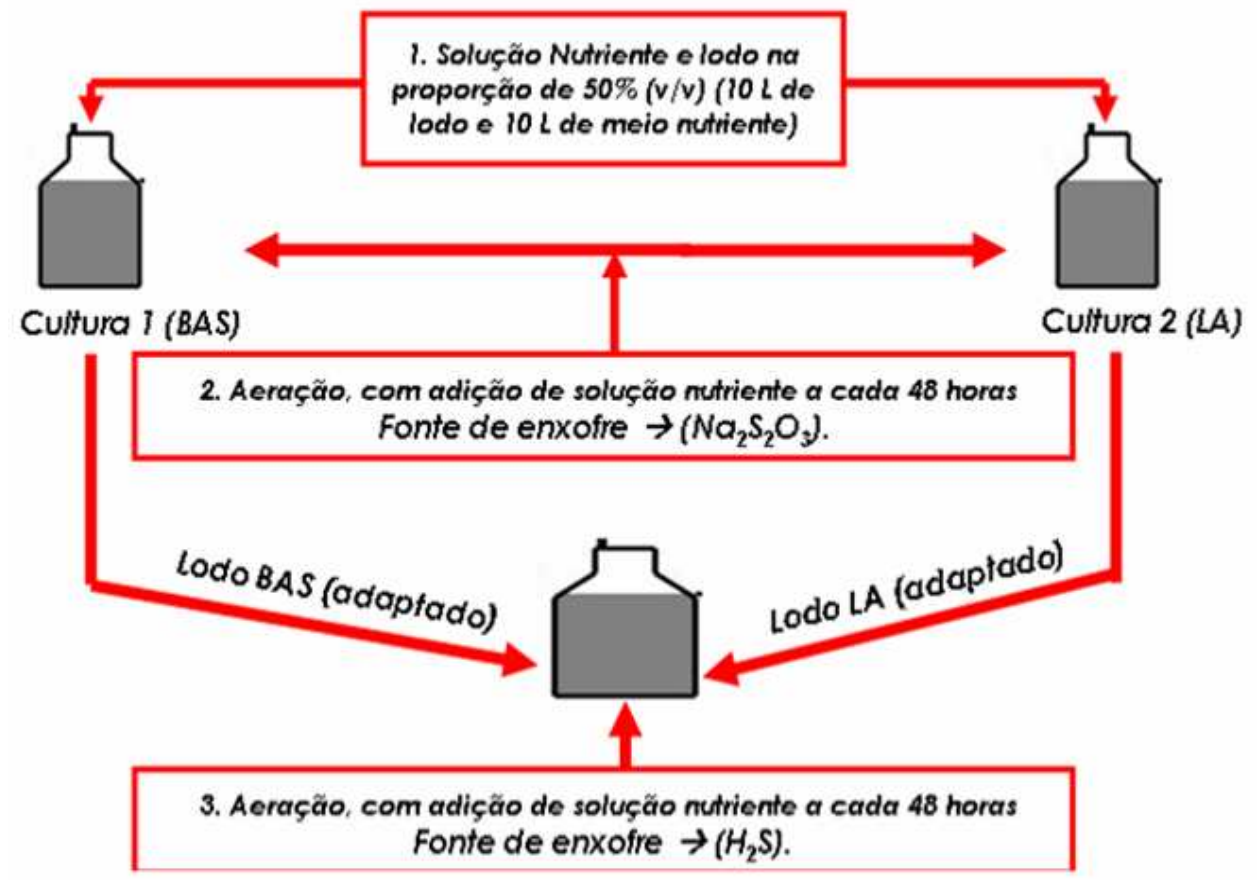

Figura 4.1: Ełapa de adaptação das culturas

\subsection{ESPUMA DE POLIURETANO, BAGAÇO DE CANA E FIBRA DE COCO COMO MEIOS SUPORTE}

Para este trabalho, três tipos de suportes foram utilizados (dois orgânicos e um sintético). Os materiais suportes empregados foram: bagaço de cana (um dos maiores resíduos da agroindústria brasileira) e fibra de coco (muito utilizada como adubo orgânico), de natureza orgânica; e a espuma de poliuretano, de natureza sintética. 
O fluxograma mostrado na Figura 4.2 apresenta as etapas de preparação dos materiais suportes orgânicos que foram inseridos nos reatores.

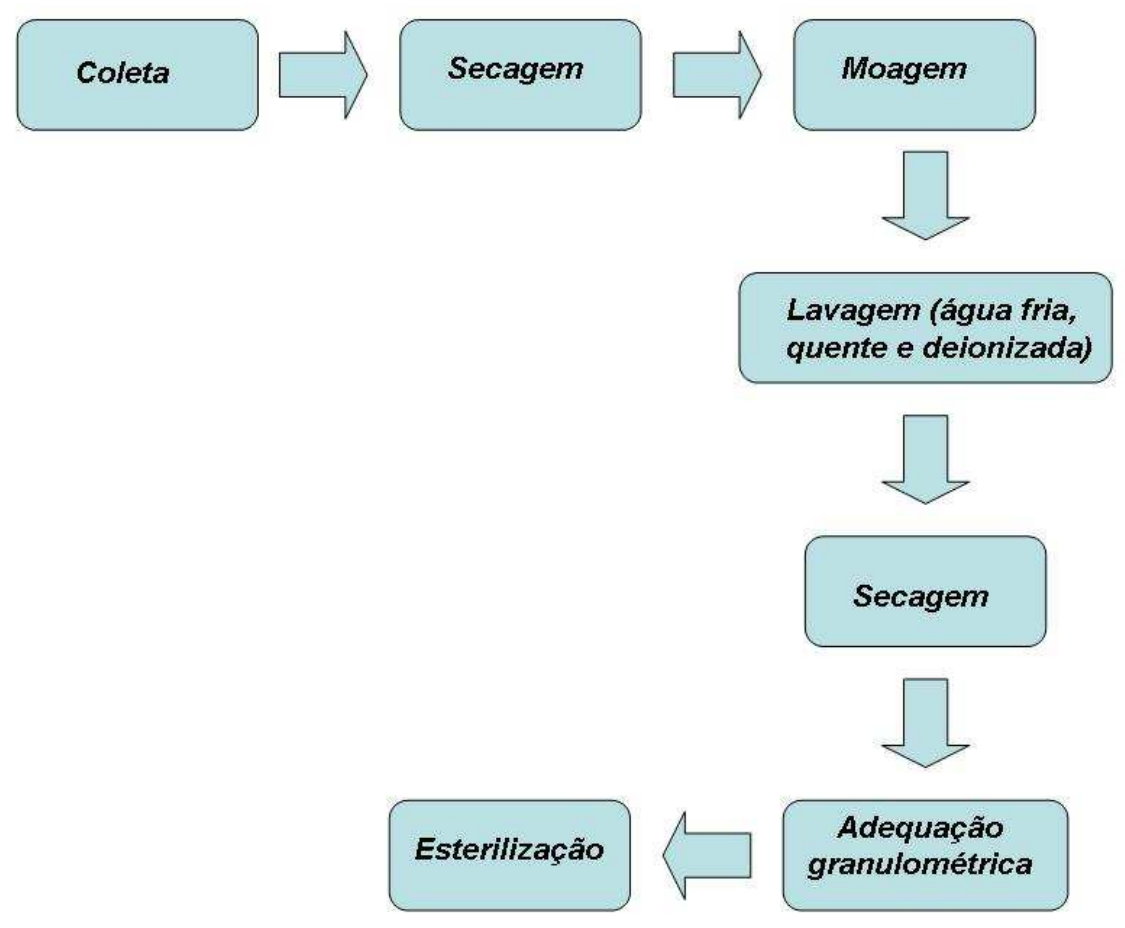

Figura 4.2: Ełapas de preparação dos meios suportes orgânicos Fonte: Adaptado de TACLA (2004).

Baseando-se no método explicitado em Tacla (2004), os materiais suportes orgânicos foram coletados, secos ao ar livre e, em seguida, cominuídos em moinho de facas. Após a moagem, os mesmos, com exceção da espuma de poliuretano, foram lavados inicialmente com água quente, depois com água corrente e, finalmente, com água deionizada.

Após a etapa de lavagem, os meios orgânicos foram novamente secos ao ar livre, para, em seguida, serem peneirados com a finalidade de adequar a granulometria das partículas (na faixa de 2,6 a 5,6 mm, correspondente a 3,5 - 9 na escala MESH). Em seguida, os mesmos foram esterilizados em autoclave (temperatura de $121^{\circ} \mathrm{C}$ e pressão de $1 \mathrm{~atm}$ ). Após a etapa de esterilização, os suportes foram secos em estufa, à temperatura de $50^{\circ} \mathrm{C}$, para em seguida serem inseridos no reator. 
No caso do meio suporte sintético, representado pela espuma de poliuretano, procedeu-se o corte da mesma em cubos de aproximadamente $5 \mathrm{~mm}$ de aresta para manter a relação de 1:10 com o diâmetro do reator, com o objetivo de se evitar ao máximo o efeito de parede no biofiltro (ZOTIN, 1985).

Na Figura 4.3 estão apresentados os materiais suportes utilizados neste trabalho.

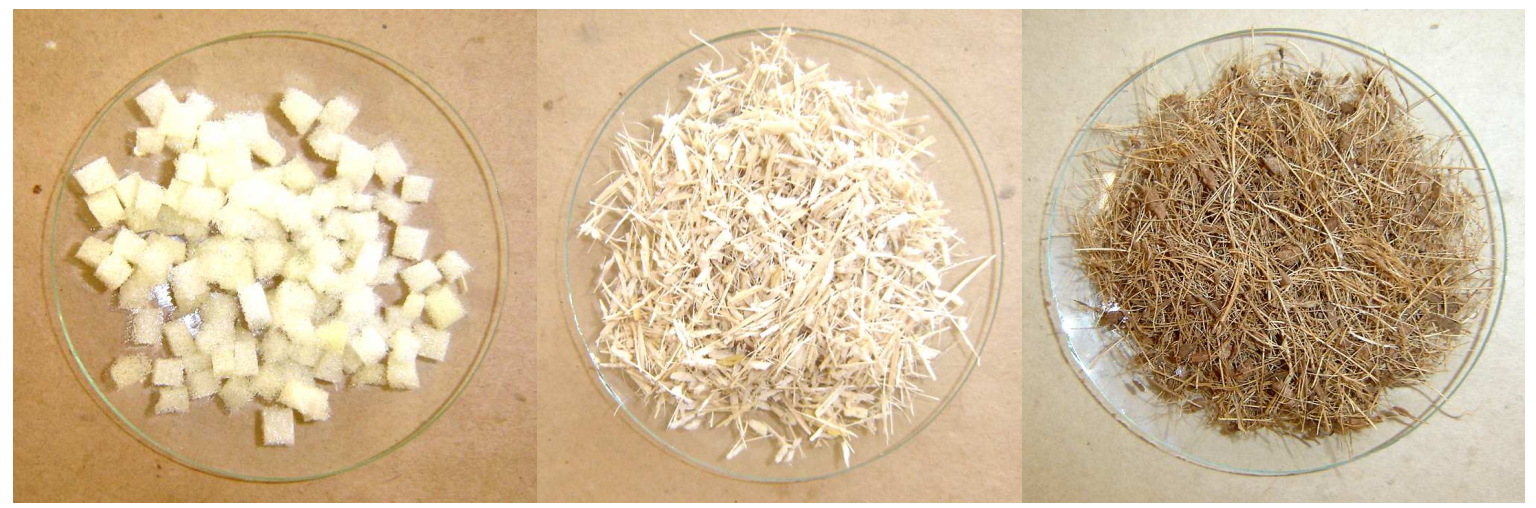

Figura 4.3: Materiais suportes prontos para serem inseridos no biofiltro (da esquerda para direita: espuma de poliuretano, bagaço de cana e fibra de coco).

Com a finalidade de estabelecer o valor inicial de referência dos meios suportes, o $\mathrm{pH}$ dos mesmos, com exceção da espuma de poliuretano, foi medido em água a uma proporção de peso do material seco / volume de água de 1:9 (BARONA et al., 2004; ELIAS et al. 2001). Cabe ressaltar, que em todos os suportes foi adicionado carbonato de sódio, na proporção de $5 \%$ em massa em relação ao suporte, na tentativa de tamponar o sistema pelo maior tempo possível ao longo do experimento (TACLA, 2004).

\subsection{EMPACOTAMENTO DO RECHEIO}

O empacotamento do recheio seguiu as mesmas etapas descritas em Moraes Júnior (1991), Maia (2003) e Rocha (2007).

Os meios suportes foram saturados com o lodo previamente enriquecido para, em seguida, serem inseridos no interior do biofiltro. Com o intuito de não remover o inóculo 
presente nos poros dos materiais suporte, o empacotamento foi concluído dando-se leves batidas na parede do reator com o auxilio de um martelo de borracha, para possibilitar melhor acomodação do recheio. A distribuição deste dentro do reator seguiu apenas orientação visual para tentar proporcionar o melhor acomodamento possivel com a finalidade de evitar a formação de caminhos preferenciais, zonas estagnadas ou com diferentes compactações.

\subsection{APARATO EXPERIMENTAL E CONDIÇÕES DE OPERAÇÃO}

A configuração do sistema baseou-se naquela estudada por Rocha (2007). Para este trabalho, houve a ampliação da instalação a fim de permitir a operação dos três biofiltros.

Os reatores foram construídos em acrílico e preenchidos com diferentes materiais suportes (especificados no item 4.2), tendo 7 pontos de amostragens instalados em cada biofiltro. A instalação destas tomadas de amostras teve a finalidade de permitir a verificação do perfil de degradação de $\mathrm{H}_{2} \mathrm{~S}$ ao longo do leito.

Na Tabela 4.2 são apresentadas as dimensões dos biofiltros. 
Tabela 4.2 - Principais dimensões dos biofiltros

\begin{tabular}{cccc}
\hline Parâmetro & $\begin{array}{c}\text { Espuma de } \\
\text { poliuretano }\end{array}$ & $\begin{array}{c}\text { Bagaço de } \\
\text { cana }\end{array}$ & Fibra de coco \\
\hline Altura total (cm) & 100 & 96 & 96 \\
Altura útil (cm) & 88 & 84 & 84 \\
Diâmetro (cm) & 5,2 & 5,2 & 5,2 \\
Volume Total (cm $\left.{ }^{3}\right)$ & 2124 & 2039 & 2039 \\
Volume útil (cm $\left.{ }^{3}\right)$ & 1868 & 1783 & 1783 \\
Área superficial (cm²) & 21,2 & 21,2 & 21,2 \\
Relação L/D (útil) & 17 & 16 & 16 \\
Relação L/D (total) & 19 & 18 & 18 \\
\hline
\end{tabular}

O fluxograma do sistema de biofiltração é apresentado na Figura 4.4. 


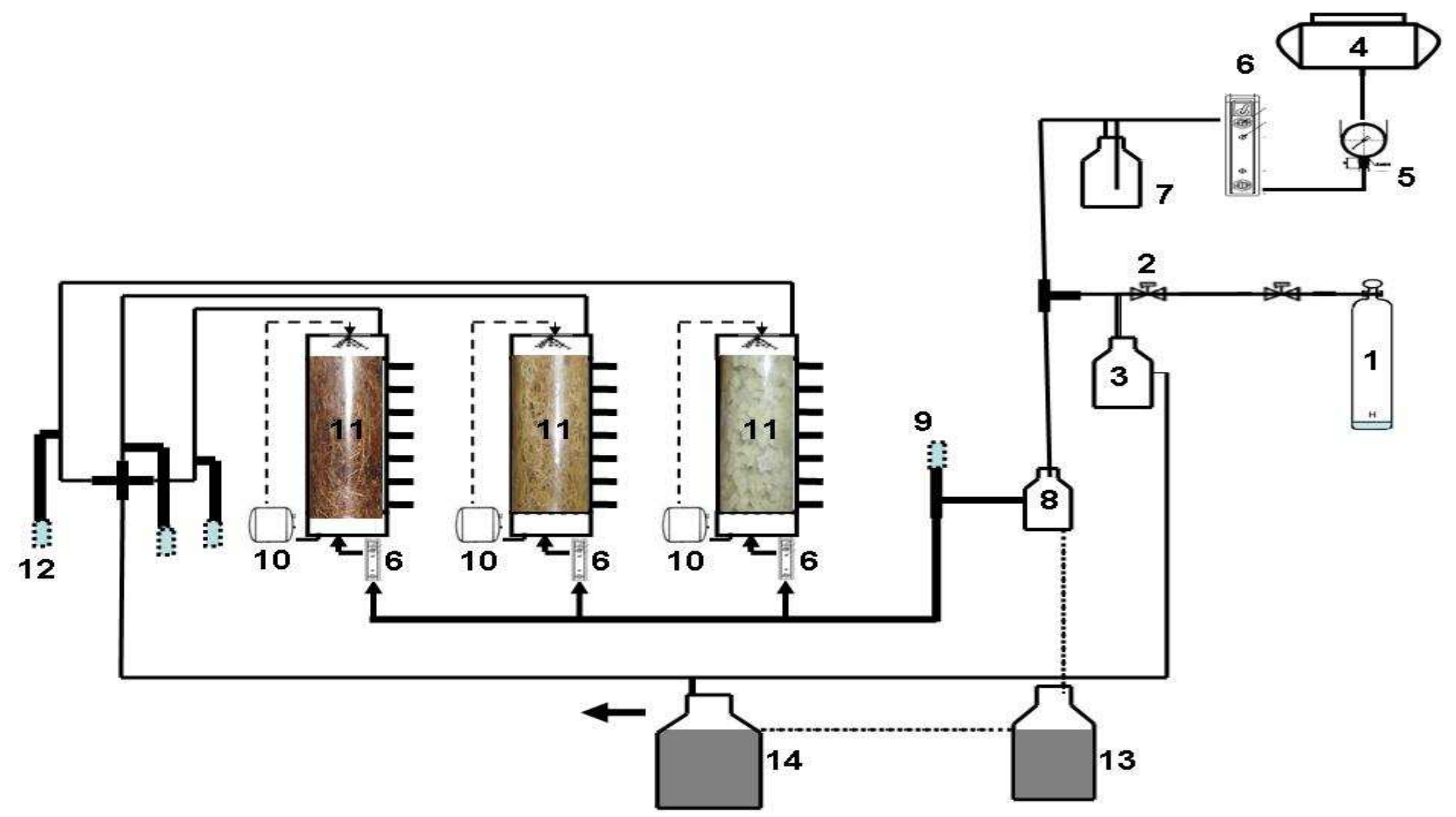

Figura 4.4: Sistema de biofiltração (1) Cilindro de $\mathrm{H}_{2} \mathrm{~S}$; (2) Válvula agulha; (3) Contador de bolhas; (4) Compressor; (5) Manômetro de Bourdon; (6) Rotâmetros; (7) Umidificador; (8) Misturador; (9) Amostrador de entrada; (10) Bombas de recirculação; (11) Biofiltros; (12) Amostradores de Saída; (13) Inóculo Reserva; (14) Tanque de Soda. 
A seguir, na Tabela 4.3, podem ser verificados os componentes e as funções de cada componente dentro do sistema de biofiltração.

Tabela 4.3 - Componentes e suas respectivas finalidades no processo de biofiltração

\begin{tabular}{|c|c|c|}
\hline Legenda & Componente & Função \\
\hline 1 & Cilindro de $\mathrm{H}_{2} \mathrm{~S}$ & $\begin{array}{l}\text { Fornecer ao sistema o poluente puro a ser } \\
\text { estudado }\end{array}$ \\
\hline 2 & Válvula de agulha & Controlar a vazão de $\mathrm{H}_{2} \mathrm{~S}$ puro \\
\hline 3 & Contador de bolhas & $\begin{array}{c}\text { Permitir a estimativa da concentração de } \mathrm{H}_{2} \mathrm{~S} \\
\text { experimentalmente, através de medidas antes } \\
\text { da entrada no biofiltro. }\end{array}$ \\
\hline 4 & Compressor & Fornecer ar para o sistema \\
\hline 5 & Manômetro de Bourdon & Verificar a pressão no sistema \\
\hline 6 & Rotâmetros & Medir a vazão de diluição e a vazão de mistura \\
\hline 7 & Umidificador & $\begin{array}{c}\text { Prover a umidificação da corrente de ar no } \\
\text { sistema }\end{array}$ \\
\hline 8 & Misturador & Misturar as correntes de $\mathrm{H}_{2} \mathrm{~S}$ e ar \\
\hline 9 & Amostrador de entrada & $\begin{array}{l}\text { Coletar amostras para determinação da } \\
\text { concentração afluente de } \mathrm{H}_{2} \mathrm{~S}\end{array}$ \\
\hline 10 & $\begin{array}{l}\text { Bombas de recirculação de } \\
\text { nutrientes }\end{array}$ & $\begin{array}{c}\text { Prover ao sistema a circulação intermitente de } \\
\text { nutrientes indispensáveis ao crescimento da } \\
\text { biomassa imobilizada. }\end{array}$ \\
\hline 11 & Biofiltros & Promover a biodegradação do $\mathrm{H}_{2} \mathrm{~S}$ \\
\hline 12 & Amostradores de Saída & $\begin{array}{c}\text { Coletar amostras para determinação da } \\
\text { concentração efluente de } \mathrm{H}_{2} \mathrm{~S}\end{array}$ \\
\hline 13 & Inoculo reserva & $\begin{array}{c}\text { Prover rapidamente ao sistema, em caso de } \\
\text { pane, lodo adaptado às concentrações } \\
\text { estudadas }\end{array}$ \\
\hline 14 & Tanque de $\mathrm{NaOH}$ & $\begin{array}{c}\text { Reter todo o } \mathrm{H}_{2} \mathrm{~S} \text { que, porventura, ainda reste } \\
\text { no sistema. }\end{array}$ \\
\hline
\end{tabular}


A seguir, nas Figuras 4.5 e 4.6, é apresentada uma visão geral do sistema de biofiltração:

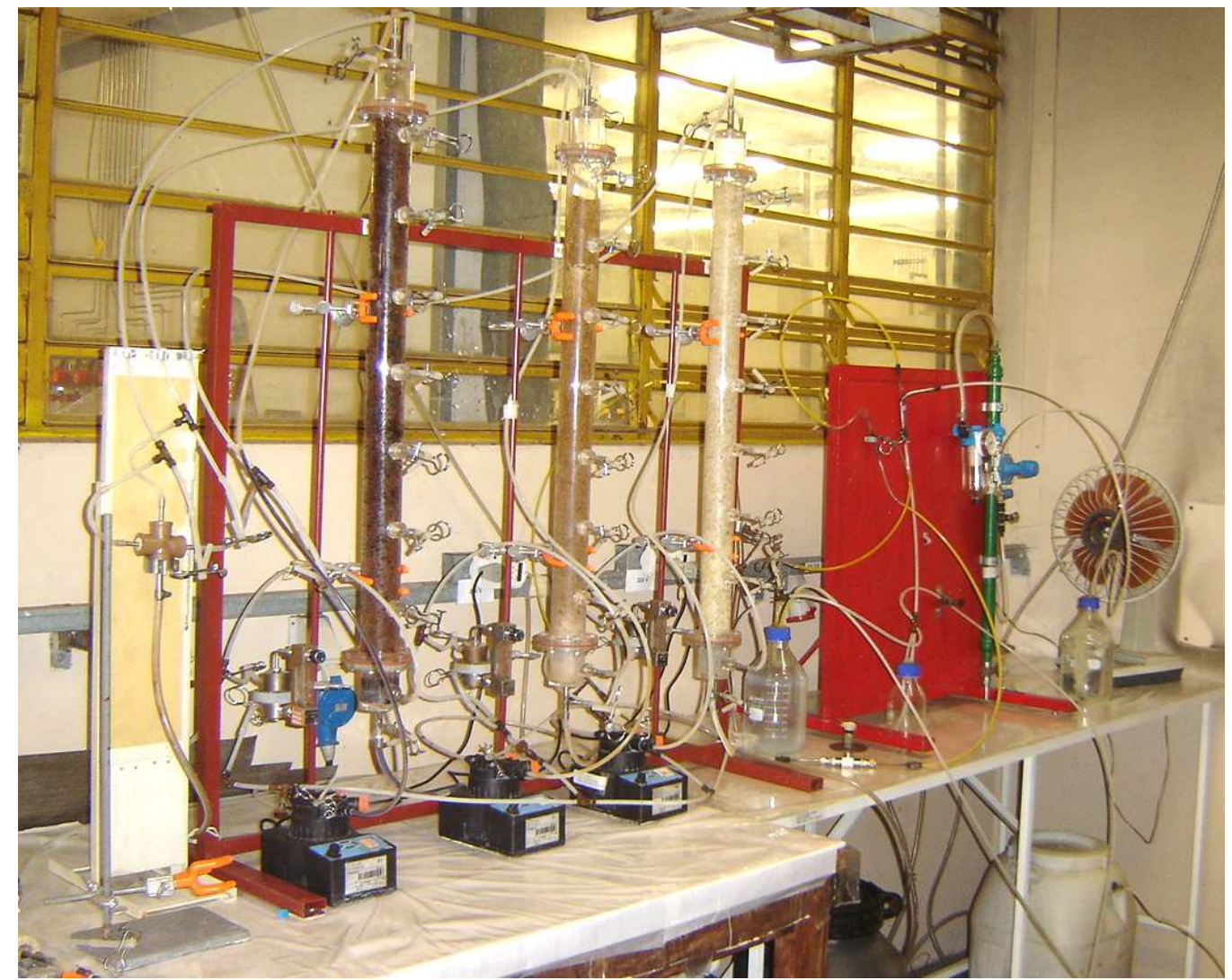

Figura 4.5: Visão geral do sistema de biofiltração (vista diagonal)

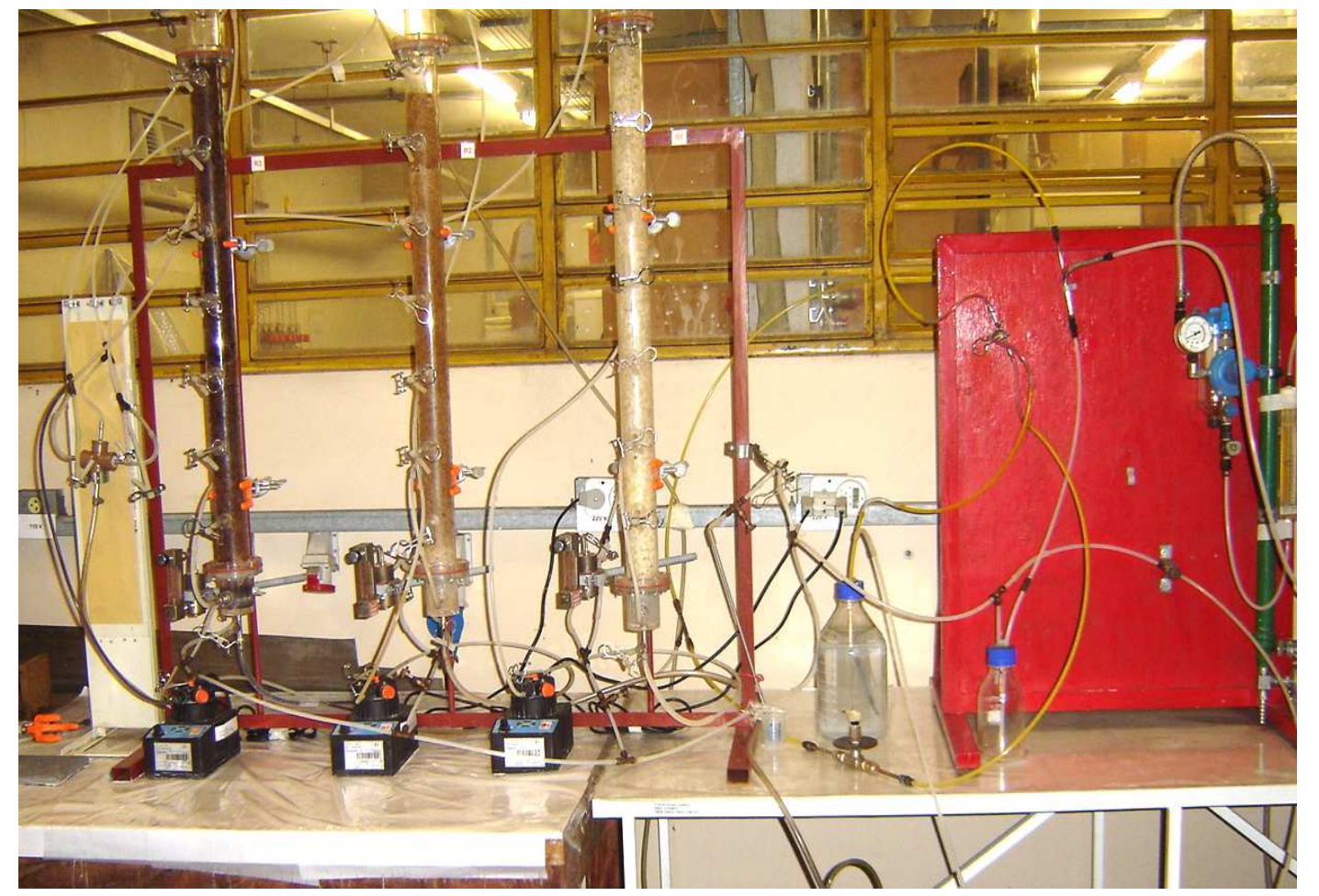

Figura 4.6: Visão geral do sistema de biofiltração (vista frontal) 
As condições de operação do sistema estão apresentadas na Tabela 4.4.

Tabela 4.4 - Condições de operação do sistema

\begin{tabular}{|c|c|c|c|}
\hline Parâmetro & Bagaço de cana & Fibra de coco & $\begin{array}{l}\text { Espuma de } \\
\text { poliuretano }\end{array}$ \\
\hline Vazão $\left(m^{3} \cdot h^{-1}\right)$ & 0,13 & 0,13 & 0,13 \\
\hline $\begin{array}{c}\text { Tempo de Residência do } \\
\text { Leito Vazio (s) }\end{array}$ & 49 & 49 & 49 \\
\hline $\begin{array}{l}\text { Taxa de carregamento } \\
\text { superficial }\left(m^{3} \cdot m^{-2} \cdot h^{-1}\right)\end{array}$ & 61 & 61 & 61 \\
\hline $\begin{array}{l}\text { Taxa de carregamento } \\
\text { volumétrico }\left(\mathrm{h}^{-1}\right)\end{array}$ & 73 & 74 & 74 \\
\hline $\begin{array}{c}\text { Vazão de } \\
\text { diluição/aeração }\left(\mathrm{m}^{3} \cdot \mathrm{h}^{-1}\right)\end{array}$ & 0,45 & 0,45 & 0,45 \\
\hline $\begin{array}{l}\text { Velocidade Superficial } \\
\left(\mathrm{cm} \cdot \mathrm{s}^{-1}\right)\end{array}$ & 1,70 & 1,70 & 1,70 \\
\hline
\end{tabular}

\subsection{ADIÇÃO DE NUTRIENTES}

A adição de nutrientes aos biofiltros foi realizada diariamente, utilizando-se aproximadamente $50 \mathrm{~mL}$ de solução nutriente preparada com os sais específicos, com exceção do $\mathrm{Na}_{2} \mathrm{~S}_{2} \mathrm{O}_{3}$, conforme descrito na Tabela 3.1 do item 4.1. Caso o pH do sistema estivesse fora da faixa considerada ideal (entre 6 e 8), também foi acrescentado 50 g.L.-1 de bicarbonato de sódio $\left(\mathrm{NaHCO}_{3}\right)$, para elevar a alcalinidade dos biofiltros e ajustar os valores de $\mathrm{pH}$. 


\subsection{POROSIDADE DO LEITO}

A porosidade dos materiais suporte foi calculada pesando-se a massa seca e a massa úmida dos materiais suporte para determinar volume de água no leito. Com esses valores e adotando-se a massa específica da água a $25^{\circ} \mathrm{C}$ como sendo 0,997 g.cm (Fox e McDonald, 1998) e com o auxílio da Equação 4.1, obteve-se o volume de água presente no leito de espuma de poliuretano, bagaço de cana e fibra de coco, o que é equivalente ao volume de vazios:

$\rho=\frac{\left(m_{t}-m_{e}\right)}{V}$

Em que:

p é a massa específica da água a $25^{\circ}\left(\mathrm{g} \cdot \mathrm{cm}^{-3}\right)$;

m† é a massa do total do leito (suporte+água, g);

me é a massa do suporte seco ( $g$ );

V é o volume de água no leito $\left(\mathrm{cm}^{3}\right)$.

Depois de calculado o volume de água nos leitos (equivalente ao volume de vazios), calculou-se então o volume do leito. Utilizando-se a Equação 4.2, obteve-se a porosidade dos materiais:

$$
\varepsilon=\frac{V_{v}}{V_{t}}
$$


Em que:

$\varepsilon$ é a porosidade;

Vvé o volume de vazios $\left(\mathrm{cm}^{3}\right)$;

$V_{\dagger}$ é o volume total do leito $\left(\mathrm{cm}^{3}\right)$.

\subsection{ENSAIOS FLUIDODINÂMICOS}

\subsubsection{Equação utilizada}

A equação de Darcy (4.3) é a mais tradicionalmente utilizada para se prever a queda de pressão em função da vazão aplicada em leito fixo com enchimento, por isto foi escolhida para os cálculos. Matematicamente, tem-se:

$$
\frac{\Delta P}{L}=\frac{\mu}{k} . v
$$

Em que:

$\Delta P$ é a queda de pressão (dyn. $\mathrm{cm}^{-2}$ );

L é o comprimento do leito (cm);

$\mu$ é a viscosidade do fluido $\left(\mathrm{g} \cdot \mathrm{cm}^{-1} \cdot \mathrm{s}^{-1}\right)$;

K é a permeabilidade do leito poroso $\left(\mathrm{cm}^{-2}\right)$;

vé a Velocidade superficial $\left(\mathrm{cm} \cdot \mathrm{s}^{-1}\right)$. 


\subsubsection{Obtenção experimental dos dados / fluidodinâmica.}

Os ensaios de fluidodinâmica foram realizados, sob condições abióticas, nos biofiltros preenchidos com s materiais suporte - espuma de poliuretano, bagaço de cana e fibra de coco - secos. As colunas preenchidas foram conectadas ao sistema e a perda de carga foi determinada por manômetro inclinado com água na coluna, ligado à saída própria para essa finalidade.

As tomadas de pressão foram instaladas na base e no topo dos biofiltros para permitir que altura efetiva do leito pudesse ser utilizada como altura das tomadas de pressão. Para cada repetição, as massas empacotadas foram as mesmas da utilizadas no experimento no intuito de permitir que a densidade global do leito fosse mantida.

As colunas foram submetidas então a corrente de ar oriunda de um compressor e previamente reguladas por válvulas de pressão. A vazão do gás foi aferida por um manômetro em " $U$ " acoplado a uma placa de orifício devidamente calibrada por bolhômetro.

As medidas de perda de carga foram obtidas variando-se a vazão de ar na entrada da coluna e avaliando o efeito dessa mudança no manômetro acoplado ao reator, verificando-se assim a sua perda de carga em "cm de coluna de água".

Cabe ressaltar que este método foi adaptado daquele descrito por RAMIREZ-LOPEZ et al., (2003), MORGAN-SAGASTUME e NOYOLA (2006) e MA, ZHAO e YANG (2006).

De posse dos dados de perda de carga e velocidade superficial, foi feita a regressão linear das curvas obtidas e com esse resultado aplicado na equação de Darcy (4.3), obteve-se a permeabilidade do leito. 


\subsection{MÉTODOS ANALÍTICOS UTILIZADOS}

\subsubsection{Determinação de Sulfeto}

A análise de sulfeto baseou-se no método do azul de metileno (APHA, 1999), com alterações para coleta do sulfeto em fase gasosa, que consiste no borbulhamento do gás um frasco contendo certo volume de solução de $\mathrm{NaOH}$. O princípio do método é a reação do sulfeto de hidrogênio com oxalato de N-dimetil-p-fenilenodiamina para formar azul de metileno. A intensidade da cor azul é proporcional a concentração de sulfeto.

Para a determinação da concentração de sulfeto, converteu-se, em um primeiro momento, a equação encontrada no espectrofotômetro ( $\left.m g \cdot \mathrm{L}^{-1}\right)$ para a concentração real da amostra (mg. $\left.L^{-1}\right)$, conforme pode ser verificado na Equação 4.4:

$$
C(m g / L)=\frac{C_{E} \cdot D \cdot V_{(L)}}{Q_{(L / h)} \cdot t_{(h)}}
$$

Em que:

$\mathrm{C}_{E}$ é a Concentração lida no espectrofotômetro $\left(\mathrm{mg} \cdot \mathrm{L}^{-1}\right)$;

D é o Fator de diluição da amostra;

VL é o Volume da amostra (L);

Q é a Vazão da corrente gasosa (L.h-1);

té o Tempo de coleta da amostra (h).

Finalmente, a concentração obtida na Equação 4.4 foi inserida na Equação 4.5, para se determinar a concentração de $\mathrm{H}_{2} \mathrm{~S}$ em partes por milhão (ppm): 


$$
C_{H_{2} S}(p p m)=C\left(m g \cdot m^{-3}\right) \cdot \frac{24,44}{m o l_{H_{S} S}}
$$

Em que:

C (mg.m-3) é Concentração calculada na Equação 4.4. C (mg.L-1);

24,44 é o Volume molar corrigido para $1 \mathrm{~atm}$ e $25^{\circ} \mathrm{C}\left(\mathrm{L} . \mathrm{mol}^{-1}\right)$.

Maiores detalhes sobre este método podem ser encontrados em Rodrigues (2002), Maia (2003) e Rocha (2007).

\subsubsection{Determinação do $\mathrm{pH}$}

Durante a operação do biofiltro foram realizadas medidas diárias do $\mathrm{pH}$ do percolado, coletado antes da alimentação do sistema. Para a determinação do pH, foi utilizado o método potenciométrico.

\subsection{ENSAIO DE ADSORÇÃO}

A fim de avaliar a quantidade de $\mathrm{H}_{2} \mathrm{~S}$ adsorvida nos meios suportes orgânicos e na espuma de poliuretano, a quantidade de contaminante adsorvido nos materiais foi determinada pela plotagem de curvas de ruptura para várias concentrações de entrada.

Barona et al. (2005) estudou uma faixa de concentração entre 40 a 330 ppm, por considerá-la a mais comumente produzida nas estações de tratamento de efluentes. Ainda de acordo com os autores, a água afeta a adsorção de certos compostos orgânicos pelo decrescimento de sua retenção de um grau maior para compostos aromáticos e alifáticos para um grau menor para compostos polares. Portanto, a fim de evitar esta interferência, 
tanto o fluxo de gás afluente aos reatores como os materiais suporte foram previamente secos.

Tomando como base os dados de adsorção de Moe e Irvine (2000b) e Rocha (2007), realizou-se a primeira coleta das concentrações de entrada e saída com 15 minutos de operação do ensaio de adsorção, sendo o restante das análises de concentrações do $\mathrm{H}_{2} \mathrm{~S}$ realizadas na entrada $\mathrm{C}_{0}\left(\mathrm{H}_{2} \mathrm{~S}\right)$ e na saída $\mathrm{C}_{s}\left(\mathrm{H}_{2} \mathrm{~S}\right)$ da coluna conforme os intervalos apresentados na Tabela 4.5.

Tabela 4.5 - Freqüência de análises dos ensaios de adsorção

\begin{tabular}{cc}
\hline \multicolumn{2}{c}{ Tempos } \\
\hline $\mathrm{C}_{0}\left(\mathrm{H}_{2} \mathrm{~S}\right)$ & 15 minutos, $1,2,4,6,8,12,16,20$ horas \\
$\mathrm{C}_{s}\left(\mathrm{H}_{2} \mathrm{~S}\right)$ & 15 minutos, $1,2,4,6,8,12,16,20$ horas \\
\hline
\end{tabular}

Os testes de adsorção foram realizados, sob condições abióticas, empacotando-se uma coluna seca contendo a mesma massa de meio suporte $(37,1 \mathrm{~g} ; 72,6 \mathrm{~g}$ e 108,1g para os biofiltros preenchidos com espuma de poliuretano, bagaço de cana e fibra de coco, respectivamente) utilizada na operação do biofiltro, para que a quantidade de sulfeto adsorvida pudesse ser subtraída da concentração tratada biologicamente. Foi realizado paralelamente, o ajuste da concentração do $\mathrm{H}_{2} \mathrm{~S}$ e da vazão do sistema.

Com o intuito de se minimizar perturbações e variações bruscas nas concentrações de entrada da coluna de adsorção, devido ao intervalo de tempo que a coluna ficaria sem alimentação durante a amostragem, preferiu-se aumentar os intervalos de amostragem das concentrações de entrada.

\subsection{MICROSCOPIA ÓPTICA E ELETRÔNICA DE VARREDURA}

\section{- Microscopia óptica}

A fim de se verificar a existências das morfologias típicas presentes no processo de oxidação de sulfetos, foram coletadas amostras do lodo utilizado como inóculo após a fase 
de adaptação e do percolado, e observadas ao microscópio óptico. O acompanhamento das morfologias foi realizado por exame microscópico de contraste de fase e fluorescência utilizando microscópio Leica DMLB, com sistema de captura de imagem Optronics e software Image Pro-Plus. A observação das morfologias foi realizada no Laboratório de Processos Biológicos do Departamento de Hidráulica e Saneamento da USP - São Carlos.

\section{- Microscopia Eletrônica de Varredura}

Ao término da operação dos biofiltros, foi realizada a visualização das morfologias presentes nos biofiltros por meio da análise de Microscopia Eletrônica de Varredura, em microscópio de propriedade do Instituto de Física da USP - São Carlos.

O preparo das amostras para a microscopia eletrônica de varredura (MEV) foi realizado de acordo com Araújo (1995), cujo procedimento está descrito a seguir.

O processo de fixação foi feito com a inserção dos meios suportes numa solução de glutaraldeido (2,5\% em tampão de fosfato) por $12 \mathrm{~h} \mathrm{a} 4{ }^{\circ} \mathrm{C}$. Esta etapa teve por objetivo fixar a morfologia da amostra.

Decorridas $12 \mathrm{~h}$ os materiais suportes passaram por um processo de lavagem com uma solução tampão de fosfato 0,1 M com pH 7,3 durante 10 min, em seguida os meios suporte passaram por um processo de secagem. Realizando-se uma seqüência de lavagens com soluções de etanol, cada uma de 10 minutos: 50\%, 70\%, 80\%, 90\%, 95\% e 100\%, sendo que na solução de 100\% foram efetuadas 3 lavagens de 10 minutos cada.

Após a secagem com o etanol foi utilizado HMDS (hexametildesilasani), efetuando-se 2 lavagens de 30 s cada, para o processo final de secagem.

Os materiais suportes foram, então, fixados no suporte para microscopia eletrônica com esmalte base e então submetida ao banho de ouro. 


\subsection{CAPACIDADE DE ELIMINAÇÃO, TAXA DE CARREGAMENTO E EFICIÊNCIA DE REMOÇÃO}

A capacidade de eliminação fornece uma medida da habilidade do biofiltro em remover poluentes. Desta definição, parece evidente que se a eficiência de remoção desejada é próxima a 100\%, a capacidade de eliminação também se torna máxima (CONVERTI et al., 2001). Este parâmetro é calculado em função das concentrações de entrada e saída, conforme está apresentado na Equação 4.6.

$C e=\frac{Q\left(C_{0}-C_{s}\right)}{V_{f}}$

Em que:

CE é a capacidade de eliminação $\left(\mathrm{g} \cdot \mathrm{m}^{-3} \cdot \mathrm{h}^{-1}\right)$;

Qé a vazão volumétrica $\left(m^{3} \cdot h^{-1}\right)$;

Co é a concentração de entrada do gás $\left(\mathrm{g} \cdot \mathrm{m}^{-3}\right)$;

$\mathrm{C}_{s}$ é a concentração de saída do gás $\left(\mathrm{g} \cdot \mathrm{m}^{-3}\right)$;

$V_{f}$ é o volume total do leito filtrante $\left(\mathrm{m}^{3}\right)$.

A taxa de carregamento mássico está descrita na Equação 4.7.

$T C M=\frac{Q \cdot C_{0}}{V_{f}}$

Em que:

TCM é a Taxa de carregamento mássico $\left(\mathrm{g} \cdot \mathrm{h}^{-1} \cdot \mathrm{m}^{-3}\right)$;

Q é a vazão volumétrica $\left(m^{3} \cdot h^{-1}\right)$;

Co é a concentração de entrada do gás $\left(\mathrm{g} \cdot \mathrm{m}^{-3}\right)$;

$V_{f}$ é o volume total do leito filtrante $\left(\mathrm{m}^{3}\right)$. 
A eficiência de remoção foi calculada a partir das médias dos pontos coletados na entrada e na saída dos biofiltros, de acordo com a Equação 4.8.

$$
E R=\frac{\left(C_{0}-C_{s}\right)}{C_{s}} .100
$$

Em que:

ER é a eficiência de remoção (\%);

Co é a concentração de entrada do gás $\left(\mathrm{g} \cdot \mathrm{m}^{-3}\right)$;

$\mathrm{C}_{\mathrm{s}}$ é a concentração de saída do gás $\left(\mathrm{g} \cdot \mathrm{m}^{-3}\right)$.

\subsection{DESCRIÇÃO MATEMÁTICA DO PROCESSO}

\subsubsection{Modelo Utilizado}

Foi utilizado o modelo proposto, cuja solução é analítica, por Ottengraf e Van de Oever (1983), previamente descrito no item 3.4.4.

Oyarzún et al. (2003) afirmaram que o ponto-chave deste modelo é a hipótese para a microcinética do substrato utilizado pela população microbiana. Estas dependem da concentração de $\mathrm{H}_{2} \mathrm{~S}$ na camada líquida que reveste as células imobilizadas no meio suporte. Foi considerada, para efeito de modelagem, a cinética de ordem zero, no caso de limitação pela difusão, prevista no modelo de Ottengraf e Van de Oever (1983), logo, a expressão utilizada foi: 


$$
\frac{C s}{C_{0}}=\left[1-\frac{h}{v_{a}} \sqrt{\frac{K_{0} D_{e f f} a_{s}}{2 m C_{0} \delta}}\right]^{2}
$$

Em que:

Cs é a concentração de saída do gás $\left(\mathrm{g} \cdot \mathrm{m}^{-3}\right)$;

Co é a concentração de entrada do gás $\left(\mathrm{g} \cdot \mathrm{m}^{-3}\right)$;

h é a altura do biofiltro (m);

$v_{a}$ é a velocidade superficial $(\mathrm{m} / \mathrm{s})$

Ko é a constante de reação de ordem zero $\left(\mathrm{g} \cdot \mathrm{m}^{-3} \cdot \mathrm{s}^{-1}\right)$;

m é o coeficiente de distribuição (partição gás-líquido), conforme ditado pela lei de Henry;

$a_{s}$ é a área específica $\left(m^{2} \cdot m^{-3}\right)$;

Deff é o coeficiente de difusividade efetiva $\left(m^{2} \cdot s^{-1}\right)$;

$\delta$ é a espessura do biofilme (m).

O parâmetro $K_{f}$ foi estimado a partir da utilização da ferramenta Solver do Software Microsoft Excel, representa todos os parâmetros descritos a seguir:

$$
k_{f}=\sqrt{\frac{K_{0} D_{e f f} a_{s}}{2 m C_{0} \delta}}
$$

De acordo com Yang e Allen (1994) e Oyarzún et al (2003), $K_{f}$ é um coeficiente de reação de ordem fracionária que, sob condições de estado estacionário, é constante. Então, das Equações 4.11 e 4.12, tem-se:

$$
\frac{C_{s}}{C_{0}}=\left(1-k_{f} t\right)^{2}
$$

ou

$$
1-\sqrt{\frac{C_{s}}{C_{0}}}=k_{f} t
$$


Em que:

Cs é a concentração de saída do gás ( $\left.g \cdot \mathrm{m}^{-3}\right)$;

Co é a concentração de entrada do gás $g \cdot \mathrm{m}^{-3}$ );

$k_{f}$ é o coeficiente de ordem fracionária $\left(\mathrm{g} \cdot \mathrm{m}^{-3} \cdot \mathrm{s}^{-1}\right)$;

$\dagger=$ tempo (s).

Essa simples abordagem pode ser utilizada para prever desempenho geral e também no projeto de biofiltros. Dessa forma, os resultados obtidos para os três sistemas estudados, estão descritos nos itens que se seguem.

\section{- Estimativa da espessura do biofilme $(\delta)$}

Sabe-se que a capacidade de eliminação do biofiltro, com o aumento da velocidade superficial tende a não ser constante, pois decresce para um valor crítico abaixo da concentração do gás. Este fenômeno é explicado por Ottengraf e Van de Oever (1983) como sendo a limitação da difusão no biofilme. Com base nisso, pode-se obter a concentração crítica do gás para as respectivas capacidades de eliminação críticas. Essas capacidades de eliminação críticas $\left(k^{*}\right)$ no ensaio de variação do TRLV são ocasionadas por concentrações de $\mathrm{H}_{2} \mathrm{~S}$ críticas para os biofiltros preenchidos com a espuma de poliuretano, o bagaço de cana e a fibra de coco, respectivamente. De posse dos valores dessas capacidades de eliminação críticas $\left(k^{*}\right)$, é possivel calcular o valor de $k$, que representa a velocidade de reação por unidade de volume do biofilme.

Com relação aos outros parâmetros, foi necessário lançar de mão da obtenção de dados obtidos na literatura, como por exemplo, o coeficiente de distribuição $(m)$ para o $\mathrm{H}_{2} \mathrm{~S}$ que, de acordo com El-Hawagi (1997), equivale a 0,368; o coeficiente de difusividade efetiva do $\mathrm{H}_{2} \mathrm{~S}$ para o biofilme que é de $1.10^{-10} \mathrm{~m}^{2} . \mathrm{s}^{-1}$, de acordo com Farooq e Viswanathan (1999). 
Após isso, e utilizando a Equação 4.13, determinou-se o valor da espessura do biofilme.

$$
\delta=\sqrt{\frac{2 D_{e f f} C_{g}}{k_{0} m}}
$$

Em que:

$\delta$ é a espessura total do biofilme $(m)$;

Deff é o coeficiente de difusividade efetiva $\left(\mathrm{m}^{2} \cdot \mathrm{s}^{-1}\right)$;

$\mathrm{C}_{g}$ é a concentração da fase gasosa a uma altura h da coluna (g.m $\left.\mathrm{m}^{-3}\right)$;

ko é a constante cinética de ordem zero $\left(\mathrm{g} \cdot \mathrm{m}^{-3} \cdot \mathrm{s}^{-1}\right)$;

m é o coeficiente de distribuição (partição gás-líquido), conforme ditado pela lei de Henry;

\subsubsection{Obtenção experimental dos dados / modelo matemático}

Os ensaios de variação do tempo de retenção do gás nos biofiltros, necessários para a modelagem do sistema, foram realizados após o término da operação dos mesmos, logo após $0100^{\circ}$ dia de operação. Procedeu-se a diminuição do tempo de retenção do gás, que se deu pelo aumento da vazão afluente aos biofiltros. Como resultado disso, o tempo de retenção que estava em torno de 52 segundos, foi reduzido primeiramente para 26 segundos e, finalmente, para 17 segundos. 


\section{RESULTADOS E DISCUSSÃO}

\subsection{ENSAIOS HIDRODINÂMICOS}

\subsubsection{Porosidade}

De acordo com Cohen (2001) a porosidade do material suporte é importante fator na adsorção dos microrganismos. O material suporte que possui interiormente grande quantidade de espaços vazios permite que os microrganismos ataquem em melhores condições, enquanto a vazão de ar ao redor desses materiais suportes pode ser introduzida a maiores velocidades. De acordo com Leson e Winer, 2001, a máxima acumulação da biomassa ocorre quando o tamanho dos poros é de uma a cinco vezes o tamanho da bactéria.

Desse modo, considerando que as densidades da espuma de poliuretano, do bagaço de cana e da fibra de coco como sendo de 0,023 (Maia, 2003; Rocha, 2007); 0,045 e 0,067 (Ramírez-Lópes et al. 2003), respectivamente. Também considerando que a massa específica da água a $25^{\circ} \mathrm{C}$ como sendo $0,997 \mathrm{~g} \cdot \mathrm{cm}^{-3}$ (Fox e Macdonald, 1998), calculou-se a porosidade dos leitos.

Nas Tabelas 5.1 e 5.2 estão dispostos os resultados dos ensaios realizados para determinação da porosidade dos materiais suporte espuma de poliuretano, bagaço de cana e fibra de coco e de seus respectivos leitos a partir das Equações 4.1 e 4.2. 
Tabela 5.1 - Porosidade dos materiais suporte

\begin{tabular}{|c|c|c|c|}
\hline & $\begin{array}{l}\text { Espuma de } \\
\text { Poliuretano } \\
\end{array}$ & $\begin{array}{c}\text { Bagaço de } \\
\text { Cana }\end{array}$ & Fibra de Coco \\
\hline $\begin{array}{c}\text { Massa específica da água a } \\
25^{\circ} \mathrm{C}(\mathrm{g} . \mathrm{cm})\end{array}$ & 0,997 & 0,997 & 0,997 \\
\hline $\begin{array}{l}\text { Massa total de material } \\
\text { suporte úmido }(\mathrm{g})\end{array}$ & 1620,02 & 1211,20 & 1602,22 \\
\hline $\begin{array}{l}\text { Massa total de meio suporte } \\
\qquad \operatorname{seco}(\mathrm{g})\end{array}$ & 37,10 & 72,59 & 108,08 \\
\hline Volume de vazios $(\mathrm{cm})$ & 1587,68 & 1142,04 & 1498,64 \\
\hline $\begin{array}{l}\text { Volume total do leito/total } \\
\qquad\left(\mathrm{cm}^{3}\right)\end{array}$ & 1867,63 & 1783,02 & 1783,02 \\
\hline $\begin{array}{l}\text { Densidade do material } \\
\qquad\left(\mathrm{g}^{\mathrm{cm}} \mathrm{cm}^{-3}\right)\end{array}$ & 0,023 & 0,045 & 0,067 \\
\hline Porosidade (Material) & 0,85 & 0,64 & 0,84 \\
\hline
\end{tabular}

Tabela 5.2 - Porosidade dos leitos em função dos procedimentos experimentais

\begin{tabular}{cccc}
\hline & $\begin{array}{c}\text { Espuma de } \\
\text { Poliuretano }\end{array}$ & Bagaço de Cana & Fibra de Coco \\
\hline $\begin{array}{c}\text { Massa total de meio suporte } \\
\text { seco }(\mathrm{g})\end{array}$ & 37,10 & 72,59 & 108,08 \\
Volume de vazios (cm) & 578,57 & 374,43 & 490,03 \\
Volume total do leito (cm3) & 1867,63 & 1783,02 & 1783,02 \\
& 0,019 & 0,040 & 0,060 \\
Densidade do leito (g.cm-3) & 0,31 & 0,21 & 0,27 \\
\hline
\end{tabular}

Maia (2003), que também utilizou espuma de poliuretano em seu sistema, obteve valores de porosidade de 0,61. A porosidade de 0,85 obtida neste trabalho é igual ao valor encontrado por Moe e Irvine (2002) e muito próximo do obtido por Rocha (2007), que 
verificou em seus ensaios valor igual a 0,85.

O valor de porosidade para o bagaço de cana determinado nesta pesquisa foi de 0,64, o que está muito próximo daquele verificado por Soares (2006), que encontrou valor de porosidade de 0,62 para este material.

Com relação aos valores de porosidade da fibra de coco, não foram encontrados na literatura trabalhos que tenham disponibilizado tais resultados.

\subsubsection{Perda de carga}

Pela sua importância como um dos fatores limitantes do processo, a perda de carga foi verificada nos leitos de espuma de poliuretano, fibra de coco e bagaço de cana, a partir dos ensaios hidrodinâmicos realizados. Portanto, calculou-se através da equação de Darcy a permeabilidade do leito nos materiais secos, por meio da regressão linear dos dados obtidos. Para os cálculos, considerou-se a viscosidade do ar a $20^{\circ} \mathrm{C}$, equivalente a $1,81.10^{-5}$ N.s.m² (FOX e MACDONALD, 1998).

Sabe-se que a perda de carga no leito do biofiltro é função, principalmente, da qualidade e quantidade do material suporte e da velocidade superficial do gás de alimentação (RAMÍREZ-LÓPEZ et al., 2003), que neste estudo foi de, aproximadamente, 1,7 $\mathrm{cm} / \mathrm{s}$.

Assim, nas Figuras 5.1, 5.2 e 5.3 estão dispostos os gráficos com os valores de perda de carga $(\Delta P / L)$, obtidos nos ensaios hidrodinâmicos, bem como a média dos mesmos, para os materiais suporte secos utilizados neste trabalho, como função da velocidade superficial de ar (v). 


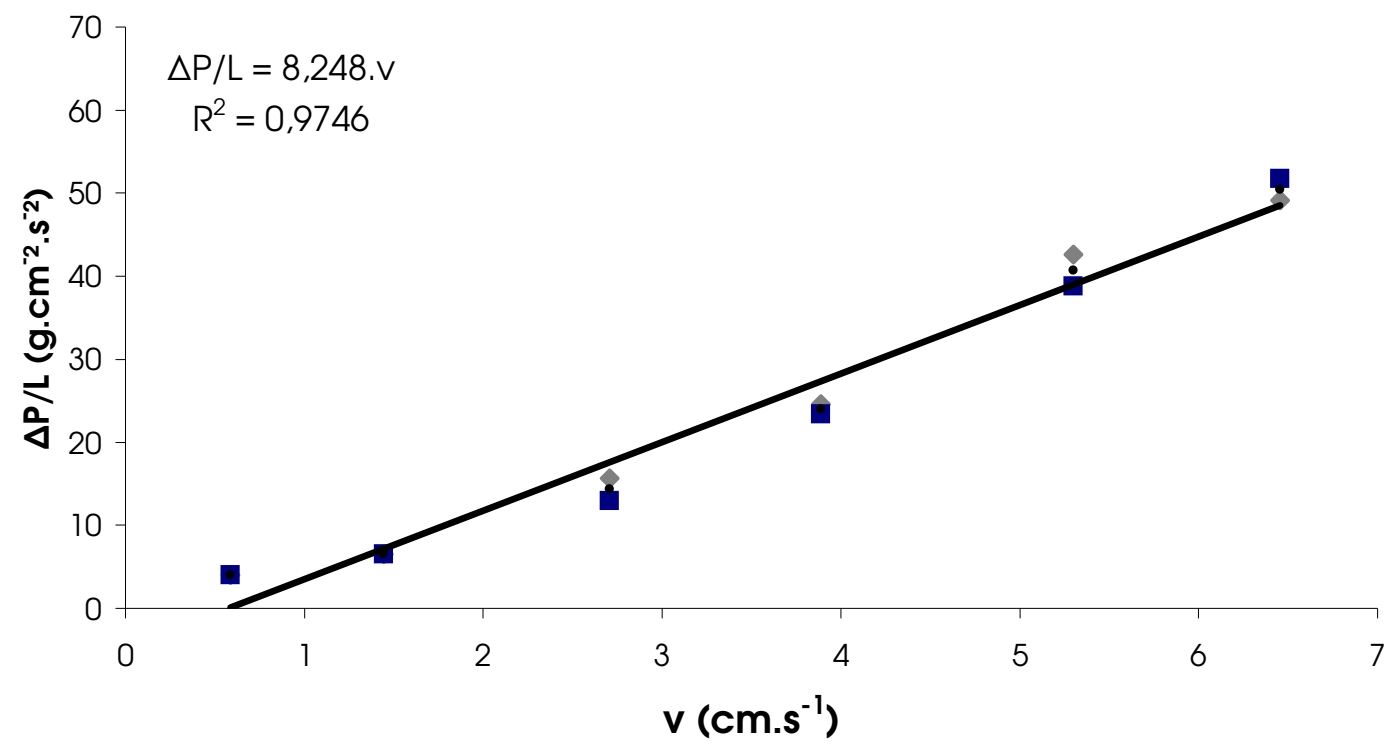

- Medida 1 - Medida 2 - Média

Figura 5.1: Perda de carga da espuma de poliuretano seca em função da velocidade superficial do ar

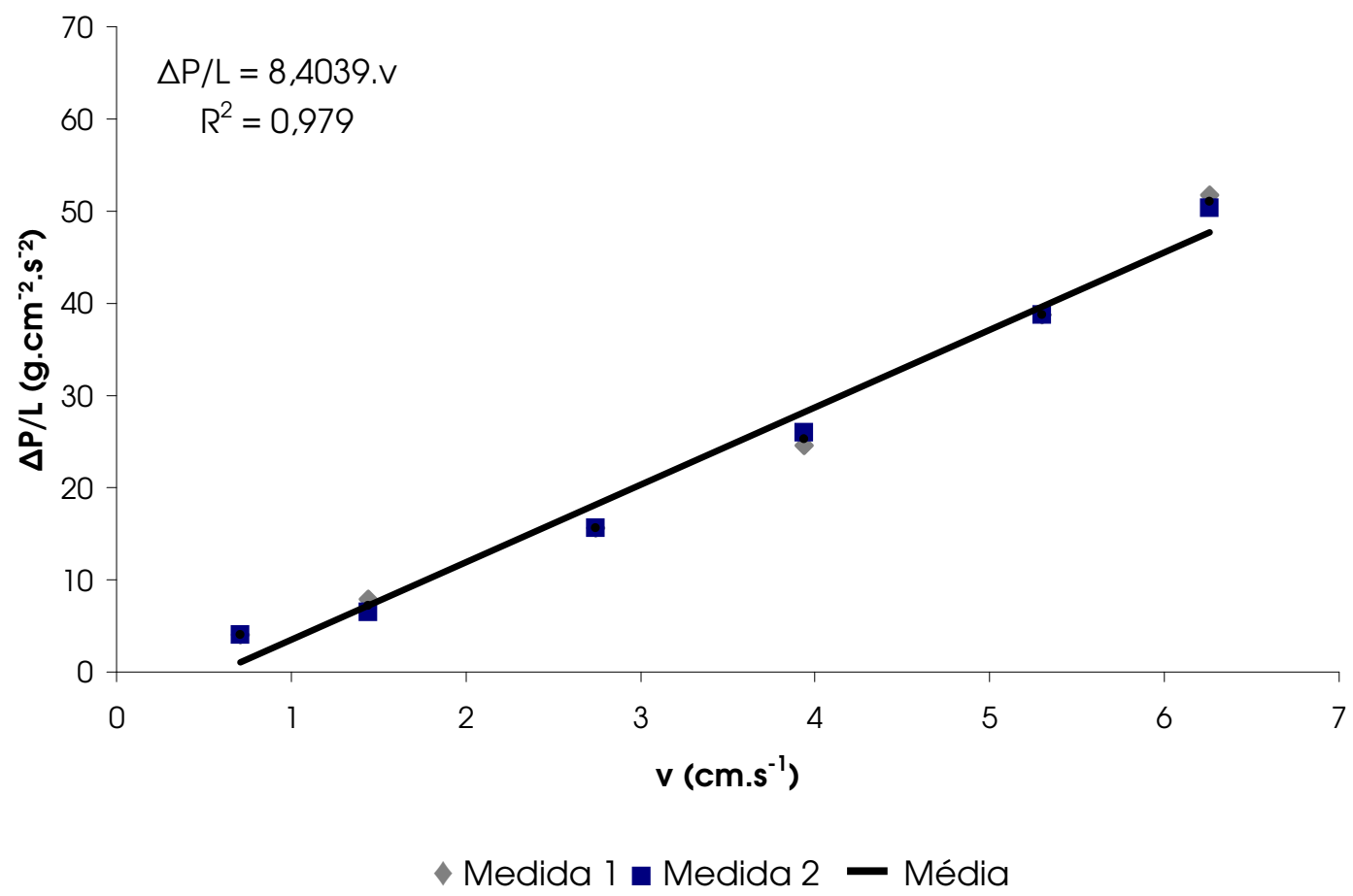

Figura 5.2: Perda de carga do bagaço de cana seco em função da velocidade superficial do ar 


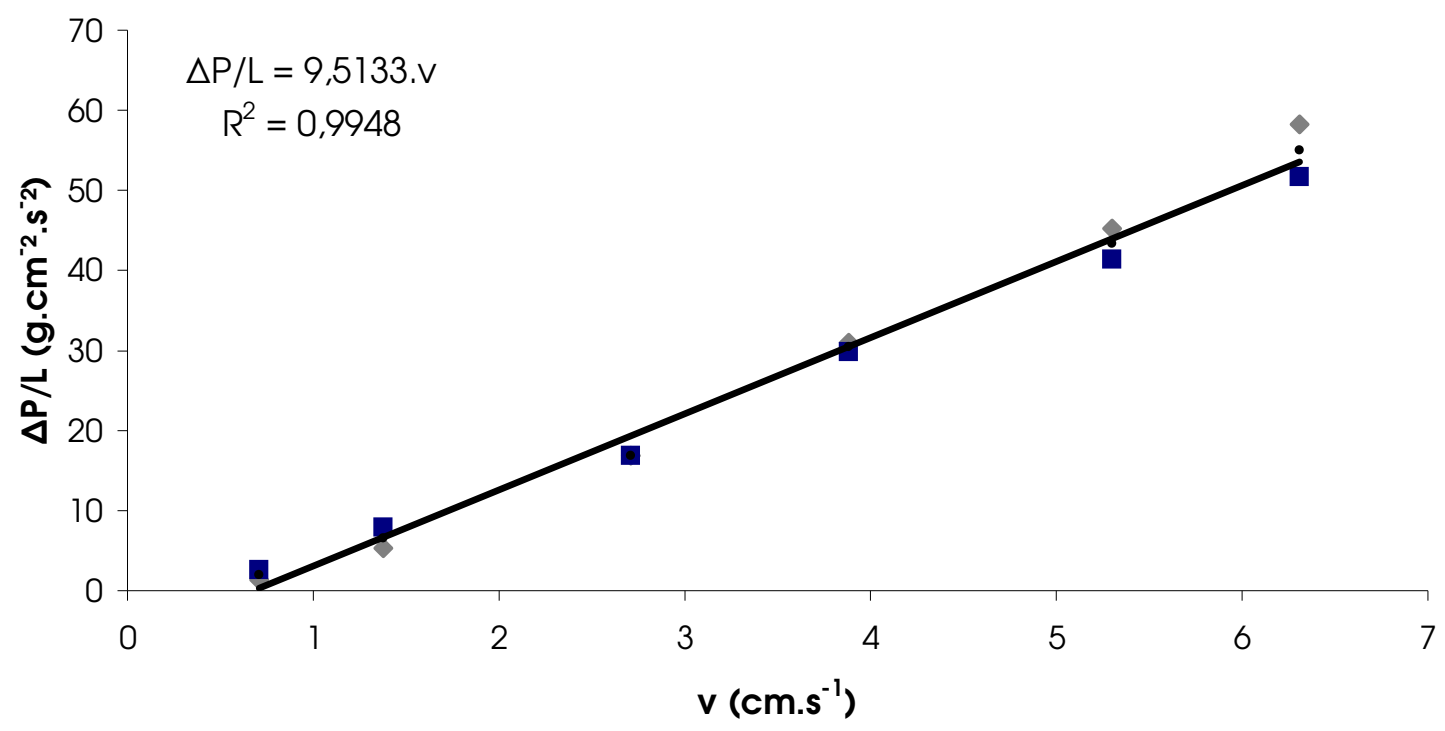

- Medida 1 a Medida 2 - Média

Figura 5.3: Perda de carga da fibra de coco seca em função da velocidade superficial do ar

Conforme pode ser observado nas Figuras 5.1, 5.2 e 5.3, os valores da relação $\Delta P / L$ como função de $\vee$ apresentaram comportamento linear, o que está de acordo com o previsto pela Equação de Darcy. A fim de proporcionar melhor comparação entre os três materiais suportes estudados, na Figura 5.4 foram plotados os valores médios de perda de carga da espuma de poliuretano, bagaço de cana e fibra de coco.

Assim como observado por PÁCA e KOUTSKÝ (2000), pode ser verificado nas Figuras 5.1, 5.2 e 5.3 que o aumento da vazão e, conseqüentemente, da velocidade superficial do ar (de 0,6 para $6,5 \mathrm{~cm}^{-1}$ ), ocasionou maior perda de carga dos leitos. A perda de carga ocasionada pelo sistema foi diretamente proporcional ao aumento da velocidade superficial do gás, segundo uma correlação linear de 0,9746, 0,979 e 0,9948 para os biofiltros preenchidos com espuma de poliuretano, bagaço de cana e fibra de coco, respectivamente. 


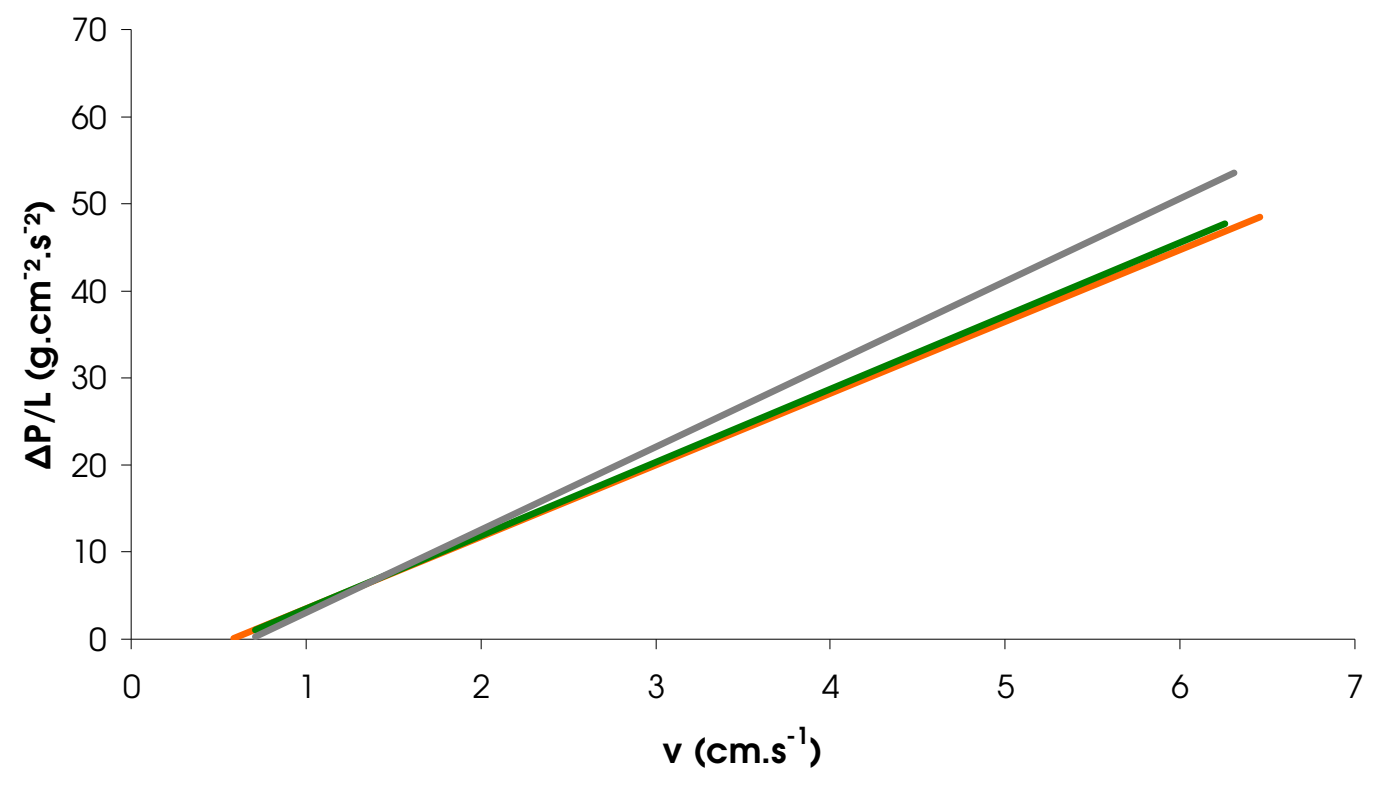

- Espuma de poliuretano - Bagaço de cana - Fibra de coco

Figura 5.4: Comparativo entre os valores médios de perda de carga dos leitos preenchidos com espuma de poliuretano, bagaço de cana e fibra de coco.

De acordo com o gráfico da Figura 5.4, pode ser verificado que a fibra de coco foi o material que proporcionou a maior perda de carga, com média de $\Delta \mathrm{P} / \mathrm{L}$ alcançando 55 g.cm-2.s-2 $\left(4.10^{-2} \mathrm{mca}\right)$ para velocidade em torno de $6 \mathrm{~cm} \cdot \mathrm{s}^{-1}$. Para este mesmo valor de velocidade, a média de $\Delta \mathrm{P} / \mathrm{L}$ para os biofiltros preenchidos com espuma de poliuretano $e$ bagaço de cana alcançaram cerca de $51 \mathrm{~g} \cdot \mathrm{cm}^{-2} \cdot \mathrm{s}^{-2}$.

Segundo Yang e Allen (1994), a perda de carga depende da maneira como o biofiltro foi empacotado. Quanto maior a densidade do empacotamento, maior será a perda de carga para uma mesma velocidade do gás. Como a densidade de empacotamento da fibra de coco $\left(0,060 \mathrm{~g} \mathrm{~cm}^{-3}\right)$ é a maior entre os três materiais testados, isto pode explicar os maiores valores de perda de carga proporcionados por este material.

Em trabalho realizado por Ramírez-Lópes et al. (2003), no qual foram caracterizados 5 materiais suporte de origem agrícola, foi realizado o estudo hidrodinâmico da fibra de coco e do bagaço de cana. No trabalho dos autores, para todas as velocidades testadas, o bagaço de cana proporcionou perda de carga maior que a fibra de coco. Sendo que para 
velocidade superficial de $150 \mathrm{~m}^{\mathrm{h}} \mathrm{h}^{-1}$, a relação $\Delta \mathrm{P} / \mathrm{L}$ para o bagaço alcançou 15 Pa.h.m-2, enquanto que para a mesma velocidade a fibra proporcionou perda de cerca de 50 Pa.h.m-2. Logo, os resultados do ensaio hidrodinâmico apresentados na Figura 5.4 não foram coerentes com aqueles apresentados por Ramires-Lópes et al. (2003), pois a fibra de coco proporcionou perda de carga maior que o bagaço. Isto pode ser explicado pelo fato de que, associadas à fibra e a despeito do peneiramento promovido, podiam ser observadas partículas dos mais diversos tamanhos. Essas partículas, por sua vez, tendiam a preencher os vazios entre as fibras, o que teria proporcionado esse aumento de perda de carga da fibra de coco.

Para as velocidades superficiais utilizada no decorrer da operação dos biofiltros $(1,7$ $\mathrm{cm}^{-1}{ }^{-1}$ ), os valores de perda de carga foram baixos, com $\Delta P / L$ aproximado de $7,7,8,9$ e 8,2 g. $\mathrm{cm}^{-2} . \mathrm{s}^{-2}$, o que corresponde a 0,59.10-2, $0,6210^{-2}$ e $0,6810^{-2} \mathrm{mca}$, para os biofiltros preenchidos com a espuma de poliuretano, o bagaço de cana e a fibra de coco.

Com relação à espuma de poliuretano, de acordo com Moe e Irvine (2000a), Rodrigues (2002) e Maia (2003), os valores de perda de carga podem oscilar de 0,14.10-2 mca a 1,53.10-2 mca. Rocha (2007) observou valores de perda de carga que variaram entre 0,18.10-2 mca, com velocidade superficial de ar de $0,40 \mathrm{~cm} \cdot \mathrm{s}^{-1}$, até $1,21.10^{-2} \mathrm{mca}$, com velocidade superficial de $1,96 \mathrm{~cm} \cdot \mathrm{s}^{-1}$, para colunas secas e úmidas, respectivamente.

A Tabela 5.3 mostra os resultados obtidos por diferente pesquisadores referentes a perda de carga: 
Tabela 5.3 - Comparação dos resultados de perda de carga da literatura com os obtidos neste trabalho

\begin{tabular}{|c|c|c|c|}
\hline Autor & Suporte & $\Delta \mathrm{P}\left(10^{-2} \mathrm{mca}\right)$ & Velocidade $\left(\mathrm{cm}^{-\mathrm{s}^{-1}}\right)$ \\
\hline $\begin{array}{l}\text { Moraes Júnior } \\
\text { (1991) }\end{array}$ & Solo; $\mathrm{D}<2 \mathrm{~mm}$ & $66-119$ & $0-0,16$ \\
\hline Yang e Allen (1994) & Composto; $\mathrm{D}<1,2$ & Até 347 & $2-28$ \\
\hline Wu et al. (1999) & Turfa + agentes; $\mathrm{D}=10 \mathrm{~mm}$ & 3 & 2 \\
\hline Rodrigues (2002) & $\begin{array}{l}\text { Solo, } \mathrm{D}=0,5 \mathrm{~mm} \text {; Espuma de } \\
\text { poliuretano, cubos de } 5 \mathrm{~mm}\end{array}$ & $\begin{array}{c}\text { Solo }=58-98 \\
\text { Espuma }=0,14- \\
0,98\end{array}$ & $0,71-2,27$ \\
\hline Maia (2003) & $\begin{array}{l}\text { Espuma de poliuretano, cubos } \\
\text { de } 5 \mathrm{~mm}\end{array}$ & 0,66 & 1,40 \\
\hline Rocha (2007) & $\begin{array}{l}\text { Espuma de poliuretano, cubos } \\
\text { de } 5 \mathrm{~mm}\end{array}$ & 0,54 & 1,31 \\
\hline Este trabalho & $\begin{array}{l}\text { Espuma de poliuretano, cubos } \\
\text { de } 5 \mathrm{~mm} \text {; Bagaço de cana = } 2 \text { - } \\
5,6 \mathrm{~mm} \text {; Fibra de coco }=2-5,6 \\
\mathrm{~mm}\end{array}$ & $\begin{array}{c}\text { Espuma de } \\
\text { poliuretano 0,59; } \\
\text { Bagaço de } \\
\text { cana = 0,62; } \\
\text { Fibra de coco = } \\
0,68\end{array}$ & 1,7 \\
\hline
\end{tabular}

Na Tabela 5.4 estão apresentados os resultados de permeabilidade obtidos nos ensaios com a espuma de poliuretano, o bagaço de cana e a fibra de coco, secos. 
Tabela 5.4 - Permeabilidade dos leitos de espuma de poliuretano, bagaço de cana e fibra de coco.

\begin{tabular}{cccc}
\hline & \multicolumn{3}{c}{$\Delta \mathrm{P} / \mathrm{L}$ em função de $\mathrm{V}$} \\
\cline { 2 - 4 } & Regressão & $\mathrm{K}\left(\mathrm{cm}^{2}\right)$ & $\mathrm{R}^{2}$ \\
\hline Espuma de poliuretano & $8,248 . \mathrm{v}$ & $1,46 \mathrm{E}-06$ & 0,9746 \\
Bagaço de cana & $8,4039 . v$ & $1,44 \mathrm{E}-06$ & 0,979 \\
Fibra de coco & $9.5133 . \mathrm{V}$ & $1,27 \mathrm{E}-06$ & 0,9948 \\
\hline
\end{tabular}

De acordo com a Tabela 5.4, os valores de permeabilidade do bagaço de cana e da espuma de poliuretano foram similares. Apenas o valor da permeabilidade da fibra de coco foi ligeiramente maior.

Com relação à espuma de poliuretano, Rocha (2007) e Rodrigues (2002) encontraram permeabilidade de 9,17E-5 e 1,07E-5 em seus sistemas. Portanto, valores que diferem dos determinados neste trabalho. Entretanto, a ordem de grandeza verificada nos valores de permeabilidade deste trabalho foi a mesma encontrada por Maia (2003).

Com relação aos valores de permeabilidade do bagaço de cana e da fibra de coco, não foram encontrados trabalhos que tenham disponibilizado tais resultados.

\subsection{ENSAIO DE ADSORÇÃO}

A fim de avaliar a quantidade de $\mathrm{H}_{2} \mathrm{~S}$ adsorvido sobre os materiais suporte orgânicos e o material sintético, foram realizados ensaios de adsorção sob condições abióticas. A concentração média afluente de sulfeto utilizada nas colunas preenchidas com espuma de poliuretano e fibra de coco, cujos ensaios foram realizados simultaneamente, ficou em torno de 209 ppm. Para o ensaio realizado no biofiltro preenchido com bagaço de cana 
(realizado após o término dos ensaios nos biofiltros EP e FC), a concentração média aplicada foi de, aproximadamente, 230 ppm.

A justificativa para a adoção destas concentrações afluentes de $\mathrm{H}_{2} \mathrm{~S}$ se dá em função, principalmente, da questão de segurança laboratorial. Adicionalmente, esta concentração está dentro da faixa utilizada por Barona et al. (2005), que realizaram trabalho importante a respeito de adsorção de materiais suportes orgânicos e inorgânicos para biofiltros. Os autores trabalharam numa faixa que variou de 50 a 330 ppm.

Ainda com relação às concentrações médias afluentes a que foram submetidos os biofiltros nesses ensaios, é importante ressaltar que estas foram similares àquelas aplicadas durante a primeira fase de operação dos sistemas. Cabe salientar ainda, que todos os ensaios tiveram duração de 20 horas.

As Tabelas 5.5, 5.6 e 5.7 mostram os dados obtidos no ensaio de adsorção (Concentração de entrada de $\mathrm{H}_{2} \mathrm{~S}, \mathrm{C}_{0}$ e concentração de saída de $\mathrm{H}_{2} \mathrm{~S}, \mathrm{C}_{\mathrm{s}}$ ) assim como a freqüência das análises realizadas.

Tabela 5.5 - Dados obtidos no ensaio de adsorção para o Biofiltro preenchido com Espuma de Poliuretano.

\begin{tabular}{ccc}
\hline Tempo $(\mathrm{h})$ & $\mathrm{C}_{0}\left(\mathrm{H}_{2} \mathrm{~S}\right)(\mathrm{ppm})$ & $\mathrm{Cs}\left(\mathrm{H}_{2} \mathrm{~S}\right)(\mathrm{ppm})$ \\
\hline 0,17 & 225 & 198 \\
1 & 258 & 248 \\
2 & 218 & 226 \\
4 & 255 & 222 \\
6 & 171 & 204 \\
8 & 162 & 228 \\
12 & 218 & 208 \\
16 & 172 & 187 \\
20 & 198 & 198 \\
\hline
\end{tabular}


Tabela 5.6 - Dados obtidos no ensaio de adsorção para o Biofiltro preenchido com Fibra de Coco.

\begin{tabular}{ccc}
\hline Tempo $(\mathrm{h})$ & $\mathrm{C}_{0}\left(\mathrm{H}_{2} \mathrm{~S}\right)(\mathrm{ppm})$ & $\mathrm{Cs}\left(\mathrm{H}_{2} \mathrm{~S}\right)(\mathrm{ppm})$ \\
\hline 0,17 & 225 & 275 \\
1 & 258 & 281 \\
2 & 218 & 266 \\
4 & 255 & 259 \\
6 & 171 & 209 \\
8 & 162 & 192 \\
12 & 218 & 215 \\
16 & 172 & 172 \\
20 & 198 & 200 \\
\hline
\end{tabular}

Tabela 5.7 - Dados obtidos no ensaio de adsorção para o Biofiltro preenchido com Bagaço de Cana.

\begin{tabular}{ccc}
\hline Tempo $(\mathrm{h})$ & $\mathrm{C}_{0}\left(\mathrm{H}_{2} \mathrm{~S}\right)(\mathrm{ppm})$ & $\mathrm{Cs}\left(\mathrm{H}_{2} \mathrm{~S}\right)(\mathrm{ppm})$ \\
\hline 0,17 & 242 & 215 \\
1 & 262 & 218 \\
2 & 245 & 276 \\
4 & 255 & 266 \\
6 & 257 & 258 \\
8 & 176 & 177 \\
12 & 172 & 180 \\
16 & 221 & 248 \\
20 & 241 & 243 \\
\hline
\end{tabular}

Pode ser verificado nas Tabelas 5.5, 5.6 e 5.7 que houve oscilações na concentração afluente de sulfeto durante os ensaios. Com relação às oscilações verificadas, uma possível explicação reside na variação da pressão da corrente de ar utilizada para promover a diluição do sulfeto de hidrogênio e/ou pelo próprio método de determinação da concentração de sulfeto. Especialmente na Figura 5.5, na medida realizada na oitava hora do ensaio, um ponto ficou muito acima de faixa aceitável (marcado com um círculo). Isto pode ter ocorrido em virtude de uma possivel falha na coleta e/ou na análise de sulfeto de hidrogênio.

Nas Figuras 5.5, 5.6 e 5.7 são apresentados os dados referentes ao teste de adsorção realizado na espuma de poliuretano, na fibra de coco e no bagaço de cana. Vale ressaltar que os testes foram realizados em ausência de umidade, tanto com relação ao fluxo de ar quanto com os materiais suporte. 


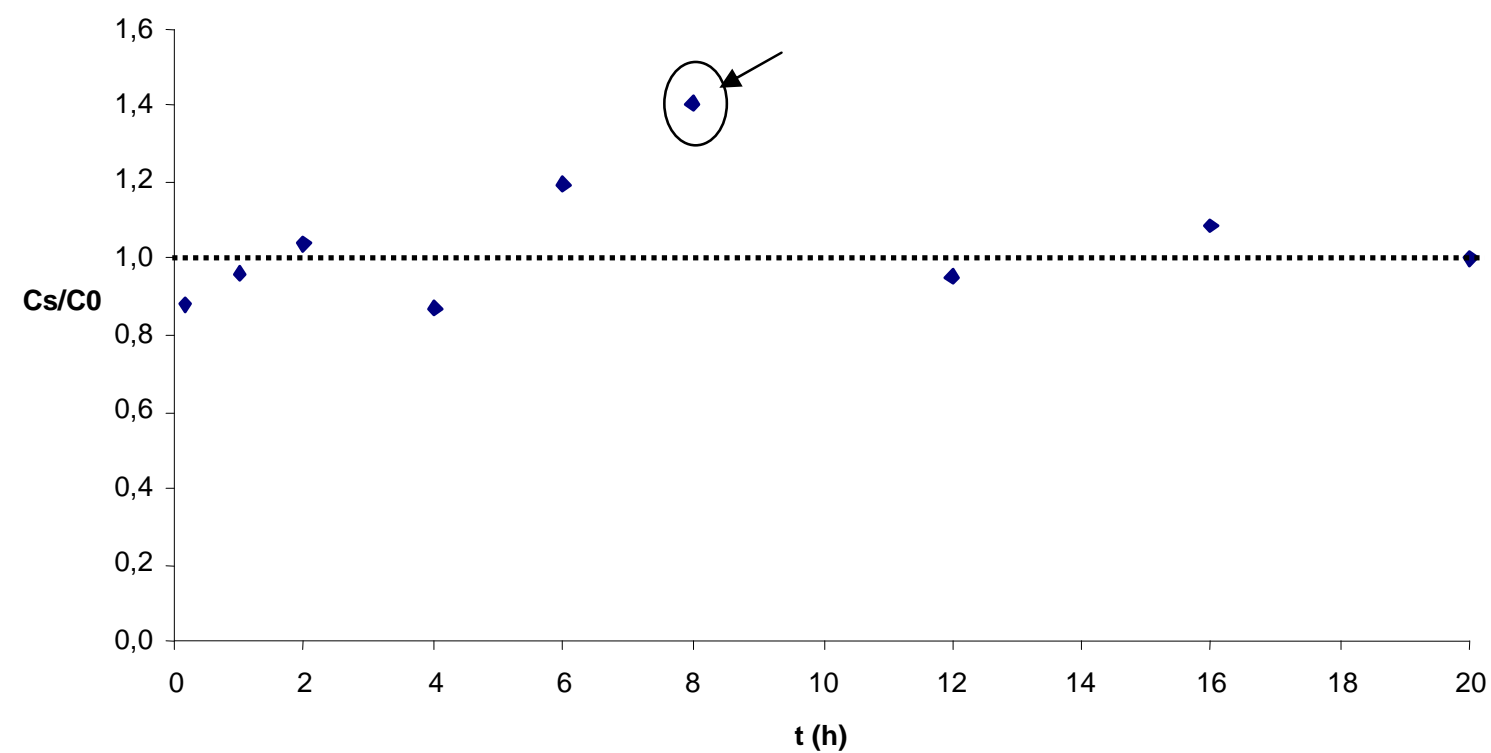

Figura 5.5: Curva de Ruptura para o Biofiltro preenchido com Espuma de Poliuretano.

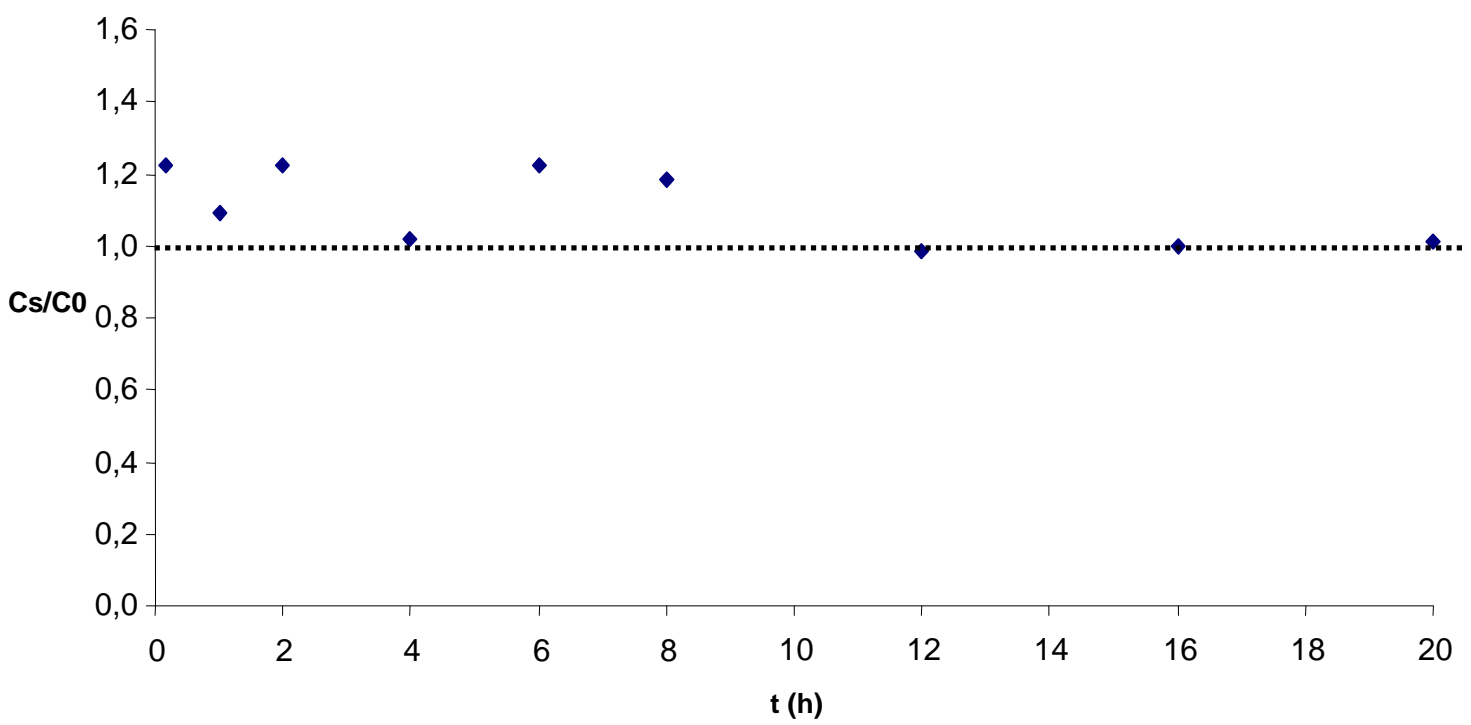

Figura 5.6: Curva de Ruptura para o Biofiltro preenchido com Fibra de Coco. 


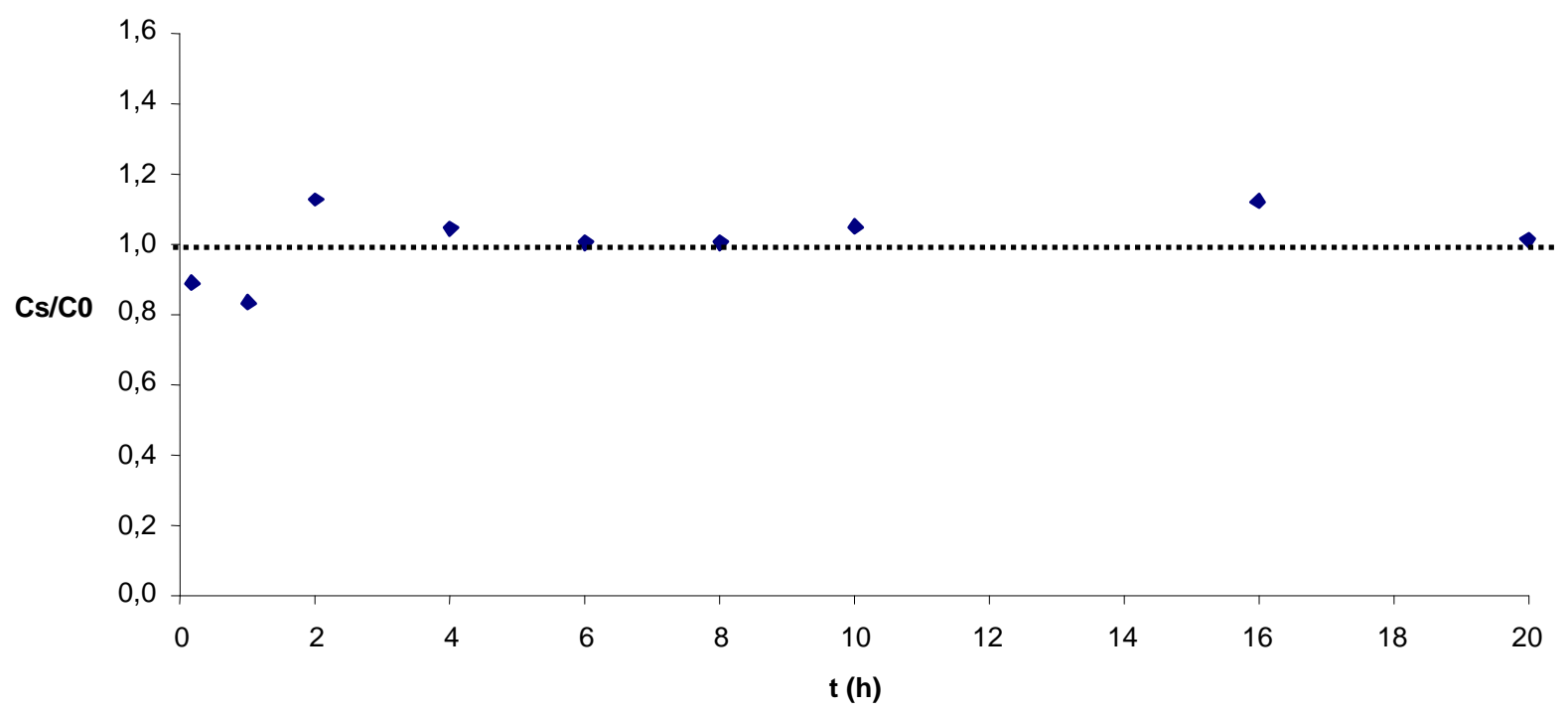

Figura 5.7: Curva de Ruptura para o Biofiltro preenchido com Bagaço de Cana.

Os gráficos de adsorção apresentados nas Figuras 5.5, 5.6 e 5.7 mostram que todos os materiais suporte possuem baixa capacidade adsorvente, pois a saturação ocorreu em alguns minutos. Logo, pode-se afirmar que o efeito da adsorção não é um parâmetro relevante para todos os materiais suportes avaliados, independente de sua natureza, em se tratando de uma operação em longo prazo.

\subsection{MICRORGANISMOS}

\subsubsection{Pré-inoculação: Microscopia ótica}

Na Figura 5.8 podem ser visualizados os microrganismos logo após a coleta junto à unidade de Lodos Ativados da São Carlos Indústria de Papel S/A, e ao Biofiltro Aerado Submerso da ETE - Água Vermelha, pertencente ao Sistema Autônomo de Água e Esgoto do Município de São Carlos.

De acordo com Metcalf e Eddy (2002), as bactérias presentes nos processos aeróbios de tratamento de efluentes, incluindo lodo ativado e biofiltro aerado submerso, são 
gram-negativas e incluem os gêneros Pseudomonas, Zoogloea, Achromobacter, Flavobacterium, Nocardia, Bdellovibrio, Mycobacterium além das bactérias nitrificantes, Nitrosomonas e Nitrobacter. Também são encontradas várias morfologias filamentosas como Sphaerotilus, Beggiatoa, Thiothrix, Lecicothrix e Geotrichum.

Na Figura 5.8 (a1 e a2) é possivel verificar as seguintes morfologias: cocos, filamentos e bacilos, o que comprova a heterogeneidade da amostra de lodo ativado. Já a amostra de biofiltro aerado, Figura 5.8 (b1 e b2), apresenta as mesmas morfologias encontradas no lodo ativado, exceto pelos filamentos.

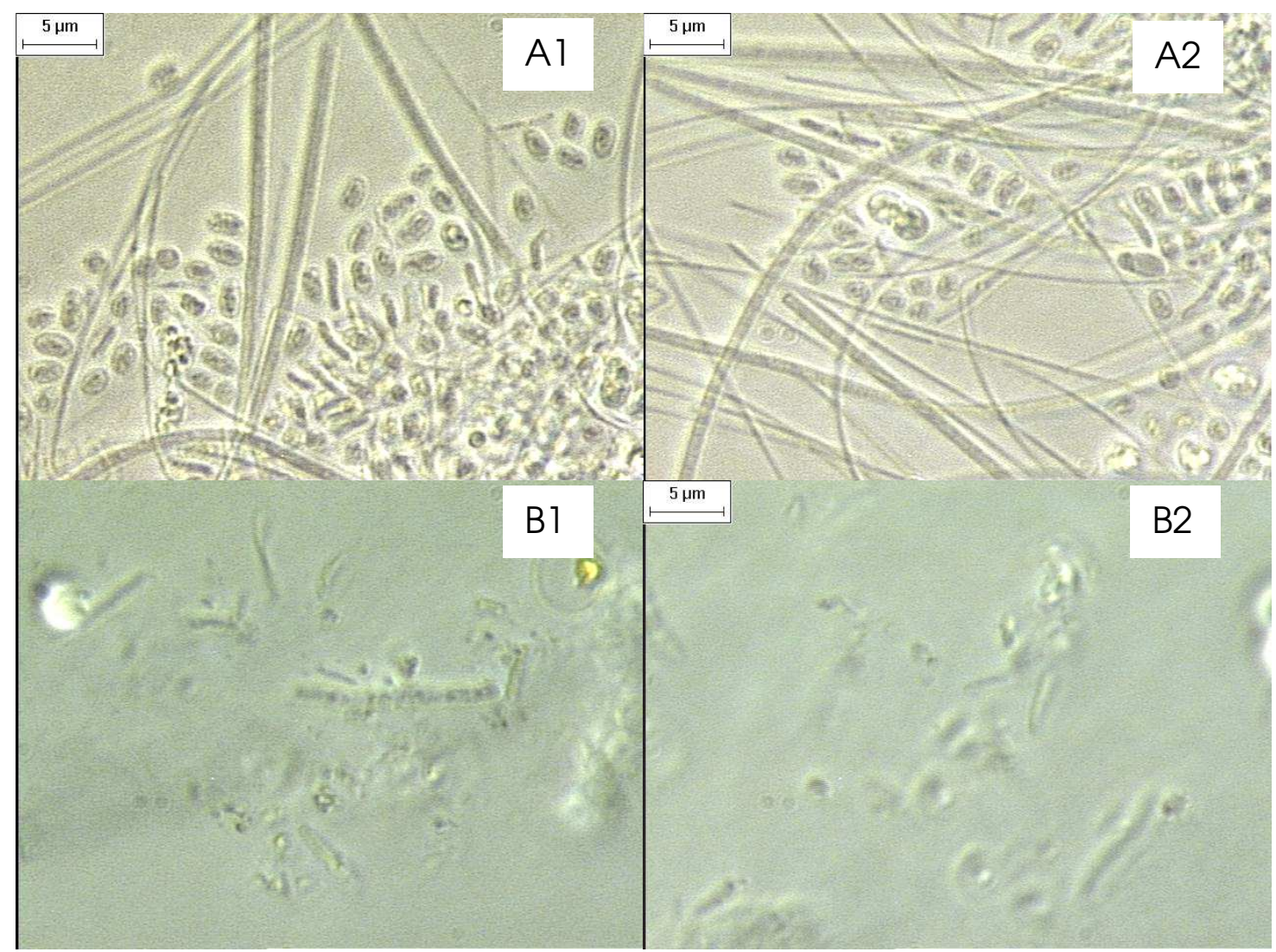

Figura 5.8: Microscopia ótica das amostras brutas de Lodo ativado (a1 e a2) e Biofiltro Aerado Submerso (b1 e b2)

Mesmo após o enriquecimento em meio específico para Thiobacillus sp., tendo o tiossulfato como fonte principal de enxofre, ainda é possivel observar morfologias como cocos e outras semelhantes a leveduras na Figura 5.9, todavia também é possivel observar a predominância de bacilos em ambas as culturas. 


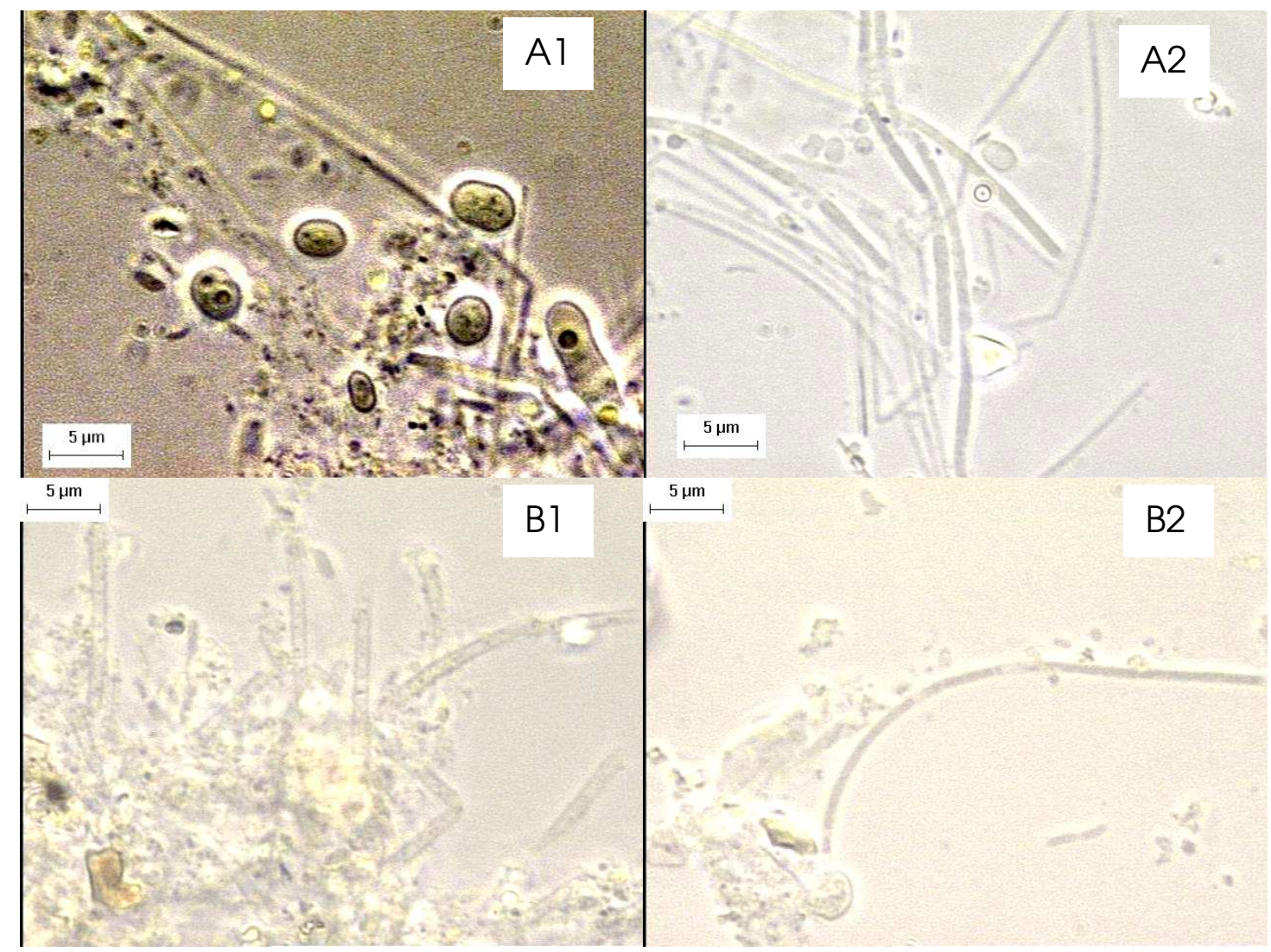

Figura 5.9: Microscopia ótica das amostras enriquecidas em meio ATCC 290-S6, para Thiobacillus sp. Lodo ativado ( 1 e a2) e Biofiltro Aerado Submerso (b1 e b2)

Ainda em etapa de enriquecimento em meio específico, mas neste caso substituindo a fonte de enxofre principal de tiossulfato para sulfeto de hidrogênio, pode-se notar na Figura 5.10 que os microrganismos em forma de bacilo são dominantes em ambos os meios. Contudo, ainda é possivel notar morfologias como vibriões e cocos. 


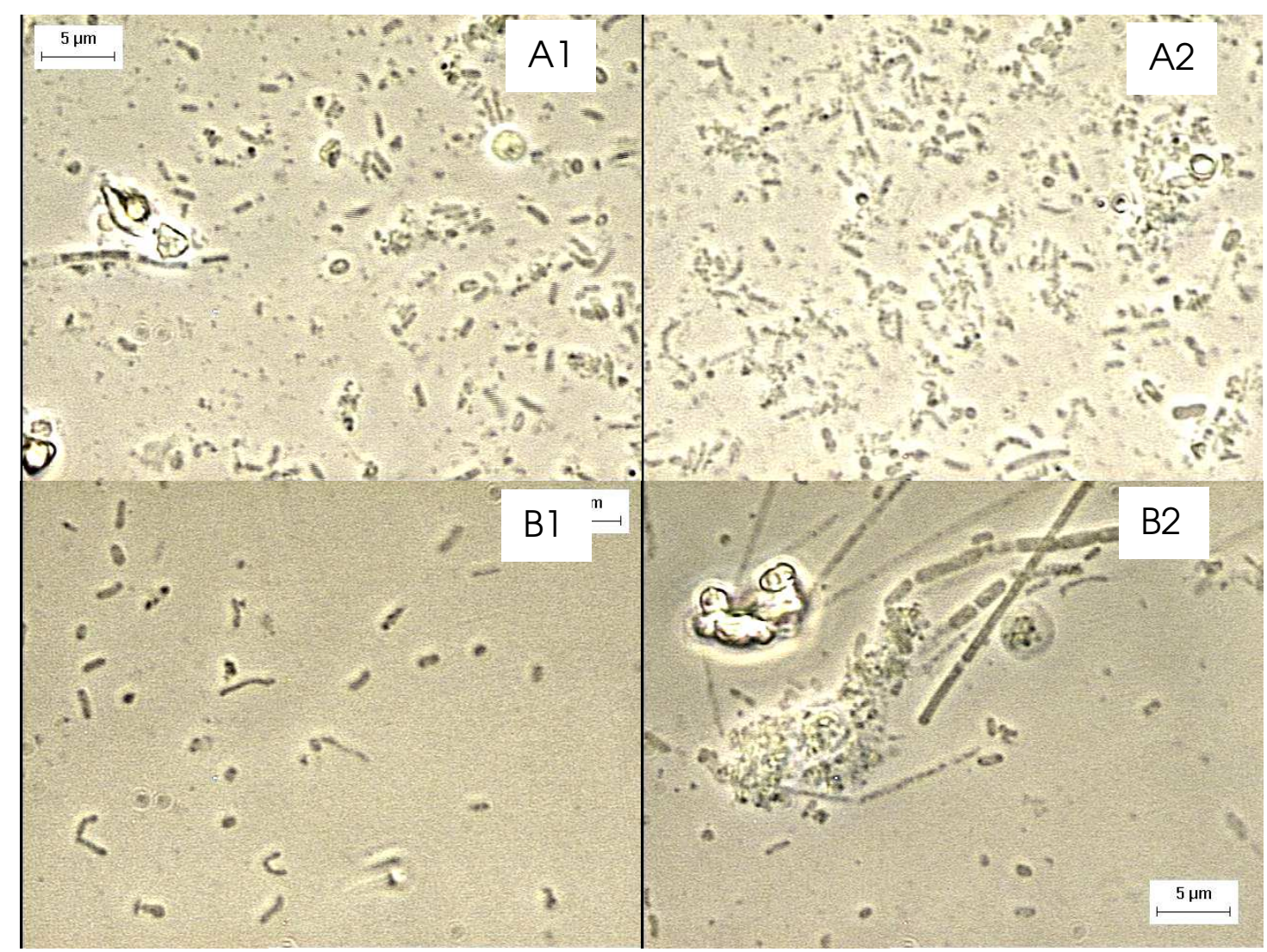

Figura 5.10: Microscopia ótica das amostras enriquecidas em meio ATCC 290-S6, para Thiobacillus sp, tendo como fonte de enxofre o $\mathrm{H}_{2} \mathrm{~S}$ ao invés de tiossulfato. Lodo ativado (a 1 e a2) e Biofiltro Aerado Submerso (b 1 e b2)

Na Figura 5.11, que corresponde a etapa na qual foram misturadas no mesmo barrilete as culturas até então cultivadas em barriletes separados, pode-se verificar a predominância de bacilos e cocos.

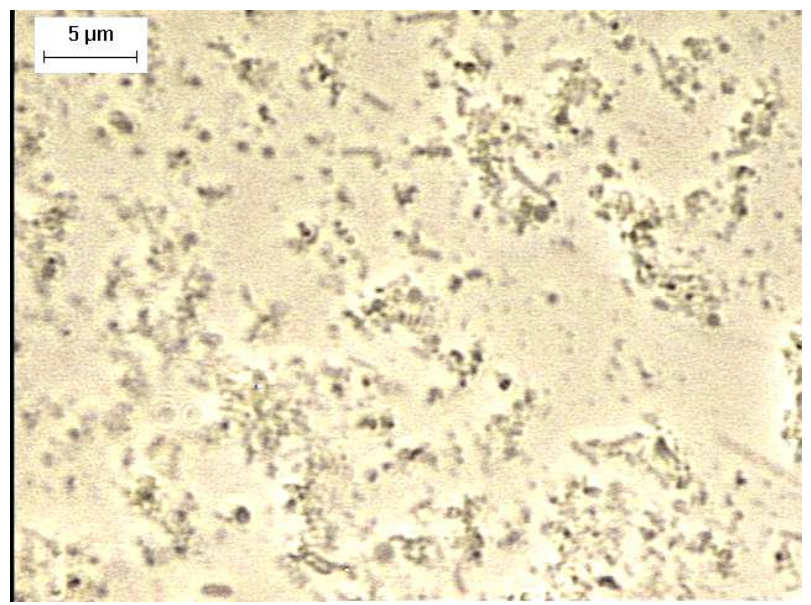

Figura 5.11: Microscopia ótica das amostras misturadas, enriquecidas em meio ATCC 290-S6, para Thiobacillus sp., tendo como fonte de enxofre o $\mathrm{H}_{2} \mathrm{~S}$, ao invés de tiossulfato 


\subsubsection{Operação contínua: Microscopia Eletrônica de Varredura}

Após o término da operação dos sistemas, foram retiradas amostras da base, do centro e do topo dos biofiltros preenchidos com espuma de poliuretano, bagaço de cana e fibra de coco, para que as mesmas fossem submetidas à análise de microscopia eletrônica de varredura (MEV).

Nas Figuras 5.12, 5.13 e 5.14 podem ser observadas as morfologias presentes nas amostras retiradas dos biofiltros preenchidos com a espuma de poliuretano, o bagaço de cana e a fibra de coco, respectivamente.

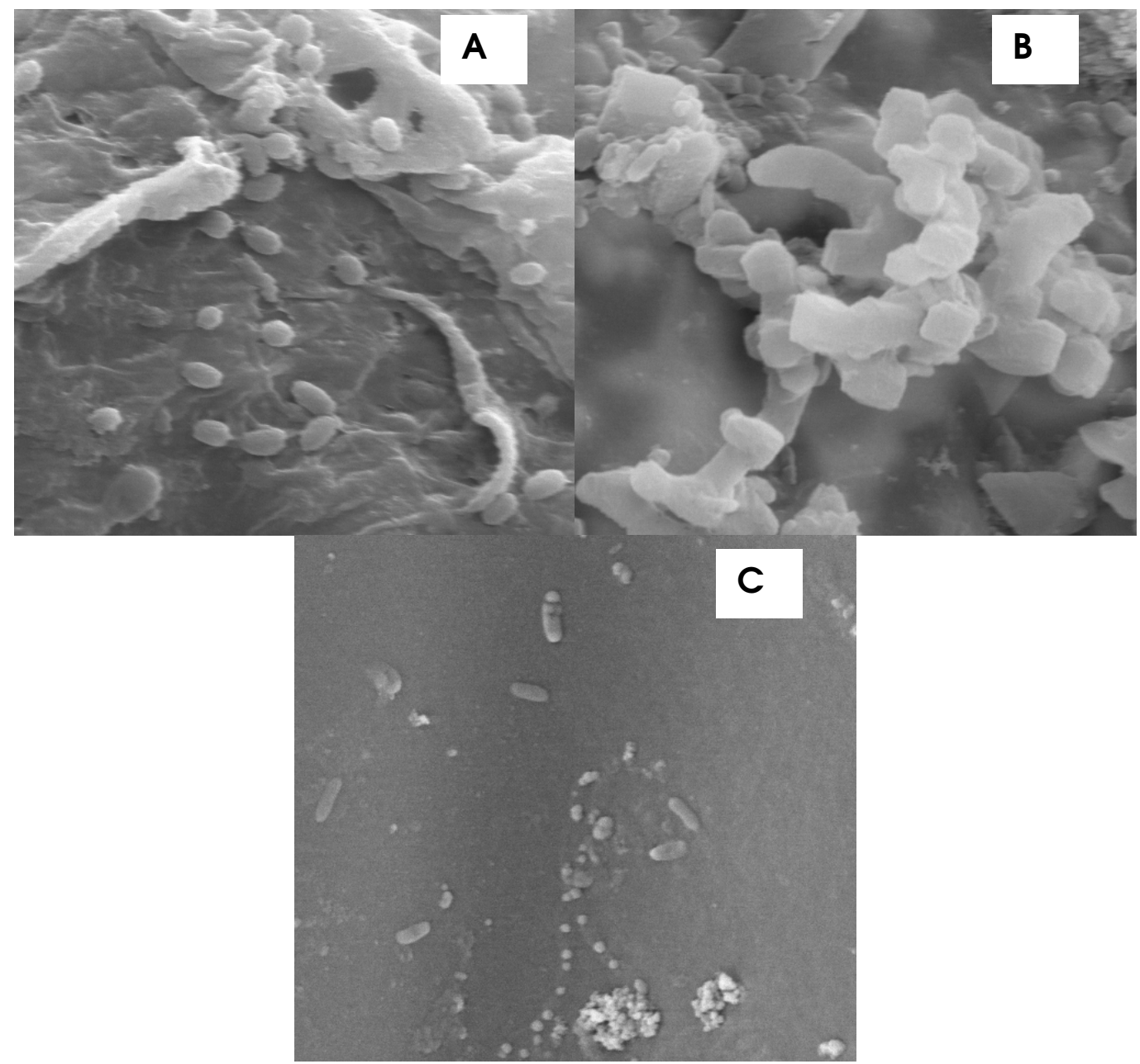

Figura 5.12: Microscopia eletrônica de varredura da base (a), do centro (b) e do topo (c) do biofiltro preenchido com espuma de poliuretano. 


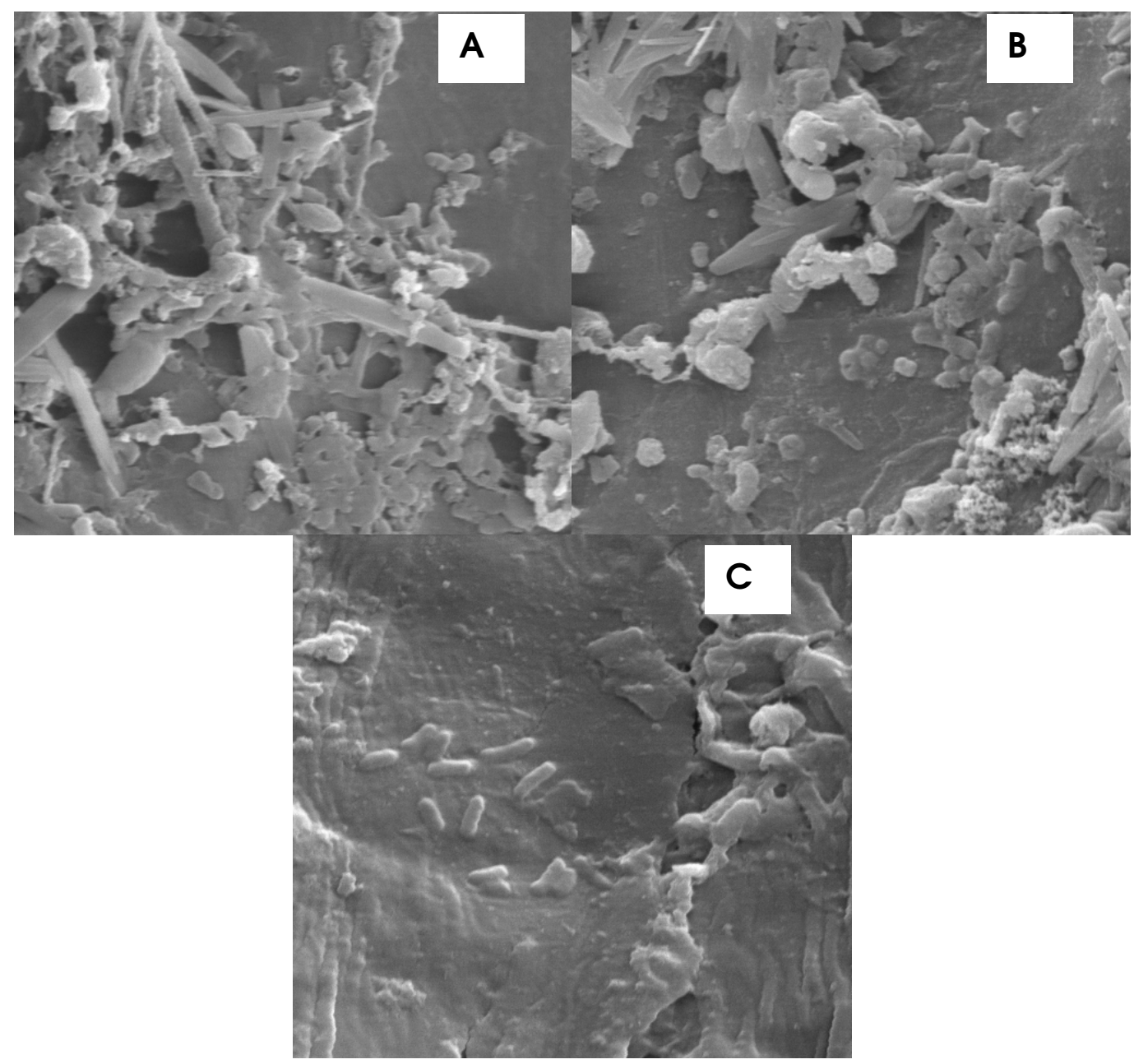

Figura 5.13: Microscopia eletrônica de varredura da base (a), do centro (b) e do topo (c) do biofiltro preenchido com bagaço de cana. 


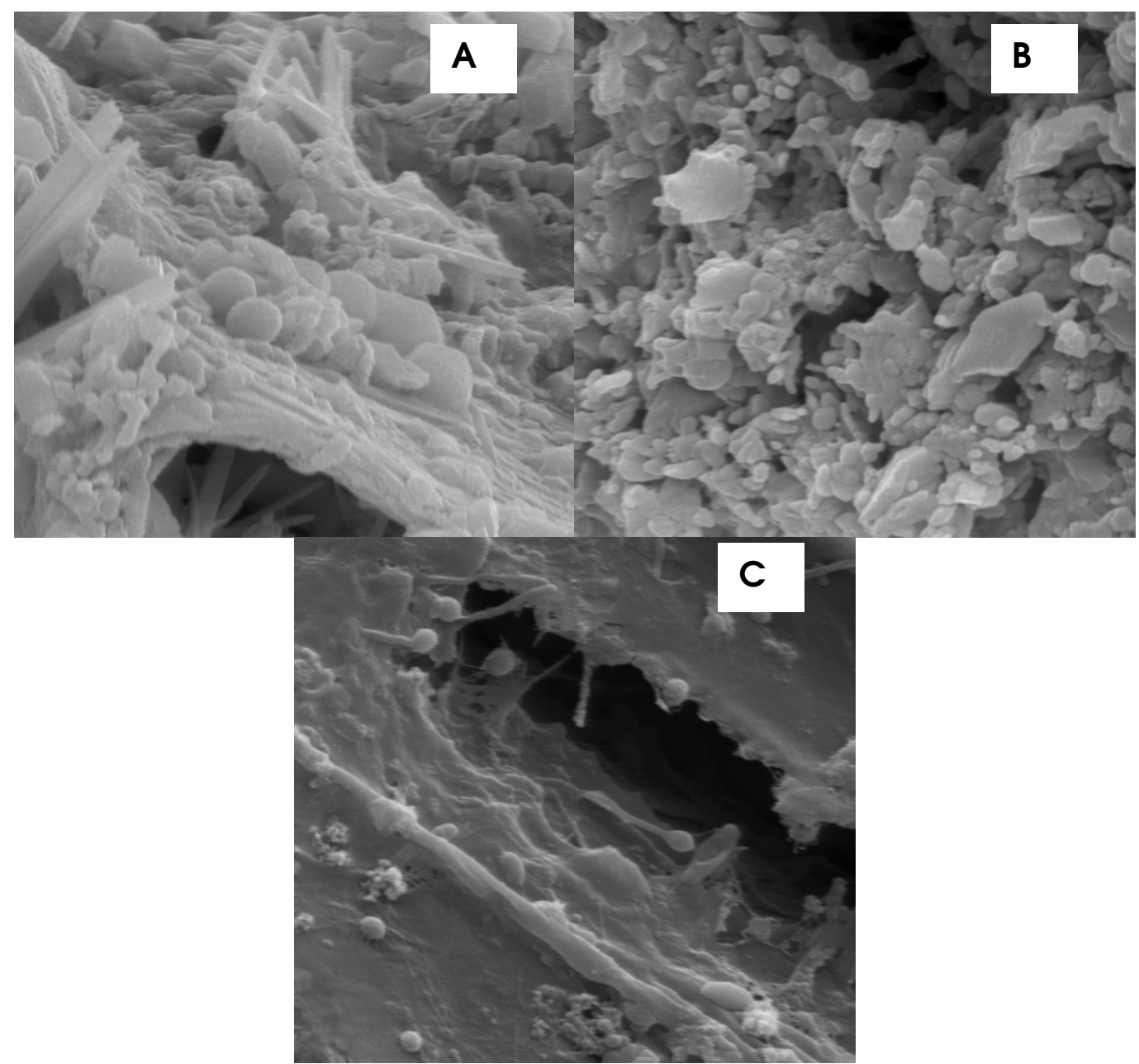

Figura 5. 14: Microscopia eletrônica de varredura da base (a), do centro (b) e do topo (c) do biofiltro preenchido com fibra de coco.

Nas Figuras 5.12, 5.13 e 5.14, pode ser observado grande acúmulo de grânulos de enxofre extracelular, o que de certa forma, prejudicou a visualização das morfologias. Mesmo assim, ainda podem ser observados cocos e bacilos em todas as amostras.

A confirmação de que os grânulos encontrados na análise de Microscopia Eletrônica de Varredura eram de enxofre elementar foi dada pela análise de Espectroscopia de Raio-X (EDX) realizada, cujos resultados estão apresentados na Tabela 5.8. 
Tabela 5.8 - Resultados obtidos a partir da análise de EDX

\begin{tabular}{cccc}
\hline Elemento & $\begin{array}{c}\text { Espuma de } \\
\text { poliuretano } \\
(\%)\end{array}$ & $\begin{array}{c}\text { Bagaço de } \\
\text { cana } \\
(\%)\end{array}$ & $\begin{array}{c}\text { Fibra de } \\
\text { coco } \\
(\%)\end{array}$ \\
\hline $\mathrm{Si}$ & 9,28 & - & - \\
$\mathrm{Na}$ & - & 35,11 & 10,65 \\
$\mathrm{Mg}$ & - & 4,27 & 1,94 \\
$\mathrm{P}$ & - & 15,81 & 4,00 \\
$\mathrm{~S}$ & 41,38 & 43,13 & 79,27 \\
$\mathrm{~K}$ & 49,34 & 1,68 & 3,18 \\
$\mathrm{Ca}$ & - & - & 0,26 \\
$\mathrm{Fe}$ & - & - & 0,71 \\
\hline
\end{tabular}

O valor percentual de enxofre detectado pela análise de EDX na espuma de poliuretano foi de $41,38 \%$, portanto inferior ao encontrado por Rocha (2007), que foi de 79,60\%. A este fato, pode-se atribuir o maior tempo de operação (120 dias) e as maiores concentrações (até 1400 ppm) estudadas por Rocha (2007).

A análise de EDX ainda apontou para valor percentual de deposição de enxofre de $43,13 \%$ para o bagaço de cana, similar ao verificado no biofiltro preenchido com espuma, e de $79,27 \%$ na fibra de coco, valor similar ao obtido por Rocha (2007) com a espuma de poliuretano. Em ambos os materiais, o enxofre foi o principal elemento presente. 


\subsection{OPERAÇÃO CONTÍNUA DOS SISTEMAS}

Os experimentos de oxidação contínua do poluente gasoso bem como a avaliação de desempenho, foram realizados de forma simultânea nos três biofiltros, pelo período de 100 dias. Assim, neste item procurou-se agrupar todos os aspectos pertinentes à efetiva operação contínua dos biofiltros.

Ademais, a fim de promover um detalhamento maior de cada fase de operação dos sistemas, este item foi subdivido no intuito de permitir a visualização mais apurada das respectivas fases de operação e aspectos relativos às mesmas.

\subsubsection{Abordagem geral}

A investigação de longo prazo sobre a remoção de sulfeto de hidrogênio a diferentes concentrações afluentes médias foi conduzida a vazão de $0,13 \mathrm{~m}^{3} \cdot \mathrm{h}^{-1}$. A operação dos biofiltros foi dividida em quatro fases, totalizando 100 dias de operação.

Especificamente, a primeira fase teve duração de 24 dias, a segunda fase durou 32 dias, a terceira fase durou 31 dias e a quarta fase estendeu-se por 13 dias.

As taxas médias de carregamento mássico aplicadas por unidade de volume nos três biofiltros foram de, aproximadamente, 19, 33, 55 e $70 \mathrm{gH}_{2} \mathrm{~S} \cdot \mathrm{m}^{-3} \cdot \mathrm{h}^{-1}$ (que correspondem a concentrações afluentes médias em torno de 185, 330, 520 e 645 ppm e tempo de retenção do gás para os leitos vazios de, aproximadamente, 50 s) para a primeira, segunda, terceira e quarta fases, respectivamente.

Na Tabela 5.9 é apresentado um panorama geral da operação contínua dos sistemas: 
Tabela 5.9 - Panorama geral da operação contínua dos sistemas

\begin{tabular}{|c|c|c|c|c|c|c|c|c|c|c|c|c|}
\hline & \multicolumn{3}{|c|}{ FASE 1} & \multicolumn{3}{|c|}{ FASE 2} & \multicolumn{3}{|c|}{ FASE 3} & \multicolumn{3}{|c|}{ FASE 4} \\
\hline & $E P$ & $\mathrm{BC}$ & FC & EP & $\mathrm{BC}$ & FC & EP & $\mathrm{BC}$ & FC & EP & $\mathrm{BC}$ & $\mathrm{FC}$ \\
\hline $\begin{array}{c}\mathrm{H}_{2} \mathrm{~S} \text { afluente } \\
\quad(\mathrm{ppm})\end{array}$ & $\begin{array}{r}184 \\
\pm 14\end{array}$ & $\begin{array}{r}184 \\
\pm 14\end{array}$ & $\begin{array}{r}184 \\
\pm 14\end{array}$ & $\begin{array}{r}328 \\
\pm 19\end{array}$ & $\begin{array}{l}328 \\
\pm 19\end{array}$ & $\begin{array}{r}328 \\
\pm 19\end{array}$ & $\begin{array}{c}519 \pm \\
32\end{array}$ & $\begin{array}{r}519 \\
\pm 32\end{array}$ & $\begin{array}{c}519 \pm \\
32\end{array}$ & $\begin{array}{r}644 \\
\pm 41\end{array}$ & $\begin{array}{r}644 \\
\pm 41\end{array}$ & $\begin{array}{r}644 \\
\pm 41\end{array}$ \\
\hline $\mathrm{H}_{2} \mathrm{~S}$ efluente & 0,3 & 0,2 & 0,3 & 0,1 & 0,0 & 0,0 & 0,1 & 1,6 & 0,0 & 1,5 & 4,6 & 2,7 \\
\hline (ppm) & $\pm 0,6$ & $\pm 0,5$ & $\pm 0,6$ & $\pm 0,4$ & $\pm 0,2$ & $\pm 0,1$ & $\pm 0,2$ & $\pm 4,4$ & $\pm 0,1$ & $\pm 2,8$ & $\pm 4,9$ & $\pm 4,4$ \\
\hline ER & 99,8 & 99,9 & 99,8 & 99,9 & 99,9 & 99,9 & 100,0 & 99,7 & 100,0 & 99,8 & 99,3 & 99,6 \\
\hline (\%) & $\pm 0,4$ & $\pm 0,3$ & $\pm 0,4$ & $\pm 0,1$ & $\pm 0,0$ & $\pm 0,1$ & $\pm 0,0$ & $\pm 0,8$ & $\pm 0,0$ & $\pm 0,5$ & $\pm 0,0$ & $\pm 0,7$ \\
\hline TCMS & 15,7 & 15,7 & 15,7 & 28,0 & 28,0 & 28,0 & 44,3 & 44,3 & 44,3 & 55 & 55 & 55 \\
\hline$\left(\mathrm{g} / \mathrm{m}^{2}\right)$ & $\pm 1,2$ & $\pm 1,2$ & $\pm 1,2$ & $\pm 1,6$ & $\pm 1,6$ & $\pm 1,6$ & $\pm 2,7$ & $\pm 2,7$ & $\pm 2,7$ & $\pm 3,5$ & $\pm 3,5$ & $\pm 3,5$ \\
\hline CE & 17,8 & 18,7 & 18,9 & 32,0 & 35,0 & 33,8 & 52,3 & 59,0 & 53,5 & 66,7 & 72,9 & 67,9 \\
\hline$\left(\mathrm{g} / \mathrm{m}^{3} \cdot \mathrm{h}\right)$ & $\pm 1,4$ & $\pm 1,4$ & $\pm 1,5$ & $\pm 1,8$ & $\pm 2,6$ & $\pm 1,9$ & $\pm 3,2$ & $\pm 3,6$ & $\pm 3,4$ & $\pm 4,6$ & $\pm 4,6$ & $\pm 4,2$ \\
\hline
\end{tabular}

EP = Biofiltro preenchido com espuma de poliuretano; $\mathrm{BC}=$ biofiltro preenchido com bagaço de cana; FC = biofiltro preenchido com fibra de coco. 
Para melhor visualização do potencial de remoção de sulfeto nos três sistemas durante a operação dos mesmos, na Figura 5.15 é apresentado um panorama geral em termos de eficiência de remoção e concentrações de entrada e saída de $\mathrm{H}_{2} \mathrm{~S}$.

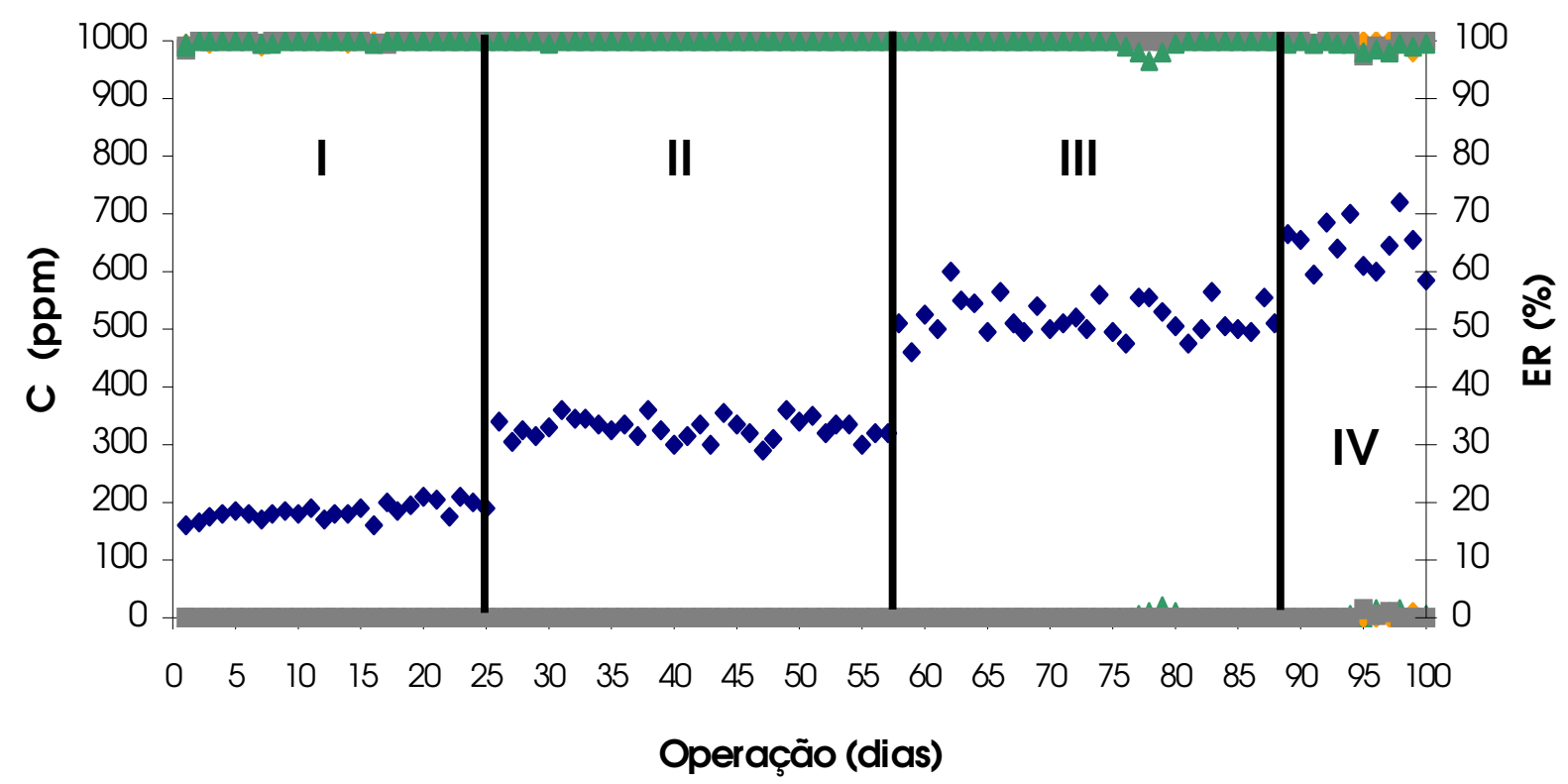

Figura 5.15: Concentração afluente ( $\downarrow)$, efluentes e eficiências de remoção para os biofiltros preenchidos com espuma de poliuretano $(\diamond)$, fibra de coco $(\square)$ e bagaço de cana $(\boldsymbol{\Delta})$.

Na Figura 5.15 pode ser observado que as concentrações de entrada sofreram ligeiras oscilações nas fases 1 e 2, e oscilações um pouco mais agudas nas fases 3 e 4 . Essas alternâncias na concentração afluente podem ter diversas causas, que vão desde oscilações de pressão na corrente de ar fornecida pelo compressor até o próprio método de coleta de amostras para análise de sulfeto.

Com relação às eficiências de remoção, nota-se que as mesmas mantiveram-se praticamente constantes, com alguma oscilação verificada somente na primeira fase de operação. Exceção deve ser feita ao biofiltro preenchido com bagaço de cana, que no $76^{\circ}$ dia de operação começou a apresentar ligeira queda nos valores de eficiência de remoção, contudo voltou ao patamar de $100 \%$ no $81^{\circ}$ dia, permanecendo assim até o término da operação. 


\subsubsection{Desempenho durante a Fase 1}

A primeira fase teve duração de 24 dias, caracterizada pela concentração média afluente de $\mathrm{H}_{2} \mathrm{~S}$ de aproximadamente 184 ppm e tempo de residência do gás em torno de $50 \mathrm{~s}$.

As concentrações afluentes, efluentes e a eficiência de remoção nos três biofiltros durante a fase inicial de operação podem ser visualizadas nas Figuras 5.16, 5.17 e 5.18.

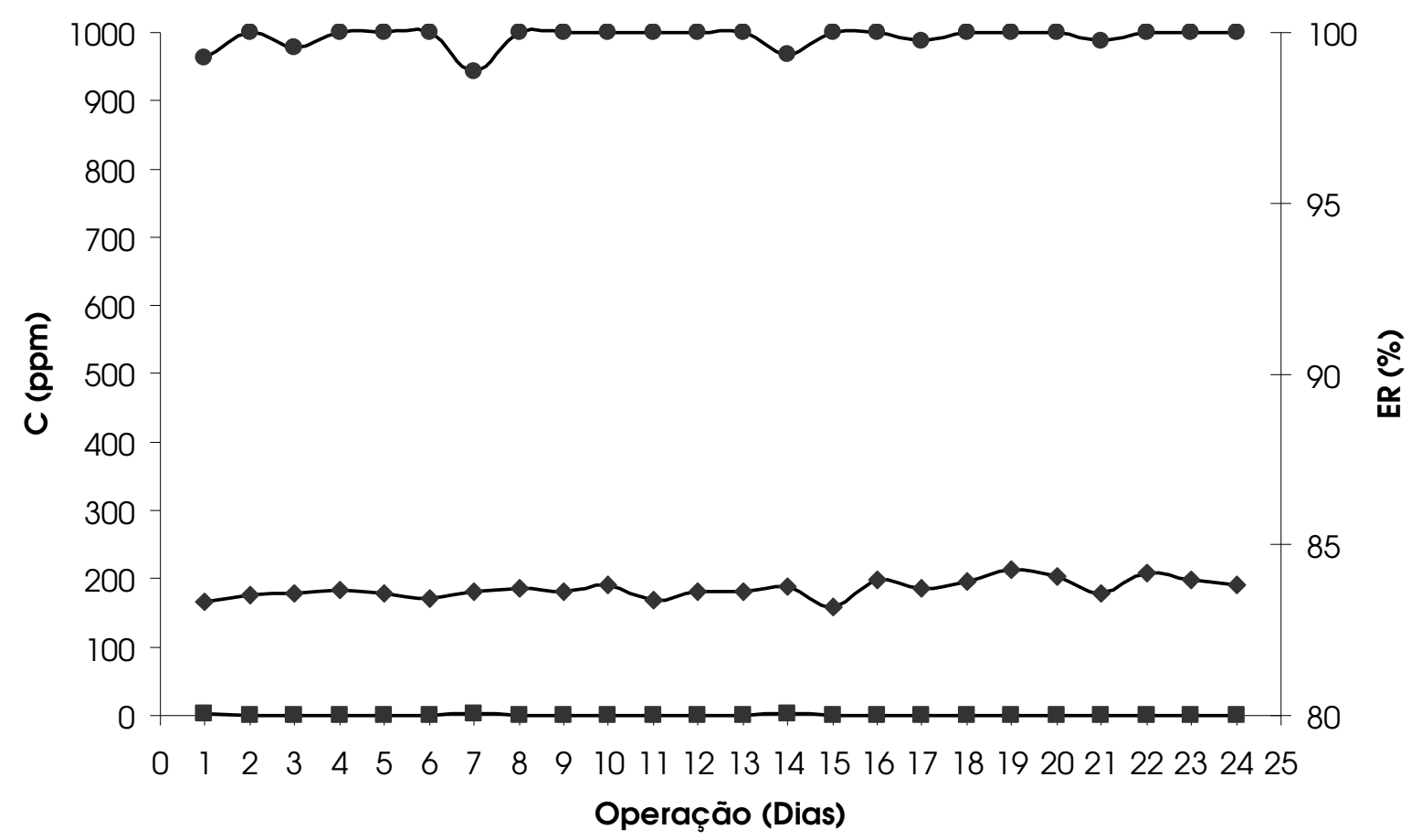

Figura 5.16: Concentração afluente ( $($ ), efluente $(\boldsymbol{\bullet})$ e eficiências de remoção $(\bullet)$ para o biofiltro preenchido com espuma de poliuretano, durante a primeira fase de operação. 


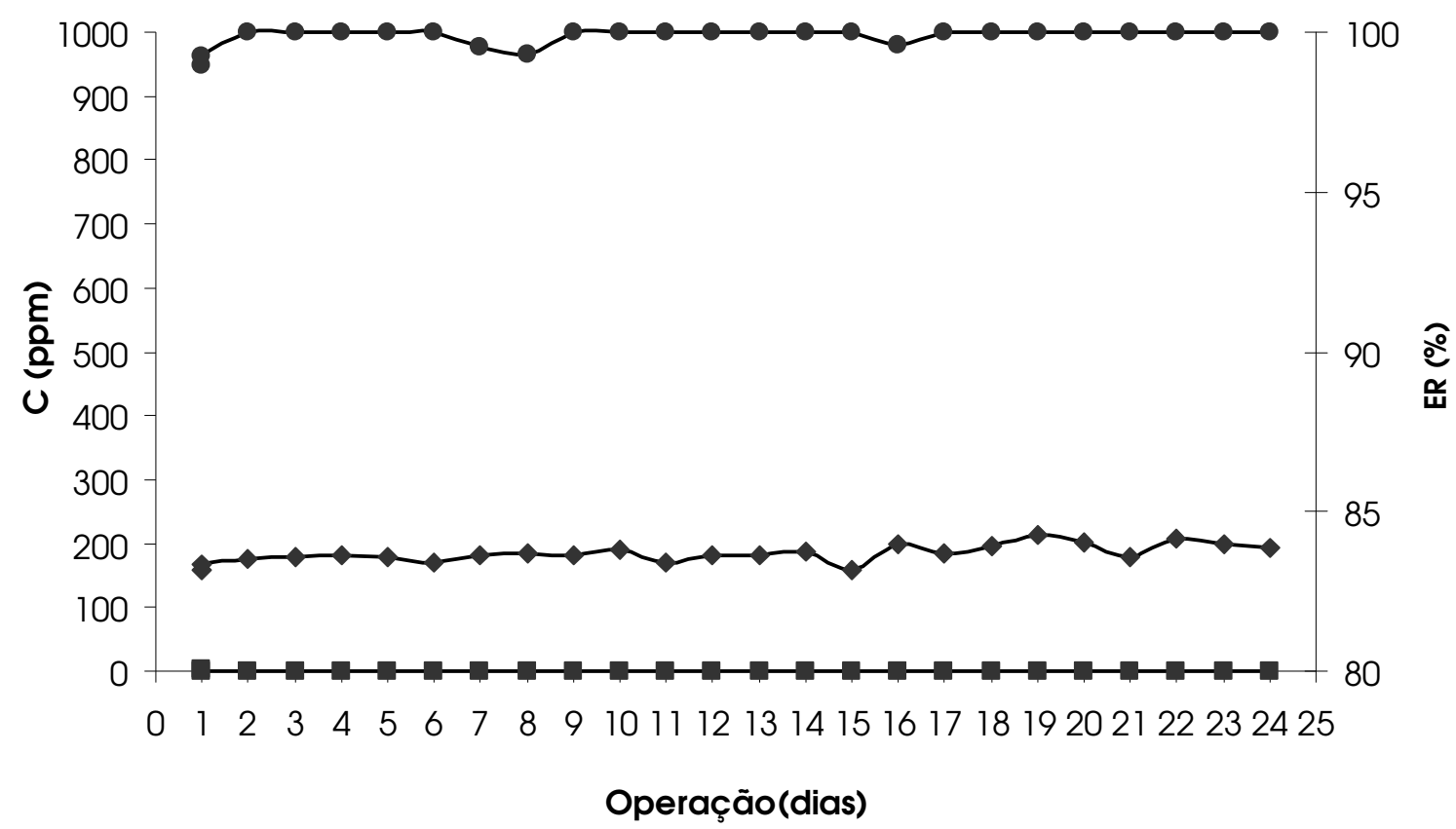

Figura 5.17: Concentração afluente $(\bullet)$, efluente $(\boldsymbol{\bullet})$ e eficiências de remoção $(\bullet)$ para o biofiltro preenchido com bagaço de cana, durante a primeira fase de operação.

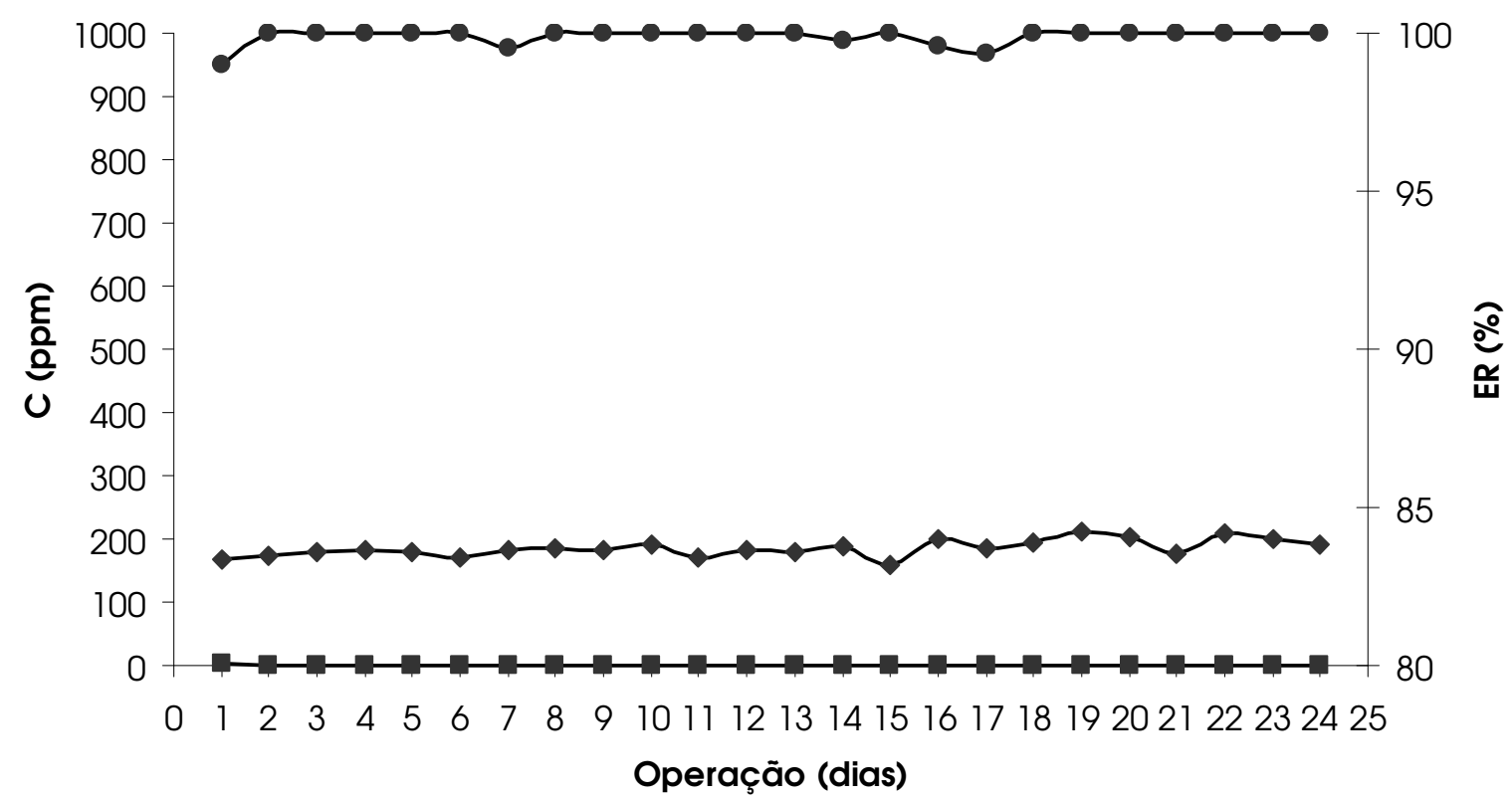

Figura 5.18: Concentração afluente ( $\bullet$ ), efluente $(\boldsymbol{\bullet})$ e eficiências de remoção $(\bullet)$ para o biofiltro preenchido com fibra de coco, durante a primeira fase de operação.

Na Tabela 5.10 podem ser verificados com maior detalhamento os resultados dos parâmetros visualizados nas Figuras 5.16, 5.17 e 5.18. 
Tabela 5.10 - Concentrações afluentes, efluentes e eficiências de remoção para os biofiltros preenchidos com Espuma de Poliuretano, Fibra de Coco e Bagaço de Cana para a Fase 1 de operação do sistema

\begin{tabular}{|c|c|c|c|c|c|c|c|}
\hline \multirow{2}{*}{ DIA } & \multirow{2}{*}{$\begin{array}{l}\mathrm{C}_{0}\left(\mathrm{H}_{2} \mathrm{~S}\right) \\
\text { (ppm) }\end{array}$} & \multicolumn{2}{|c|}{$\begin{array}{l}\text { Espuma de } \\
\text { Poliuretano }\end{array}$} & \multicolumn{2}{|c|}{ Fibra de Coco } & \multicolumn{2}{|c|}{ Bagaço de cana } \\
\hline & & $\begin{array}{c}\mathrm{C} \\
(\mathrm{ppm})\end{array}$ & ER (\%) & $\begin{array}{c}\mathrm{C} \\
(\mathrm{ppm})\end{array}$ & ER (\%) & $\begin{array}{c}\mathrm{C} \\
(\mathrm{ppm})\end{array}$ & ER (\%) \\
\hline 1 & 158 & 2 & 98,9 & 2 & 98,6 & 2 & 98,9 \\
\hline 1 & 166 & 1 & 99,2 & 2 & 99,01 & 1 & 99,2 \\
\hline 2 & 175 & 0 & 100,0 & 0 & 100,0 & 0 & 100,0 \\
\hline 3 & 179 & 1 & 99,5 & 0 & 100,0 & 0 & 100,0 \\
\hline 4 & 183 & 0 & 100,0 & 0 & 100,0 & 0 & 100,0 \\
\hline 5 & 179 & 0 & 100,0 & 0 & 100,0 & 0 & 100,0 \\
\hline 6 & 171 & 0 & 100,0 & 0 & 100,0 & 0 & 100,0 \\
\hline 7 & 181 & 2 & 98,8 & 1 & 99,5 & 1 & 99,5 \\
\hline 8 & 185 & 0 & 100,0 & 0 & 100,0 & 1 & 99,3 \\
\hline 9 & 182 & 0 & 100,0 & 0 & 100,0 & 0 & 100,0 \\
\hline 10 & 191 & 0 & 100,0 & 0 & 100,0 & 0 & 100,0 \\
\hline 11 & 170 & 0 & 100,0 & 0 & 100,0 & 0 & 100,0 \\
\hline 12 & 182 & 0 & 100,0 & 0 & 100,0 & 0 & 100,0 \\
\hline 13 & 180 & 0 & 100,0 & 0 & 100,0 & 0 & 100,0 \\
\hline 14 & 189 & 1 & 99,3 & 0 & 99,7 & 0 & 100,0 \\
\hline 15 & 160 & 0 & 100,0 & 0 & 100,0 & 0 & 100,0 \\
\hline 16 & 199 & 0 & 100,0 & 1 & 99,5 & 1 & 99,5 \\
\hline 17 & 185 & 0 & 99,7 & 1 & 99,3 & 0 & 100,0 \\
\hline 18 & 195 & 0 & 100,0 & 0 & 100,0 & 0 & 100,0 \\
\hline 19 & 212 & 0 & 100,0 & 0 & 100,0 & 0 & 100,0 \\
\hline 20 & 203 & 0 & 100,0 & 0 & 100,0 & 0 & 100,0 \\
\hline 21 & 177 & 0 & 99,7 & 0 & 100,0 & 0 & 100,0 \\
\hline 22 & 208 & 0 & 100,0 & 0 & 100,0 & 0 & 100,0 \\
\hline 23 & 199 & 0 & 100,0 & 0 & 100,0 & 0 & 100,0 \\
\hline 24 & 192 & 0 & 100,0 & 0 & 100,0 & 0 & 100,0 \\
\hline
\end{tabular}

Por ser um sistema que, via de regra, apresenta altas eficiências de remoção, considera-se que a partida de um biofiltro é o período compreendido entre a inoculação e o dia no qual o mesmo apresente eficiência de remoção igual a 100\% (DEVINNY, DESHUSSES e WEBSTER, 1999). Com base nas Figuras 5.16, 5.17 e 5.18 e na Tabela 5.10, pode-se afirmar que os três sistemas, mesmo submetidos à concentrações superiores a 150 ppm, tiveram período considerado de partida de apenas 2 dias, visto que no terceiro dia todos reatores já apresentaram $100 \%$ de remoção do sulfeto. Cabe ressaltar que no dia seguinte à inoculação ( $1^{\circ}$ dia de operação) já foi possivel verificar eficiências de remoção acima de $99 \%$. 
Nos trabalhos de Cho, Hirai e Shoda (1992b) utilizando turfa com Thiobacillus sp. e Hartikainen, Ruuskanen e Martikainen (2001) bem como em Hartikainen et al. (2002), utilizando turfa com Xantomonas sp é possivel observar imediatas eficiências de 99\%. Shojaosadati e Elyasi (1999) verificaram eficiências de remoção de 99\% poucas horas depois de dar partida em seu sistema.

Chung, Huang e Tseng (1996), utilizando cultura pura de Thiobacillus thioparus, observaram eficiências superiores a $98,5 \%$ somente após o $7^{\circ}$ dia de operação, período que determinaram ser o de partida do sistema. Contudo, àquela altura, as concentrações afluentes ao seu sistema eram de apenas 60 ppm.

Duan et al (2006), analisando o desempenho de seus sistemas inoculados com Thiobacillus thiooxidans (reator 1: preenchido com carvão biológico ativado - CBA; e reator 2: preenchido com carvão ativado virgem - CAV) durante o período de partida (que consideraram como sendo de 21 dias), verificaram que as eficiências de remoção começaram a aumentar durante o primeiro dia de operação até atingir, no sexto dia, 90\% na coluna 1, que continha $\circ \mathrm{CAB}$ e $70 \%$ na coluna 2 , que continha $\circ \mathrm{CAV}$. Durante todo esse período as concentrações de entrada de $\mathrm{H}_{2} \mathrm{~S}$ oscilaram entre 15 e 120 ppm.

Rocha (2007), operando biofiltro preenchido com espuma de poliuretano e inoculado com lodo ativado, observou que o período de partida do sistema durou cerca de 9 dias. Rodrigues (2002) e Maia (2003), trabalhando com a espuma de poliuretano, também observaram um período de adaptação similar ao verificado por Rocha (2007), mas neste caso, os autores utilizaram culturas puras de Thiobacillus thioparus.

Tanto nas Figuras 5.16, 5.17 e 5.18 quanto na Tabela 5.10 é possível notar variações nas eficiências de remoção no $7^{\circ}$ dia de operação (biofiltros EP, BC, e FC), no $8^{\circ}$ dia (biofiltro BC), no $14^{\circ}$ dia (biofiltros EP e BC), no $16^{\circ}$ dia (biofiltros BC e FC) e no $17^{\circ}$ dia de operação (biofiltros EP e FC). Todavia, estes pontos encontram-se dentro da faixa de erro descrita pelo método de determinação de sulfeto.

A concentração média para esta fase ficou próxima àquela observada por Rocha (2007), que trabalhou com 141 ppm de média em sua fase inicial de operação. O autor verificou eficiências de remoção superiores a 92,5\% nos primeiros 8 dias e em 100\% do 9 dia 
em diante até enfrentar problemas de rompimento da coluna. Duan et al. (2006) trabalhou com concentrações de $\mathrm{H}_{2} \mathrm{~S}$ variando entre 10 a 125 ppm, obtendo média de $94 \%$ de eficiência de remoção. Kim, René e Park (2007) também trabalharam com concentrações de $\mathrm{H}_{2} \mathrm{~S}$ em faixa que variou entre 10 e 130 ppm, sendo que as eficiências de remoção, durante as diferentes etapas de operação, variaram de 45 a 100\%.

Shojaosadati e Elyasi. (1999) trabalharam com concentrações de 110 ppm durante os 45 dias em que operaram um biofiltro preenchido com composto de cogumelos utilizando lodo de curtumes. Observaram eficiências sempre acima dos $98 \%$ durante 0 período de operação.

No caso deste trabalho, os sistemas já se mostraram robustos nesta fase inicial de operação, sendo possivel observar altas eficiências de remoção, com ligeiras oscilações de $98,9 \%$ a $100 \%$, no biofiltro preenchido com a espuma de poliuretano; de $98,6 \%$ a $100 \%$, no biofiltro preenchido com a fibra e coco; e de $98,9 \%$ a $100 \%$ no biofiltro preenchido com o bagaço de cana.

\subsubsection{Desempenho durante a Fase 2}

A segunda fase teve duração de 32 dias, caracterizada pela concentração média afluente de $\mathrm{H}_{2} \mathrm{~S}$ igual a 328 ppm e tempo de residência do gás em torno de $50 \mathrm{~s}$.

As concentrações afluentes, efluentes e a eficiência de remoção nos três biofiltros durante a segunda fase de operação podem ser visualizadas nas Figuras 5.19, 5.20 e 5.21. 


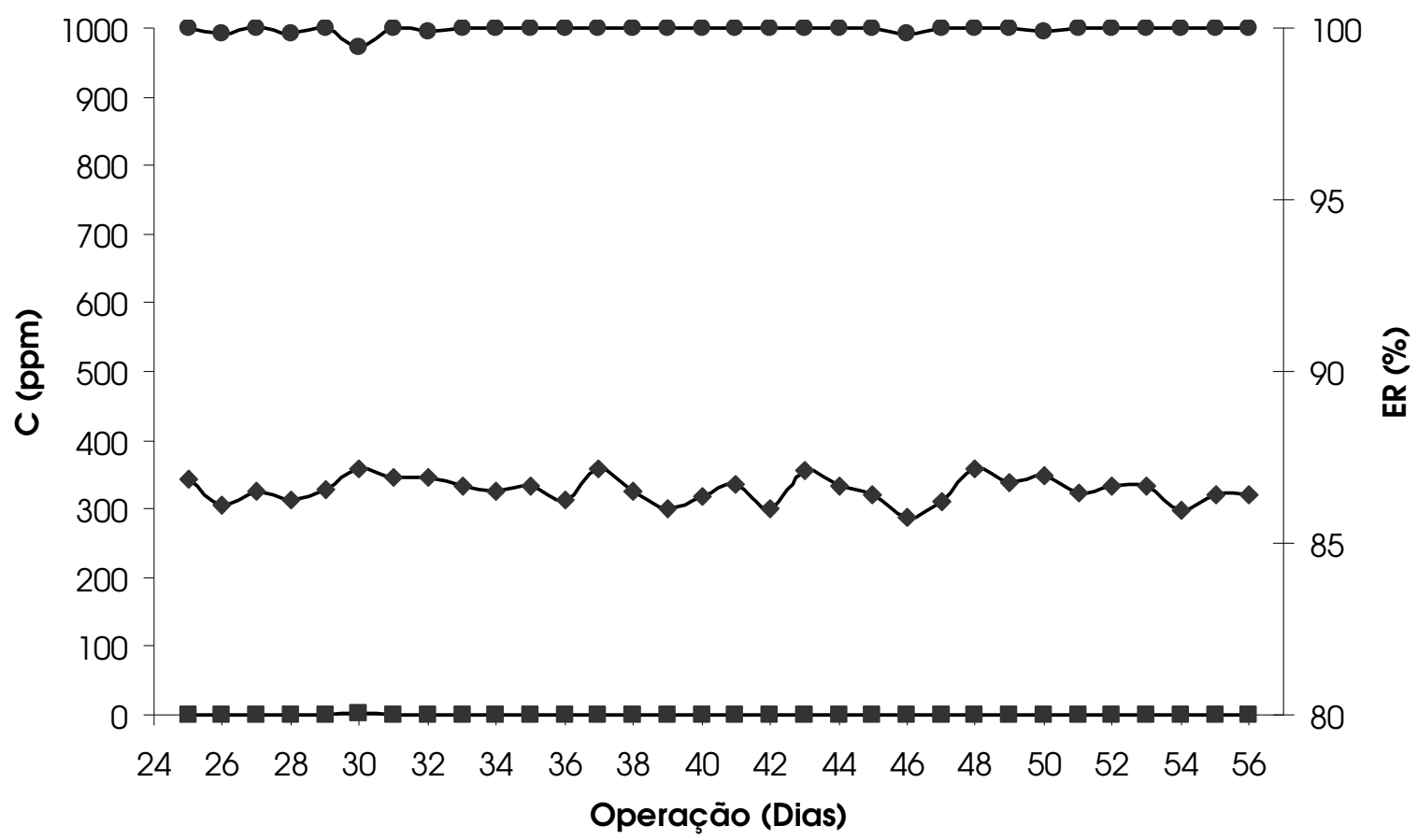

Figura 5.19: Concentração afluente ( $\bullet$ ), efluente $(\boldsymbol{\bullet})$ e eficiências de remoção $(\bullet)$ para o biofiltro preenchido com espuma de poliuretano, durante a segunda fase de operação.

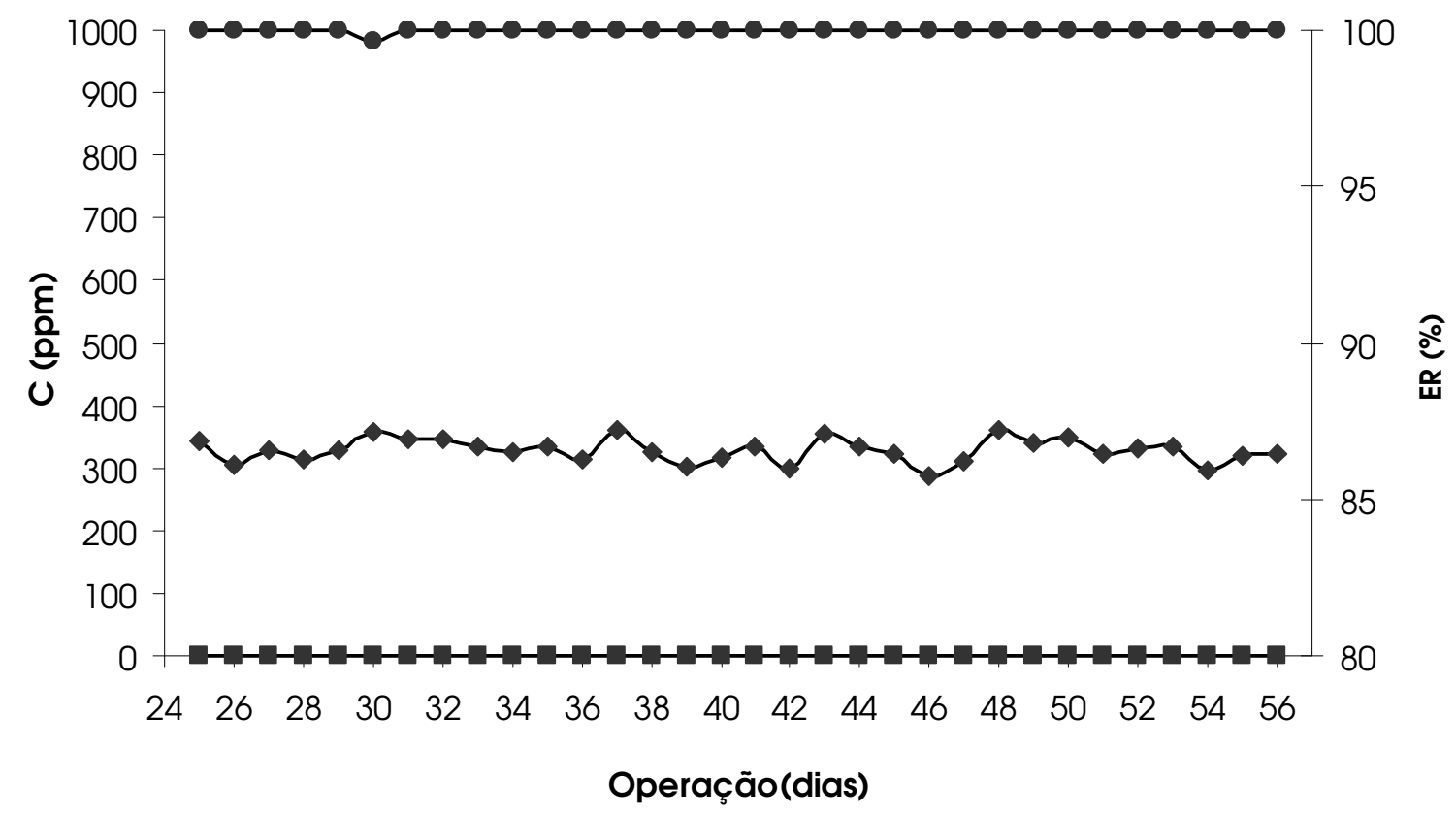

Figura 5.20: Concentração afluente ( $\bullet$, efluente $(\boldsymbol{\bullet})$ e eficiências de remoção $(\bullet)$ para o biofiltro preenchido com bagaço de cana, durante a segunda fase de operação. 


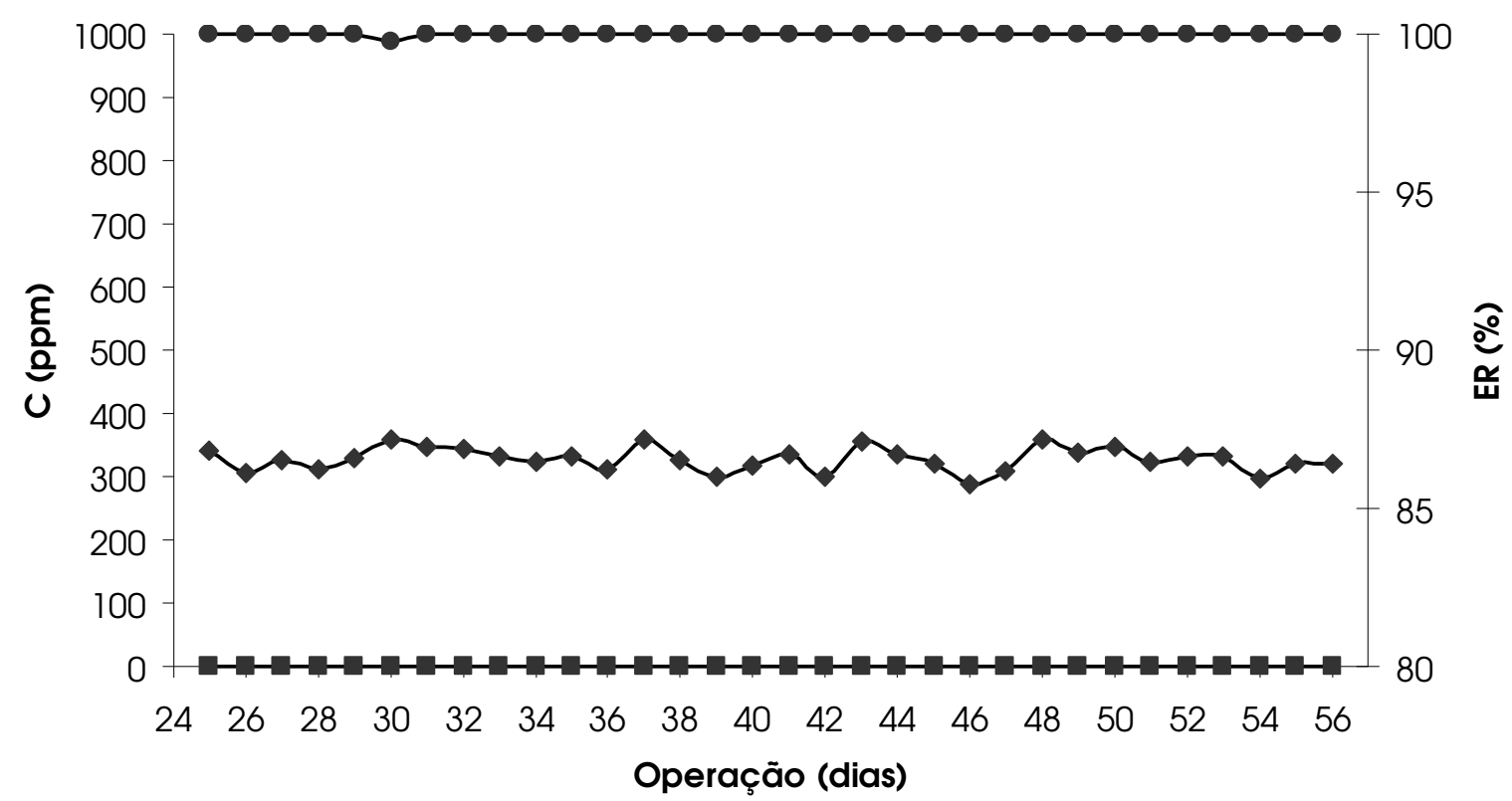

Figura 5.21: Concentração afluente ( $\bullet$ ), efluente $(\boldsymbol{\bullet})$ e eficiências de remoção $(\bullet)$ para o biofiltro preenchido com fibra de coco, durante a segunda fase de operação.

Na Tabela 5.11 podem ser verificados, com maior detalhamento, os resultados dos parâmetros visualizados nas Figuras 5.19, 5.20 e 5.21. 
Tabela 5.11 - Concentrações afluentes, efluentes e eficiências de remoção para os biofiltros preenchidos com espuma de poliuretano, fibra de coco e bagaço de cana para a fase 2 de operação do sistema

\begin{tabular}{|c|c|c|c|c|c|c|c|}
\hline \multirow{2}{*}{ DIA } & \multirow{2}{*}{$\begin{array}{c}\mathrm{C}_{0}\left(\mathrm{H}_{2} \mathrm{~S}\right) \\
(\mathrm{ppm})\end{array}$} & \multicolumn{2}{|c|}{$\begin{array}{l}\text { Espuma de } \\
\text { Poliuretano }\end{array}$} & \multicolumn{2}{|c|}{ Fibra de Coco } & \multicolumn{2}{|c|}{ Bagaço de cana } \\
\hline & & $\begin{array}{c}\mathrm{C} \\
(\mathrm{ppm})\end{array}$ & ER (\%) & $\begin{array}{c}\mathrm{C} \\
(\mathrm{ppm})\end{array}$ & ER (\%) & $\begin{array}{c}\mathrm{C} \\
(\mathrm{ppm})\end{array}$ & ER (\%) \\
\hline 25 & 342 & 0 & 100,0 & 0 & 100,0 & 0 & 100,0 \\
\hline 26 & 306 & 0 & 99,8 & 0 & 100,0 & 0 & 100,0 \\
\hline 27 & 327 & 0 & 100,0 & 0 & 100,0 & 0 & 100,0 \\
\hline 28 & 313 & 0 & 99,8 & 0 & 100,0 & 0 & 100,0 \\
\hline 29 & 329 & 0 & 100,0 & 0 & 100,0 & 0 & 100,0 \\
\hline 30 & 358 & 2 & 99,4 & 1 & 99,8 & 1 & 99,6 \\
\hline 31 & 347 & 0 & 100,0 & 0 & 100,0 & 0 & 100,0 \\
\hline 32 & 345 & 0 & 99,8 & 0 & 100,0 & 0 & 100,0 \\
\hline 33 & 333 & 0 & 100,0 & 0 & 100,0 & 0 & 100,0 \\
\hline 34 & 325 & 0 & 100,0 & 0 & 100,0 & 0 & 100,0 \\
\hline 35 & 333 & 0 & 100,0 & 0 & 100,0 & 0 & 100,0 \\
\hline 36 & 313 & 0 & 100,0 & 0 & 100,0 & 0 & 100,0 \\
\hline 37 & 360 & 0 & 100,0 & 0 & 100,0 & 0 & 100,0 \\
\hline 38 & 325 & 0 & 100,0 & 0 & 100,0 & 0 & 100,0 \\
\hline 39 & 301 & 0 & 100,0 & 0 & 100,0 & 0 & 100,0 \\
\hline 40 & 317 & 0 & 100,0 & 0 & 100,0 & 0 & 100,0 \\
\hline 41 & 335 & 0 & 100,0 & 0 & 100,0 & 0 & 100,0 \\
\hline 42 & 299 & 0 & 100,0 & 0 & 100,0 & 0 & 100,0 \\
\hline 43 & 356 & 0 & 100,0 & 0 & 100,0 & 0 & 100,0 \\
\hline 44 & 334 & 0 & 100,0 & 0 & 100,0 & 0 & 100,0 \\
\hline 45 & 321 & 0 & 100,0 & 0 & 100,0 & 0 & 100,0 \\
\hline 46 & 288 & 0 & 99,8 & 0 & 100,0 & 0 & 100,0 \\
\hline 47 & 309 & 0 & 100,0 & 0 & 100,0 & 0 & 100,0 \\
\hline 48 & 359 & 0 & 100,0 & 0 & 100,0 & 0 & 100,0 \\
\hline 49 & 339 & 0 & 100,0 & 0 & 100,0 & 0 & 100,0 \\
\hline 50 & 348 & 0 & 99,8 & 0 & 100,0 & 0 & 100,0 \\
\hline 51 & 322 & 0 & 100,0 & 0 & 100,0 & 0 & 100,0 \\
\hline 52 & 333 & 0 & 100,0 & 0 & 100,0 & 0 & 100,0 \\
\hline 53 & 334 & 0 & 100,0 & 0 & 100,0 & 0 & 100,0 \\
\hline 54 & 298 & 0 & 100,0 & 0 & 100,0 & 0 & 100,0 \\
\hline 55 & 321 & 0 & 100,0 & 0 & 100,0 & 0 & 100,0 \\
\hline 56 & 322 & 0 & 100,0 & 0 & 100,0 & 0 & 100,0 \\
\hline
\end{tabular}

Conforme pode ser observado na Tabela 5.11, na segunda fase, as concentrações afluentes aplicadas foram de 288 ppm (valor mínimo) até 360 ppm (valor máximo). A concentração média de entrada foi de aproximadamente 328 ppm e a eficiência de remoção esteve muito próxima aos 100\% em todos os sistemas.

Oyarzún et al. (2003), utilizando turfa e Thiobacillus thioparus, também atingiram eficiências de 100\% remoção de sulfeto, quando submeteram seu sistema a concentrações 
de entrada de 355 ppm de sulfeto, no entanto o tempo de residência do gás em leito vazio foi de quase 3 minutos, valor este mais de 3 vezes superior ao utilizado neste trabalho. Isto fica mais evidente quando se compara as taxas de carregamento mássicas aplicadas e as capacidades de eliminação obtidas pelos sistemas. Para que isto fique mais claro, estas variáveis serão abordadas em tópico posterior neste trabalho.

Tanto nas Figuras 5.19, 5.20 e 5.21 quanto na Tabela 5.11 é possivel notar que, mesmo após 56 dias de operação, os sistemas continuaram a apresentar a robustez verificada durante toda a fase inicial de operação, sendo possivel observar altas eficiências de remoção, com ligeiras oscilações de 99,4 \% a 100\%, no biofiltro preenchido com a espuma de poliuretano; de $99,9 \%$ a $100 \%$, no biofiltro preenchido com a fibra e coco; e de $98,6 \%$ a 100\% no biofiltro preenchido com o bagaço de cana.

\subsubsection{Desempenho durante a Fase 3}

A terceira fase de operação teve duração de 31 dias, caracterizada pela concentração média afluente de $\mathrm{H}_{2} \mathrm{~S}$ aproximada de 520 ppm e manutenção do tempo de residência do gás em torno de $50 \mathrm{~s}$.

As concentrações afluentes, efluentes e a eficiência de remoção nos três biofiltros durante a terceira fase de operação podem ser visualizadas nas Figuras 5.22, 5.23 e 5.24. 


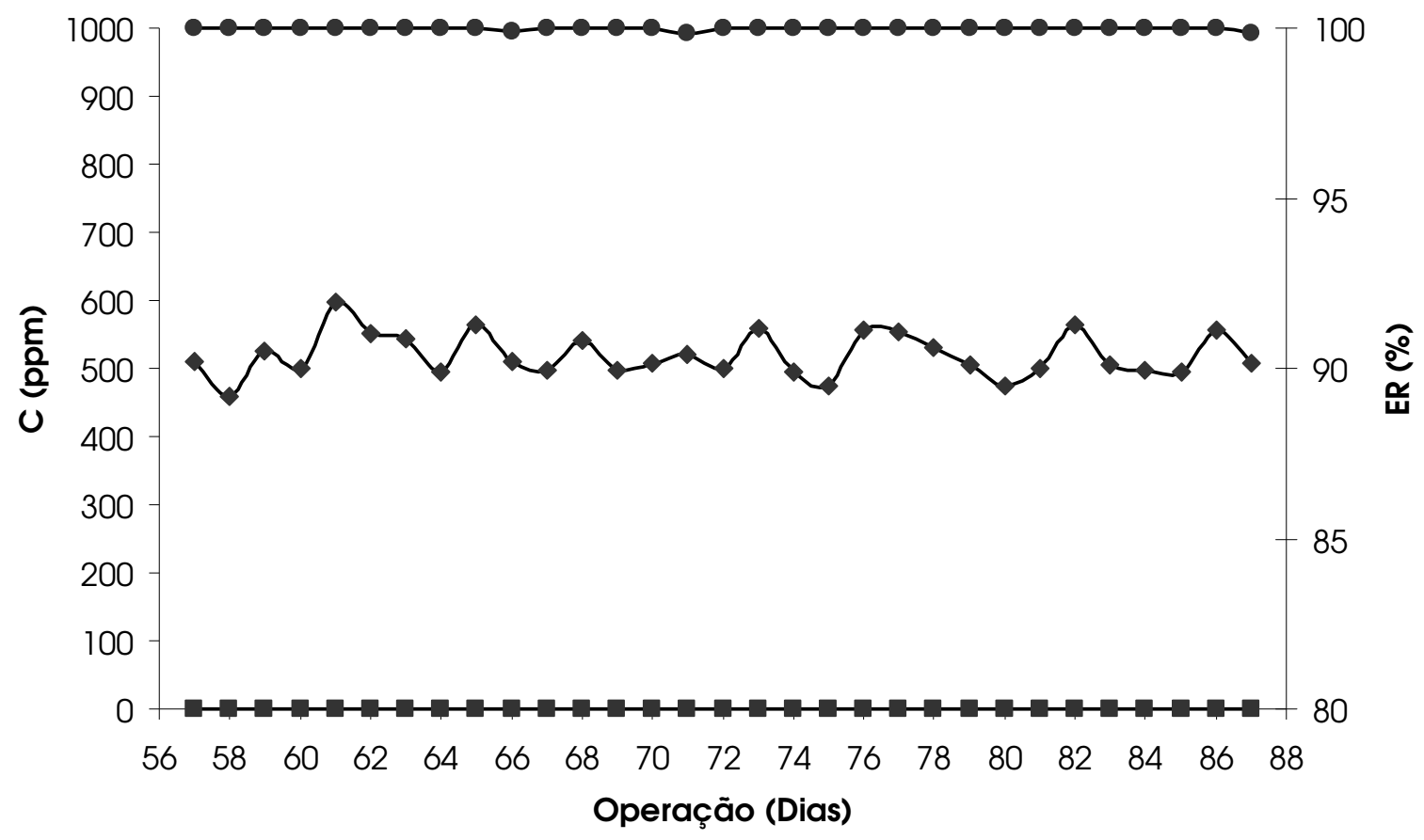

Figura 5.22: Concentração afluente $(\bullet)$, efluente $(\boldsymbol{\bullet})$ e eficiências de remoção $(\bullet)$ para o biofiltro preenchido com espuma de poliuretano, durante a terceira fase de operação.

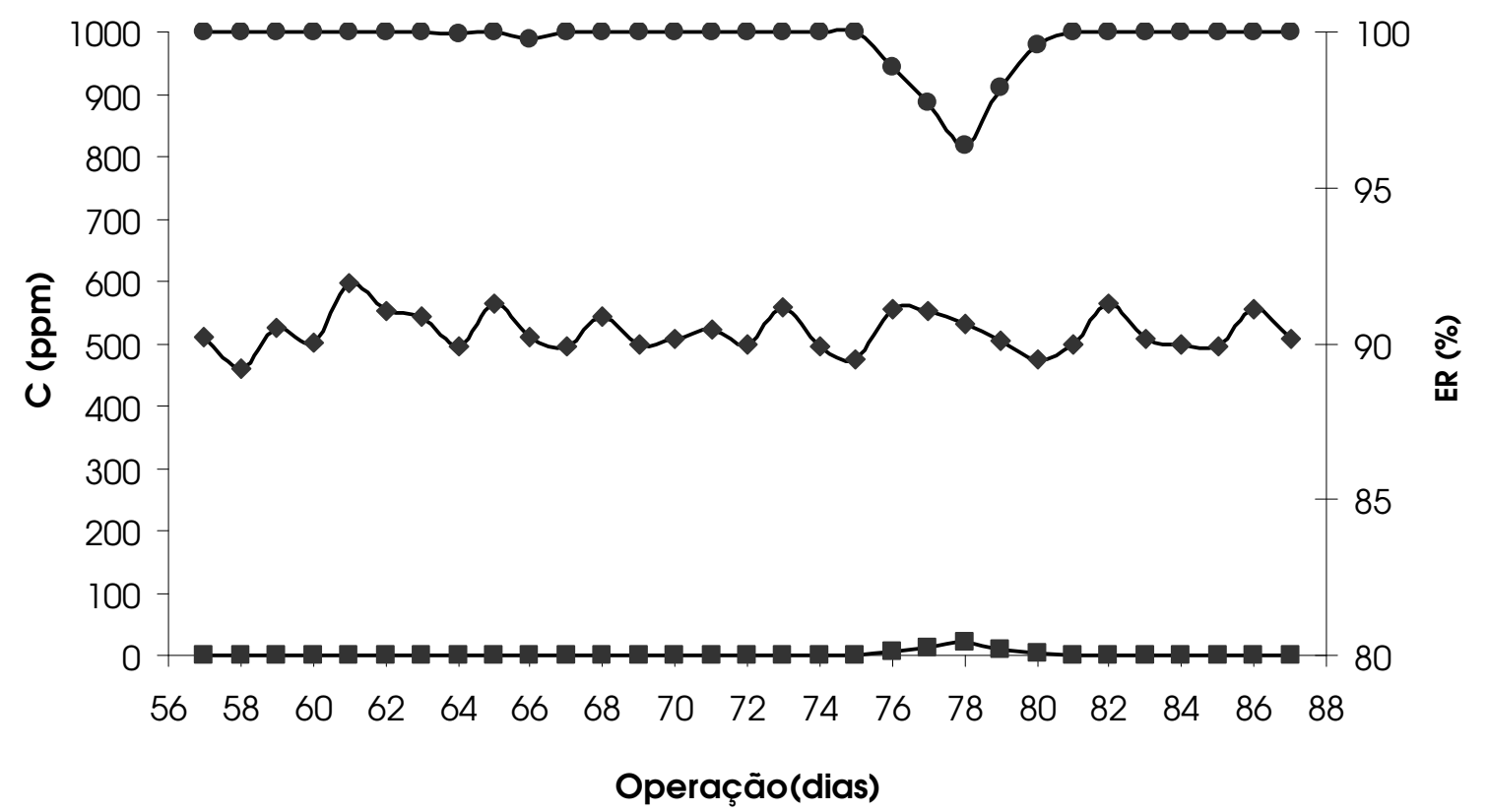

Figura 5.23: Concentração afluente ( $\bullet$ ), efluente $(\boldsymbol{\bullet})$ e eficiências de remoção $(\bullet)$ para o biofiltro preenchido com bagaço de cana, durante a terceira fase de operação. 


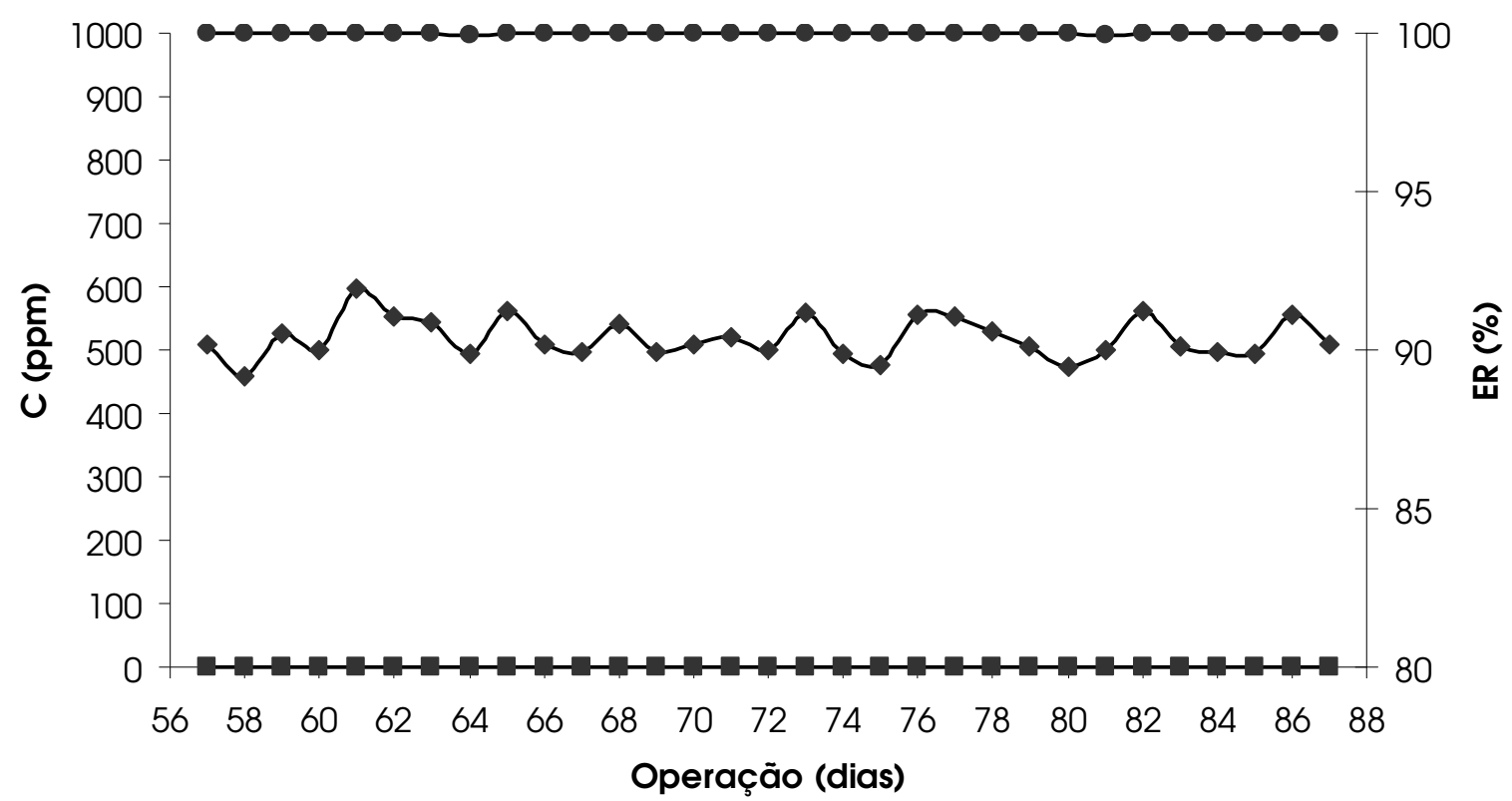

Figura 5.24: Concentração afluente ( $\bullet$ ), efluente $(\boldsymbol{\bullet})$ e eficiências de remoção $(\bullet)$ para o biofiltro preenchido com fibra e coco, durante a terceira fase de operação.

Na Tabela 5.12 podem ser verificados, com maior detalhamento, os resultados dos parâmetros visualizados nas Figuras 5.22, 5.23 e 5.24. 
Tabela 5.12 - Concentrações afluentes, efluentes e eficiências de remoção para os biofiltros preenchidos com espuma de poliuretano, fibra de coco e bagaço de cana para a fase 3 de operação do sistema

\begin{tabular}{|c|c|c|c|c|c|c|c|}
\hline \multirow[b]{2}{*}{ DIA } & \multirow{2}{*}{$\begin{array}{c}\mathrm{C}_{0}\left(\mathrm{H}_{2} \mathrm{~S}\right) \\
(\mathrm{ppm})\end{array}$} & \multicolumn{2}{|c|}{ Espuma de Poliuretano } & \multicolumn{2}{|c|}{ Fibra de Coco } & \multicolumn{2}{|c|}{ Bagaço de canc } \\
\hline & & $\begin{array}{c}\mathrm{C} \\
(\mathrm{ppm})\end{array}$ & ER (\%) & $\begin{array}{c}\mathrm{C} \\
(\mathrm{ppm})\end{array}$ & ER (\%) & $\begin{array}{c}\mathrm{C} \\
\text { (ppm) }\end{array}$ & ER (\%) \\
\hline 57 & 509 & 0 & 100,0 & 0 & 100,0 & 0 & 100,0 \\
\hline 58 & 459 & 0 & 100,0 & 0 & 100,0 & 0 & 100,0 \\
\hline 59 & 526 & 0 & 100,0 & 0 & 100,0 & 0 & 100,0 \\
\hline 60 & 501 & 0 & 100,0 & 0 & 100,0 & 0 & 100,0 \\
\hline 61 & 598 & 0 & 100,0 & 0 & 100,0 & 0 & 100,0 \\
\hline 62 & 551 & 0 & 100,0 & 0 & 100,0 & 0 & 100,0 \\
\hline 63 & 544 & 0 & 100,0 & 0 & 100,0 & 0 & 100,0 \\
\hline 64 & 495 & 0 & 100,0 & 0 & 99,9 & 0 & 99,9 \\
\hline 65 & 563 & 0 & 100,0 & 0 & 100,0 & 0 & 100,0 \\
\hline 66 & 509 & 0 & 99,9 & 0 & 100,0 & 1 & 99,8 \\
\hline 67 & 497 & 0 & 100,0 & 0 & 100,0 & 0 & 100,0 \\
\hline 68 & 542 & 0 & 100,0 & 0 & 100,0 & 0 & 100,0 \\
\hline 69 & 498 & 0 & 100,0 & 0 & 100,0 & 0 & 100,0 \\
\hline 70 & 508 & 0 & 100,0 & 0 & 100,0 & 0 & 100,0 \\
\hline 71 & 521 & 1 & 99,8 & 0 & 100,0 & 0 & 100,0 \\
\hline 72 & 499 & 0 & 100,0 & 0 & 100,0 & 0 & 100,0 \\
\hline 73 & 559 & 0 & 100,0 & 0 & 100,0 & 0 & 100,0 \\
\hline 74 & 496 & 0 & 100,0 & 0 & 100,0 & 0 & 100,0 \\
\hline 75 & 475 & 0 & 100,0 & 0 & 100,0 & 0 & 100,0 \\
\hline 76 & 556 & 0 & 100,0 & 0 & 100,0 & 6 & 98,9 \\
\hline 77 & 554 & 0 & 100,0 & 0 & 100,0 & 12 & 97,8 \\
\hline 78 & 531 & 0 & 100,0 & 0 & 100,0 & 19 & 96,3 \\
\hline 79 & 506 & 0 & 100,0 & 0 & 100,0 & 9 & 98,2 \\
\hline 80 & 473 & 0 & 100,0 & 0 & 100,0 & 2 & 99,6 \\
\hline 81 & 500 & 0 & 100,0 & 0 & 99,9 & 0 & 100,0 \\
\hline 82 & 563 & 0 & 100,0 & 0 & 100,0 & 0 & 100,0 \\
\hline 83 & 506 & 0 & 100,0 & 0 & 100,0 & 0 & 100,0 \\
\hline 84 & 498 & 0 & 100,0 & 0 & 100,0 & 0 & 100,0 \\
\hline 85 & 494 & 0 & 100,0 & 0 & 100,0 & 0 & 100,0 \\
\hline 86 & 556 & 0 & 100,0 & 0 & 100,0 & 0 & 100,0 \\
\hline 87 & 508 & 1 & 99,8 & 0 & 100,0 & 0 & 100,0 \\
\hline
\end{tabular}

Durante a terceira fase de operação, o biofiltro preenchido com bagaço de cana, que até então vinha atingindo $100 \%$ de remoção de sulfeto, apresentou quedas na eficiência para valores não observados até o momento, chegando ao $96,3 \%$ no $78^{\circ}$ dia. Entretanto, retornou ao patamar de $100 \%$ no $81^{\circ}$ dia, permanecendo assim até o final da fase 3. Como não foi verificada visualmente nenhuma anomalia no biofiltro ou oscilação brusca na concentração afluente e o pH não sofreu alteração considerável, somado ao 
fato de que o sistema voltou eliminar todo o sulfeto presente no fluxo gasoso afluente poucos dias depois, esta queda de eficiência pode ser atribuída a um possivel erro na coleta de amostras ou à própria metodologia utilizada na análise de sulfeto.

Em contrapartida, nota-se que os biofiltros preenchidos com fibra de coco e espuma de poliuretano mantiveram as eficiências obtidas na segunda fase de operação, apresentando eficiências muito próximas a 100\%.

Este ótimo resultado também foi obtido por Rocha (2007), que durante certo período de seu trabalho, aplicou concentrações de sulfeto que variaram de 412 a 594 ppm obtendo sempre eficiências de remoção de $100 \%$, até enfrentar o problema advindo do rompimento do biofiltro preenchido com espuma de poliuretano, que provocou esperada queda de eficiência no sistema, com seu posterior restabelecimento poucos dias depois.

\subsubsection{Desempenho durante a Fase 4}

A quarta fase de operação estendeu-se por 13 dias, caracterizada pela concentração média afluente de $\mathrm{H}_{2} \mathrm{~S}$ aproximada de 645 ppm e manutenção do tempo de residência do gás em torno de $50 \mathrm{~s}$.

As concentrações afluentes, efluentes e a eficiência de remoção nos três biofiltros durante a terceira fase de operação podem ser visualizadas nas Figuras 5.25, 5.26 e 5.27. 


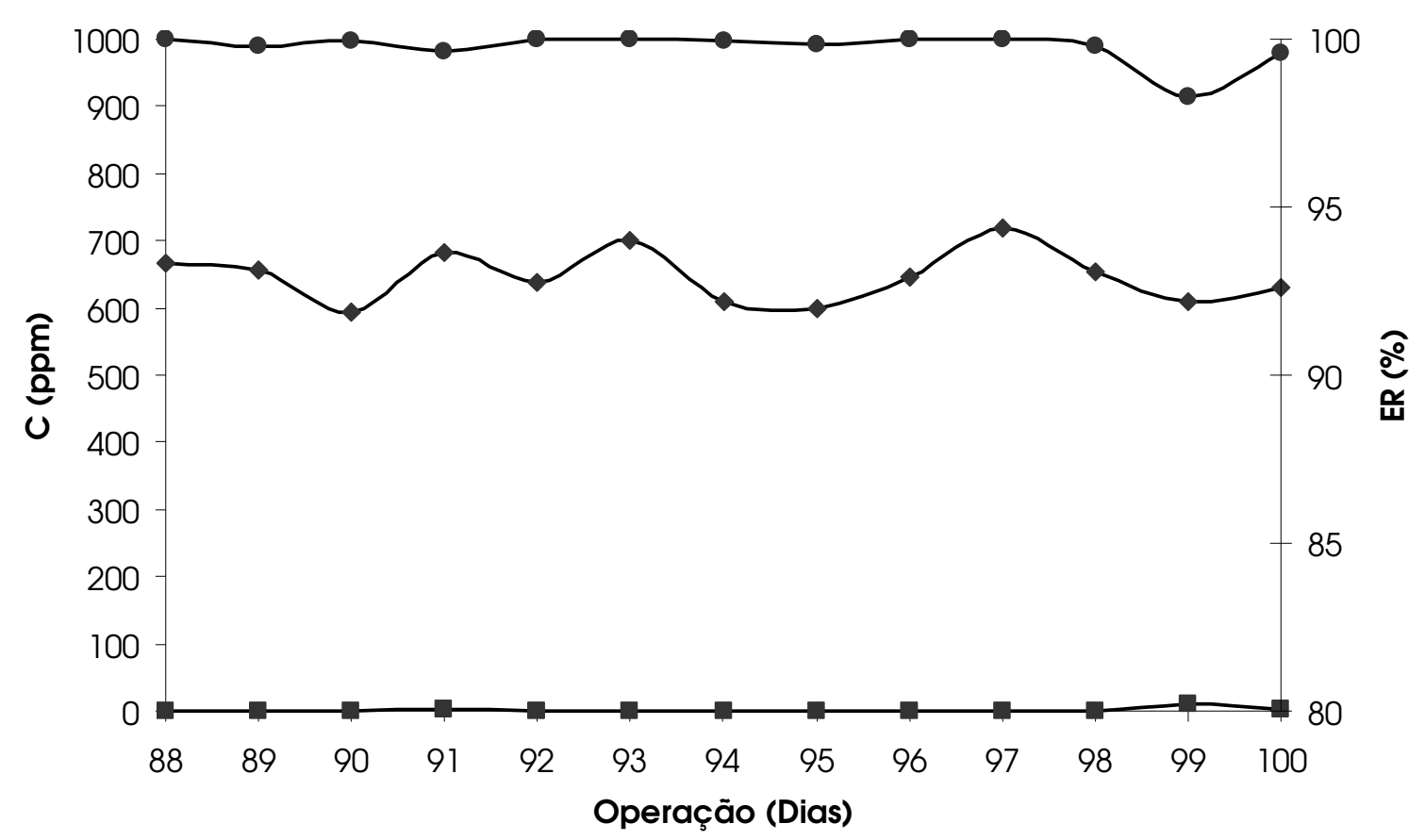

Figura 5.25: Concentração afluente ( $\bullet$ ), efluente $(\bullet)$ e eficiências de remoção $(\bullet)$ para o biofiltro preenchido com espuma de poliuretano, durante a quarta fase de operação.

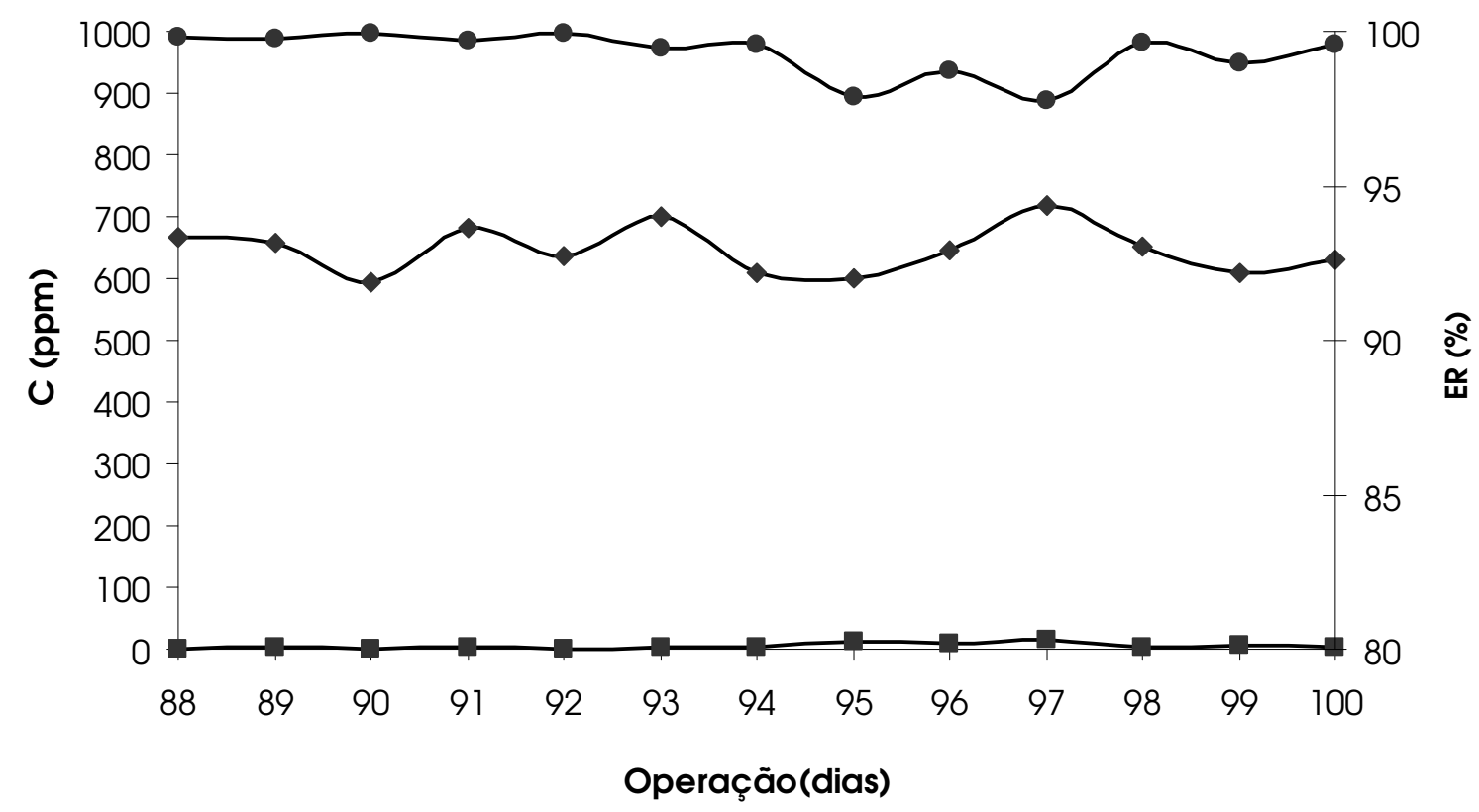

Figura 5.26: Concentração afluente $(\bullet)$, efluente $(\boldsymbol{\bullet})$ e eficiências de remoção $(\bullet)$ para o biofiltro preenchido com bagaço de cana, durante a quarta fase de operação. 


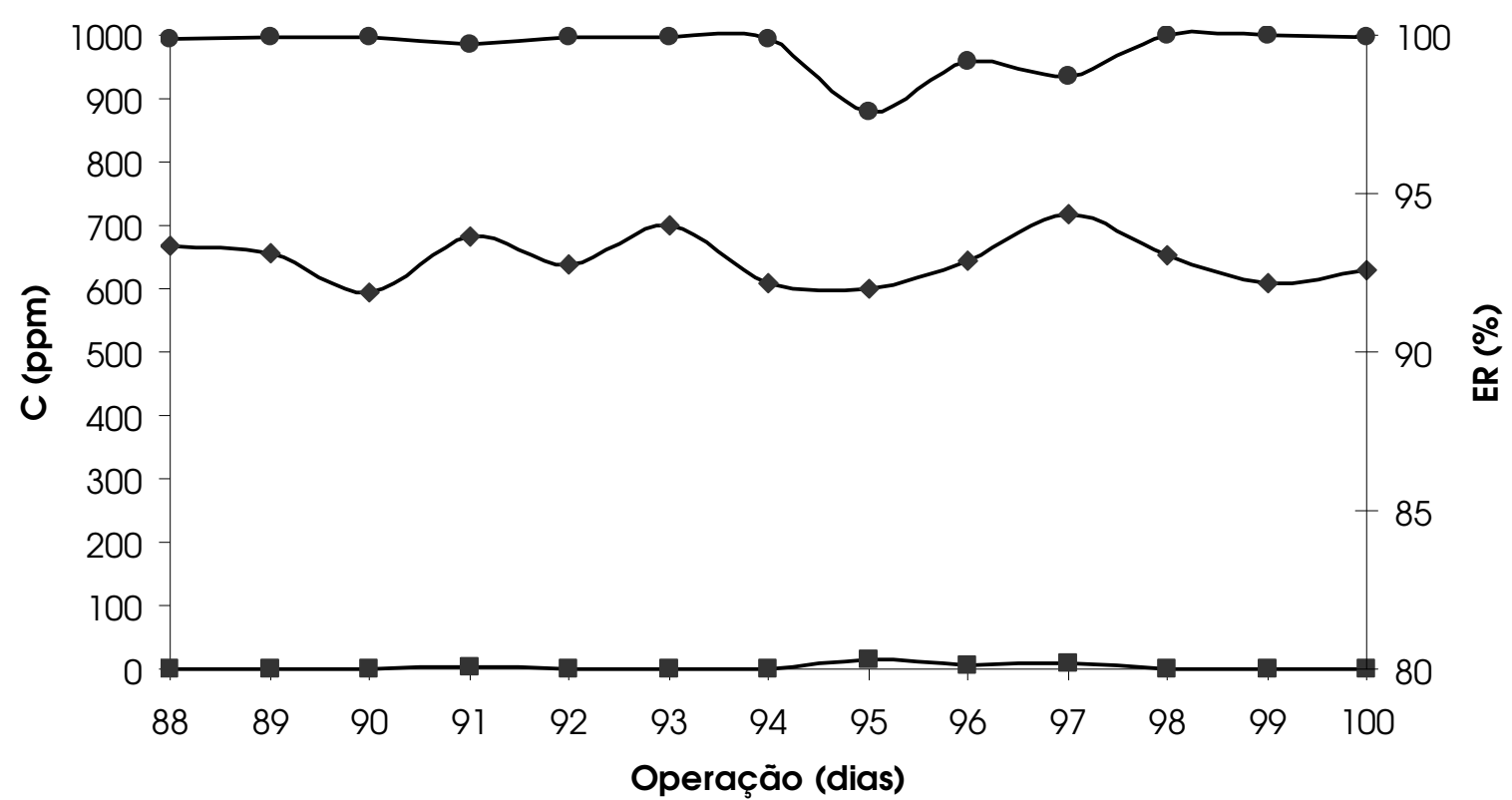

Figura 5.27: Concentração afluente $(\bullet)$, efluente $(\boldsymbol{\bullet})$ e eficiências de remoção $(\bullet)$ para o biofiltro preenchido com fibra do coco, durante a quarta fase de operação.

Na Tabela 5.13 podem ser verificados, com maior detalhamento, os resultados dos parâmetros visualizados nas Figuras 5.25, 5.26 e 5.27. 
Tabela 5.13 - Concentrações afluentes, efluentes e eficiências de remoção para os biofiltros preenchidos com espuma de poliuretano, fibra de coco e bagaço de cana para a fase 4 de operação do sistema

\begin{tabular}{cccccccc}
\hline & & \multicolumn{2}{c}{$\begin{array}{c}\text { Espuma de } \\
\text { Poliuretano }\end{array}$} & \multicolumn{2}{c}{ Fibra de Coco } & \multicolumn{2}{c}{ Bagaço de cana } \\
\cline { 3 - 8 } DIA & $\begin{array}{c}\mathrm{C}_{0}\left(\mathrm{H}_{2} \mathrm{~S}\right) \\
\mathrm{ppm}\end{array}$ & $\mathrm{C}(\mathrm{ppm})$ & $\mathrm{ER}(\%)$ & $\begin{array}{c}\mathrm{C} \\
(\mathrm{ppm})\end{array}$ & $\mathrm{ER}(\%)$ & $\begin{array}{c}\mathrm{C} \\
(\mathrm{ppm})\end{array}$ & $\mathrm{ER}(\%)$ \\
\hline 88 & 666 & 0 & 100,0 & 1 & 99,9 & 1 & 99,8 \\
89 & 657 & 1 & 99,8 & 0 & 99,9 & 2 & 99,7 \\
90 & 595 & 0 & 99,9 & 0 & 99,9 & 0 & 99,9 \\
91 & 683 & 2 & 99,6 & 2 & 99,7 & 2 & 99,7 \\
92 & 638 & 0 & 100,0 & 0 & 99,9 & 0 & 99,9 \\
93 & 701 & 0 & 100,0 & 0 & 99,9 & 4 & 99,5 \\
94 & 610 & 0 & 99,9 & 1 & 99,9 & 2 & 99,6 \\
95 & 600 & 1 & 99,9 & 14 & 97,6 & 13 & 97,9 \\
96 & 645 & 0 & 100,0 & 5 & 99,2 & 8 & 98,7 \\
97 & 719 & 0 & 100,0 & 9 & 98,7 & 16 & 97,7 \\
98 & 653 & 1 & 99,8 & 0 & 100,0 & 2 & 99,6 \\
99 & 610 & 10 & 98,3 & 0 & 100,0 & 6 & 98,9 \\
100 & 629 & 2 & 99,6 & 0 & 99,9 & 2 & 99,6 \\
\hline
\end{tabular}

Rocha (2007), na quinta fase de operação, concentração média de $\mathrm{H}_{2} \mathrm{~S}$ afluente igual a 536 ppm, de seu biofiltro preenchido com espuma de poliuretano, atingiu eficiência de 100\%. Park at al. (2002) também obteve $100 \%$ de eficiência de remoção de $\mathrm{H}_{2} \mathrm{~S}$, utilizando cultura pura de Thiobacillus imobilizados em alginato de cálcio, para concentrações em torno de 600 ppm.

No decorrer da quarta fase de operação, de acordo com a Tabela 5.13 e os gráficos das Figuras 5.25, 5.26 e 5.27, é possível verificar que os biofiltros continuaram mantendo boa eficiência observada nas fases anteriores, atingindo valores de 100\%. No $99^{\circ}$ dia, o biofiltro preenchido com espuma de poliuretano registrou sua menor eficiência, com 98,2\% de remoção; no $95^{\circ}$ dia, o biofiltro preenchido com fibra de coco chegou ao mínimo de 97,6\%; e o biofiltro preenchido com bagaço de cana removeu $97,7 \%$ de sulfeto no $97^{\circ}$ dia. No entanto, cabe ressaltar que estes valores ainda são altamente satisfatórios, visto que a concentração a que os sistemas foram submetidos foi substancialmente alta, com picos de 719 ppm. 


\subsection{TAXA DE CARREGAMENTO MÁSSICO}

A taxa de carregamento mássico é uma importante variável para o projeto de biofiltros, pois relaciona a concentração do poluente e seu tempo de passagem pelo leito filtrante, permitindo, então, que se possa avaliar o real desempenho desses sistemas.

Durante os 100 dias de operação, as mudanças nas taxas de carregamento se deram exclusivamente pelo aumento gradativo da concentração de entrada de $\mathrm{H}_{2} \mathrm{~S}$, visto que o tempo de retenção do gás em leito vazio foi considerado constante ao longo do experimento, a despeito das diferentes porosidades de cada meio suporte.

Na Figura 5.28, pode ser verificada a evolução da taxa de carregamento mássico e da eficiência de remoção durante a operação nos três biofiltros.

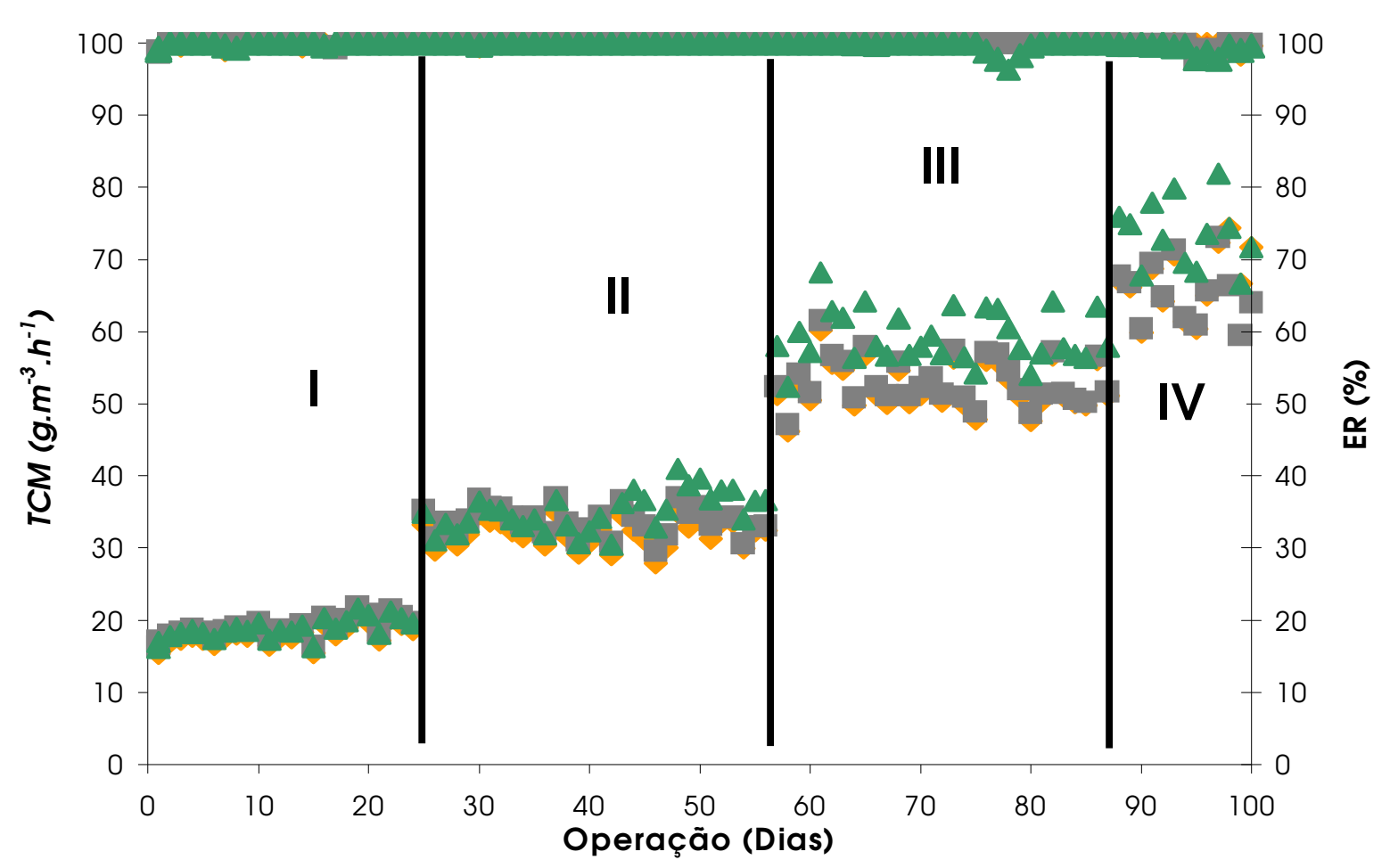

Figura 5.28: Taxas de carregamento mássico e eficiência de remoção para os biofiltros preenchidos com espuma de poliuretano ( $($ ), fibra de coco $(\square)$ e bagaço de cana $(\boldsymbol{\Delta})$.

Durante cada aumento na taxa de carregamento média relativas às fases 2 (19 para $32 \mathrm{~g} \mathrm{H}_{2} \mathrm{~S} \cdot \mathrm{m}^{-3} \cdot \mathrm{h}^{-1}$ ), 3 (32 para $52 \mathrm{~g} \mathrm{H}_{2} \mathrm{~S} \cdot \mathrm{m}^{-3} \cdot \mathrm{h}^{-1}$ ) e 4 de operação (52 para $70 \mathrm{~g} \mathrm{H}_{2} \mathrm{~S} \cdot \mathrm{m}^{-3} \cdot \mathrm{h}^{-1}$ ), 
percebeu-se que os biofiltros prontamente adaptaram-se às novas condições, não sendo observada nenhuma oscilação nas concentrações efluentes. Durante toda a operação, o biofiltros preenchidos com espuma de poliuretano e fibra de coco atingiram patamares máximos, próximos à $75 \mathrm{~g} \mathrm{H}_{2} \mathrm{~S} \cdot \mathrm{m}^{-3} \cdot \mathrm{h}^{-1}$ e o biofiltro preenchido com bagaço de cana alcançou quase $80 \mathrm{gH}_{2} \mathrm{~S} \cdot \mathrm{m}^{-3} \cdot \mathrm{h}^{-1}$.Conseqüentemente, fica claro, para este estudo, que os microrganismos são aptos a degradar o sulfeto de hidrogênio até concentrações aproximadas de $80 \mathrm{gH}_{2} \mathrm{~S} \cdot \mathrm{m}^{-3} \cdot \mathrm{h}^{-1}$.

Elias et al. (2002) afirma que a taxa de carregamento de $45 \mathrm{~g} \mathrm{H}_{2} \mathrm{~S} \cdot \mathrm{m}^{-3} \cdot \mathrm{h}^{-1}$ é um valor típico em muitas emissões industriais, o que significa que as taxas a que os três biofiltros foram submetidos durante a pesquisa foram consideráveis, pois superaram com folga este valor.

O biofiltro preenchido com bagaço de cana foi exceção no tocante à eficiência de remoção, pois a partir do $76^{\circ}$ de operação, começou a experimentar breve e ligeiro decréscimo de eficiência, com queda de 100\% para 96,34\%, com recuperação para 100\% novamente no $81^{\circ}$ de operação. Os outros dois biofiltros permaneceram removendo praticamente todo o $\mathrm{H}_{2} \mathrm{~S}$ afluente.

De qualquer forma, as taxas de carregamento obtidas no trabalho foram superiores àquelas verificadas por Kim, René e Park (2007), que estudando um biofiltro preenchido com material suporte que chamaram de "biomeio", encapsulado por alginato de sódio e álcool polivinil (PVA), obtiveram taxa de carregamento máxima de $13 \mathrm{~g} \mathrm{H}_{2} \mathrm{~S} \cdot \mathrm{m}^{-3} \cdot \mathrm{h}^{-1}$. Os autores reportaram que a cada aumento na taxa de carregamento, o sistema apresentou queda na eficiência de remoção e requerendo alguns dias para o retorno aos valores de eficiência de $100 \%$. Isto não aconteceu neste trabalho.

Chung, Huang e Tseng (1996), trabalhando com cultura de Thiobacillus imobilizada em alginato de cálcio, apontaram como taxa de carregamento ótima para o sistema como sendo de $25 \mathrm{~g} \mathrm{H}_{2} \mathrm{~S} \cdot \mathrm{m}^{-3} \cdot \mathrm{h}^{-1}$, para qual as eficiências de remoção foram superiores a 98\%. Elias et al. (2002), que utilizaram esterco de porco e serragem como materiais suporte, variaram as taxas de carregamento de 10 para $45 \mathrm{~g} \mathrm{H}_{2} \mathrm{~S} \cdot \mathrm{m}^{-3} \cdot \mathrm{h}^{-1}$, reportando que as eficiências de remoção mantiveram sempre acima dos $90 \%$. 


\subsection{CAPACIDADE DE ELIMINAÇÃO}

O desempenho durante a operação de longo prazo dos biofiltros preenchidos com espuma de poliuretano, bagaço de cana e fibra de coco está apresentado na forma de capacidade de eliminação como função da concentração afluente (Figura 5.29) e da taxa de carregamento mássico aplicada.

A importância de se verificar a capacidade de eliminação de biofiltros reside no fato de que se trata de um parâmetro crucial na análise desses reatores, por isso é utilizada para comparar o desempenho de diferentes sistemas de controles de gases.

Na Figura 5.29 é apresentada a capacidade de eliminação dos biofiltros como função da concentração de entrada de $\mathrm{H}_{2} \mathrm{~S}$ :

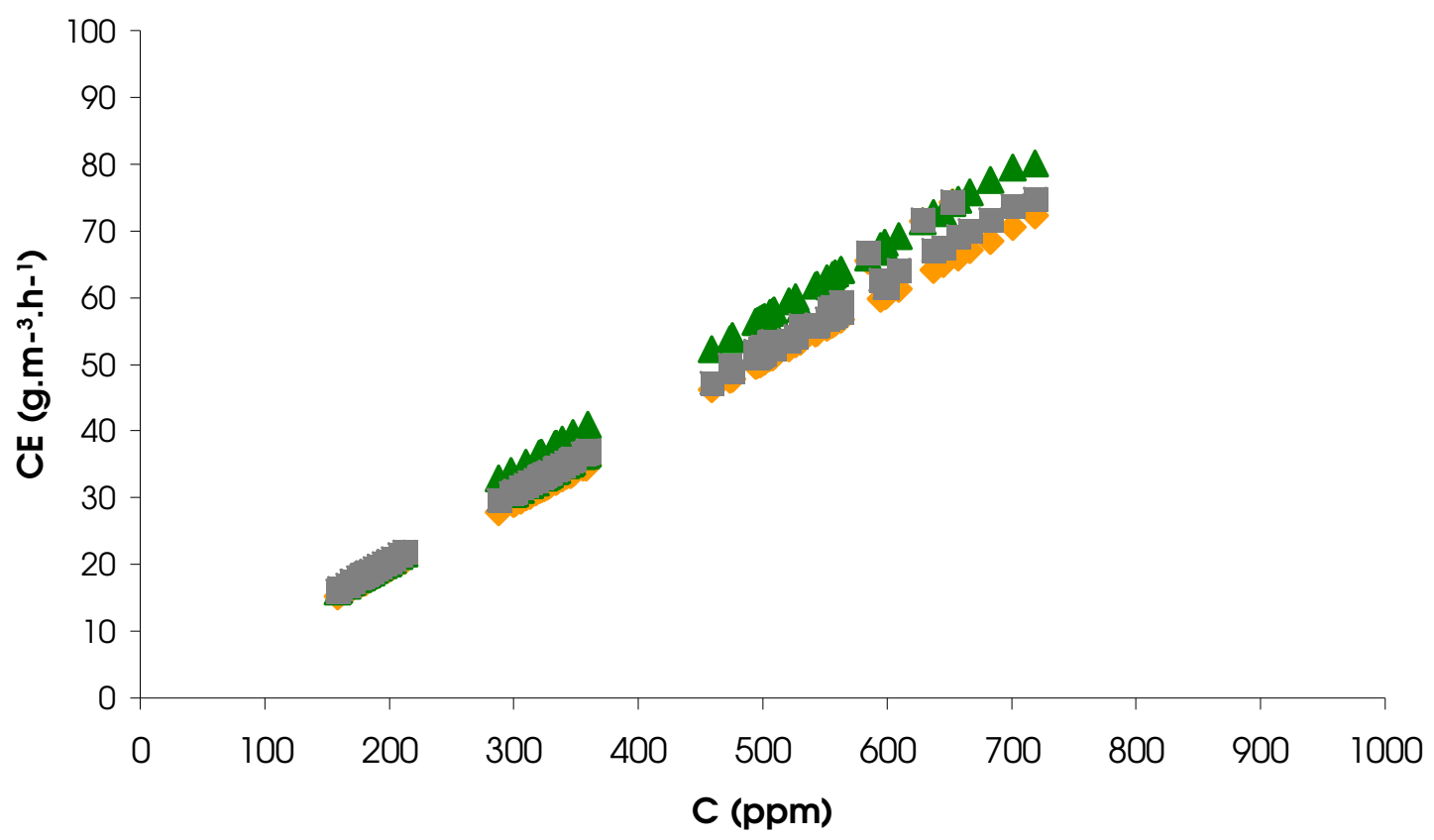

Figura 5.29: Capacidade de eliminação (CE) como função da concentração afluente (C) de $\mathrm{H}_{2} \mathrm{~S}$ para os para os biofiltros preenchidos com espuma de poliuretano ( $\diamond$ ), fibra de coco $(\square)$ e bagaço de cana ( $\boldsymbol{\Delta})$.

Os valores de capacidades de eliminação são determinados experimentalmente, sendo usualmente relacionados como uma função da taxa de carregamento, por 
promover uma análise mais efetiva. Relações essencialmente lineares entre a capacidade de eliminação e taxa de carregamento têm sido observadas no tratamento de sulfeto de hidrogênio e outros compostos odorosos.

Por esse motivo, na Figura 5.30 é apresentada a capacidade eliminação como função da taxa de carregamento de $\mathrm{H}_{2} \mathrm{~S}$.

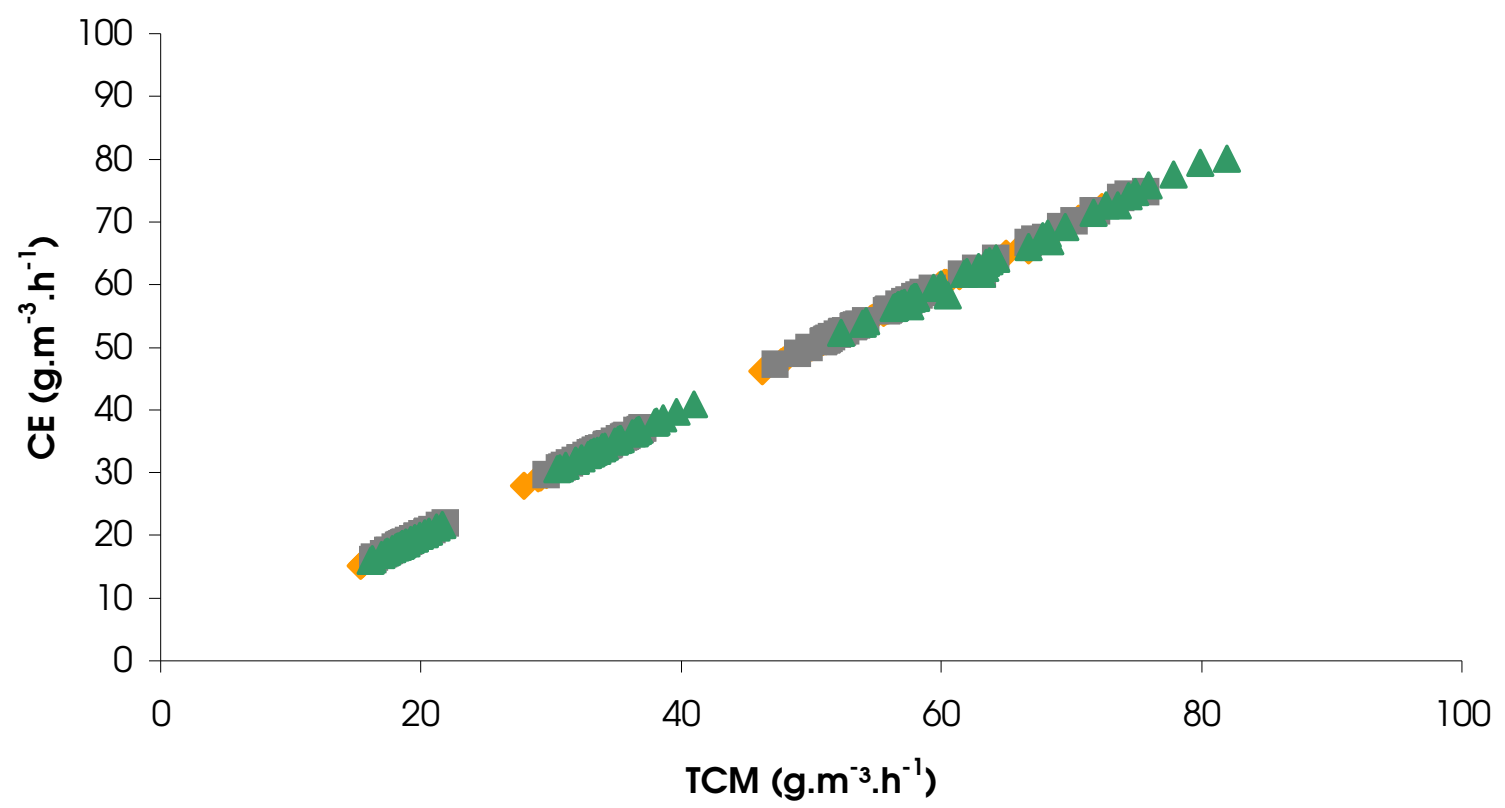

Figura 5.30: Capacidade de eliminação como função da taxa de carregamento mássico de $\mathrm{H}_{2} \mathrm{~S}$ para os biofiltros preenchidos com espuma de poliuretano ( () , fibra de coco ( $\square$ ) e bagaço de cana $(\boldsymbol{\Delta})$

As Figuras 5.29 e 5.30 seguem a mesma tendência linear. Como os biofiltros apresentaram estáveis ao final da operação, pode-se afirmar que a capacidade total de eliminação não foi alcançada.

Durante a pesquisa, foram obtidas capacidades de eliminação máximas de 74, 79 e $75 \mathrm{gH}_{2} \mathrm{~S} \mathrm{~m}^{-3} \cdot \mathrm{h}^{-1}$ e médias de 66, 73 e $68 \mathrm{gH}_{2} \mathrm{~S} \mathrm{~m} \mathrm{~m}^{-3} \cdot \mathrm{h}^{-1}$ para os biofiltros preenchidos com espuma de poliuretano, bagaço de cana e fibra de coco, respectivamente.

Essas diferenças de capacidade de eliminação, tanto nos valores médios quanto nos máximo devem-se, fundamentalmente, às diferentes alturas úteis de leito verificadas nos três sistemas em função do rebaixo dos leitos nos três biofiltros. 
Os valores atingidos no trabalho foram superiores aos encontradas nos seguintes trabalhos que utilizaram a turfa como meio suporte (material mais utilizado em estudos deste tipo): Hirai, Ohtake e Shoda (1990), obtiveram 25 g.m-3.h-1; Zhang, Hirai e Shoda (1991), com diferentes tipos de inóculo, atingiram valores de 15 e 30 g.m-3.h-1; Cho, Hirai e Shoda. (1991), que obtiveram $50 \mathrm{~g} \cdot \mathrm{m}^{-3} \cdot \mathrm{h}^{-1}$; e Oyarzún et al. (2003), que obtiveram valores máximos de 55 $g \cdot m^{-3} \cdot h^{-1}$

Outros trabalhos foram realizados utilizando outros materiais de preenchimento do leito, como os de Chung, Huang e Tseng (1996) que atingiu valores máximos de $33 \mathrm{~g} \cdot \mathrm{m}^{-3} \cdot \mathrm{h}^{-1}$, utilizando alginato de cálcio; Elias et al. (2002), que utilizaram pellets de estrume e serragem, trataram até $45 \mathrm{~g} \cdot \mathrm{m}^{-3} \cdot \mathrm{h}^{-1}$; e Malhautier et al. (2003), utilizando lodo desidratado, atingiram valores de $28 \mathrm{~g} \cdot \mathrm{m}^{-3} \cdot \mathrm{h}^{-1}$. Mesmo estas pesquisas atingiram valores de capacidade de eliminação inferiores aos durante este trabalho.

Na Tabela 5.14 é apresentado um resumo dos trabalhos realizados em biofiltração com as máximas capacidades de eliminação encontradas e os microrganismos utilizados como inoculo. 
Tabela 5.14 - Capacidades de eliminação verificadas na literatura

\begin{tabular}{|c|c|c|c|}
\hline Autor & $\begin{array}{c}\mathrm{EC} \\
\left(\mathrm{gH}_{2} \mathrm{~S} \cdot \mathrm{m}^{-3} \cdot \mathrm{h}^{-1}\right)\end{array}$ & Suporte & Inóculo \\
\hline Hirai et al. (1990) & 25 & Turfa & Resíduo sólido \\
\hline Zang et al. (1991) & 30 & Turfa & Resíduo sólido \\
\hline Zang et al. (1991) & 15 & Turfa & Thiobacillus thioparus \\
\hline Cho et al. (1991) & 50 & Turfa & Thiobacillus HA 43 \\
\hline Cho et al. (1992a) & 25 & Turfa & $\begin{array}{c}\text { Thiobacillus thioparus } \\
\text { DW } 44\end{array}$ \\
\hline Cho et al. (1992b) & 14 & Turfa & Xantomonas DY 44 \\
\hline Yang \& Allen (1994) & 130 & composto & Não utilizou \\
\hline Chung et al. (1996) & 33 & Alginato de cálcio & Thiobacillus thioparus \\
\hline Li et al. (1998) & 63 & Fibra plástica & Lodo ativado \\
\hline Elias et al. (2002) & 45 & $\begin{array}{c}\text { Pellets de estrume de } \\
\text { porco e serragem }\end{array}$ & Não utilizou \\
\hline Oyarzún et al. (2003) & 55 & Turfa & Thiobacillus thioparus \\
\hline $\begin{array}{l}\text { Malhautier et al. } \\
\qquad(2003)\end{array}$ & 28 & $\begin{array}{l}\text { Lodo desidratado } \\
\text { proveniente de ETE }\end{array}$ & Lodo ativado \\
\hline Lee et. al. (2005) & 815 & $\begin{array}{l}\text { Partículas de } \\
\text { cerâmica }\end{array}$ & $\begin{array}{l}\text { Acidithiobacillus } \\
\text { thiooxidans TAS }\end{array}$ \\
\hline Lee et al. (2006) & 670 & Cerâmica porosa & $\begin{array}{l}\text { Acidithiobacillus } \\
\text { thiooxidans AZ } 11\end{array}$ \\
\hline Duan et al. (2006) & 181 & $\begin{array}{l}\text { Carvão ativado } \\
\text { biológico }\end{array}$ & $\begin{array}{c}\text { Acidithiobacillus } \\
\text { thiooxidans }\end{array}$ \\
\hline Rocha (2007) & 155 & $\begin{array}{l}\text { Espuma de } \\
\text { poliuretano }\end{array}$ & Lodo ativado \\
\hline Este trabalho & $74 / 79 / 75$ & $\begin{array}{c}\text { Espuma de } \\
\text { Poliuretano / Bagaço } \\
\text { de Cana / Fibra de } \\
\text { coco }\end{array}$ & $\begin{array}{l}\text { Mistura de Lodo } \\
\text { ativado e Biofiltro } \\
\text { Aerado Submerso }\end{array}$ \\
\hline
\end{tabular}




\subsection{PERFIL DE DEGRADAÇÃO DO SULFETO AO LONGO DO LEITO}

O ensaio do perfil de degradação espacial, em biofiltros, tem grande importância, pois permite uma melhor compreensão da maneira como o sulfeto é consumido ao longo do meio filtrante.

Por isso, foram realizados ensaios nos quais foram coletadas amostras das correntes gasosas, em diferentes alturas do leito por meio de 7 pontos de coleta de amostras instalados a partir da base dos reatores, no seguintes dias de operação:

- biofiltro preenchido com a espuma de poliuretano (dia 16, correspondente à primeira fase de operação; dia 31, correspondente à segunda fase; dia 72, correspondente a terceira fase de operação; e dia 98, durante a quarta fase de operação);

- biofiltro preenchido com bagaço de cana (dia 17, correspondente à primeira fase de operação; dia 32, correspondente à segunda fase; dia 73, correspondente a terceira fase de operação; e dia 99, durante a quarta fase de operação);

- biofiltro preenchido com fibra de coco (dia 18, correspondente à primeira fase de operação; dia 33, correspondente à segunda fase; dia 74, correspondente a terceira fase de operação; e dia 100, na quarta fase de operação).

Nas Figuras 5.31, 5.32, 5.33 e 5.34 são apresentados os resultados referentes aos ensaios realizados: 
- Perfis de degradação relativos à primeira fase de operação:
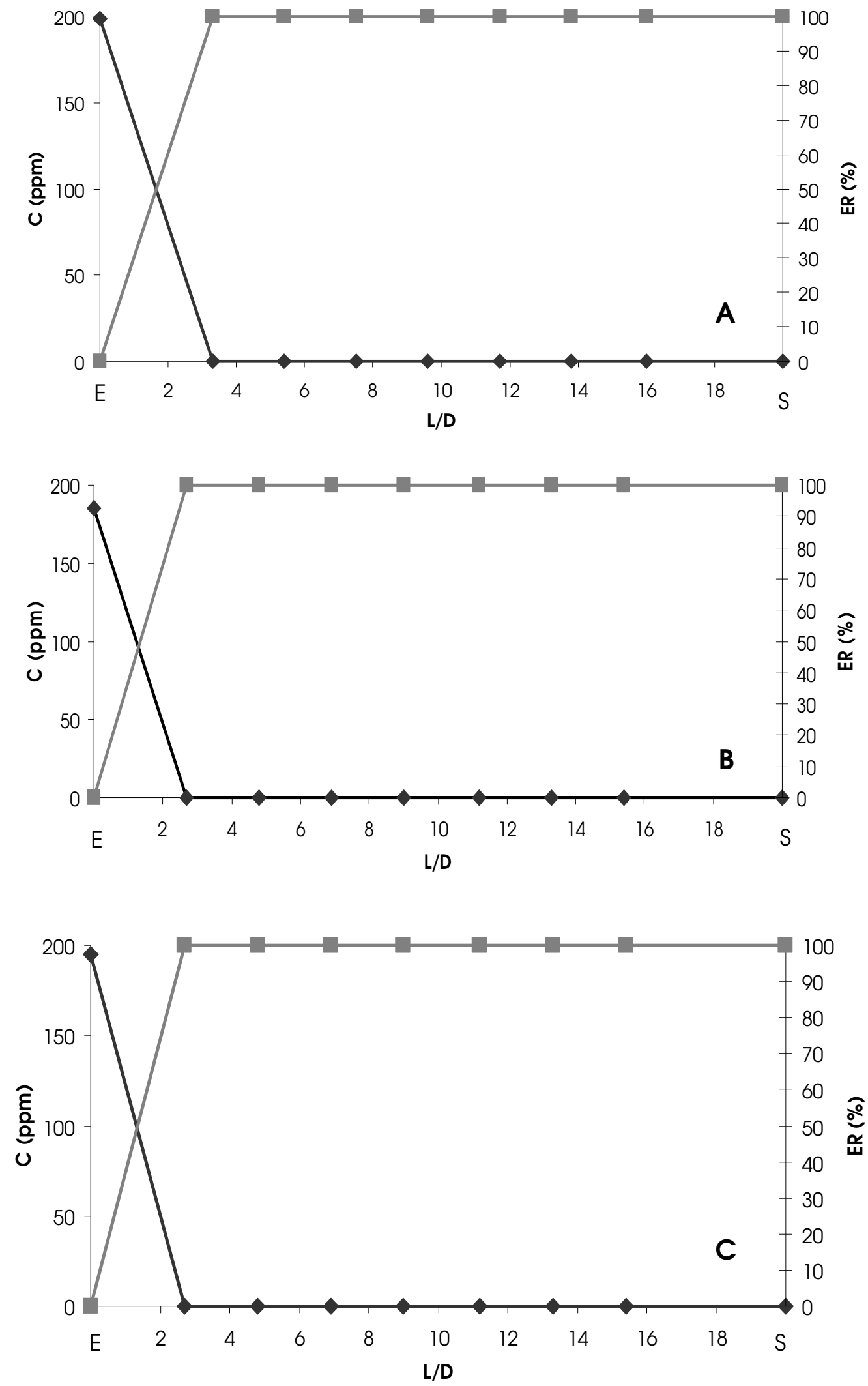

Figura 5.31: Perfis de degradação de sulfeto para biofiltros preenchidos com espuma de poliuretano (a), bagaço de cana (b) e fibra de coco (c), durante a primeira fase de operação. (- Concentração de sulfeto - Eficiência de Remoção ) 
- Perfis de degradação relativos à segunda fase de operação:
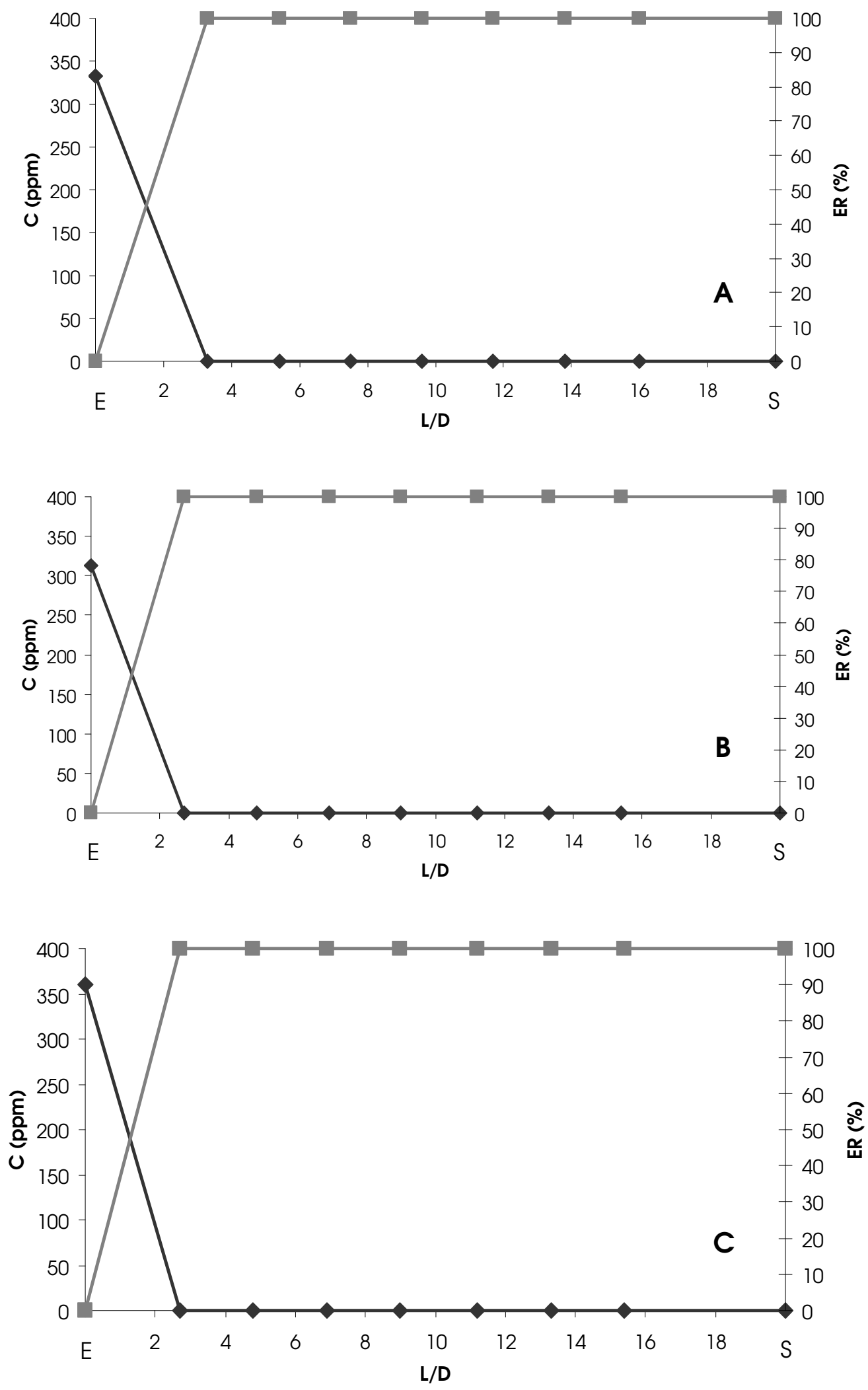

Figura 5.32: Perfis de degradação de sulfeto para biofiltros preenchidos com espuma de poliuretano (a), bagaço de cana (b) e fibra de coco (c), durante a segunda fase de operação. ( Concentração de sulfeto - Eficiência de Remoção ) 
- Perfis de degradação relativos à terceira fase de operação:
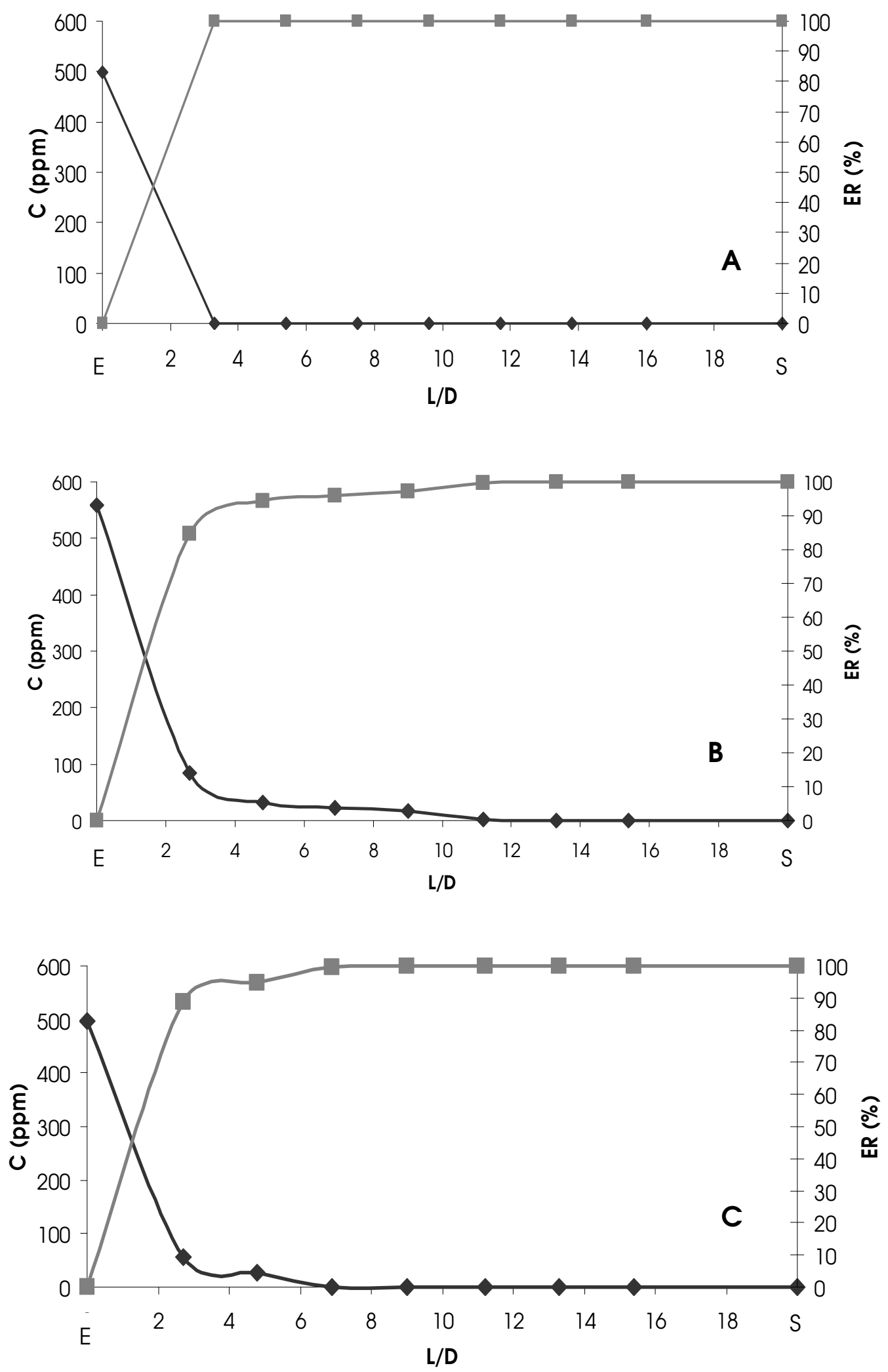

Figura 5.33: Perfis de degradação de sulfeto para biofiltros preenchidos com espuma de poliuretano (a), bagaço de cana (b) e fibra de coco (c), durante a terceira fase de operação. ( Concentração de sulfeto - Eficiência de Remoção ) 
- Perfis de degradação relativos à quarta fase de operação:
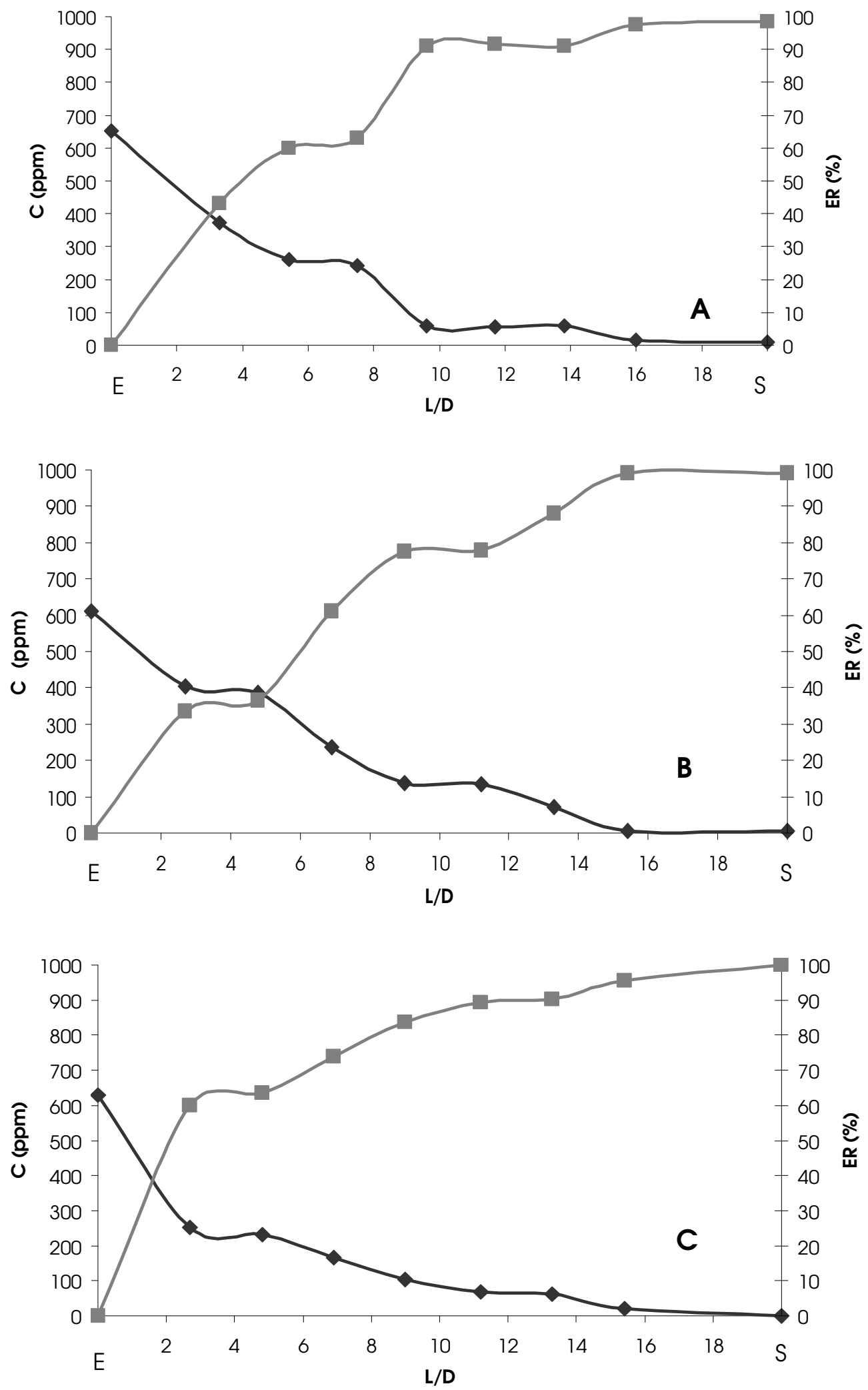

Figura 5.34: Perfis de degradação de sulfeto para biofiltros preenchidos com espuma de poliuretano (a), bagaço de cana (b) e fibra de coco (c), durante a quarta fase de operação. ( Concentração de sulfeto Eficiência de Remoção ) 
É raro encontrar na literatura, trabalhos que contemplem a realização de ensaios de perfil espacial de degradação de sulfeto. Com relação a trabalhos nos quais tenha sido avaliada a degradação do sulfeto de hidrogênio ao longo do leito do reator, tem-se notícia apenas dos trabalhos de Morgan-Sagastume e Noyola (2006), que ainda durante a partida do reator, realizaram perfil espacial em seu biofiltro preenchido com composto maturado, e Rocha (2007), utilizando espuma de poliuretano, em fase final de operação.

Com base nas Figuras 5.18 e 5.19 verifica-se que, nos perfis relativos à primeira e a segunda fases de operação, houve um consumo total de sulfeto já no primeiro ponto de coleta (L/D $\equiv 3)$. Pode ser verificado que nos dias nos quais os ensaios relativos à segunda fase de operação foram realizados, as concentrações de $\mathrm{H}_{2} \mathrm{~S}$ foram de aproximadamente 350 ppm, o que proporciona taxa de carregamento aproximada para os três sistemas de 40 $\mathrm{gH}_{2} \mathrm{~S} \cdot \mathrm{m}^{3} \cdot \mathrm{h}^{-1}$, que é um valor considerável.

Uma possivel explicação para essa degradação efetiva ocorrida antes da primeira tomada de amostras foi dada por Elias et al. (2002). Os autores mostraram que as populações de microrganismos desenvolvem-se mais rapidamente na região próxima a entrada do reator, portanto, é nesta região que ocorre a maior parte da degradação do contaminante.

É somente na Figura 5.20, referente ao perfil realizado durante a fase 3 de operação, que pode-se notar que os biofiltros já não apresentaram o excepcional desempenho dos ensaios anteriores, com exceção feita ao biofiltro preenchido com espuma de poliuretano, que continuou com a mesma desenvoltura com relação à eficiência de remoção, verificadas nos perfis previamente realizados.

Cabe ressaltar, no entanto, que nesta etapa, o biofiltro preenchido com bagaço de cana, por exemplo, já apresentava sinais claros de rebaixo do leito. Percebeu-se neste biofiltro, que o sulfeto só foi consumido por completo até a tomada 5 , que dista $58 \mathrm{~cm}$ da base $(L / D \equiv 11)$.

Na coleta realizada na tomada 4, que dista $47 \mathrm{~cm}(L / D \equiv 9)$, do biofiltro preenchido com fibra de coco, que não havia apresentado colmatação até então, já não foi detectada a presença de sulfeto. Por sua vez, o biofiltro preenchido com o meio sintético, 
que removeu cerca de 500 ppm até primeiro ponto de coleta (L/D $\equiv 3)$, teve desempenho similar ao verificado por Rocha (2007).

O autor, já no final de seu experimento, durante os dias operação 120 e 121, quando seu biofiltro tratava concentrações que ultrapassavam os 1400 ppm, notou que cerca de 40 a $50 \%$ do $\mathrm{H}_{2} \mathrm{~S}$ fora removido nos primeiros $10 \mathrm{~cm}$ de leito constituído pela espuma de poliuretano ( $L / D \equiv 2)$, sendo que a uma altura de $37 \mathrm{~cm}(L / D \equiv 7)$ verificou que $70 \%$ do sulfeto fora removido.

Durante a quarta fase de operação, é possivel verificar que os biofiltros sentiram mais os efeitos da alta concentração afluente aplicada (em torno de 600 ppm). Como era de se esperar o rebaixo do leito interferiu nos resultados, conforme fora observado na fase anterior. Nota-se que foi somente na última tomada que os biofiltros conseguiram eliminar praticamente todo o sulfeto.

Mesmo assim, com base em todos os ensaios de perfil de degradação realizados, verifica-se que todos os biofiltros degradaram com relativa folga o sulfeto de hidrogênio ao longo de seus respectivos leitos. Portanto, pode-se concluir que os biofiltros apresentaram-se robustos para degradar de forma efetiva $\circ \mathrm{H}_{2} \mathrm{~S}$.

\subsection{COLMATAÇÃO DO LEITO}

Dentre algumas limitações observadas durante a operação dos sistemas, a mais visivel foi, sem dúvida, a colmatação do leito. Todos os biofiltros sofreram com este fenômeno durante a pesquisa. A colmatação, a principal causadora do rebaixo de leito, é fenômeno corriqueiro em sistemas cuja operação seja de longo prazo. Em trabalhos de curto prazo, como o de Elias et al. (2002), que operou o sistema por apenas 2500 h, não há relatos de aparecimento de colmatação.

Nos biofiltros preenchidos com espuma de poliuretano e fibra de coco foi observada ligeiro rebaixo de $3 \mathrm{~cm}$, sendo que próximo ao final da operação o biofiltro preenchido com fibra de coco ainda perdeu mais $1 \mathrm{~cm}$ de leito. No biofiltro preenchido com bagaço de 
cana esse fenômeno se deu de forma mais efetiva, chegando aos $9 \mathrm{~cm}$ de rebaixo de leito.

Na Figura 5.35, pode ser observado, claramente, o rebaixo dos leitos em todos os biofiltros.

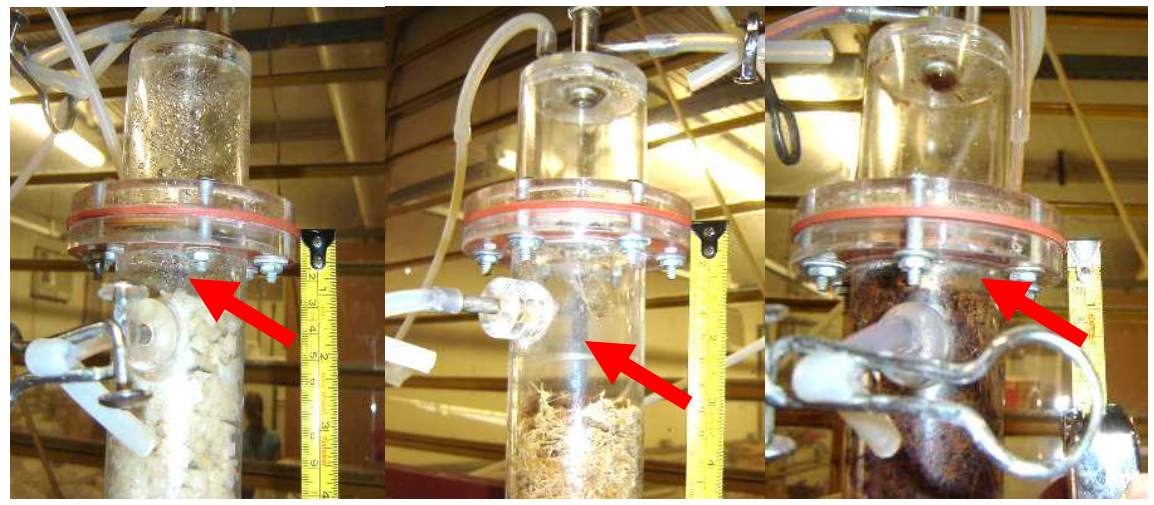

Figura 5.35: Rebaixo de leito observado nos biofiltros preenchidos com espuma de poliuretano (a), bagaço de cana (b) e fibra de coco (c).

O biofiltro preenchido com o bagaço de cana foi o que apresentou maiores problemas com relação à colmatação. No $20^{\circ}$ dia de operação, pôde ser verificada uma perda de $5 \mathrm{~cm}$ de altura útil de leito. Para corrigir este problema, foi imediatamente preenchido o espaço vazio provocado pela colmatação do leito, inserindo-se massa de bagaço correspondente 20 gramas. Contudo, no 44 dia de operação já foi possível verificar novamente a colmatação, desta feita próxima aos $9 \mathrm{~cm}$. Mas neste caso, optou-se por não preencher o espaço vazio com mais material suporte.

O biofiltro preenchido com a espuma de poliuretano apresentou rebaixo correspondente a $3 \mathrm{~cm}$ no $63^{\circ}$ dia de operação, porém não foi verificada queda na eficiência de remoção. A colmatação ocorrida neste biofiltro ocorreu antes do verificado por Rocha (2007), que observou colmatação somente a partir do $95^{\circ}$ dia de operação, no qual verificou perda de altura de $16 \mathrm{~cm}$, após a paralisar o sistema.

O biofiltro preenchido com fibra de coco foi o último a apresentar colmatação, também de $3 \mathrm{~cm}$, assim como a ocorrida no biofiltro preenchido com espuma de poliuretano. Tal fato deu-se no $77^{\circ}$ dia de operação e não comprometeu a eficiência de remoção do sistema. Próximo ao encerramento da operação, no dia 98, notou-se um ligeiro rebaixo de mais $1 \mathrm{~cm}$ neste biofiltro. 
Vale ressaltar que o rebaixo do leito foi considerado nos cálculos de taxa de carregamento e capacidade de eliminação, bem como nos cálculos de perda de carga dos biofiltros.

Durante a operação dos biofiltros, depósitos brancos foram observados sobre a superfície dos meios suportes em algumas regiões dos biofiltros, conforme pode ser verificado na Figura 5.36.

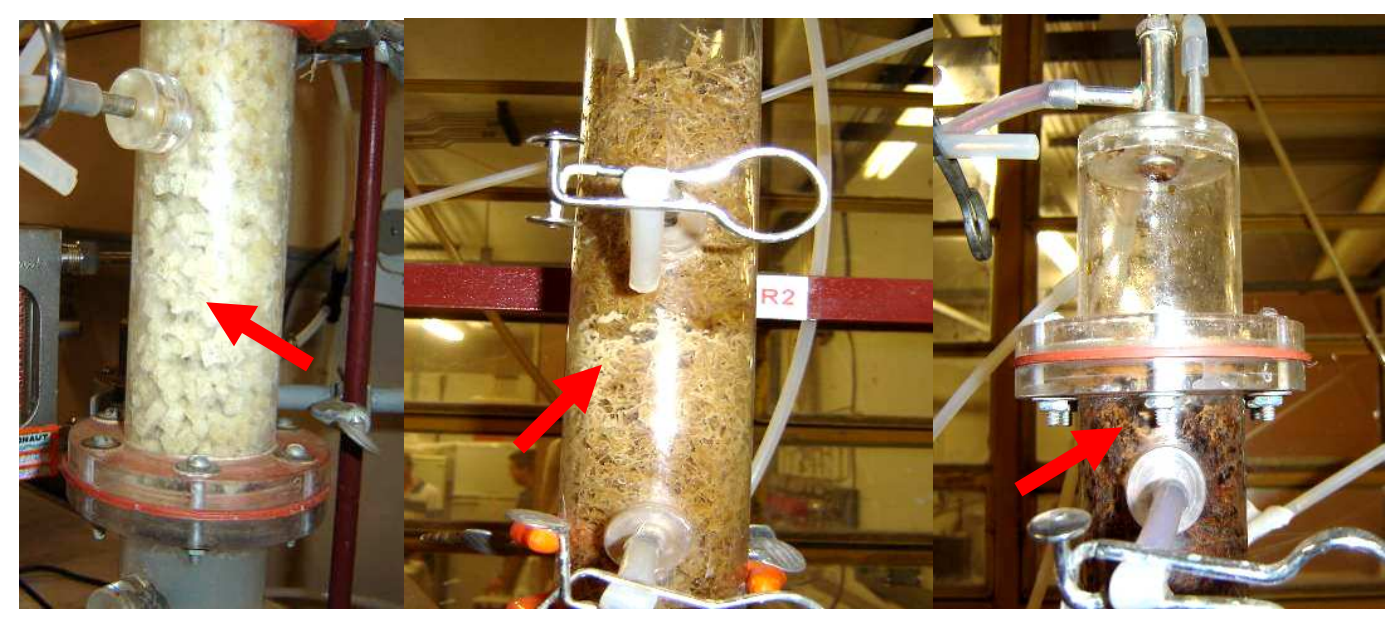

Figura 5.36: Formação de depósitos na cor branca nos biofiltros preenchidos com espuma de poliuretano, bagaço de cana e fibra de coco.

No visual, a taxa de deposição pareceu ser proporcional a taxa de carregamento de $\mathrm{H}_{2} \mathrm{~S}$. $\mathrm{O}$ aumento progressivo da taxa de carregamento de sulfeto e a prolongada operação à taxas relativamente altas podem ter ocasionado o acúmulo de forma rápida de material na cor branca.

Duan et al. (2006), tratando $\mathrm{H}_{2} \mathrm{~S}$ com biofiltro preenchido com carvão ativado também verificou tal fenômeno, que os autores explicaram como sendo devido ao acúmulo de sulfato e o excesso de biomassa no leito filtrante. 


\subsection{POTENCIAL HIDROGENIÔNICO - pH}

Na Figura 5.37 são apresentados os valores de pH do percolado medidos durante a operação do biofiltro.

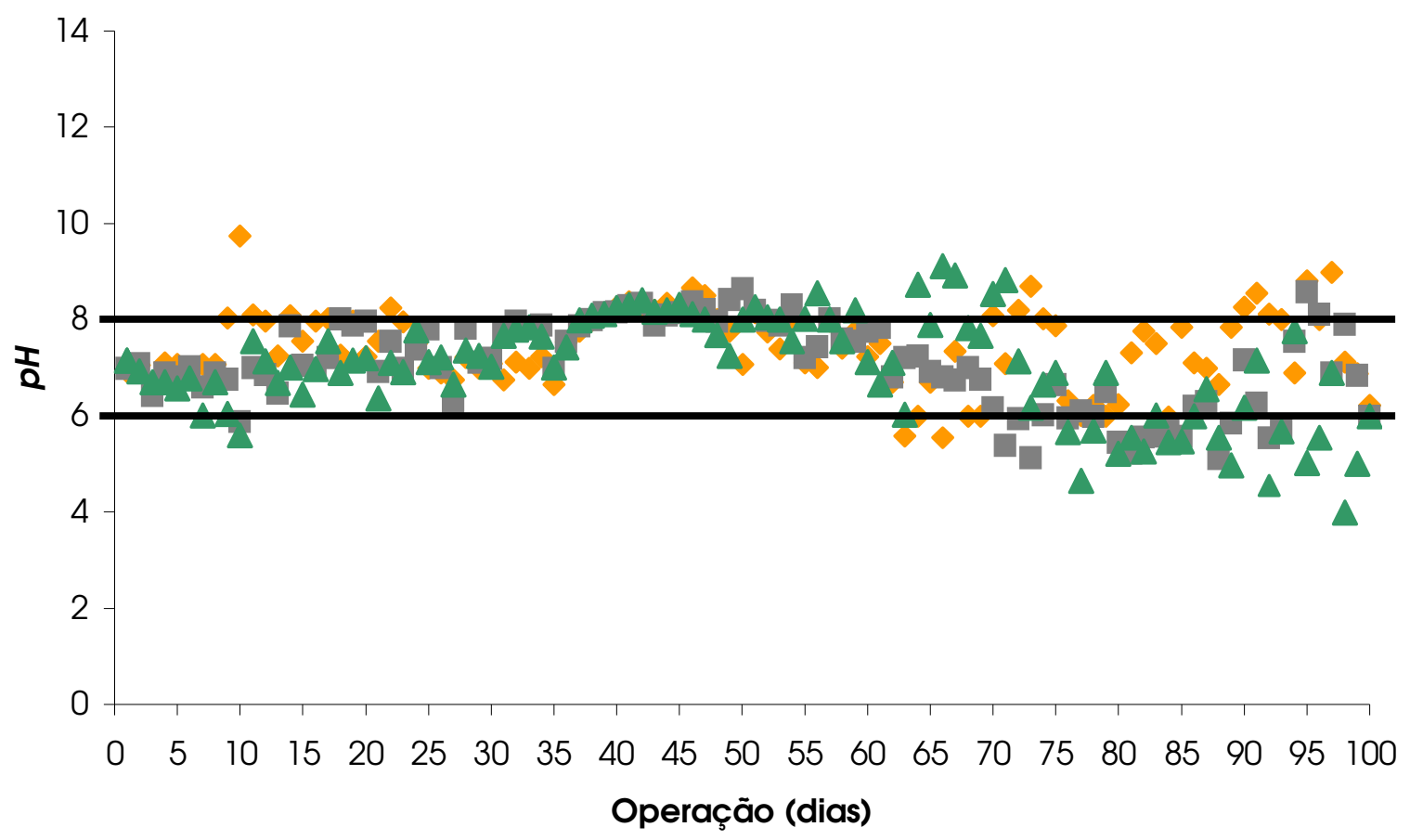

Figura 5.37 - Variação do pH para os biofiltros preenchidos com espuma de poliuretano (४), fibra de $\operatorname{coco}(\boldsymbol{\square})$ e bagaço de cana $(\boldsymbol{\Lambda})$ durante a operação contínua dos sistemas.

Conforme pode se verificado no gráfico da Figura 5.37, os valores de $\mathrm{pH}$ do percolado dos sistemas não apresentaram oscilações abruptas, mantendo-se, na maior da operação, dentro da faixa considerada como ótima para sistemas deste tipo, que é entre 6 e 8. Isso pode ser devido a adição de carbonato de sódio nos meios suportes antes da inserção dos mesmos nos biofiltros. O composto atuou, desta forma, como agente neutralizador do sistema, tornando desnecessárias adições diárias de solução para correção do $\mathrm{pH}$.

Tacla (2004) valeu-se desta técnica na tentativa de provocar o tamponamento de seus biofiltros durante os pouco mais de 30 dias de operação e obteve resultados diferentes. A autora verificou somente os valores de $\mathrm{pH}$ dos meios suportes no início e no final de seu 
experimento e verificou que 5 biofiltros apresentaram características ácidas e 4 características básicas.

Wani et al. (1999) misturou cal em cada meio suporte para tamponá-los. Só percebeu decréscimo significativo do $\mathrm{pH}$ após operar seus biofiltros por um período de 6 meses.

De acordo com o gráfico da Figura 5.37, somente a partir do $63^{\circ}$ dia, quando os sistemas já se encontravam na terceira fase de operação, foram realizadas as adições da solução tamponante, pois os biofiltros BC e EP começaram a apresentar sinais claros de queda dos valores de $\mathrm{pH}$.

Ainda de acordo com o gráfico, pode-se perceber que em alguns pontos, o pH do percolado ficou fora dessa faixa. Isto pode ser explicado quando abaixo de 6 pela formação de compostos ácidos e quando acima de 8 pela formação de polissulfetos.

Chung, Huang e Tseng (1996), Ma, Zhao e Yang (2006) e Elias et al. (2002) observaram que $\mathrm{o} \mathrm{pH}$ a foi mantido a um nível relativamente constante, sem tratamento adicional, durante a operação de seus sistemas, que consideram muito importante para os biofiltros. Ma, Zhao e Yang (2006) sugerem que isto pode ter sido causado pelas propriedades neutras do enxofre elementar como o principal produto metabólico da T. Denitrificans. Ademais, o enxofre elementar é neutro e produtos neutros de enxofre não alteram o pH para condições ácidas em biofiltros. 


\subsection{APLICAÇÃO DO MODELO MATEMÁTICO}

Para a modelagem do sistema, foi necessário submeter os biofiltros a três diferentes tempos de retenção do gás (17, 26 e 52 segundos), procurando-se manter a mesma concentração afluente para os tempos estudados.

Foi considerada, para efeito de modelagem, a cinética de ordem zero, no caso de limitação pela difusão, prevista no modelo de Ottengraf e Van de Oever (1983), com as modificações previstas pela abordagem semi-empírica de Oyarzún et al. (2003), na qual o coeficiente de ordem da reação é fracionário e, sob condições de estado estacionário, é constante.

Na Tabela 5.15 podem ser visualizados os resultados do ensaio experimental realizado para a simulação matemática nos biofiltros preenchidos com espuma de poliuretano, bagaço de cana e fibra de coco.

Tabela 5.15 - Resultados do ensaio experimental realizado para a modelagem matemática nos biofiltros preenchido com espuma de poliuretano, bagaço de cana e fibra de coco.

\begin{tabular}{ccccccc}
\hline & \multicolumn{2}{l}{ Espuma de Poliuretano } & \multicolumn{2}{l}{ Bagaço de cana } & \multicolumn{2}{c}{ Fibra de coco } \\
\cline { 2 - 7 } TRLV (s) & $\mathrm{C}_{0}(\mathrm{H} 2 \mathrm{~S})$ & $\mathrm{Cs}(\mathrm{H} 2 \mathrm{~S})$ & $\mathrm{C}_{0}(\mathrm{H} 2 \mathrm{~S})$ & $\mathrm{Cs}(\mathrm{H} 2 \mathrm{~S})$ & $\mathrm{C}_{0}(\mathrm{H} 2 \mathrm{~S})$ & $\mathrm{Cs}(\mathrm{H} 2 \mathrm{~S})$ \\
& $\mathrm{ppm}$ & $(\mathrm{ppm})$ & $(\mathrm{ppm})$ & $(\mathrm{ppm})$ & $\mathrm{ppm}$ & $(\mathrm{ppm})$ \\
\hline 52 & 328 & 0 & 490 & 2 & 360 & 0 \\
26 & 318 & 118 & 425 & 87 & 370 & 145 \\
17 & 341 & 168 & 429 & 196 & 362 & 225 \\
\hline
\end{tabular}

Os gráficos das Figuras 5.38, 5.39 e 5.40 apresentam os resultados baseados no modelo de Ottengraf e Van de Oever (1983) - a partir de concentrações médias afluentes de, aproximadamente, 320, 470 e 365 ppm - para os biofiltros preenchidos com espuma de poliuretano, bagaço de cana e fibra de coco. 


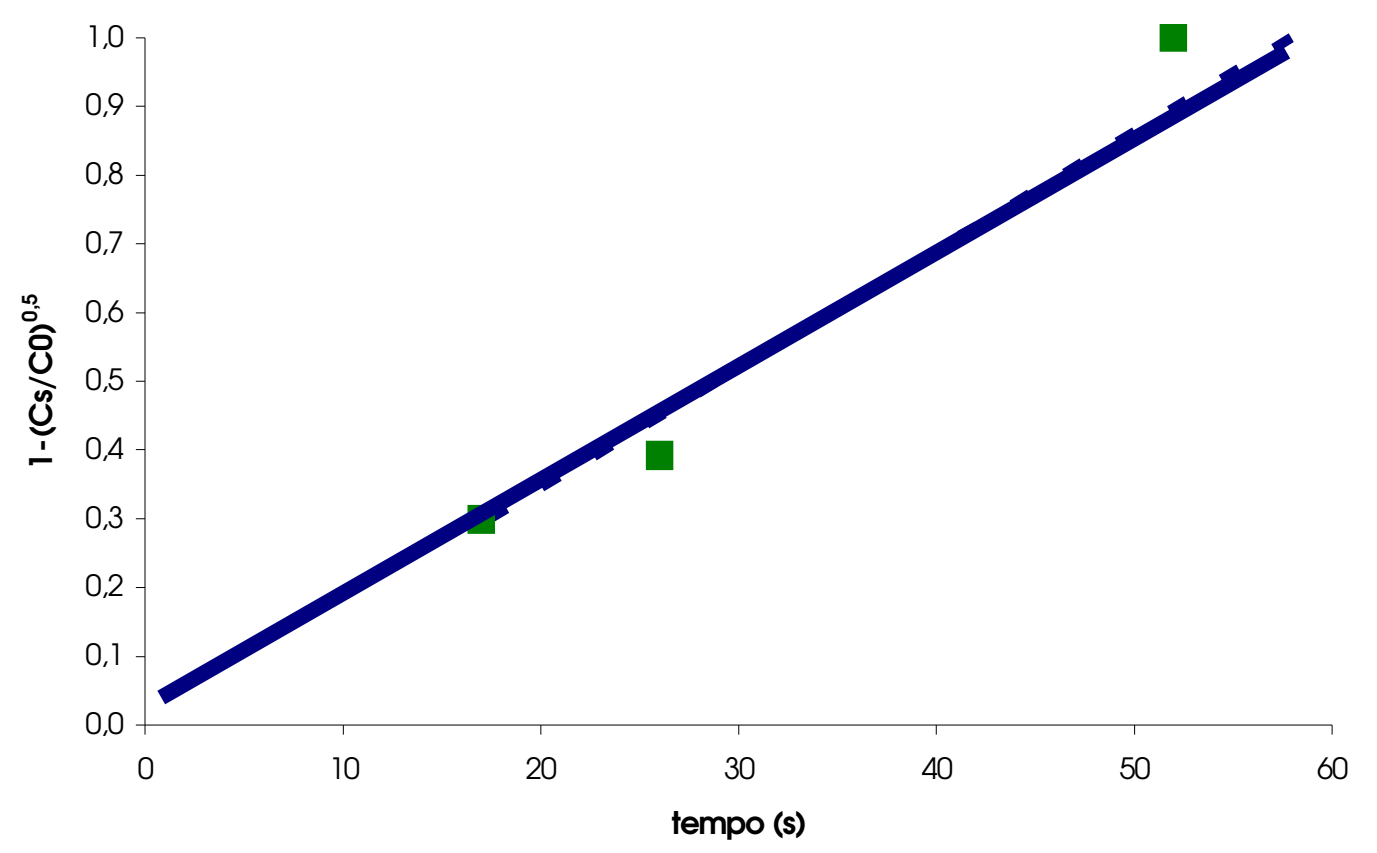

- Modelo Dados experimentais

Figura 5.38: Previsão do processo de biofiltração, tendo a espuma como material suporte, de acordo com o modelo de Ottengraf e Van de Oever (1983) (regime de limitação pela difusão), para uma concentração de entrada de aproximadamente 320 ppm.

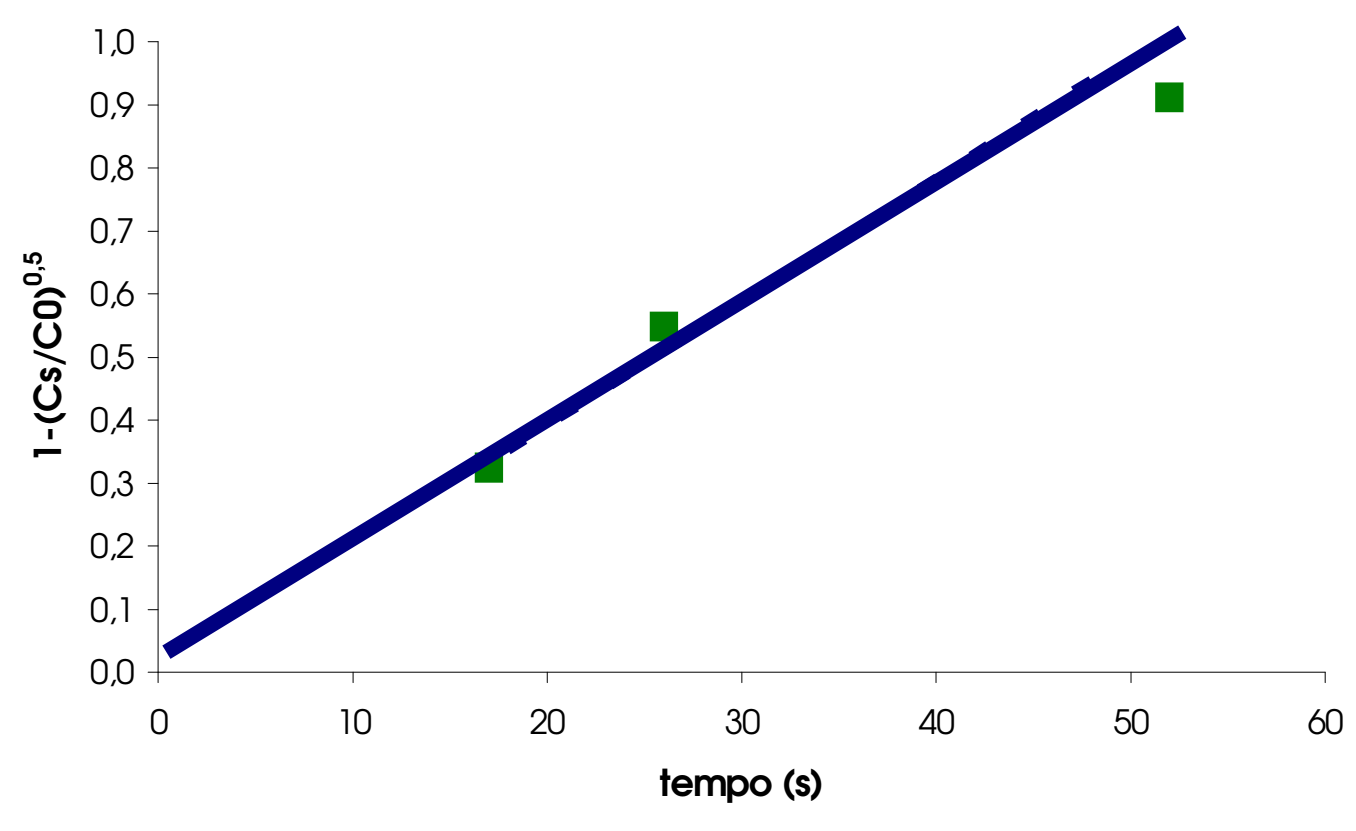

- Modelo $\quad$ Dados experimentais

Figura 5.39: Previsão do processo de biofiltração, tendo o bagaço de cana como material suporte, de acordo com o modelo de Ottengraf e Van de Oever (1983) (regime de limitação pela difusão), para uma concentração de entrada de aproximadamente 470 ppm. 


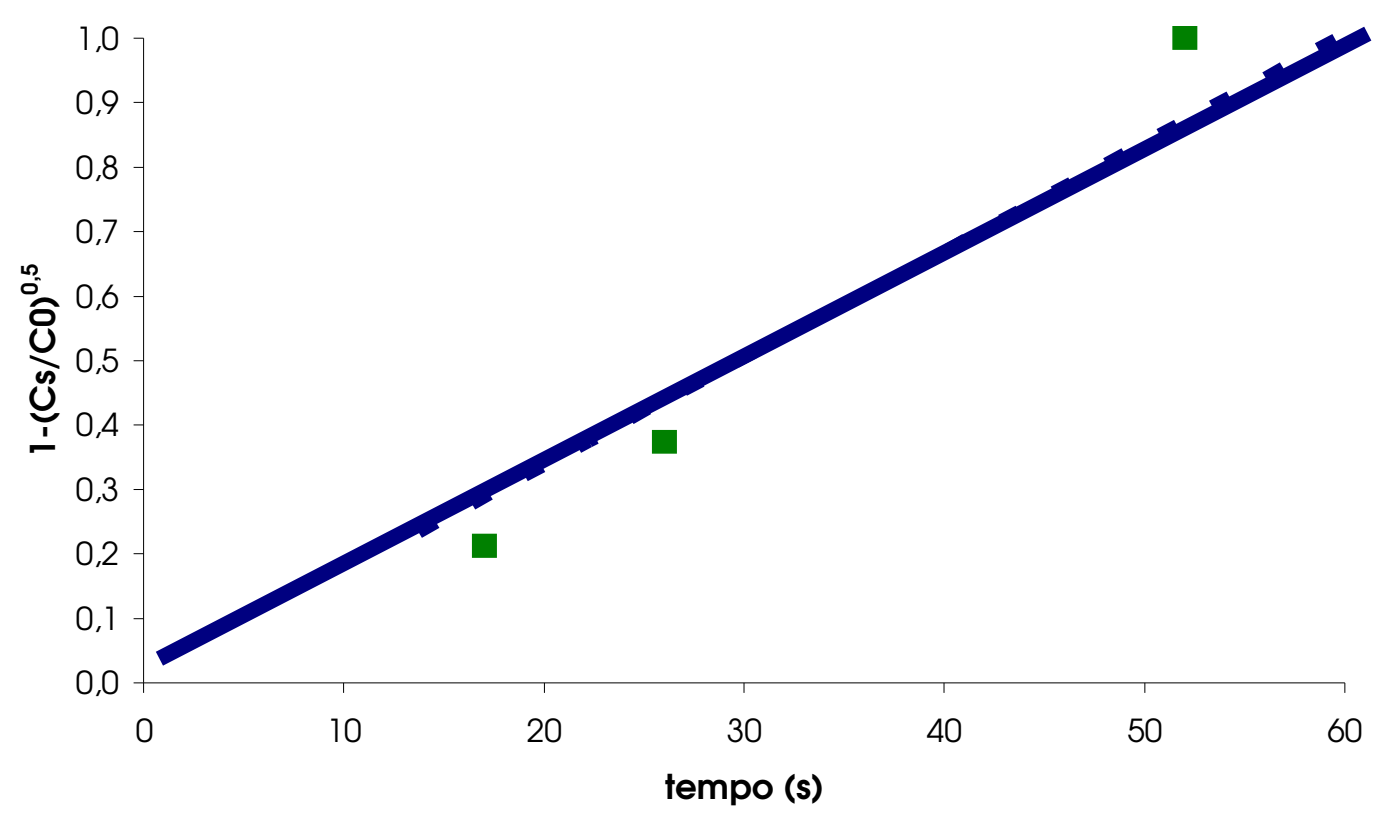

- Modelo - Dados experimentais

Figura 5.40: Previsão do processo de biofiltração, tendo a fibra de coco como material suporte, de acordo com o modelo de Ottengraf e Van de Oever (1983) (regime de limitação pela difusão), para uma concentração de entrada de aproximadamente 360 ppm.

Sob condições de estado estacionário, o grau de conversão para um tempo de residência do gás de, aproximadamente, 52 s esteve sempre próximo à 100\% em todos os biofiltros para as faixas das concentrações estudadas. Entretanto, quando os sistemas foram submetidos à um baixo tempo de retenção do gás (da ordem de, aproximadamente, 17 s), houve queda considerável da eficiência de remoção, de 100\% para algo em torno de 30\% nos biofiltros preenchidos com espuma de poliuretano e bagaço de cana, e $20 \%$ no biofiltro preenchido com fibra de coco.

Portanto, de acordo com os gráficos das Figuras 5.38, 5.39 e 5.40, pode-se afirmar que os efeitos combinados do aumento da velocidade superficial ( $\left.V_{a}\right)$ (que correspondeu à diminuição do tempo de retenção do gás), e a concentração afluente ( $\left.C_{0}\right)$ afetaram o desempenho de todos os biofiltros.

Para a determinação do coeficiente $k_{f}$ (coeficiente de reação, que sob condições de estado estacionário é constante) foi utilizando a ferramenta Solver do Software Microsoft 
Excel (2003), cujos valores estimados foram de 0,0173, 0,0194 e 0,0168 para os biofiltros preenchidos em espuma de poliuretano, bagaço de cana e fibra de coco, respectivamente.

É possivel notar, observando os gráficos das Figuras 5.38, 5.39 e 5.40, que houve bom ajuste do modelo com relação aos dados experimentais, para todas as concentrações estudadas (320, 470 e 365 ppm), assim como fora relatado no trabalho de Oyarzún et al. (2003) e Zilli, Del Borghi e Converti (2000).

No trabalho de Zilli, Del Borghi e Converti (2000), que utilizaram um biofiltro em escala de bancada tratando vapor de tolueno, a relação entre as concentrações de entrada e saída do poluente (tolueno) foi reportada como função da razão entre a velocidade superficial mínima do gás $\left(17,8 \mathrm{~m} \cdot \mathrm{h}^{-1}\right)$ e aquela considerada em cada experimento. $\mathrm{O}$ procedimento adotado neste trabalho foi similar ao de Zilli, Del Borghi e Converti (2000) e Oyarzún et al. (2003), no qual houve apenas a variação das velocidades superficiais, com manutenção das concentrações afluentes.

Dessa forma, como o esperado, tanto neste trabalho quanto no trabalho de Zilli, Del Borghi e Converti (2000) e Oyarzún et al. (2003), pode ser verificado de forma explícita, que a eficiência de remoção $\left(1-C_{s} / C_{0}\right)$ decresce, de forma linear (cinética de ordem zero para limitação pela difusão), com o aumento va ou de $C_{0}$.

Especificamente na biofiltração de sulfeto de hidrogênio, Oyarzún et al. (2003) operaram biofiltro tendo turfa como meio suporte e inoculado com Thiobacillus thioparus, e publicaram importante trabalho aplicando o modelo de Ottengraf e Van de Oever (1983). Considerando o regime como sendo limitado pela difusão, obtiveram bons ajustes para a concentração por eles verificada, que foi de 257 ppm $\left(k_{f}=0,0075\right)$. Concluíram, então, que o modelo permitiu, de forma bastante satisfatória, a previsão do desempenho do biofiltro por eles estudado.

A despeito das peculiaridades das culturas e dos materiais suportes utilizados tanto neste trabalho quanto no trabalho de Oyarzún et al. (2003), a boa aplicabilidade do modelo 
de Ottengraf e Van de Oever (1983) foi constatada, em se tratando de uma única fonte poluente, no caso o sulfeto de hidrogênio.

- Estimativa da espessura do biofilme $(\delta)$

Conforme pode ser verificado na Tabela 5.16, os valores de espessura total do biofilme estão muito próximos aos obtidos por Ottengraf e Van de Oever (1983). Zarook e Shaikh (1997), utilizando seu modelo cuja solução é numérica, contudo baseado no modelo de Ottengraf e Van de Oever (1983), reportaram valores que não excederam 0,11 mm, valor muito distante do verificado neste trabalho. Contudo quando os autores utilizaram o modelo de Otengraff e Van de Oever (1983), no caso de cinética de ordem zero (limitação pela difusão) nos seus dados, o modelo previu valores para a espessura efetiva do biofilme numa faixa entre 1,7 e 8,8 $\mathrm{mm}$ (que corresponde aproximadamente ao verificado neste trabalho e no de Ottengraf e Van de Oever, 1983).

A estimativa da espessura do biofilme e a comparação com os dados da literatura está apresentada na Tabela 5.16. 
Tabela 5.16 - Valores calculados para a espessura do biofilme nos biofiltros preenchidos com espuma de poliuretano, bagaço de cana e fibra de coco e comparação com dados da literatura.

\begin{tabular}{|c|c|c|c|c|c|c|c|}
\hline Poluente & $\mathrm{m}$ & $\begin{array}{c}k^{*} \\
\left(g \cdot m^{-3} \cdot h^{-1}\right)\end{array}$ & $\begin{array}{c}k \\
\left(g \cdot m^{-3} \cdot h^{-1}\right)\end{array}$ & $\begin{array}{c}D^{\prime} \\
\left(m^{2} \cdot s^{-1}\right)\end{array}$ & $\begin{array}{l}\text { Cgrc } \\
\left(\mathrm{g} / \mathrm{m}^{3}\right)\end{array}$ & $\begin{array}{c}\delta \\
(\mathrm{mm})\end{array}$ & Referência \\
\hline Tolueno & 0,2700 & 20 & 50 & $0,85 \cdot 10^{-9}$ & 3,0 & 1,2 & $\begin{array}{c}\text { Ottengraf e } \\
\text { Van de } \\
\text { Oever } \\
\text { (1983) }\end{array}$ \\
\hline $\begin{array}{l}\text { Acetato } \\
\text { de Butila }\end{array}$ & 0,0085 & 30 & 55 & $0,85 \cdot 10^{-9}$ & 0,2 & 1,5 & $\begin{array}{c}\text { Ottengraf e } \\
\text { Van de } \\
\text { Oever } \\
\text { (1983) }\end{array}$ \\
\hline $\begin{array}{l}\text { Acetato } \\
\text { de Etila }\end{array}$ & 0,0051 & 30 & 45 & $1.10^{-9}$ & 0,2 & 2,5 & $\begin{array}{c}\text { Ottengraf e } \\
\text { Van de } \\
\text { Oever } \\
\text { (1983) }\end{array}$ \\
\hline $\mathrm{H}_{2} \mathrm{~S}$ & 0,368 & 48 & 100 & 1. $10^{-10}$ & 0,44 & 1,55 & $\begin{array}{c}\text { Este } \\
\text { trabalho } \\
\text { EP }\end{array}$ \\
\hline $\mathrm{H}_{2} \mathrm{~S}$ & 0,368 & 80 & 150 & 1. $10^{-10}$ & 0,59 & 1,46 & $\begin{array}{c}\text { Este } \\
\text { trabalho } \\
\text { BC }\end{array}$ \\
\hline $\mathrm{H}_{2} \mathrm{~S}$ & 0,368 & 53 & 95 & 1. $10^{-10}$ & 0,52 & 1,72 & $\begin{array}{c}\text { Este } \\
\text { trabalho } \\
\text { FC }\end{array}$ \\
\hline
\end{tabular}

Legenda: $\mathrm{EP}=$ Biofiltro preenchido com espuma de poliuretano, $\mathrm{BC}=$ Biofiltro preenchido com bagaço de cana, $\mathrm{FC}=$ Biofiltro preenchido com fibra de coco.

Devido a essa discrepância nos valores da espessura do biofilme, os autores questionaram a hipótese proposta por Ottengraf e Van de Oever (1983) de que a geometria do biofilme é plana. Fizeram ponderações a respeito de que a espessura do biofilme é 
baseada na depleção do poluente apenas, por isso sugeriram que se o oxigênio também fosse assumido como um composto limitante (o que não ocorre no modelo de Ottengraf e Van de Oever, 1983), então um valor mais realista para a espessura do biofilme poderia ser encontrado.

Mas como pode ser visto neste trabalho, o modelo de Ottengraf e Van de Oever (1983), considerando a limitação pela difusão, mesmo com todas as hipóteses simplificadoras ajustou-se bem aos dados experimentais, a despeito de todas as considerações feitas por Zarook e Shaikh (1997).

Por fim, embora seja baseado em algumas hipóteses simplistas o modelo utilizado neste trabalho permite, facilmente, que se validem os dados experimentais obtidos em sistemas de bancada. Adicionalmente, permite a obtenção de parâmetros importantes nos projetos de unidades piloto de biofiltros. 


\section{CONCLUSÕES}

Os resultados obtidos durante a realização dos experimentos, permitem concluir que é possivel a utilização dos materiais suportes testados - espuma de poliuretano, bagaço de cana e fibra de coco - na biofiltração do sulfeto de hidrogênio na faixa das condições experimentais utilizadas.

Especificamente, podem-se tirar as seguintes conclusões adicionais:

a) a utilização da mistura de lodos ativados e lodo de biofiltro aerado submerso como inóculo para os biofiltros no tratamento de sulfeto de hidrogênio se mostrou bastante viável pelas altas eficiências atingidas (100\%) na remoção do sulfeto e a rápida partida do sistema (apenas 2 dias para atingir a eficiência de 100\%);

b) todos os materiais suportes mostraram-se bastante adequados, e os caminhos preferenciais que ocorrem nesses suportes não afetaram a eficiência do sistema nas condições trabalhadas;

c) os ensaios de perda de carga dos materiais suporte secos apresentaram um bom ajuste com relação a equação de Darcy, proposta para avaliar a permeabilidade do meio;

d) para as velocidades superficiais utilizada no decorrer da operação dos biofiltros (cerca de $1,7 \mathrm{~cm} / \mathrm{s}$ ), os valores de perda de carga foram baixos, 0,59.10-2 , 0,62 10-2 e 0,68 10-2 mca, para os biofiltros preenchidos com a espuma de poliuretano, o bagaço de cana e a fibra de coco;

e) o modelo empregado apresentou bom ajuste com relação aos dados experimentais. 
f) o efeito da adsorção não se mostrou relevante para todos os materiais suportes avaliados, em se tratando de uma operação em longo prazo, visto que os mesmos possuem baixa capacidade adsorvente, saturando em alguns minutos;

g) como o auxílio da microscopia eletrônica de varredura, observou-se grande acúmulo de grânulos de enxofre extracelular, corroborada com a análise de EDX, além da constatação da presença de cocos e bacilos em todas as amostras;

h) o rebaixo e a colmatação do leito, provavelmente por produtos da oxidação do $\mathrm{H}_{2} \mathrm{~S}$, não afetaram consideravelmente a eficiência do sistema;

i) o tempo de detenção aproximado de 50 segundos mostrou-se viável para este sistema;

j) a adição de bicarbonato nos meios suportes antes do preenchimento das colunas tamponou os sistemas por 63 dias. Após isso, ouve necessidade de adição de fonte de bicarbonato para a manutenção do pH na faixa de 6-8;

k) as taxas de carregamento aplicadas (até $80 \mathrm{~g} \cdot \mathrm{m}^{3} \cdot \mathrm{h}^{-1}$ ) são superiores ao valor típico verificado em muitas emissões industriais;

I) as eficiências atingidas nesse estudo se mantiveram acima dos 97\% e muito próximas a 100\% o que comprova a efetiva capacidade de degradação dos biofiltros;

m) as capacidades máximas de eliminação de sulfeto de hidrogênio para os biofiltros preenchidos com espuma de poliuretano, bagaço de cana e fibra de coco não foi alcançada, mas as capacidades de eliminação médias foram, respectivamente, 74, 79 e 75 $g \cdot m^{-3} \cdot h^{-1}$. 


\section{SUGESTÕES}

Como sugestões de continuidade deste trabalho, têm-se:

a) avaliar a utilização de outros materiais suporte alternativos;

b) estudar a cinética de crescimento de diferentes inóculos aeróbios para o tratamento de $\mathrm{H}_{2} \mathrm{~S}$;

c) estudar a dinâmica de crescimento da biomassa durante a operação dos biofiltros;

d) encontrar a máxima capacidade de eliminação do sistema;

e) avaliar outros métodos de determinação do sulfeto de hidrogênio, como a cromatografia gasosa;

f) submeter o sistema à diferentes misturas de gases, como por exemplo, o $\mathrm{H}_{2} \mathrm{~S}$ e a amônia;

g) avaliar a aplicação de biofiltros em escalas maiores;

h) modelar o sistema a partir de outras equações propostas ou elaborar um modelo para o biofiltro;

i) realizar estudos de repetitividade e reprodutibilidade;

j) quantificar a eficiência de distribuidores e redistribuidores de líquidos;

k) realizar estudos com traçadores para verificar o real comportamento hidrodinâmico do sistema;

I) relacionar a perda de carga em função do tempo de crescimento da biomassa;

m) verificar o comportamento do sistema em função da variação da temperatura. 


\section{REFERÊNCIAS}

ABBATI, C.; SILVA, E. L. Remoção de sulfetos em efluentes líquidos por bactérias fotossintéticas em biorreator convencional. In: VI CONGRESSO BRASILEIRO DE ENGENHARIA QUÍMICA EM INICIAÇÃO CIENTÍFICA, 2005, Campinas. Anais do VI Congresso Brasileiro de Engenharia Química em Iniciação Científica. Campinas: 2005.

ENVIRONMENTAL PROTECTION AGENCY. Hydrogen sulfide EPA-CASRN 7783-06-4).Setembro 2006.

ACID RAIN. In: ENVIRONMENTAL PROTECTION AGENCY, Disponível em: $<$ http://www.epa.gov/acidrain/>. Acesso em 29 de jul. 2007

AMERICAN PUBLIC HEALTH ASSOCIATION. Standard Methods for the Examination of Water and Wastewater. 18 th Ed. Washington: APHA, 1999. 1268 p.

ARAÚJO, J. C. Caracterização e evolução do biofilme em reator anaeróbio de leito fluidificado alimentado com esgoto sanitário sintético. 1995. Dissertação (Mestrado em Engenharia Hidráulica e Saneamento) - Escola de Engenharia de São Carlos, Universidade de São Paulo, São Carlos, 1995.

BAQUERIZO, G.; MAESTRE, J.P.; SAKUMA, T.; DESHUSSES, M.A.; GAMISANS, X.; GABRIEL, D.; LAFUENTE, J. A detailed model of a biofilter for ammonia removal:model parameters analysis and model validation. Chemical Engineering Journal, v. 113, p. 205-214, 2005.

BARONA, A.; ELIAS, A.; ARIAS, R.; CANO, R.; GONZÁLES, I.R. Biofilter response to gradual and sudden variations in operating conditions. Biochemical Engineering Journal, v. 22, p. 25-31, 2004.

BARONA, A.; ELIAS, A.; AMURRIO, A.; CANO, I.; ARIAS, R. Hydrogen Sulphide adsorption on a waste material used in bioreactors. Biochemical Engineering Journal, v. 24, p. 79-86, 2005.

BOHN, H. L.; BOHN, K. H. Moisture in biofilters. Environmental Progress, v. 18, p. 156-161, 1999.

BUORNICORE, A.G.; DAVIS, W.T. Air Pollution Engineering Manual. New York: Van Nostrand Reinolds, 1992. $918 \mathrm{p}$.

BURGESS, J. E.; PARSONS, S. A.; STUETZ, R. M. Developments in odor control and waste gas treatment biotechnology: a review. Biotechnology Advances, v. 19, p. 35-63, 2001.

CABRAL, F.A.S.; BELLI, P. Tratamento de odores em digestor anaeróbio utilizando o processo de biofiltração. In: XXVIII CONGRESSO INTERAMERICANO DE INGENÍERIA SANITÁRIA Y 
AMBIENTAL, 2002, Cancun-Mexico. Anais do XXVIII Congresso Interamericano de Ingeníeria Sanitária y Ambiental. Cancun, México: Associación Interamericana de Ingenieria Sanitária y Ambiental, 2002.

CHO, K.S.; RYU, H.W.; LEE, N.Y. Biological Deodorization of Hydrogen Sulfide Using Porous Lava as a Carrier of Thiobacillus thiooxidans. Journal of Bioscience and Bioengineering, v. 90, p. 25$31,2000$.

CHO, K.S., HIRAI, M., AND SHODA, M. Degradation characteristics of hydrogen sulfide, methanethiol, dimethyl sulfide and dimethyl disulfide by Thiobacillus thioparus DW44 isolated from peat biofilter. Journal of Fermentation Bioengineering, v. 71, p. 384-389, 1991.

CHO, K.S.; HIRAI, M.; SHODA, M. Degradation of hydrogen sulfide by Xantomonas sp. strain DY44 isolated from peat. Applied and environmental microbiology, p. 1183-1189, 1992a.

CHO, K.S.; HIRAI, M.; SHODA, M. Enhanced removal efficiency of malodorous gases in a pilotscale peat biofilter inoculated with Thiobacillus thioparus DW44. Journal of fermentation and bioengineering, $v .73, \mathrm{p} .46-50,1992 \mathrm{~b}$.

CHUNG, Y.C.; HUANG, C.; TSENG, C.P. Operation optimization of Thiobacillus thioparus GCH1 1 biofilter for hydrogen sulfide removal. Journal of Biotechnology, v. 52, p. 31-38, 1996.

CHUNG, Y.C.; HUANG C. LI. C.F. Removal characteristics of H2S by Thiobacillus novellus $\mathrm{CH} 3$ biofilter in autotrophic and mixotrophic environments. Journal of Environmental Science and Health, v. A32, p. 1435-1450, 1997.

CHUNG, Y. C.; HUANG, C.; TSENG, C. P.; PAN, J. R. Biotreatment of $\mathrm{H}_{2} \mathrm{~S}$ and $\mathrm{NH}_{3}$ containing waste gases by co-immobilized cells biofilter. Chemosphere, v. 41, p. 329-336, 2000.

CHUNG, Y.C.; HUANG, C.; TSENG, C.P. Biological elimination of $\mathrm{H}_{2} \mathrm{~S}$ and $\mathrm{NH}_{3}$ from waste gases by biofilter packed with immobilized heterotrophic bacteria. Chemosphere, v. 43, 1043-1050, 2001.

CHRISTEN, P.; DOMÉNECH, F.; MICHELENA, G.; AURIA, R.; REVAH, S. Biofiltration of volatile ethanol using sugar cane bagasse inoculated with Candida utilis. Journal of Hazardous Materials, v. B89, p. $253-265,2002$.

COHEN, Y. Biofiltration: the treatment of fluids by microorganisms immobilized into the filter bedding material: a review. Bioresource Technology, v. 77, p. 257-274, 2001.

CONAMA. Conselho Nacional do Meio Ambiente. In: PROGRAMA NACIONAL DE CONTROLE DA QUALIDADE DO AR. Disponível em:

<http://www.mp.rs.gov.br/ambiente/legislacao/id2008.htm>. Acesso em: 07 out. 2007.

CONVERTI, A.; ZILLI, M.; SENE, L.; SATO, S. Biofiltração: uma tecnologia já afirmada no tratamento de emissões gasosas. Farmácia \& Química, São Paulo, v. 34(2), p. 26- 36, 2001. 
CORSI, R. L.; SEED, L. Biofiltration of BTEX: media, substrates and loadings effects. Environmental Program, v. 14, n. 3, 151-158, 1995.

COX, H. H. J.; DESHUSSES, M.A. Biotrickling filters for air pollution control. In: THE ENCYCLOPEDIA OF ENVIRONMENTAL MICROBIOLOGY, 2000. Disponível em: $<$ http://engr.ucr.edu/ mdeshuss/>. Acesso em 10 de ago. 2007.

DEVINNY, J. S.; DESHUSSES, M. A.; WEBSTER, T. S. Biofiltration for air pollution control. $7^{\text {st }}$ Ed. Florida: Lewis Publishers, 1999. 299 p.

DUAN, H.; KOEA, L.C.C.; YANG, R.; CHENG, X. Biological treatment of $\mathrm{H}_{2} \mathrm{~S}$ using pellet activated carbon as a carrier of microorganisms in a biofilter. Water Research, v. 40, p. 26292636, 2006.

EDWARDS, F.G.; NIRMALAKHANDAN, N. Biological Treatment of Airstreams Contamined with VOC's: An overview. Water Science Technology, v. 43, p. 565-571, 1996.

ELIAS, A.; BARONA, A.; ARREGUY, A.; RIOS, J.; ARANGUIZ, I.; PEÑAS, J. Evaluation of a packing material for the biodegradation of $\mathrm{H}_{2} \mathrm{~S}$ and product analysis. Process Biochemistry, v. 37, p. 813-820, 2002.

ESPUMA de poliuretano. In: SERVIÇO NACIONAL DA INDÚSTRIA. SERVIÇO BRASILEIRO DE RESPOSTAS TÉCNICAS. Disponivel em: <http://www.sbrt.ibict.br/upload/sbrt3423.pdf?PHPSESSID=f83393c95dcca6b06a02bb841e26d 26a>. Acesso em: 09 set. 2007.

FAROOQ , M. A. S.; VISWANATHAN , S. Modeling and Simulation of a Biofilter. Industrial Engineering Chemical Research, Vol. 38, No. 7, 1999.

FIBRA DE CÔCO e sua reutilização. In: MINISTÉRIO DA CIÊNCIA DE TECNOLOGIA. Disponível em:

<http://www.canalciencia.ibict.br/pesquisas/pesquisa.php?ref_pesquisa=222>. Acesso em: 11 set. 2007.

FOX, R.W.; MACDONALD, A.D. Introdução a mecânica dos fluidos. 5 ed. Rio de Janeiro, Editora LTC, 1998. 504 p.

FUTIWAKI, L. Utilização de bactérias fotossintéticas para a remoção de sulfeto em efluentes líquidos. 2004. Dissertação (Mestrado em Engenharia Química) - Departamento de Engenharia Química, Universidade Federal de São Carlos, São Carlos-SP, 2004.

GABRIEL, D.; MAESTRE, J.; MARTÍN, J. P.; GAMISANS, X.; LAFUENTE, J. Characterization and performance of coconut fibre as packing material in the removal of ammonia in gas-phase biofilters. Biosystems Engineering, v. 97, p. 481-490, 2007. 
GOSTOMSKI, P.A.; SISSON, J.B.; CHERRY, R.S. Water content dynamics in Biofiltration: the role of humidity and microbial heat generation. Journal of Air and Waste Management, v. 47, p. 936944, 1997.

HARTIKAINEN, T.; RUUSKANEN, J.; MARTIKAINEN, P. J. Carbon disulfide and hydrogen sulfide removal with a peat biofilter. Journal of Air and Waste Management Association, v.51, p. 387$392,2001$.

HARTIKAINEN, T.; MARTIKAINEN, P. J.; OLKONNEN, M.; RUUSKANEN, J. Peat biofilters in long-term experiment for removing odorous sulphur compounds. Water, Air and Soil Pollution, v. 133, p. 335-348, 2002.

HENSHAW, P.F.; SYED, M.A. Effect of tube size on performance of a fixed film tubular bioreactor for conversion of hydrogen sulfide to elemental sulfur. Water research, v. 37, p. 1932-1938, 2003.

HIRAI, M., OHTAKE, M., AND SHODA, M.. Removal kinetics of hydrogen sulfide, methanethiol and dimethyl sulfide by peat biofilters. J. Fermentation Bioengineering, v 70, p. 334-339, 1990.

JEONG, G.S.; KIM. B.W. The influence of light/dark cycle at low frequency on the desulphurization by a photosynthetic microorganism. Journal of Bioscience and Bioengineering, v. 87, p. 481-488, 1999.

JORIO, H.; BIBEAU, L.; VIEL, G.; HEITZ, M. Effects of gas flow rate and inlet concentration on xylene vapors on biofiltration performance. Chemical Engineering Journal, v. 76, p. 209-221, 2000.

KIM, J. H.; RENE, E.R.; PARK, H.S. Biological oxidation of hydrogen sulfide under steady and transient conditions in an immobilized cell biofilter. Bioresource technology, 2007.

KOBAYASHI, H. A.; STENSTROM, M.; MAH, R.A. Use of photosynthetic bacteria for hydrogen sulfide removal from anaerobic waste treatment effluent. Water Research, v. 17, p. 579-587, 1983.

LEE, E.Y.; CHO, K.S.; RYU, H.W. Simultaneous removal of $\mathrm{H}_{2} \mathrm{~S}$ and $\mathrm{NH}_{3}$ in biofilter inoculated with Acidithiobacillus thiooxidans TAS. Journal of Bioscience and Bioengineering, v. 99, p. 611-615, 2005.

LEE, E.Y.; LEE, N.Y.; CHO, K.S.; RYU, H.W. Removal of hydrogen sulphide by sulfate resistant Acidithiobacillus thiooxidans AZ1 1. Journal of Bioscience and Bioengineering, v. 101, p. 309$314,2006$.

LENS, P.N.L.; KUENEN, J.G. The biological sulfur cycle: novel opportunities for environmental biotechnology. Water Science and Technology, v. 44, p. 57-66, 2001. 
LESON, G.; WINER, A. M. Biofiltration: an innovative air pollution control technology for VOC emissions. Air \& Waste Management Association. v. 41, n.8, p. 1045-1054, 1991.

LI, X.Z.; WU,J.S.; SUN,D.L.Hydrogen sulphide and volatile fatty acid removal from foul air in a fibrous bed bioreactor. Water Science and Technology, vol. 38, n.3,p.323-329,1998.

MA,Y.L.; YANG, B.L.; ZHAO, J.L. Removal of $\mathrm{H}_{2} \mathrm{~S}$ by Thiobacillus denitrificans immobilized on different matrices. Bioresource Technology, v. 97, p. 2041-2046, 2006.

MA, Y.L.; ZHAO, J.L.; YANG, B.L. Removal of $\mathrm{H}_{2} \mathrm{~S}$ in waste gases by an activated carbon bioreactor. International Biodeterioration \& Biodegradation, v. 57, p. 93-98, 2006.

MAIA, G.D. Tratamento biológico de gás sulfídrico $\left(\mathrm{H}_{2} \mathrm{~S}\right)$ em biofiltro. 2003. Dissertação (Mestrado em Engenharia Química) - Departamento de Engenharia Química, Universidade Federal de São Carlos, São Carlos-SP, 2003.

MALHAUTIER, L.; GRACIAN, C.; ROUX, C.J.; FANLO, L.J.; LE CLOIREC, P. Biological treatment process of air loaded with an ammonia and hydrogen sulfide mixture. Chemosphere, v. 50, p. 145-153, 2003.

MANAHAN, S. E. Environmental chemistry. $7^{\text {th }}$ Ed. London: Boca Raton, Lewis Publishers, 2000. $811 \mathrm{p}$.

EL-HAWAGI, M. M. Pollution prevention through process integration - Sstematic Design tools. San Diego: Academic Press, 1997.

MELO, I. S.; AZEVEDO, J. L. Microbiologia ambiental. Jaguariúna: Embrapa, 1997. 440 p.

METCALF \& EDDY. INC. Wastewater engineering: treatment and reuse. $4^{\text {th }}$ Ed. New York: McGraw Hill, Inc., 2002. 1334 p.

MOE, W. M.; IRVINE, R. L. Polyurethane foam medium for biofiltration I: Characterization. Journal of Environmental Engineering, v. september, p. 815-825, 2000a.

MOE, W. M.; IRVINE, R. L. Polyurethane foam medium for biofiltration II: Operation and performance. Journal of Environmental Engineering, v. september, p. 826-835, 2000b.

MORAES JÚNIOR, D. Metodologia para o estudo de um sistema biológico de tratamento de emissões gasosas e aplicação na depuração do gás amoníaco. 1991. 197 f. Tese (Doutorado) - Escola de Engenharia de São Carlos, Universidade de São Paulo, São CarlosSP, 1991. 
MORGAN-SAGASTUME, M.J.; NOYOLA, A.; REVAH, S.; ERGAS, J.S. Changes in physical properties of a compost biofilter treating hydrogen sulfide. Journal of Air \& Waste Management Association, v. 53, p. 1011-1021, 2003.

MORGAN-SAGASTUME, J.M.; NOYOLA, A. Hydrogen sulfide removal by compost biofiltration: Effect of mixing of the filter media on operational factors. Bioresource Technology, v. 97, p. 1546-1553, 2006.

NEAL, A.B.; LOEHR, R.C. Use of biofilters and suspended-growth reactors to treat VOC's. Waste management, v. 20, p. 59-68, 2000.

OTTENGRAF, S.P.P.; VAN DER OEVER, A.H.C. Kinetics of organic compounds removal from waste gases with biological filter. Biotechnology and Bioengineering, v. 25, p. 3089-3102, 1983.

OTTENGRAF, S.P.P.; MEESTERS, A.H.C.; van de OEVER, A.H., ROZEMA, H.R. Biological elimination of volatile xenobiotic compounds in biofilters. Bioprocess Engineering, v. 1, p. 61-69, 1986.

OYARZÚN, P.; ARANCIBIA, F.; CANALES, C.; AROCA, G. E. Biofiltration of high concentration of hydrogen sulphide using Thiobacillus thioparus. Process Biochemistry, v. 00, p. 1-6, 2003.

PÁCA, J.; KOUTSKÝ, B. Effect of the packing materials on styrene removal in the biofilter. In: Proceedings of the 2000 USC-TRG Conference on Biofiltration, an Air Pollution Control, p. 21 29, 2000 .

PARK, D.H.; CHA, J.M.;RYU, H.W.; LEE, G.W.;YU, E,Y.;RHEE, J.L.;PARK, J.J.; KIM, S.W.;LEE, I.W.;JOE, Y.W.;RYU, Y.W.;HUR, B.H.;PARK, J.K.;PARK, K. Hydrogen sulfide removal utilizing immobilized Thiobacillus sp. IW with Ca-alginate bread, Biochemical Engineering Journal, 11,p.167173,2002 .

PRESCOTT, M.L.; HARLEY, P.J.; KLEIN, A.D. Microbiology, 5th Ed. New York: McGraw-Hill Companies. 2003.

RAMÍREZ-LOPEZ, E.; CORONA-HERNÁNDEZ, J.; DENDOOVEN, L.; RANGEL, P.; THALASO, F. Characterization of five agricultural by-products as potential biofilter carriers. Bioresource Technology, v. 88, p. 259-263, 2003.

ROCHA, A.P. Desempenho de filtro biológico na depuração e desodorização de emissões de sulfeto de hidrogênio. 2007. Dissertação (Mestrado em Engenharia Hidráulica e Saneamento) - Escola de Engenharia de São Carlos, Universidade de São Paulo, São Carlos-SP, 2007.

RODRIGUES, K. B. Desenvolvimento de uma unidade experimental para degradação de gás sulfídrico $\left(\mathrm{H}_{2} \mathrm{~S}\right)$ em filtro biológico. 2002. Dissertação (Mestrado em Engenharia Química) Departamento de Engenharia Química, Universidade Federal de São Carlos, São Carlos-SP, 2002. 
SHOJAOSADATI , S.A.; ELYASI, S. Removal of hydrogen sulfide by the compost biofilter with sludge of leather industry Resources. Conservation and Recycling, v. 27, p. 139-144, 1999.

SOARES, M. Aplicação da biofiltração no tratamento de vapores de gasolina. 2007. Teses (Doutorado em Processos Biotecnológicos) - Universidade Federal do Paraná, Curitiba, 2006.

SYED, M.; SOREANU, G.; FALLETA, P.; BÉLAND, M. Removal of hydrogen sulfide from gas streams using biological processes - A review. Canadian Biosystems Engineering, v. 48, 2006.

TACLA, R. Aproveitamento de Resíduos Industriais para a Biofiltração do Sulfeto De Hidrogênio. 2004. Dissertação (Mestrado em Tecnologia de Alimentos) - Unniversidade Federal do Paraná, Curitiba, 2004.

VAN LANGENHOVE, H.; WUYTS, E.; SCHAMP, N. Elimination of hydrogen sulphide from odorous air by a wood bark biofilter. Water Research, v. 20, p. 1471-1476, 1986.

YANG, Y.; ALLEN, E.R. Biofiltration control of hydrogen sulfide - Design and operational parameters. Journal of Air and Waste Management Association, v. 44, p. 863, 1994.

WANI, A.H.;LAU,A.K.;BRANION, R.M.R. Biofiltration control of pumping odors hydrogensulfide:performance, macrokinetics and coexistence effects of organo-sulfur species. Journal of chemical technology and biotechnology, v.74, p.9-16.1999.

WU,G.;CONT,B.; VIEL, G.;LEROUX, A.;BRZEZINSKI,R.;HEITZ, M. Ahigh performance biofilter for VOC emission control. Journal of air and waste management, 49(2): 185-192. 1999

ZAROOK, S.M.; SHAIKH, A.A.; ANSAR, Z. Development, experimental validation and dynamic analysis of a general transient biofilter model. Chemical Engineering Science, v. 52, p. 759$773,1997$.

ZHANG, L., HIRAI, M., AND SHODA, M.. Removal characteristics of dimethyl sulfide, methanethiol and hydrogen sulfide by Hyphomicrobium sp. 155 isolated from peat biofilter. Journal of Fermentation Bioengineering, v. 72, p. 392-396, 1991.

ZAROOK, S.M.; SHAIKH, A.A. Analisys and comparison of biofilter models. The chemical Engineering Journal, v. 65, p. 55-61, 1997.

ZILLI, M.; DEL BORGHI, A.; CONVERTI, A. Toluene vapour renoval in a laboratory-scale biofilter.Applied Microbiology Biotechnology, v. 54, p. 248-254, 2000.

ZOTIN, F.Z. O efeito de parede em colunas de recheio. 1985. Dissertação (Mestrado em Engenharia Química) - Departamento de Engenharia Química, Universidade Federal de São Carlos, São Carlos-SP, 1985. 165 p. 
Apêndice 
Tabela A1 - Dados da operação do Biofiltro preenchido com Espuma de Poliuretano

\begin{tabular}{|c|c|c|c|c|c|c|c|}
\hline \multirow{2}{*}{$\begin{array}{c}\text { Dia de } \\
\text { operação }\end{array}$} & \multicolumn{2}{|c|}{ Centrada } & \multicolumn{2}{|c|}{ Csaída } & \multirow{2}{*}{ Eficiência (\%) } & \multirow[t]{2}{*}{ TCMV $\left(g \cdot m^{3} \cdot h^{-1}\right)$} & \multirow[t]{2}{*}{ CE $\left(g \cdot m^{3} \cdot h^{-1}\right)$} \\
\hline & $(\mathrm{mg} / \mathrm{L})$ & (ppm) & $(\mathrm{mg} / \mathrm{L})$ & (ppm) & & & \\
\hline 1 & 0,2320 & 166 & 0,0017 & 1 & 99,3 & 16,13 & 16,01 \\
\hline 3 & 0,2490 & 179 & 0,0012 & 1 & 99,5 & 17,31 & 17,23 \\
\hline 4 & 0,2545 & 183 & 0,0000 & 0 & 100,0 & 17,69 & 17,69 \\
\hline 5 & 0,2490 & 179 & 0,0000 & 0 & 100,0 & 17,31 & 17,31 \\
\hline 8 & 0,2585 & 185 & 0,0000 & 0 & 100,0 & 17,97 & 17,97 \\
\hline 9 & 0,2540 & 182 & 0,0000 & 0 & 100,0 & 17,66 & 17,66 \\
\hline 10 & 0,2670 & 191 & 0,0000 & 0 & 100,0 & 18,56 & 18,56 \\
\hline 11 & 0,2370 & 170 & 0,0000 & 0 & 100,0 & 16,48 & 16,48 \\
\hline 12 & 0,2535 & 182 & 0,0000 & 0 & 100,0 & 17,62 & 17,62 \\
\hline 17 & 0,2580 & 185 & 0,0006 & 0 & 99,8 & 17,94 & 17,90 \\
\hline 18 & 0,2725 & 195 & 0,0000 & 0 & 100,0 & 18,94 & 18,94 \\
\hline 19 & 0,2960 & 212 & 0,0000 & 0 & 100,0 & 20,58 & 20,58 \\
\hline 20 & 0,2825 & 203 & 0,0000 & 0 & 100,0 & 19,64 & 19,64 \\
\hline 21 & 0,2475 & 177 & 0,0006 & 0 & 99,8 & 17,21 & 17,17 \\
\hline 22 & 0,2905 & 208 & 0,0000 & 0 & 100,0 & 20,20 & 20,20 \\
\hline 23 & 0,2780 & 199 & 0,0000 & 0 & 100,0 & 19,33 & 19,33 \\
\hline 24 & 0,2675 & 192 & 0,0000 & 0 & 100,0 & 18,60 & 18,60 \\
\hline 25 & 0,4775 & 342 & 0,0000 & 0 & 100,0 & 33,20 & 33,20 \\
\hline 26 & 0,4260 & 306 & 0,0006 & 0 & 99,9 & 29,61 & 29,57 \\
\hline 27 & 0,4560 & 327 & 0,0000 & 0 & 100,0 & 31,70 & 31,70 \\
\hline
\end{tabular}


Tabela A1 - Dados da operação do Biofiltro preenchido com Espuma de Poliuretano (Continuação)

\begin{tabular}{|c|c|c|c|c|c|c|c|}
\hline \multirow{2}{*}{$\begin{array}{c}\text { Dia de } \\
\text { operação }\end{array}$} & \multicolumn{2}{|c|}{ Centrada } & \multicolumn{2}{|c|}{ Csaída } & \multirow{2}{*}{ Eficiência (\%) } & \multirow{2}{*}{ TCMV $\left(g \cdot m^{3} \cdot h^{-1}\right)$} & \multirow{2}{*}{ CE $\left(g \cdot m^{3} \cdot h^{-1}\right)$} \\
\hline & $(\mathrm{mg} / \mathrm{L})$ & (ppm) & $(\mathrm{mg} / \mathrm{L})$ & (ppm) & & & \\
\hline 31 & 0,4835 & 347 & 0,0000 & 0 & 100,0 & 33,61 & 33,61 \\
\hline 32 & 0,4815 & 345 & 0,0006 & 0 & 99,9 & 33,47 & 33,43 \\
\hline 33 & 0,4650 & 333 & 0,0000 & 0 & 100,0 & 32,33 & 32,33 \\
\hline 34 & 0,4525 & 325 & 0,0000 & 0 & 100,0 & 31,46 & 31,46 \\
\hline 35 & 0,4650 & 333 & 0,0000 & 0 & 100,0 & 32,33 & 32,33 \\
\hline 36 & 0,4365 & 313 & 0,0000 & 0 & 100,0 & 30,34 & 30,34 \\
\hline 37 & 0,5015 & 360 & 0,0000 & 0 & 100,0 & 34,86 & 34,86 \\
\hline 38 & 0,4535 & 325 & 0,0000 & 0 & 100,0 & 31,53 & 31,53 \\
\hline 39 & 0,4200 & 301 & 0,0000 & 0 & 100,0 & 29,20 & 29,20 \\
\hline 40 & 0,4425 & 317 & 0,0000 & 0 & 100,0 & 30,76 & 30,76 \\
\hline 41 & 0,4670 & 335 & 0,0000 & 0 & 100,0 & 32,47 & 32,47 \\
\hline 42 & 0,4175 & 299 & 0,0000 & 0 & 100,0 & 29,02 & 29,02 \\
\hline 43 & 0,4960 & 356 & 0,0000 & 0 & 100,0 & 34,48 & 34,48 \\
\hline 44 & 0,4660 & 334 & 0,0000 & 0 & 100,0 & 32,40 & 32,40 \\
\hline 45 & 0,4480 & 321 & 0,0000 & 0 & 100,0 & 31,14 & 31,14 \\
\hline 46 & 0,4015 & 288 & 0,0006 & 0 & 99,9 & 27,91 & 27,87 \\
\hline 47 & 0,4315 & 309 & 0,0000 & 0 & 100,0 & 30,00 & 30,00 \\
\hline 48 & 0,5010 & 359 & 0,0000 & 0 & 100,0 & 34,83 & 34,83 \\
\hline 49 & 0,4725 & 339 & 0,0000 & 0 & 100,0 & 32,85 & 32,85 \\
\hline 50 & 0,4850 & 348 & 0,0006 & 0 & 99,9 & 33,72 & 33,68 \\
\hline 51 & 0,4495 & 322 & 0,0000 & 0 & 100,0 & 31,25 & 31,25 \\
\hline 52 & 0,4640 & 333 & 0,0000 & 0 & 100,0 & 33,51 & 33,51 \\
\hline 53 & 0,4651 & 334 & 0,0000 & 0 & 100,0 & 33,59 & 33,59 \\
\hline 54 & 0,4150 & 298 & 0,0000 & 0 & 100,0 & 29,97 & 29,97 \\
\hline 55 & 0,4470 & 321 & 0,0000 & 0 & 100,0 & 32,28 & 32,28 \\
\hline 56 & 0,4485 & 322 & 0,0000 & 0 & 100,0 & 32,39 & 32,39 \\
\hline 57 & 0,7100 & 509 & 0,0000 & 0 & 100,0 & 51,28 & 51,28 \\
\hline 58 & 0,6400 & 459 & 0,0000 & 0 & 100,0 & 46,22 & 46,22 \\
\hline 59 & 0,7340 & 526 & 0,0000 & 0 & 100,0 & 53,01 & 53,01 \\
\hline 60 & 0,6990 & 501 & 0,0000 & 0 & 100,0 & 50,48 & 50,48 \\
\hline
\end{tabular}


Tabela A1 - Dados da operação do Biofiltro preenchido com Espuma de Poliuretano (Continuação)

\begin{tabular}{|c|c|c|c|c|c|c|c|}
\hline \multirow{2}{*}{$\begin{array}{c}\text { Dia de } \\
\text { operação }\end{array}$} & \multicolumn{2}{|c|}{ Centrada } & \multicolumn{2}{|c|}{ Csaída } & \multirow{2}{*}{ Eficiência (\%) } & \multirow{2}{*}{$\begin{array}{c}\text { TCMV }\left(\mathrm{g} \cdot \mathrm{m}^{3} \cdot \mathrm{h}^{-}\right. \\
\left.{ }^{1}\right)\end{array}$} & \multirow{2}{*}{ CE $\left(\mathrm{g} \cdot \mathrm{m}^{3} \cdot \mathrm{h}^{-1}\right)$} \\
\hline & $(\mathrm{mg} / \mathrm{L})$ & (ppm) & $(\mathrm{mg} / \mathrm{L})$ & (ppm) & & & \\
\hline 61 & 0,8340 & 598 & 0,0000 & 0 & 100,0 & 60,23 & 60,23 \\
\hline 62 & 0,7690 & 551 & 0,0000 & 0 & 100,0 & 55,54 & 55,54 \\
\hline 63 & 0,7580 & 544 & 0,0000 & 0 & 100,0 & 54,74 & 54,74 \\
\hline 64 & 0,6900 & 495 & 0,0000 & 0 & 100,0 & 49,83 & 49,83 \\
\hline 65 & 0,7850 & 563 & 0,0000 & 0 & 100,0 & 56,69 & 56,69 \\
\hline 66 & 0,7100 & 509 & 0,0006 & 0 & 99,9 & 51,28 & 51,24 \\
\hline 67 & 0,6930 & 497 & 0,0000 & 0 & 100,0 & 50,05 & 50,05 \\
\hline 68 & 0,7560 & 542 & 0,0000 & 0 & 100,0 & 54,60 & 54,60 \\
\hline 69 & 0,6940 & 498 & 0,0000 & 0 & 100,0 & 50,12 & 50,12 \\
\hline 70 & 0,7090 & 508 & 0,0000 & 0 & 100,0 & 51,21 & 51,21 \\
\hline 71 & 0,7270 & 521 & 0,0012 & 1 & 99,8 & 52,51 & 52,42 \\
\hline 72 & 0,6960 & 499 & 0,0000 & 0 & 100,0 & 50,27 & 50,27 \\
\hline 73 & 0,7790 & 559 & 0,0000 & 0 & 100,0 & 56,26 & 56,26 \\
\hline 74 & 0,6910 & 496 & 0,0000 & 0 & 100,0 & 49,91 & 49,91 \\
\hline 75 & 0,6630 & 475 & 0,0000 & 0 & 100,0 & 47,88 & 47,88 \\
\hline 76 & 0,7750 & 556 & 0,0000 & 0 & 100,0 & 55,97 & 55,97 \\
\hline 77 & 0,7720 & 554 & 0,0000 & 0 & 100,0 & 55,76 & 55,76 \\
\hline 78 & 0,7400 & 531 & 0,0000 & 0 & 100,0 & 53,44 & 53,44 \\
\hline 79 & 0,7050 & 506 & 0,0000 & 0 & 100,0 & 50,92 & 50,92 \\
\hline 80 & 0,6600 & 473 & 0,0000 & 0 & 100,0 & 47,67 & 47,67 \\
\hline 81 & 0,6970 & 500 & 0,0000 & 0 & 100,0 & 50,34 & 50,34 \\
\hline 82 & 0,7850 & 563 & 0,0000 & 0 & 100,0 & 56,69 & 56,69 \\
\hline 83 & 0,7060 & 506 & 0,0000 & 0 & 100,0 & 50,99 & 50,99 \\
\hline 84 & 0,6940 & 498 & 0,0000 & 0 & 100,0 & 50,12 & 50,12 \\
\hline 85 & 0,6890 & 494 & 0,0000 & 0 & 100,0 & 49,76 & 49,76 \\
\hline 86 & 0,7760 & 556 & 0,0000 & 0 & 100,0 & 56,04 & 56,04 \\
\hline 87 & 0,7080 & 508 & 0,0012 & 1 & 99,8 & 51,13 & 51,05 \\
\hline 88 & 0,9290 & 666 & 0,0000 & 0 & 100,0 & 67,09 & 67,09 \\
\hline 89 & 0,9160 & 657 & 0,0017 & 1 & 99,8 & 66,16 & 66,03 \\
\hline 90 & 0,8290 & 595 & 0,0006 & 0 & 99,9 & 59,87 & 59,83 \\
\hline
\end{tabular}


Tabela A1 - Dados da operação do Biofiltro preenchido com Espuma de Poliuretano (Continuação)

\begin{tabular}{|c|c|c|c|c|c|c|c|}
\hline \multirow{2}{*}{$\begin{array}{c}\text { Dia de } \\
\text { operação }\end{array}$} & \multicolumn{2}{|c|}{ Centrada } & \multicolumn{2}{|c|}{ Csaída } & \multirow{2}{*}{ Eficiência (\%) } & \multirow{2}{*}{ TCMV $\left(g \cdot m^{3} \cdot h^{-1}\right)$} & \multirow{2}{*}{ CE $\left(g \cdot m^{3} \cdot h^{-1}\right)$} \\
\hline & $(\mathrm{mg} / \mathrm{L})$ & (ppm) & $(\mathrm{mg} / \mathrm{L})$ & (ppm) & & & \\
\hline 91 & 0,9520 & 683 & 0,0035 & 2 & 99,6 & 68,76 & 68,51 \\
\hline 92 & 0,8890 & 638 & 0,0000 & 0 & 100,0 & 64,21 & 64,21 \\
\hline 93 & 0,9770 & 701 & 0,0000 & 0 & 100,0 & 70,56 & 70,56 \\
\hline 94 & 0,8500 & 610 & 0,0006 & 0 & 99,9 & 61,39 & 61,35 \\
\hline 95 & 0,8360 & 600 & 0,0012 & 1 & 99,9 & 60,38 & 60,29 \\
\hline 96 & 0,9000 & 645 & 0,0000 & 0 & 100,0 & 65,00 & 65,00 \\
\hline 97 & 1,0020 & 719 & 0,0000 & 0 & 100,0 & 72,37 & 72,37 \\
\hline 98 & 0,9100 & 653 & 0,0017 & 1 & 99,8 & 74,40 & 74,26 \\
\hline 99 & 0,8160 & 585 & 0,0144 & 10 & 98,2 & 66,72 & 65,54 \\
\hline 100 & 0,8770 & 629 & 0,0035 & 2 & 99,6 & 71,70 & 71,42 \\
\hline
\end{tabular}


Tabela A2 - Dados da operação do Biofiltro preenchido com Bagaço de Cana

\begin{tabular}{|c|c|c|c|c|c|c|c|}
\hline \multirow{2}{*}{$\begin{array}{c}\text { Dia de } \\
\text { operação }\end{array}$} & \multicolumn{2}{|c|}{ Centrada } & \multicolumn{2}{|c|}{ Csaída } & \multirow{2}{*}{ Eficiência (\%) } & \multirow{2}{*}{ TCMV $\left(g \cdot \mathrm{m}^{3} \cdot \mathrm{h}^{-1}\right)$} & \multirow{2}{*}{ CE $\left(g \cdot m^{3} \cdot h^{-1}\right)$} \\
\hline & $(\mathrm{mg} / \mathrm{L})$ & (ppm) & $(\mathrm{mg} / \mathrm{L})$ & (ppm) & & & \\
\hline 1 & 0,2320 & 166 & 0,00173 & 1 & 99,25 & 16,94 & 16,82 \\
\hline 2 & 0,2440 & 175 & 0,00000 & 0 & 100,00 & 17,82 & 17,82 \\
\hline 3 & 0,2490 & 179 & 0,00000 & 0 & 100,00 & 18,22 & 18,22 \\
\hline 4 & 0,2545 & 183 & 0,00000 & 0 & 100,00 & 18,59 & 18,59 \\
\hline 5 & 0,2490 & 179 & 0,00000 & 0 & 100,00 & 18,19 & 18,19 \\
\hline 6 & 0,2380 & 171 & 0,00000 & 0 & 100,00 & 17,38 & 17,38 \\
\hline 7 & 0,2525 & 181 & 0,00115 & 1 & 99,54 & 18,44 & 18,36 \\
\hline 8 & 0,2585 & 185 & 0,00173 & 1 & 99,33 & 18,88 & 18,75 \\
\hline 9 & 0,2540 & 182 & 0,00000 & 0 & 100,00 & 18,55 & 18,55 \\
\hline 10 & 0,2670 & 191 & 0,00000 & 0 & 100,00 & 19,50 & 19,50 \\
\hline 11 & 0,2370 & 170 & 0,00000 & 0 & 100,00 & 17,31 & 17,31 \\
\hline 12 & 0,2535 & 182 & 0,00000 & 0 & 100,00 & 18,51 & 18,51 \\
\hline 13 & 0,2515 & 180 & 0,00000 & 0 & 100,00 & 18,37 & 18,37 \\
\hline 14 & 0,2630 & 189 & 0,00000 & 0 & 100,00 & 19,21 & 19,21 \\
\hline 15 & 0,2225 & 160 & 0,00000 & 0 & 100,00 & 16,25 & 16,25 \\
\hline 16 & 0,2775 & 199 & 0,00115 & 1 & 99,58 & 20,27 & 20,18 \\
\hline 17 & 0,2580 & 185 & 0,00000 & 0 & 100,00 & 18,84 & 18,84 \\
\hline 18 & 0,2725 & 195 & 0,00000 & 0 & 100,00 & 19,90 & 19,90 \\
\hline 19 & 0,2960 & 212 & 0,00000 & 0 & 100,00 & 21,62 & 21,62 \\
\hline 20 & 0,2825 & 203 & 0,00000 & 0 & 100,00 & 20,63 & 20,63 \\
\hline 21 & 0,2475 & 177 & 0,00000 & 0 & 100,00 & 18,08 & 18,08 \\
\hline 22 & 0,2905 & 208 & 0,00000 & 0 & 100,00 & 21,22 & 21,22 \\
\hline 23 & 0,2780 & 199 & 0,00000 & 0 & 100,00 & 20,30 & 20,30 \\
\hline 24 & 0,2675 & 192 & 0,00000 & 0 & 100,00 & 19,54 & 19,54 \\
\hline 25 & 0,4775 & 342 & 0,0000 & 0 & 100,00 & 34,87 & 34,87 \\
\hline 26 & 0,4260 & 306 & 0,0000 & 0 & 100,00 & 31,11 & 31,11 \\
\hline 27 & 0,4560 & 327 & 0,0000 & 0 & 100,00 & 33,30 & 33,30 \\
\hline 28 & 0,4365 & 313 & 0,0000 & 0 & 100,00 & 31,88 & 31,88 \\
\hline 29 & 0,4590 & 329 & 0,0000 & 0 & 100,00 & 33,52 & 33,52 \\
\hline 30 & 0,4990 & 358 & 0,0017 & 1 & 99,65 & 36,44 & 36,32 \\
\hline
\end{tabular}


Tabela A2 - Dados da operação do Biofiltro preenchido com Bagaço de Cana (Continuação)

\begin{tabular}{|c|c|c|c|c|c|c|c|}
\hline \multirow{2}{*}{$\begin{array}{c}\text { Dia de } \\
\text { operação }\end{array}$} & \multicolumn{2}{|c|}{ Centrada } & \multicolumn{2}{|c|}{ Csaída } & \multirow{2}{*}{ Eficiência (\%) } & \multirow{2}{*}{ TCMV $\left(g \cdot m^{3} \cdot h^{-1}\right)$} & \multirow{2}{*}{ CE $\left(g \cdot m^{3} \cdot h^{-1}\right)$} \\
\hline & $(\mathrm{mg} / \mathrm{L})$ & (ppm) & $(\mathrm{mg} / \mathrm{L})$ & (ppm) & & & \\
\hline 31 & 0,4835 & 347 & 0,0000 & 0 & 100,00 & 35,31 & 35,31 \\
\hline 32 & 0,4815 & 345 & 0,0000 & 0 & 100,00 & 35,17 & 35,17 \\
\hline 33 & 0,4650 & 333 & 0,0000 & 0 & 100,00 & 33,96 & 33,96 \\
\hline 34 & 0,4525 & 325 & 0,0000 & 0 & 100,00 & 33,05 & 33,05 \\
\hline 35 & 0,4650 & 333 & 0,0000 & 0 & 100,00 & 33,96 & 33,96 \\
\hline 36 & 0,4365 & 313 & 0,0000 & 0 & 100,00 & 31,88 & 31,88 \\
\hline 37 & 0,5015 & 360 & 0,0000 & 0 & 100,00 & 36,63 & 36,63 \\
\hline 38 & 0,4535 & 325 & 0,0000 & 0 & 100,00 & 33,12 & 33,12 \\
\hline 39 & 0,4200 & 301 & 0,0000 & 0 & 100,00 & 30,67 & 30,67 \\
\hline 40 & 0,4425 & 317 & 0,0000 & 0 & 100,00 & 32,32 & 32,32 \\
\hline 41 & 0,4670 & 335 & 0,0000 & 0 & 100,00 & 34,11 & 34,11 \\
\hline 42 & 0,4175 & 299 & 0,0000 & 0 & 100,00 & 30,49 & 30,49 \\
\hline 43 & 0,4960 & 356 & 0,0000 & 0 & 100,00 & 36,22 & 36,22 \\
\hline 44 & 0,4660 & 334 & 0,0000 & 0 & 100,00 & 38,10 & 38,10 \\
\hline 45 & 0,4480 & 321 & 0,0000 & 0 & 100,00 & 36,63 & 36,63 \\
\hline 46 & 0,4015 & 288 & 0,0000 & 0 & 100,00 & 32,83 & 32,83 \\
\hline 47 & 0,4315 & 309 & 0,0000 & 0 & 100,00 & 35,28 & 35,28 \\
\hline 48 & 0,5010 & 359 & 0,0000 & 0 & 100,00 & 40,96 & 40,96 \\
\hline 49 & 0,4725 & 339 & 0,0000 & 0 & 100,00 & 38,63 & 38,63 \\
\hline 50 & 0,4850 & 348 & 0,0000 & 0 & 100,00 & 39,65 & 39,65 \\
\hline 51 & 0,4495 & 322 & 0,0000 & 0 & 100,00 & 36,75 & 36,75 \\
\hline 52 & 0,4640 & 333 & 0,0000 & 0 & 100,00 & 37,94 & 37,94 \\
\hline 53 & 0,4651 & 334 & 0,0000 & 0 & 100,00 & 38,02 & 38,02 \\
\hline 54 & 0,4150 & 298 & 0,0000 & 0 & 100,00 & 33,93 & 33,93 \\
\hline 55 & 0,4470 & 321 & 0,0000 & 0 & 100,00 & 36,55 & 36,55 \\
\hline 56 & 0,4485 & 322 & 0,0000 & 0 & 100,00 & 36,67 & 36,67 \\
\hline 57 & 0,7100 & 509 & 0,0000 & 0 & 100,0 & 58,05 & 58,05 \\
\hline 58 & 0,6400 & 459 & 0,0000 & 0 & 100,0 & 52,33 & 52,33 \\
\hline 59 & 0,7340 & 526 & 0,0000 & 0 & 100,0 & 60,01 & 60,01 \\
\hline 60 & 0,6990 & 501 & 0,0000 & 0 & 100,0 & 57,15 & 57,15 \\
\hline
\end{tabular}


Tabela A2 -Dados da operação do Biofiltro preenchido com Bagaço de Cana (Continuação)

\begin{tabular}{|c|c|c|c|c|c|c|c|}
\hline \multirow{2}{*}{$\begin{array}{c}\text { Dia de } \\
\text { operação }\end{array}$} & \multicolumn{2}{|c|}{ Centrada } & \multicolumn{2}{|c|}{ Csaída } & \multirow{2}{*}{ Eficiência (\%) } & \multirow{2}{*}{ TCMV $\left(g \cdot \mathrm{m}^{3} \cdot \mathrm{h}^{-1}\right)$} & \multirow[t]{2}{*}{ CE $\left(\mathrm{g} \cdot \mathrm{m}^{3} \cdot \mathrm{h}^{-1}\right)$} \\
\hline & $(\mathrm{mg} / \mathrm{L})$ & (ppm) & $(\mathrm{mg} / \mathrm{L})$ & (ppm) & & & \\
\hline 61 & 0,8340 & 598 & 0,0000 & 0 & 100,0 & 68,19 & 68,19 \\
\hline 62 & 0,7690 & 551 & 0,0000 & 0 & 100,0 & 62,87 & 62,87 \\
\hline 63 & 0,7580 & 544 & 0,0000 & 0 & 100,0 & 61,97 & 61,97 \\
\hline 64 & 0,6900 & 495 & 0,0006 & 0 & 99,9 & 56,42 & 56,37 \\
\hline 65 & 0,7850 & 563 & 0,0000 & 0 & 100,0 & 64,18 & 64,18 \\
\hline 66 & 0,7100 & 509 & 0,0017 & 1 & 99,8 & 58,05 & 57,91 \\
\hline 67 & 0,6930 & 497 & 0,0000 & 0,0 & 100,0 & 56,66 & 56,66 \\
\hline 68 & 0,7560 & 542 & 0,0000 & 0,0 & 100,0 & 61,81 & 61,81 \\
\hline 69 & 0,6940 & 498 & 0,0000 & 0,0 & 100,0 & 56,74 & 56,74 \\
\hline 70 & 0,7090 & 508 & 0,0000 & 0 & 100,00 & 57,97 & 57,97 \\
\hline 71 & 0,7270 & 521 & 0,0000 & 0 & 100,00 & 59,44 & 59,44 \\
\hline 72 & 0,6960 & 499 & 0,0000 & 0 & 100,0 & 56,91 & 56,91 \\
\hline 73 & 0,7790 & 559 & 0,0000 & 0 & 100,0 & 63,69 & 63,69 \\
\hline 74 & 0,6910 & 496 & 0,0000 & 0 & 100,0 & 56,50 & 56,50 \\
\hline 75 & 0,6630 & 475 & 0,0000 & 0 & 100,0 & 54,21 & 54,21 \\
\hline 76 & 0,7750 & 556 & 0,0087 & 6 & 98,9 & 63,36 & 62,66 \\
\hline 77 & 0,7720 & 554 & 0,0173 & 12 & 97,8 & 63,12 & 61,70 \\
\hline 78 & 0,7400 & 531 & 0,0271 & 19 & 96,3 & 60,50 & 58,29 \\
\hline 79 & 0,7050 & 506 & 0,0127 & 9 & 98,2 & 57,64 & 56,60 \\
\hline 80 & 0,6600 & 473 & 0,0029 & 2 & 99,6 & 53,96 & 53,73 \\
\hline 81 & 0,6970 & 500 & 0,0000 & 0 & 100,0 & 56,99 & 56,99 \\
\hline 82 & 0,7850 & 563 & 0,0000 & 0 & 100,0 & 64,18 & 64,18 \\
\hline 83 & 0,7060 & 506 & 0,0000 & 0 & 100,0 & 57,72 & 57,72 \\
\hline 84 & 0,6940 & 498 & 0,0000 & 0 & 100,0 & 56,74 & 56,74 \\
\hline 85 & 0,6890 & 494 & 0,0000 & 0 & 100,0 & 56,33 & 56,33 \\
\hline 86 & 0,7760 & 556 & 0,0000 & 0 & 100,0 & 63,45 & 63,45 \\
\hline 87 & 0,7080 & 508 & 0,0000 & 0 & 100,0 & 57,89 & 57,89 \\
\hline 88 & 0,9290 & 666 & 0,0017 & 1 & 99,81 & 75,96 & 75,81 \\
\hline 89 & 0,9160 & 657 & 0,0023 & 2 & 99,75 & 74,89 & 74,70 \\
\hline 90 & 0,8290 & 595 & 0,0006 & 0 & 99,93 & 67,78 & 67,73 \\
\hline
\end{tabular}


Tabela A2 - Dados da operação do Biofiltro preenchido com Bagaço de Cana (Continuação)

\begin{tabular}{|c|c|c|c|c|c|c|c|}
\hline \multirow{2}{*}{$\begin{array}{c}\text { Dia de } \\
\text { operação }\end{array}$} & \multicolumn{2}{|c|}{ Centrada } & \multicolumn{2}{|c|}{ Csaída } & \multirow{2}{*}{ Eficiência (\%) } & \multirow[t]{2}{*}{$\operatorname{TCMV}\left(\mathrm{g} \cdot \mathrm{m}^{3} \cdot \mathrm{h}^{-1}\right)$} & \multirow[t]{2}{*}{ CE $\left(g \cdot m^{3} \cdot h^{-1}\right)$} \\
\hline & $(\mathrm{mg} / \mathrm{L})$ & (ppm) & $(\mathrm{mg} / \mathrm{L})$ & (ppm) & & & \\
\hline 91 & 0,9520 & 683 & 0,0029 & 2 & 99,70 & 77,84 & 77,60 \\
\hline 92 & 0,8890 & 638 & 0,0006 & 0 & 99,94 & 72,69 & 72,64 \\
\hline 93 & 0,9770 & 701 & 0,0052 & 4 & 99,47 & 79,88 & 79,46 \\
\hline 94 & 0,8500 & 610 & 0,0035 & 2 & 99,59 & 69,50 & 69,21 \\
\hline 95 & 0,8360 & 600 & 0,0179 & 13 & 97,86 & 68,35 & 66,89 \\
\hline 96 & 0,9000 & 645 & 0,0115 & 8 & 98,72 & 73,58 & 72,64 \\
\hline 97 & 1,0020 & 719 & 0,0225 & 16 & 97,75 & 81,92 & 80,08 \\
\hline 98 & 0,9100 & 653 & 0,0035 & 2 & 99,62 & 74,40 & 74,12 \\
\hline 99 & 0,8160 & 585 & 0,0087 & 6 & 98,94 & 66,72 & 66,01 \\
\hline 100 & 0,8770 & 629 & 0,0035 & 2 & 99,61 & 71,70 & 71,42 \\
\hline
\end{tabular}


Tabela A3 - Dados da operação do Biofiltro preenchido com Fibra de Coco

\begin{tabular}{|c|c|c|c|c|c|c|c|}
\hline \multirow{2}{*}{$\begin{array}{c}\text { Dia de } \\
\text { operação }\end{array}$} & \multicolumn{2}{|c|}{ Centrada } & \multicolumn{2}{|c|}{ Csaída } & \multirow{2}{*}{ Eficiência (\%) } & \multirow{2}{*}{ TCMV $\left(\mathrm{g} \cdot \mathrm{m}^{3} \cdot \mathrm{h}^{-1}\right)$} & \multirow{2}{*}{ CE $\left(\mathrm{g} \cdot \mathrm{m}^{3} \cdot \mathrm{h}^{-1}\right)$} \\
\hline & $(\mathrm{mg} / \mathrm{L})$ & (ppm) & $(\mathrm{mg} / \mathrm{L})$ & (ppm) & & & \\
\hline 1 & 0,2320 & 166 & 0,0023 & 2 & 99,01 & 17,14 & 16,97 \\
\hline 2 & 0,2440 & 175 & 0,0000 & 0 & 100,00 & 18,02 & 18,02 \\
\hline 3 & 0,2490 & 179 & 0,0000 & 0 & 100,00 & 18,43 & 18,43 \\
\hline 4 & 0,2545 & 183 & 0,0000 & 0 & 100,00 & 18,80 & 18,80 \\
\hline 5 & 0,2490 & 179 & 0,0000 & 0 & 100,00 & 18,39 & 18,39 \\
\hline 6 & 0,2380 & 171 & 0,0000 & 0 & 100,00 & 17,58 & 17,58 \\
\hline 7 & 0,2525 & 181 & 0,0012 & 1 & 99,54 & 18,65 & 18,57 \\
\hline 8 & 0,2585 & 185 & 0,0000 & 0 & 100,00 & 19,09 & 19,09 \\
\hline 9 & 0,2540 & 182 & 0,0000 & 0 & 100,00 & 18,76 & 18,76 \\
\hline 10 & 0,2670 & 191 & 0,0000 & 0 & 100,00 & 19,72 & 19,72 \\
\hline 11 & 0,2370 & 170 & 0,0000 & 0 & 100,00 & 17,51 & 17,51 \\
\hline 12 & 0,2535 & 182 & 0,0000 & 0 & 100,00 & 18,72 & 18,72 \\
\hline 13 & 0,2515 & 180 & 0,0000 & 0 & 100,00 & 18,58 & 18,58 \\
\hline 14 & 0,2630 & 189 & 0,0006 & 0 & 99,78 & 19,43 & 19,38 \\
\hline 15 & 0,2225 & 160 & 0,0000 & 0 & 100,00 & 16,43 & 16,43 \\
\hline 16 & 0,2775 & 199 & 0,0012 & 1 & 99,58 & 20,50 & 20,41 \\
\hline 17 & 0,2580 & 185 & 0,0017 & 1 & 99,33 & 19,06 & 18,93 \\
\hline 18 & 0,2725 & 195 & 0,0000 & 0 & 100,00 & 20,13 & 20,13 \\
\hline 19 & 0,2960 & 212 & 0,0000 & 0 & 100,00 & 21,86 & 21,86 \\
\hline 20 & 0,2825 & 203 & 0,0000 & 0 & 100,00 & 20,87 & 20,87 \\
\hline 21 & 0,2475 & 177 & 0,0000 & 0 & 100,00 & 18,28 & 18,28 \\
\hline 22 & 0,2905 & 208 & 0,0000 & 0 & 100,00 & 21,46 & 21,46 \\
\hline 23 & 0,2780 & 199 & 0,0000 & 0 & 100,00 & 20,53 & 20,53 \\
\hline 24 & 0,2675 & 192 & 0,0000 & 0 & 100,00 & 19,76 & 19,76 \\
\hline 25 & 0,4775 & 342 & 0,0000 & 0 & 100,00 & 35,27 & 35,27 \\
\hline 26 & 0,4260 & 306 & 0,0000 & 0 & 100,00 & 31,47 & 31,47 \\
\hline 27 & 0,4560 & 327 & 0,0000 & 0 & 100,00 & 33,68 & 33,68 \\
\hline 28 & 0,4365 & 313 & 0,0000 & 0 & 100,00 & 32,24 & 32,24 \\
\hline 29 & 0,4590 & 329 & 0,0000 & 0 & 100,00 & 33,90 & 33,90 \\
\hline 30 & 0,4990 & 358 & 0,0012 & 1 & 99,77 & 36,86 & 36,77 \\
\hline
\end{tabular}


Tabela A3 - Dados da operação do Biofiltro preenchido com Fibra de Coco (Continuação)

\begin{tabular}{|c|c|c|c|c|c|c|c|}
\hline \multirow{2}{*}{$\begin{array}{c}\text { Dia de } \\
\text { operação }\end{array}$} & \multicolumn{2}{|c|}{ Centrada } & \multicolumn{2}{|c|}{ Csaída } & \multirow{2}{*}{ Eficiência (\%) } & \multirow{2}{*}{ TCMV $\left(\mathrm{g} \cdot \mathrm{m}^{3} \cdot \mathrm{h}^{-1}\right)$} & \multirow{2}{*}{ CE $\left(g \cdot m^{3} \cdot h^{-1}\right)$} \\
\hline & $(\mathrm{mg} / \mathrm{L})$ & (ppm) & $(\mathrm{mg} / \mathrm{L})$ & (ppm) & & & \\
\hline 31 & 0,4835 & 347 & 0,0000 & 0 & 100,00 & 35,71 & 35,71 \\
\hline 32 & 0,4815 & 345 & 0,0000 & 0 & 100,00 & 35,57 & 35,57 \\
\hline 33 & 0,4650 & 333 & 0,0000 & 0 & 100,00 & 34,35 & 34,35 \\
\hline 34 & 0,4525 & 325 & 0,0000 & 0 & 100,00 & 33,42 & 33,42 \\
\hline 35 & 0,4650 & 333 & 0,0000 & 0 & 100,00 & 34,35 & 34,35 \\
\hline 36 & 0,4365 & 313 & 0,0000 & 0 & 100,00 & 32,24 & 32,24 \\
\hline 37 & 0,5015 & 360 & 0,0000 & 0 & 100,00 & 37,04 & 37,04 \\
\hline 38 & 0,4535 & 325 & 0,0000 & 0 & 100,00 & 33,50 & 33,50 \\
\hline 39 & 0,4200 & 301 & 0,0000 & 0 & 100,00 & 31,02 & 31,02 \\
\hline 40 & 0,4425 & 317 & 0,0000 & 0 & 100,00 & 32,68 & 32,68 \\
\hline 41 & 0,4670 & 335 & 0,0000 & 0 & 100,00 & 34,49 & 34,49 \\
\hline 42 & 0,4175 & 299 & 0,0000 & 0 & 100,00 & 30,84 & 30,84 \\
\hline 43 & 0,4960 & 356 & 0,0000 & 0 & 100,00 & 36,64 & 36,64 \\
\hline 44 & 0,4660 & 334 & 0,0000 & 0 & 100,00 & 34,42 & 34,42 \\
\hline 45 & 0,4480 & 321 & 0,0000 & 0 & 100,00 & 33,09 & 33,09 \\
\hline 46 & 0,4015 & 288 & 0,0000 & 0 & 100,00 & 29,66 & 29,66 \\
\hline 47 & 0,4315 & 309 & 0,0000 & 0 & 100,00 & 31,87 & 31,87 \\
\hline 48 & 0,5010 & 359 & 0,0000 & 0 & 100,00 & 37,01 & 37,01 \\
\hline 49 & 0,4725 & 339 & 0,0000 & 0 & 100,00 & 34,90 & 34,90 \\
\hline 50 & 0,4850 & 348 & 0,0000 & 0 & 100,00 & 35,82 & 35,82 \\
\hline 51 & 0,4495 & 322 & 0,0000 & 0 & 100,00 & 33,20 & 33,20 \\
\hline 52 & 0,4640 & 333 & 0,0000 & 0 & 100,00 & 34,27 & 34,27 \\
\hline 53 & 0,4651 & 334 & 0,0000 & 0 & 100,00 & 34,35 & 34,35 \\
\hline 54 & 0,4150 & 298 & 0,0000 & 0 & 100,00 & 30,65 & 30,65 \\
\hline 55 & 0,4470 & 321 & 0,0000 & 0 & 100,00 & 33,02 & 33,02 \\
\hline 56 & 0,4485 & 322 & 0,0000 & 0 & 100,00 & 33,13 & 33,13 \\
\hline 57 & 0,7100 & 509 & 0,0000 & 0 & 100,0 & 52,44 & 52,44 \\
\hline 58 & 0,6400 & 459 & 0,0000 & 0 & 100,0 & 47,27 & 47,27 \\
\hline 59 & 0,7340 & 526 & 0,0000 & 0 & 100,0 & 54,22 & 54,22 \\
\hline 60 & 0,6990 & 501 & 0,0000 & 0 & 100,0 & 51,63 & 51,63 \\
\hline
\end{tabular}


Tabela A3 - Dados da operação do Biofiltro preenchido com Fibra de Coco (Continuação)

\begin{tabular}{|c|c|c|c|c|c|c|c|}
\hline \multirow{2}{*}{$\begin{array}{c}\text { Dia de } \\
\text { operação }\end{array}$} & \multicolumn{2}{|c|}{ Centrada } & \multicolumn{2}{|c|}{ Csaída } & \multirow{2}{*}{ Eficiência (\%) } & \multirow{2}{*}{ TCMV $\left(g \cdot \mathrm{m}^{3} \cdot \mathrm{h}^{-1}\right)$} & \multirow{2}{*}{ CE $\left(g \cdot m^{3} \cdot h^{-1}\right)$} \\
\hline & $(\mathrm{mg} / \mathrm{L})$ & (ppm) & $(\mathrm{mg} / \mathrm{L})$ & (ppm) & & & \\
\hline 61 & 0,8340 & 598 & 0,0000 & 0 & 100,0 & 61,60 & 61,60 \\
\hline 62 & 0,7690 & 551 & 0,0000 & 0 & 100,0 & 56,80 & 56,80 \\
\hline 63 & 0,7580 & 544 & 0,0000 & 0 & 100,0 & 55,99 & 55,99 \\
\hline 64 & 0,6900 & 495 & 0,0006 & 0 & 99,9 & 50,97 & 50,92 \\
\hline 65 & 0,7850 & 563 & 0,0000 & 0 & 100,0 & 57,98 & 57,98 \\
\hline 66 & 0,7100 & 509 & 0,0000 & 0 & 100,0 & 52,44 & 52,44 \\
\hline 67 & 0,6930 & 497 & 0,0000 & 0,0 & 100,0 & 51,19 & 51,19 \\
\hline 68 & 0,7560 & 542 & 0,0000 & 0,0 & 100,0 & 55,84 & 55,84 \\
\hline 69 & 0,6940 & 498 & 0,0000 & 0,0 & 100,0 & 51,26 & 51,26 \\
\hline 70 & 0,7090 & 508 & 0,0000 & 0 & 100,0 & 52,37 & 52,37 \\
\hline 71 & 0,7270 & 521 & 0,0000 & 0 & 100,0 & 53,70 & 53,70 \\
\hline 72 & 0,6960 & 499 & 0,0000 & 0 & 100,0 & 51,41 & 51,41 \\
\hline 73 & 0,7790 & 559 & 0,0000 & 0 & 100,0 & 57,54 & 57,54 \\
\hline 74 & 0,6910 & 496 & 0,0000 & 0 & 100,0 & 51,04 & 51,04 \\
\hline 75 & 0,6630 & 475 & 0,0000 & 0 & 100,0 & 48,97 & 48,97 \\
\hline 76 & 0,7750 & 556 & 0,0000 & 0 & 100,0 & 57,24 & 57,24 \\
\hline 77 & 0,7720 & 554 & 0,0000 & 0 & 100,0 & 58,35 & 58,35 \\
\hline 78 & 0,7400 & 531 & 0,0000 & 0 & 100,0 & 55,93 & 55,93 \\
\hline 79 & 0,7050 & 506 & 0,0000 & 0 & 100,0 & 53,28 & 53,28 \\
\hline 80 & 0,6600 & 473 & 0,0000 & 0 & 100,0 & 49,88 & 49,88 \\
\hline 81 & 0,6970 & 500 & 0,0006 & 0 & 99,9 & 52,68 & 52,64 \\
\hline 82 & 0,7850 & 563 & 0,0000 & 0 & 100,0 & 59,33 & 59,33 \\
\hline 83 & 0,7060 & 506 & 0,0000 & 0 & 100,0 & 53,36 & 53,36 \\
\hline 84 & 0,6940 & 498 & 0,0000 & 0 & 100,0 & 52,45 & 52,45 \\
\hline 85 & 0,6890 & 494 & 0,0000 & 0 & 100,0 & 52,08 & 52,08 \\
\hline 86 & 0,7760 & 556 & 0,0000 & 0 & 100,0 & 58,65 & 58,65 \\
\hline 87 & 0,7080 & 508 & 0,0000 & 0 & 100,0 & 53,51 & 53,51 \\
\hline 88 & 0,9290 & 666 & 0,0012 & 1 & 99,88 & 70,22 & 70,13 \\
\hline 89 & 0,9160 & 657 & 0,0006 & 0 & 99,94 & 69,23 & 69,19 \\
\hline 90 & 0,8290 & 595 & 0,0006 & 0 & 99,93 & 62,66 & 62,61 \\
\hline
\end{tabular}


Tabela A3 - Dados da operação do Biofiltro preenchido com Fibra de Coco (Continuação)

\begin{tabular}{|c|c|c|c|c|c|c|c|}
\hline \multirow{2}{*}{$\begin{array}{c}\text { Dia de } \\
\text { operação }\end{array}$} & \multicolumn{2}{|c|}{ Centrada } & \multicolumn{2}{|c|}{ Csaída } & \multirow{2}{*}{ Eficiência (\%) } & \multirow{2}{*}{ TCMV $\left(g \cdot \mathrm{m}^{3} \cdot \mathrm{h}^{-1}\right)$} & \multirow[t]{2}{*}{ CE $\left(\mathrm{g} \cdot \mathrm{m}^{3} \cdot \mathrm{h}^{-1}\right.$} \\
\hline & $(\mathrm{mg} / \mathrm{L})$ & (ppm) & $(\mathrm{mg} / \mathrm{L})$ & (ppm) & & & \\
\hline 91 & 0,9520 & 683 & 0,0029 & 2 & 99,70 & 71,95 & 71,74 \\
\hline 92 & 0,8890 & 638 & 0,0006 & 0 & 99,94 & 67,19 & 67,15 \\
\hline 93 & 0,9770 & 701 & 0,0006 & 0 & 99,94 & 73,84 & 73,80 \\
\hline 94 & 0,8500 & 610 & 0,0012 & 1 & 99,86 & 64,24 & 64,16 \\
\hline 95 & 0,8360 & 600 & 0,0202 & 14 & 97,58 & 63,19 & 61,66 \\
\hline 96 & 0,9000 & 645 & 0,0075 & 5 & 99,17 & 68,02 & 67,46 \\
\hline 97 & 1,0020 & 719 & 0,0127 & 9 & 98,73 & 75,73 & 74,77 \\
\hline 98 & 0,9100 & 653 & 0,0000 & 0 & 100,00 & 74,40 & 74,40 \\
\hline 99 & 0,8160 & 585 & 0,0000 & 0 & 100,00 & 66,72 & 66,72 \\
\hline 100 & 0,8770 & 629 & 0,0006 & 0 & 99,93 & 71,70 & 71,66 \\
\hline
\end{tabular}




\section{Ensaios Hidrodinâmicos}

Tabela A4 - Dados do ensaio hidrodinâmico do ensaio com a espuma de poliuretano seca

\begin{tabular}{|c|c|c|c|c|c|c|c|c|}
\hline \multicolumn{4}{|c|}{ MEDIDA 1} & \multicolumn{4}{|c|}{ MEDIDA 2} & MÉDIA \\
\hline$Q(\mathrm{~cm} 3 / \mathrm{s})$ & $\Delta P(\mathrm{mca})$ & $\Delta \mathrm{P}\left(\right.$ dyn. $\left.\mathrm{cm}^{-2}\right)$ & $\Delta \mathrm{P} / \mathrm{L}\left(\mathrm{g} \cdot \mathrm{cm}^{-2} \cdot \mathrm{s}^{-2}\right)$ & $Q\left(\mathrm{~cm}^{3} / \mathrm{s}\right)$ & $\Delta \mathrm{P}(\mathrm{mca})$ & $\Delta \mathrm{P}\left(\mathrm{dyn} \cdot \mathrm{cm}^{-2}\right)$ & $\Delta \mathrm{P} / \mathrm{L}\left(\mathrm{g} \cdot \mathrm{cm}^{-2} \cdot \mathrm{s}^{-2}\right)$ & $\Delta \mathrm{P} / \mathrm{L}\left(\mathrm{g} \cdot \mathrm{cm}^{-2} \cdot \mathrm{s}^{-2}\right)$ \\
\hline 12,47 & 0,003 & 306,59 & 4,03 & 15,08 & 0,003 & 306,59 & 4,0341 & 4,03 \\
\hline 30,64 & 0,005 & 493,21 & 6,49 & 27,76 & 0,005 & 493,21 & 6,4896 & 6,49 \\
\hline 57,49 & 0,012 & 1186,37 & 15,61 & 54,39 & 0,01 & 986,42 & 12,9792 & 14,29 \\
\hline 82,59 & 0,019 & 1866,2 & 24,56 & 81,94 & 0,018 & 1772,89 & 23,3275 & 23,94 \\
\hline 112,56 & 0,033 & 3239,19 & 42,62 & 114,13 & 0,03 & 2945,93 & 38,7622 & 40,69 \\
\hline 137,04 & 0,038 & 3732,4 & 49,11 & 139,27 & 0,04 & 3932,35 & 51,7414 & 50,43 \\
\hline
\end{tabular}

Tabela A4 - Dados do ensaio hidrodinâmico do ensaio com o bagaço de cana seco

\begin{tabular}{|c|c|c|c|c|c|c|c|c|}
\hline \multicolumn{4}{|c|}{ MEDIDA 1} & \multicolumn{4}{|c|}{ MEDIDA 2} & \multirow{2}{*}{$\frac{\text { MÉDIA }}{\Delta \mathrm{P} / \mathrm{L}\left(\mathrm{g} \cdot \mathrm{cm}^{-2} \cdot \mathrm{s}^{-2}\right)}$} \\
\hline$Q\left(\mathrm{~cm}^{3} / \mathrm{s}\right)$ & $\Delta P(m c a)$ & $\Delta \mathrm{P}\left(\right.$ dyn. $\left.\mathrm{cm}^{-2}\right)$ & $\Delta \mathrm{P} / \mathrm{L}\left(\mathrm{g} \cdot \mathrm{cm}^{-2} \cdot \mathrm{s}^{-2}\right)$ & $Q(\mathrm{~cm} 3 / \mathrm{s})$ & $\Delta P(\mathrm{mca})$ & $\Delta P\left(\right.$ dyn. $\left.\mathrm{cm}^{-2}\right)$ & $\Delta P / L\left(g . \mathrm{cm}^{-2} \cdot \mathrm{s}^{-2}\right)$ & \\
\hline 15,08 & 0,003 & 306,59 & 4,03 & 14,93 & 0,003 & 306,59 & 4,0341 & 4,03 \\
\hline 30,54 & 0,006 & 599,85 & 7,89 & 27,76 & 0,005 & 493,21 & 6,4896 & 7,19 \\
\hline 58,22 & 0,012 & 1186,37 & 15,61 & 55,18 & 0,012 & 1186,37 & 15,6101 & 15,61 \\
\hline 83,57 & 0,019 & 1866,2 & 24,56 & 81,94 & 0,02 & 1972,84 & 25,9584 & 25,26 \\
\hline 112,53 & 0,03 & 2945,93 & 38,76 & 110,86 & 0,03 & 2945,93 & 38,7622 & 38,76 \\
\hline 132,87 & 0,04 & 3932,35 & 51,74 & 138,44 & 0,039 & 3825,71 & 50,3383 & 51,04 \\
\hline
\end{tabular}

Tabela A4 - Dados do ensaio hidrodinâmico do ensaio com a fibra de coco seca

\begin{tabular}{|c|c|c|c|c|c|c|c|c|}
\hline \multicolumn{4}{|c|}{ MEDIDA 1} & \multicolumn{4}{|c|}{ MEDIDA 2} & MÉDIA \\
\hline$Q\left(\mathrm{~cm}^{3} / \mathrm{s}\right)$ & $\Delta \mathrm{P}(\mathrm{mca})$ & $\Delta \mathrm{P}\left(\right.$ dyn. $\left.\mathrm{cm}^{-2}\right)$ & $\Delta \mathrm{P} / \mathrm{L}\left(\mathrm{g} \cdot \mathrm{cm}^{-2} \cdot \mathrm{s}^{-2}\right)$ & $Q(\mathrm{~cm} 3 / \mathrm{s})$ & $\Delta P(\mathrm{mca})$ & $\Delta \mathrm{P}\left(\right.$ dyn. $\left.\mathrm{cm}^{-2}\right)$ & $\Delta \mathrm{P} / \mathrm{L}\left(\mathrm{g} . \mathrm{cm}^{-2} \cdot \mathrm{s}^{-2}\right)$ & $\Delta P / L\left(\mathrm{~g} \cdot \mathrm{cm}^{-2} \cdot \mathrm{s}^{-2}\right)$ \\
\hline 15,08 & 0,001 & 106,64 & 1,40 & 15,08 & 0,002 & 199,95 & 2,6309 & 2,02 \\
\hline 29,18 & 0,004 & 399,9 & 5,26 & 31,85 & 0,006 & 599,85 & 7,8928 & 6,58 \\
\hline 57,47 & 0,013 & 1279,68 & 16,84 & 53,78 & 0,013 & 1279,68 & 16,8379 & 16,84 \\
\hline 82,47 & 0,024 & 2359,41 & 31,04 & 80,31 & 0,023 & 2266,1 & 29,8171 & 30,43 \\
\hline 112,53 & 0,035 & 3439,14 & 45,25 & 113,74 & 0,032 & 3145,88 & 41,3932 & 43,32 \\
\hline 133,98 & 0,045 & 4425,56 & 58,23 & 136,33 & 0,04 & 3932,35 & 51,7414 & 54,99 \\
\hline
\end{tabular}

